\title{
THE SYNTHESIS OF NOVEL BODIPY COMPOUNDS FOR DSSC APPLICATIONS
}

\author{
by \\ Devin Douglas Machin \\ BSc. Ryerson, 2012 \\ A thesis \\ presented to Ryerson University \\ in partial fulfillment of the \\ requirements for the degree of \\ Master of Science \\ in the Program of \\ Molecular Science
}

Toronto, Ontario, Canada, (2014)

(C) Devin Douglas Machin (2014) 


\section{Declaration}

I hereby declare that I am the sole author of this thesis. This is a true copy of the thesis, including any required final revisions, as accepted by my examiners.

I authorize Ryerson University to lend this thesis to other institutions or individuals for the purpose of scholarly research

I further authorize Ryerson University to reproduce this thesis by photocopying or by other means, in total or in part, at the request of other institutions or individuals for the purpose of scholarly research.

I understand that my thesis may be made electronically available to the public.

Devin D. Machin

September $30^{\text {th }} 2014$ 


\title{
THE SYNTHESIS OF NOVEL BODIPY COMPOUNDS FOR DSSC APPLICATIONS
}

\author{
Devin D. Machin \\ Master of Science, Molecular Science, Ryerson University, 2015
}

\begin{abstract}
The dye-sensitized solar cell (DSSC) represents one of the most promising next-generation photovoltaic technologies. In addition, the DSSC manifold provides an exceptional platform to further appreciate photoinduced electron transfer and the fundamental features required for light-harvesting. The dye molecule is a key component in the DSSC and has achieved minor success utilizing both an organic and inorganic photosensitizers. DSSC's show great promise owing to their inexpensive synthesis tunable optical and electrochemical properties, and a plethora of design possibilities.

The typical anatomy of organic and inorganic DSSC dyes are comprised of a redox-active donor/chromophore (D) that is connected, through a conjugated linker $(\pi)$, to an acceptor $(A)$ capable of anchoring to titania $\left(\mathrm{TiO}_{2}\right)$. Fine tuning each of these components can shift the absorption spectrum increasing the overall device efficiency. Boron-dipyrromethene (BODIPY) is an attractive moiety to integrate into DSSC dyes. BODIPY's rigid organic framework should be able to improve dye stability while the high extinction coefficients of BODIPY based molecules have the potential to increase device performance. Herein, we explore the synthesis and physicochemical properties of BODIPY in an attempt to synthesize efficient DSSC dye molecules and efficient photovoltaic technologies.
\end{abstract}

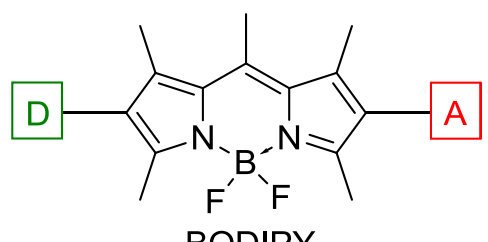

BODIPY 


\section{Acknowledgments}

First and foremost, I would like to thank Dr. Bryan Koivisto, not only for giving me this opportunity but also for the endless guidance, and support. His teachings inspired me to begin this degree and his knowledge and patience allowed it to become a success. Secondly, sincerest thanks to Dr. Russell Viirre, Dr. Robert Gossage, Dr. Andrew McWilliams whose ideas and advice led to the completion of this project. Special thanks must also be extended to Dr. Catherine Bonnier who began this project and who provided endless guidance and support.

Thanks are also in order, to my fellow lab mates Omar Abdi, Muhammad Yousaf, Maryam Abdinejad and Burhan Hussein for their assistance and advice. Thank you to all members of the Ryerson synthetic group, especially labs 202 and 323 for their advice and the occasional chemical. Finally I would like to thank my family, my friends and Kelsey Law for putting up with me through the course of this project, for their support and their understanding. Especially to Lucy for keeping me company on all of those late nights. 


\section{Table of Contents}

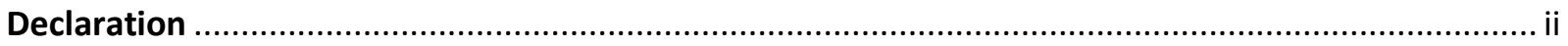

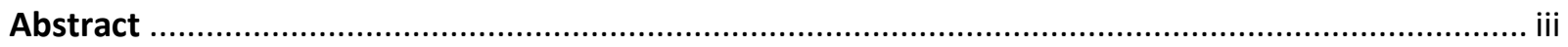

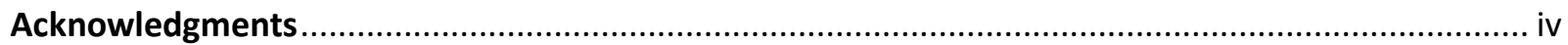

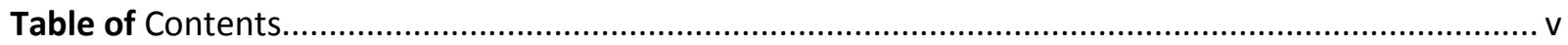

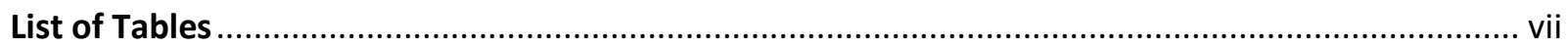

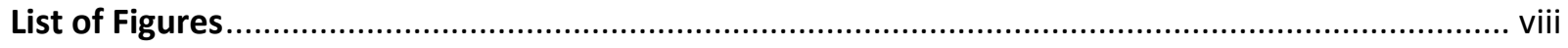

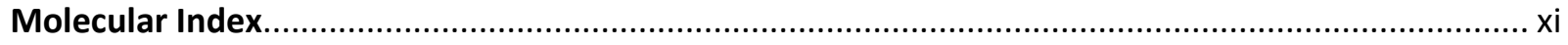

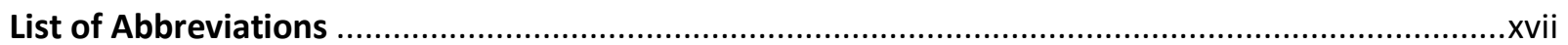

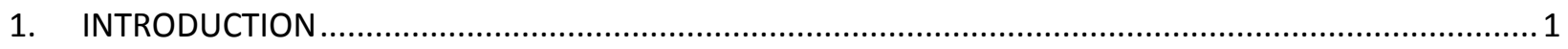

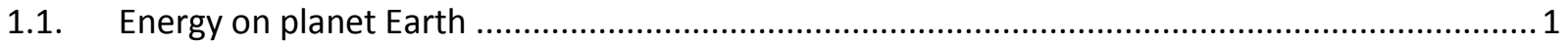

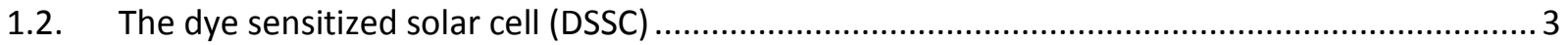

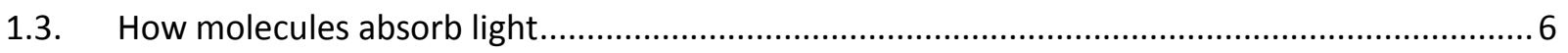

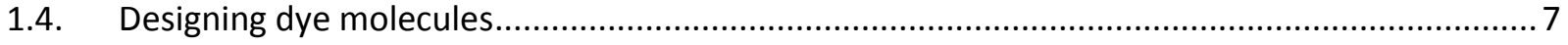

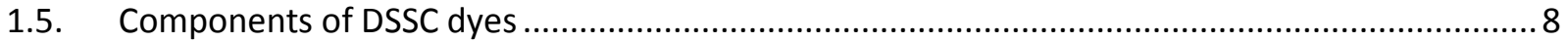

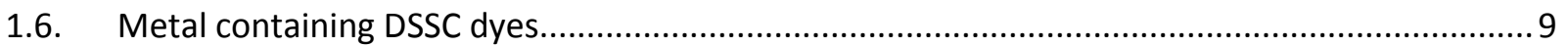

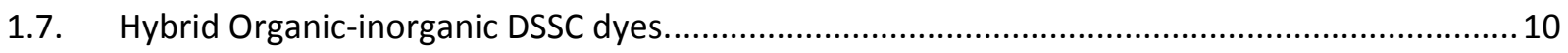

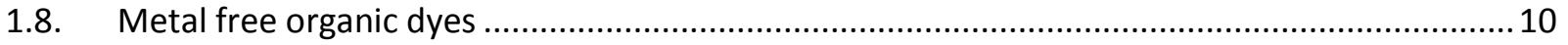

1.9. BODIPY: An attractive $\pi$-spacer for DSSC applications ….................................................. 14

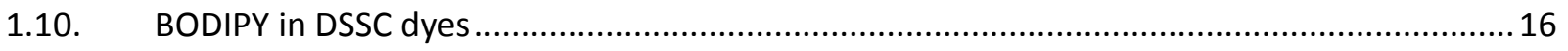

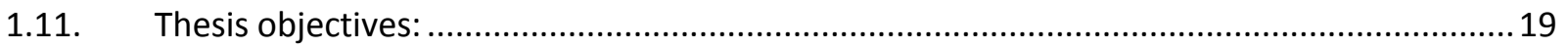

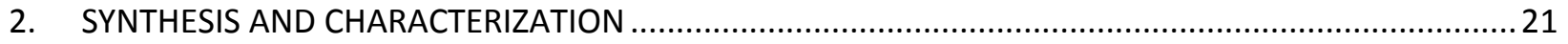

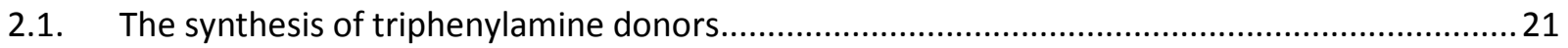

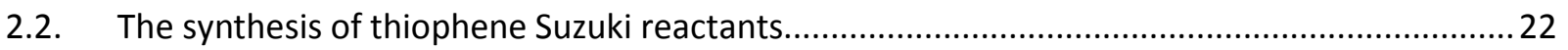

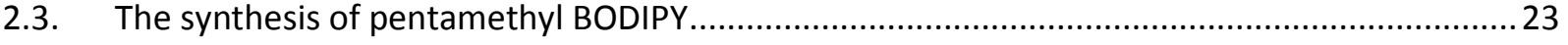

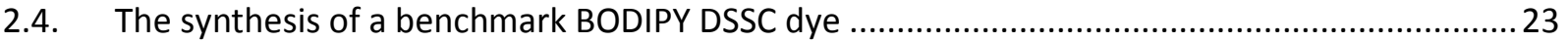

2.5. The synthesis of a BODIPY dye with extended conjugation between BODIPY and the anchor .24

2.6. The synthesis of a BODIPY dye with a thiophene spacer adjacent to the TPA donor ................25

2.7. The synthesis of BODIPY with two thiophene spacers for maximum conjugation.....................26

2.8. meso-substituted BODIPY building blocks for DSSC applications...........................................28 
2.9. The synthesis of BODIPY molecules with push-pull characteristics........................................29

2.10. Characterization of $\mathbf{2 . 3 9}$ and a possible synthetic mechanism ........................................ 31

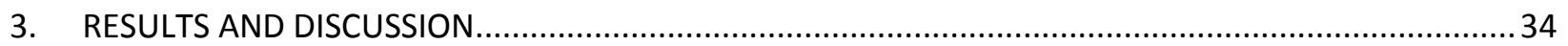

3.1. Physicochemical properties of BODIPY DSSC dyes (1.24a-b - 1.27a-b) ................................. 34

3.1.1 Density Functional Theory (DFT) Calculations of Dyes 1.24a $\mathbf{- 1 . 2 7 a}$...................................... 34

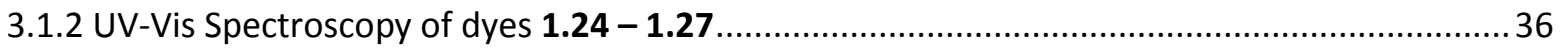

3.1.3 Electrochemistry of dye molecules $1.24 a, b$ to 1.27 a,b ..................................................... 38

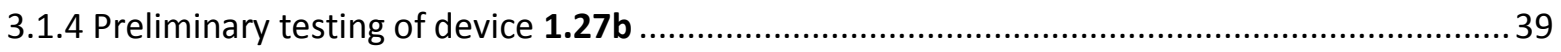

3.2. Physicochemical properties of meso-substituted BODIPY cores............................................. 41

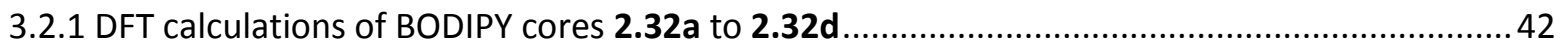

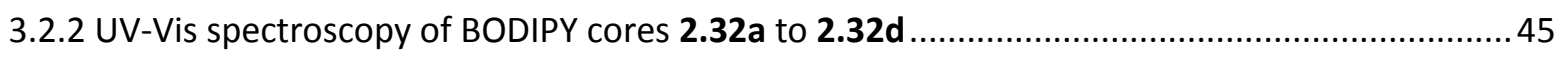

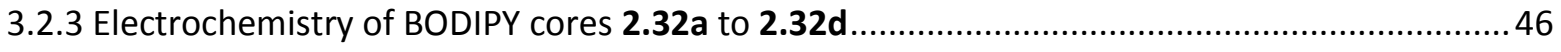

3.3. The physicochemical properties of push pull BODIPY molecules and dye precursors ...............47

3.3.1 The synthesis of BODIPY containing dye precursors ........................................................... 48

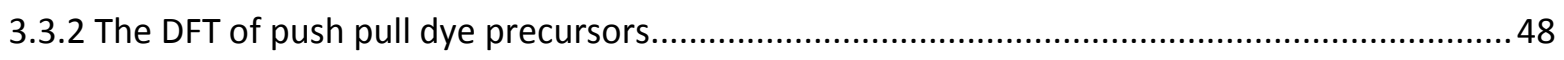

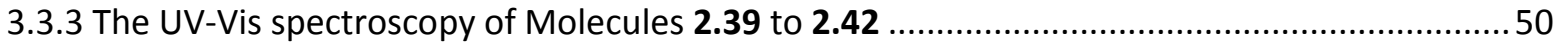

3.3.4 Electrochemistry of BODIPY containing building blocks ...................................................... 51

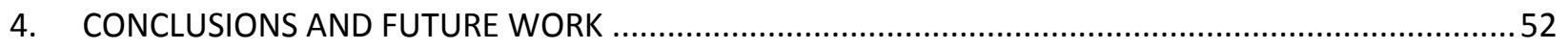

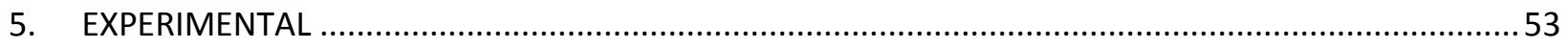

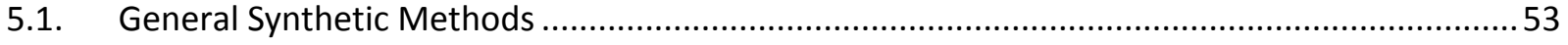

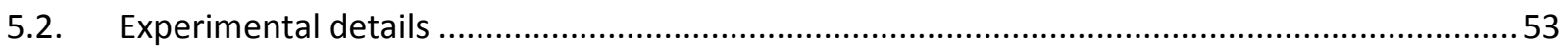

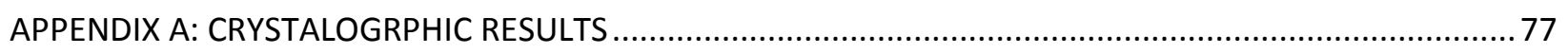

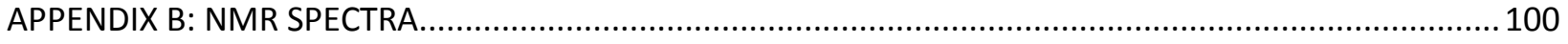

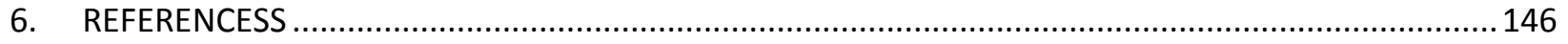




\section{List of Tables}

Table 1.1 Dye performance of dyes utilizing TPA as the electron donor ............................................. 12

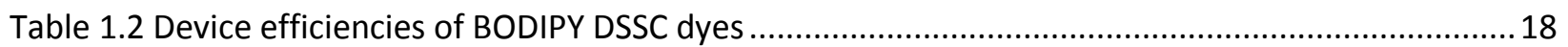

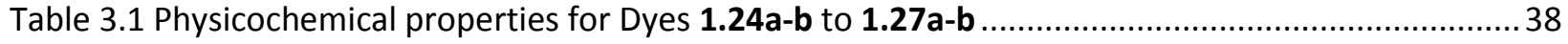

Table 3.2 Comparing the GI5 and Z1137 Electrolyte in 1.27b DSSC Device ............................................40

Table 3.3 DFT calculated energy levels in BODIPY cores (all energies reported in Hartrees) .....................44

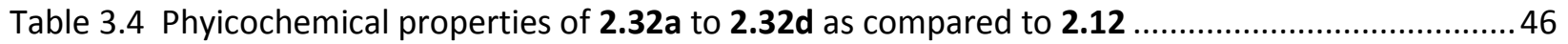

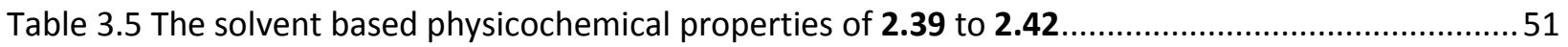




\section{List of Figures}

Figure 1.1 Total predicted future energy demand and feasible energy sources...................................... 1

Figure 1.2 Total energy reserves of fossil fuels and uranium compared to total annual solar irradiance ... 2

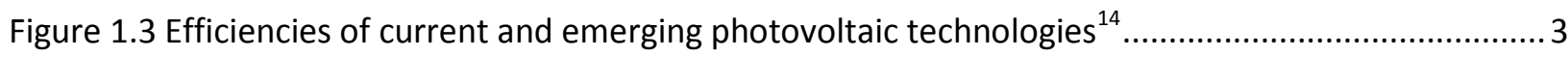

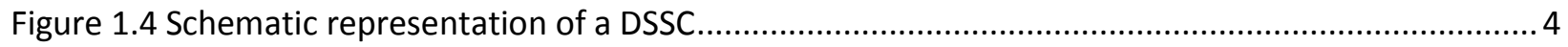

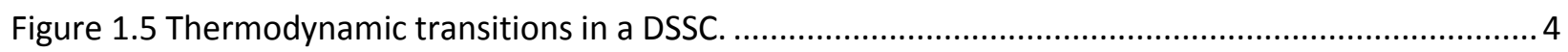

Figure 1.6 Favourable and unfavourable kinetic processes in a DSSC .................................................. 5

Figure 1.7 Factors affecting the extinction coefficient $\varepsilon$, and the Donor- $\pi$-acceptor motif ....................... 6

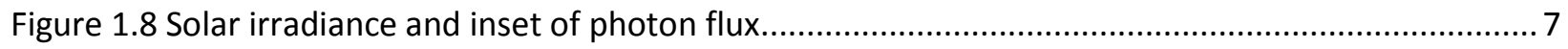

Figure 1.9 Donor $\pi$-spacer acceptor motif present in DSSC dyes ....................................................... 8

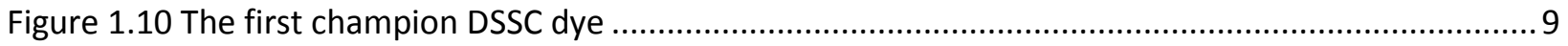

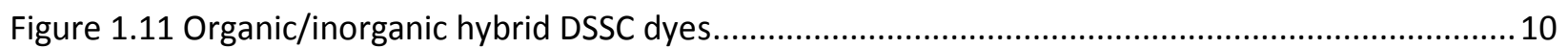

Figure 1.12 The Sun dye, a benchmark for efficiency.......................................................................... 11

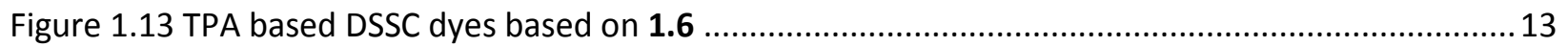

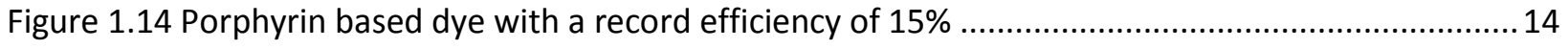

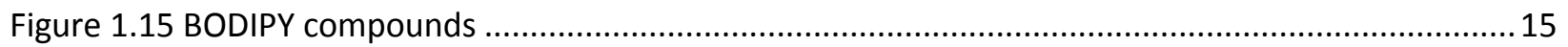

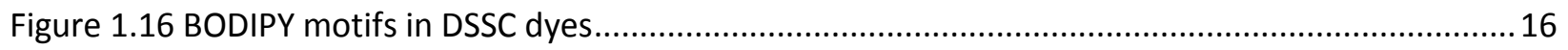

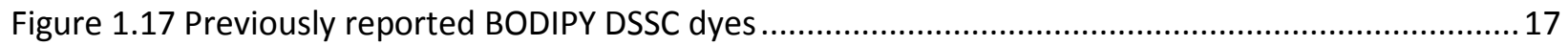

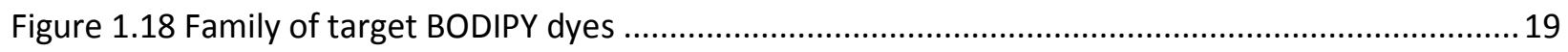

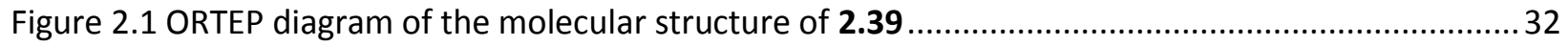

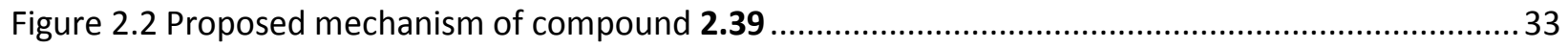

Figure 3.1 DFT calculations of the frontier molecular orbitals (FMO) of BODIPY DSSC dyes as calculated by B3LYP 6-31G Basis set. Red arrow indicates the dominant transition as predicted by TD-DFT. ...........35

Figure 3.2 UV-Vis of Dye 1.24a as predicted with TD-DFT. (1) The HOMO-LUMO transition, (2) the

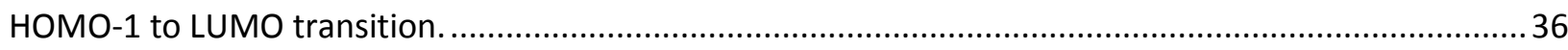

Figure 3.3 UV-Vis data of 2.12 and BODIPY Dyes 1.24a to 1.27a. Data Collected In DCM Solutions......... 37 Figure 3.4 Cyclic voltammogram of dye 1.26a as recorded in a solution of DCM. Data collected in $\mathrm{CH}_{2} \mathrm{Cl}_{2}$ using $0.1 \mathrm{M}\left[n \mathrm{Bu}_{4} \mathrm{~N}\right]\left[\mathrm{PF}_{6}\right]$ at $100 \mathrm{mV} / \mathrm{s}$ and referenced to a $[\mathrm{Fc}] /[\mathrm{Fc}]^{+}$internal standard $(+765 \mathrm{mV}$ vs. NHE

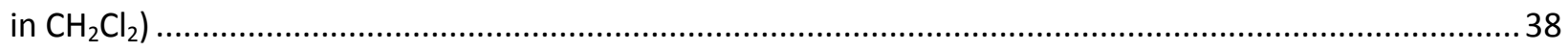

Figure 3.5 Preliminary device data of dye $1.27 \mathrm{~b}$. GI5* represents the same device as GI5 after 80

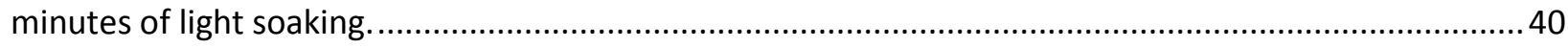

Figure 3.6 Predicted energy density diagrams of BODIPYs 2.32a to 2.32d ........................................... 42

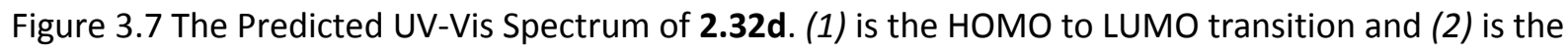

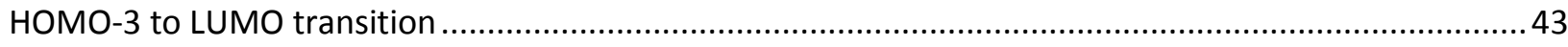

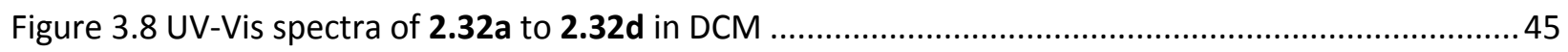

Figure $3.9 \mathrm{CV}$ of 2.32a showing a reversible reduction and oxidation. Data collected in $\mathrm{CH}_{2} \mathrm{Cl}_{2}$ using $0.1 \mathrm{M}$ $\left[\mathrm{nBu}_{4} \mathrm{~N}\right]\left[\mathrm{PF}_{6}\right]$ at $100 \mathrm{mV} / \mathrm{s}$ and referenced to a $[\mathrm{Fc}] /[\mathrm{Fc}]^{+}$internal standard $\left(+765 \mathrm{mV}\right.$ vs. NHE in $\left.\mathrm{CH}_{2} \mathrm{Cl}_{2}\right) 47$ Figure 3.10 Predicted optical transitions in molecules 2.39-2.42 ......................................................48

Figure 3.11 Predicted UV-Vis spectrum of 2.42. (1) HOMO - LUMO transition (2) HOMO - LUMO+1

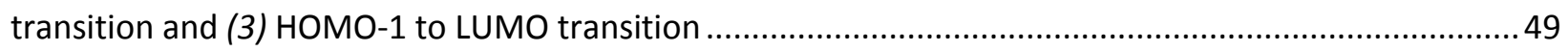

Figure 3.12 The Uv-vis spectra of molecules 2.39 to 2.42 in DCM ......................................................50 
Figure 4.1 Possible BODIPY based polymer (4.1) or OPV material (4.2) 


\section{List of Schemes}

Scheme 2.1: The synthesis of TPA donor moieties for organic DSSC dyes ...........................................21

Scheme 2.2: The synthesis of a protected aldehyde $\pi$-spacer for DSSC applications ..............................22

Scheme 2.3: The synthesis of a pentamethyl BODIPY for use as a non-innocent $\pi$-spacer for organic

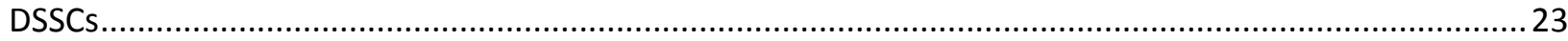

Scheme 2.4: The synthesis of an organic DSSC dye with a 2,6 modified BODIPY $\pi$-spacer .......................24

Scheme 2.5: The synthesis of a BODIPY dye with extended conjugation near the electron acceptor........ 25

Scheme 2.6: The synthesis of BODIPY with extended conjugation near the electron donor ..................... 26

Scheme 2.7: The synthesis of a BODIPY dye with extended conjugation on the 2 and the 6 position .......27

Scheme 2.8: The synthesis of electron rich BODIPY dyes through modification of the meso-position ..... 29

Scheme 2.9: Synthesis of BODIPY precursors for photovoltaic applications ............................................ 30 

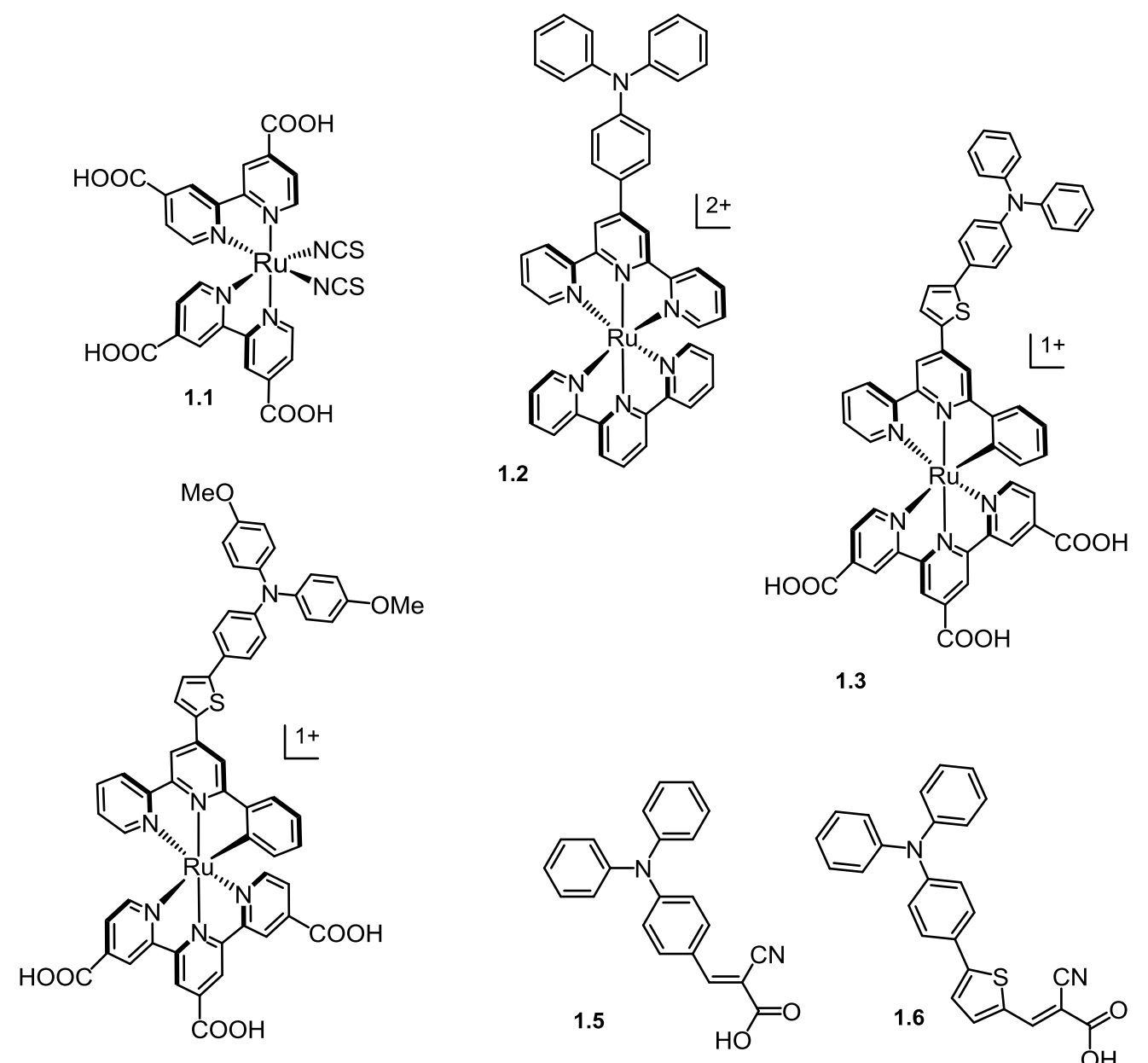

1.3
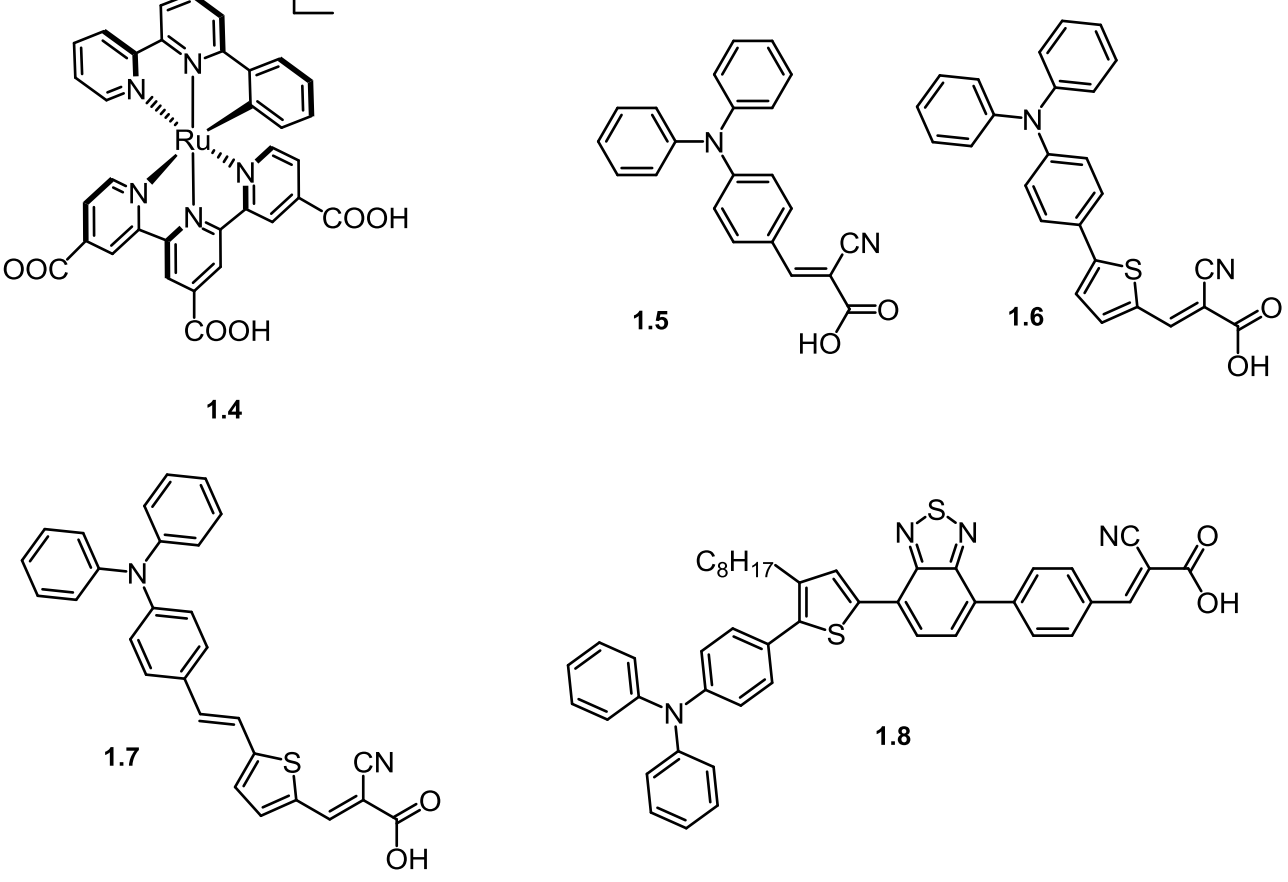


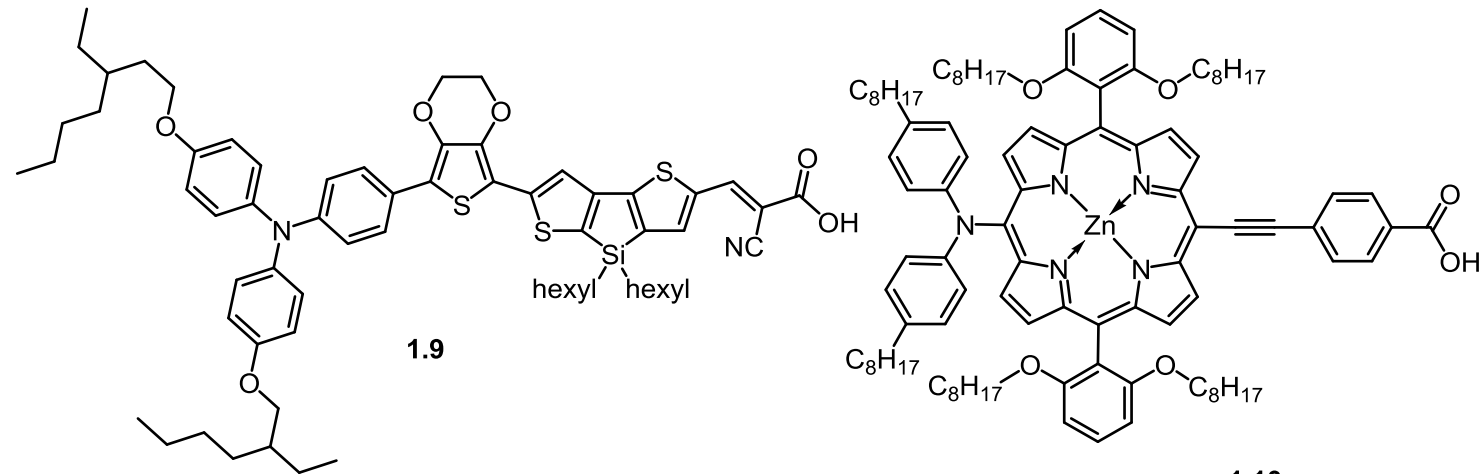<smiles></smiles><smiles></smiles>

1.10

1.11<smiles></smiles>

1.15

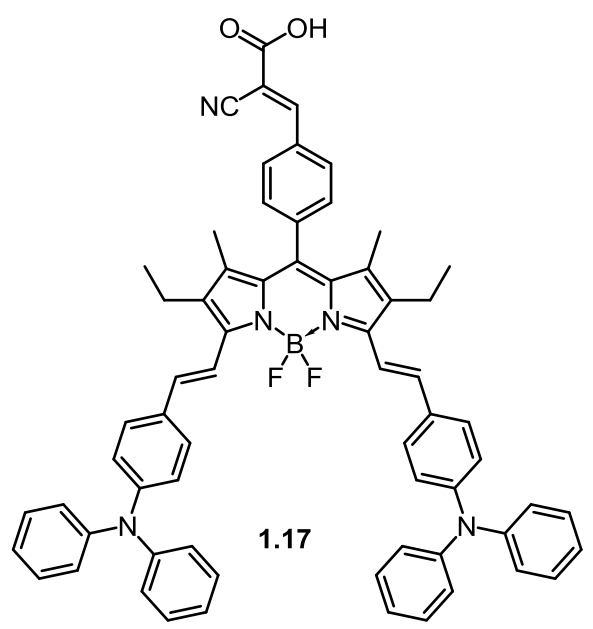<smiles></smiles>

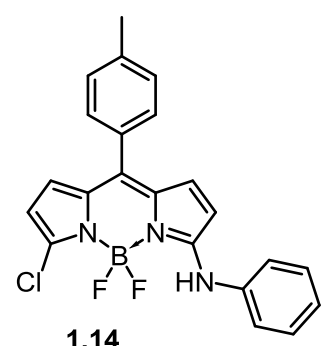

1.14

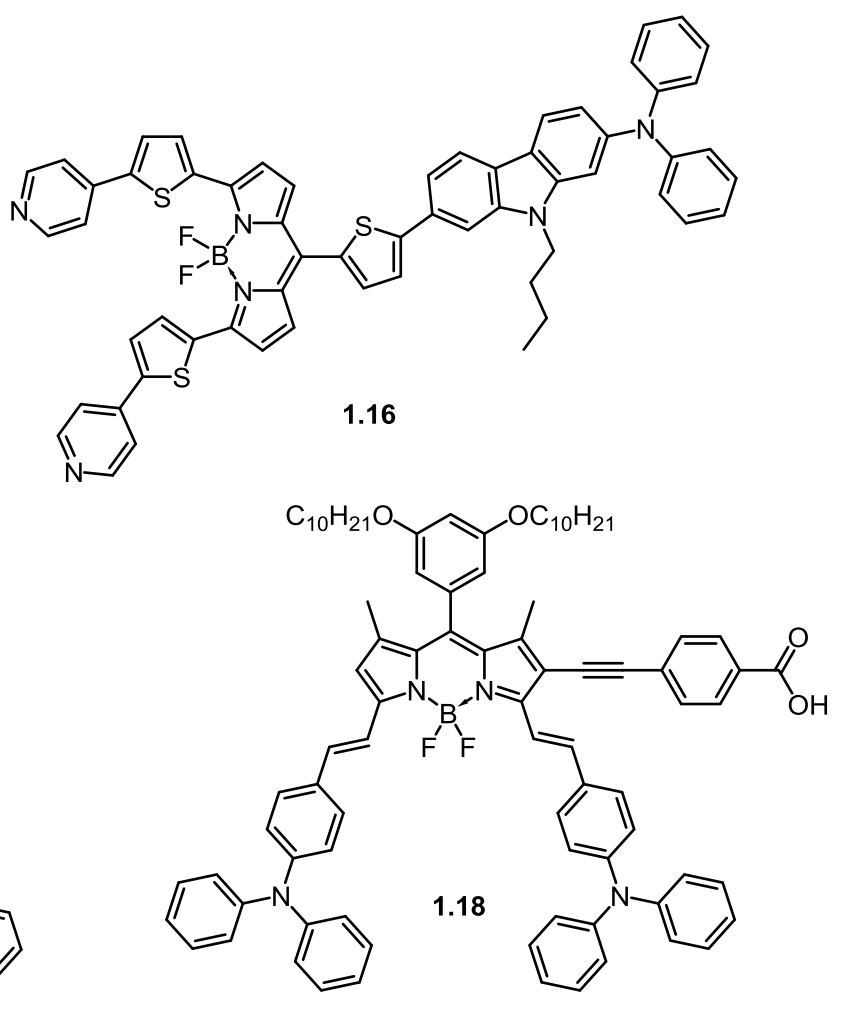

xii 
<smiles></smiles>

1.19a<smiles></smiles>

1.20<smiles></smiles>

1.22

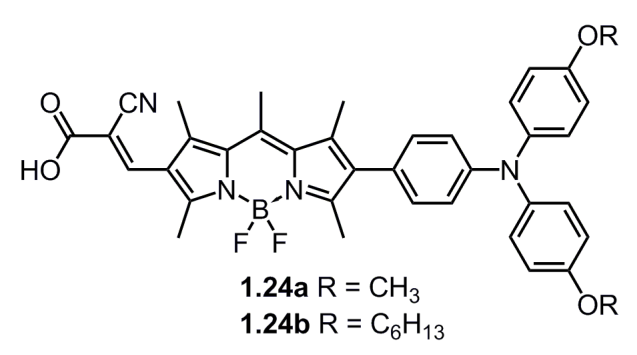<smiles>[R2]Oc1ccc(N(c2ccc([R20])cc2)c2ccc(-c3ccc(C4=C(C)C5=C(C)c6c(C)c(/C=C(\C)C(=O)O)c(C)n6B(F)N5C(C)=C4C)s3)cc2)cc1</smiles> 
<smiles>Cc1ccc(O)cc1</smiles>

2.1a $\mathrm{R}=\mathrm{CH}_{3}$ 2.1b $R=\mathrm{C}_{6} \mathrm{H}_{13}$<smiles>Nc1ccccc1</smiles>

2.2<smiles>[R2]Oc1ccc(N(c2ccccc2)c2ccc([R20])cc2)cc1</smiles>

2.3a $\mathrm{R}=\mathrm{CH}_{3}$ 2.3b $\mathrm{R}=\mathrm{C}_{6} \mathrm{H} 13$<smiles>[R]Oc1ccc(N(c2ccc(O)cc2)c2ccc(Br)cc2)cc1</smiles>

2.4a $\mathrm{R}=\mathrm{CH}_{3}$

2.4b $\mathrm{R}=\mathrm{C}_{6} \mathrm{H} 13$<smiles>[R7]Oc1ccc(N(c2ccc(O[R2])cc2)c2ccc(B3OC(C)(C)C(C)(C)O3)cc2)cc1</smiles><smiles>O=Cc1ccc(Br)s1</smiles><smiles>Brc1ccc(C2OCCO2)s1</smiles><smiles>CC1(C)OB(c2ccc(C3OCCO3)s2)OC1(C)C</smiles><smiles>CCOC(=O)CC(C)=O</smiles><smiles>[Z20]COC(=O)c1c(C)[nH]c(C(=O)OCC)c1C</smiles><smiles>Cc1c[nH]c(C)c1</smiles><smiles></smiles><smiles></smiles>

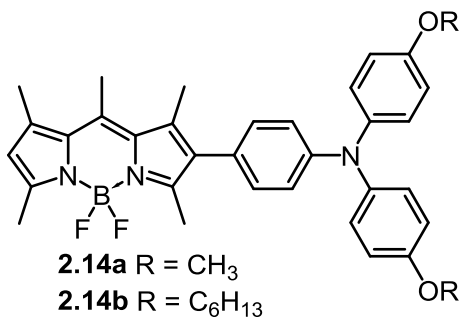

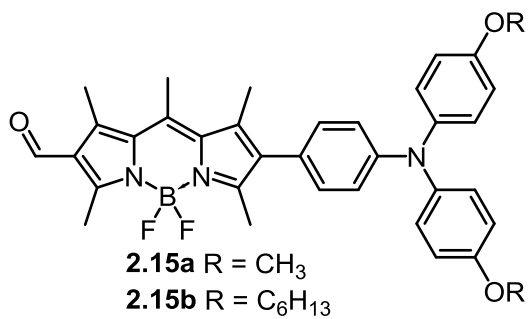<smiles>CC1(C)OB(c2cccs2)OC1(C)C</smiles>

2.16

$\mathrm{RO}$

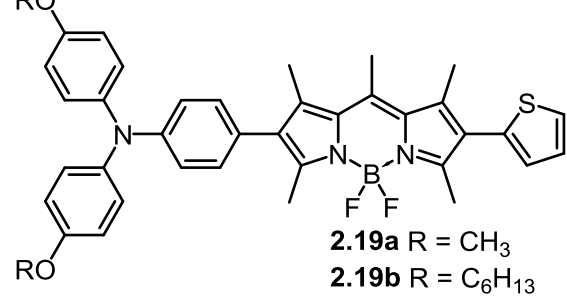

2.17

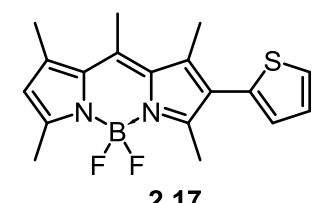<smiles>[Z16]Cc1c(-c2cccs2)c(C)c2n1B(F)n1c(C)c(I)c(C)c1C2C</smiles>

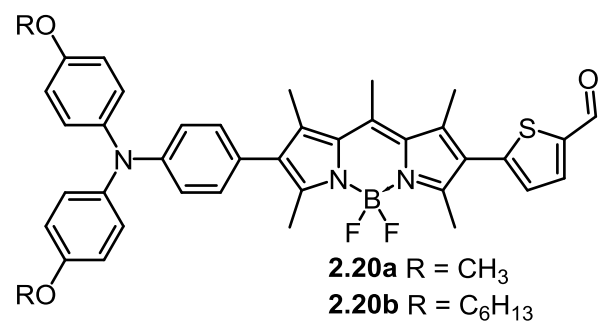



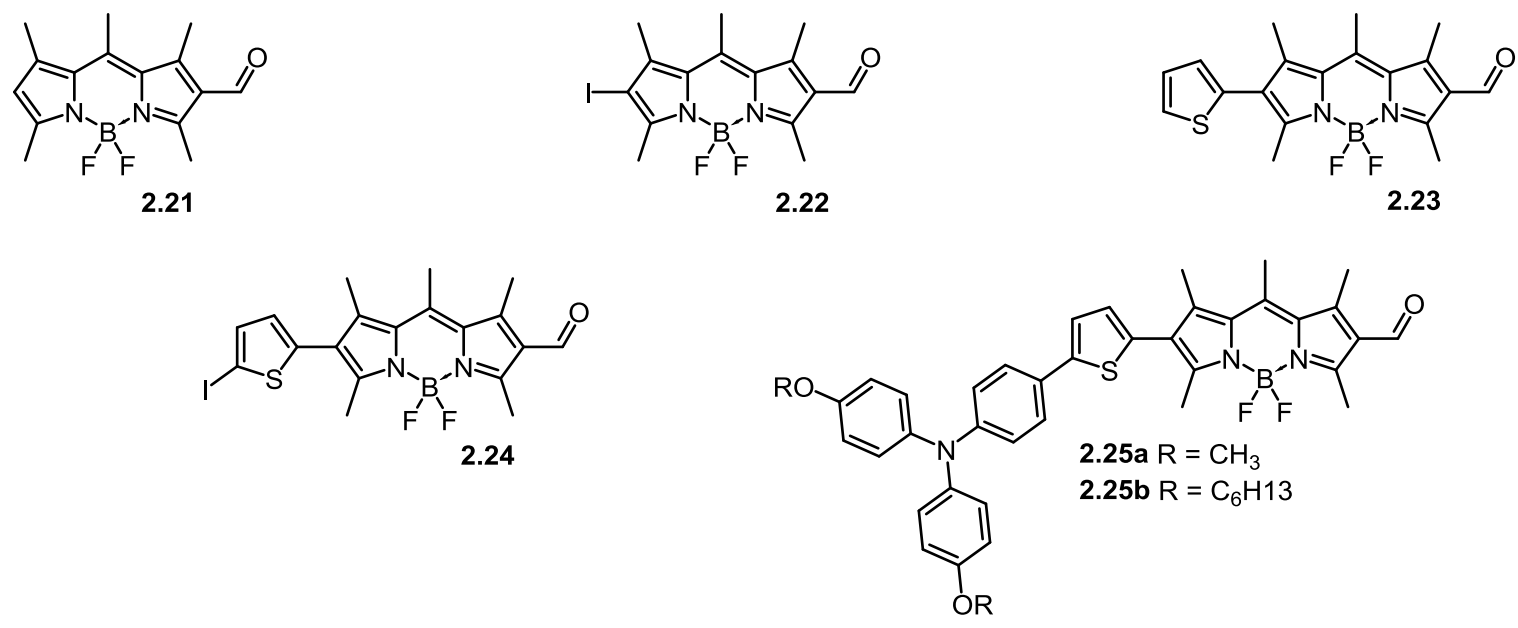

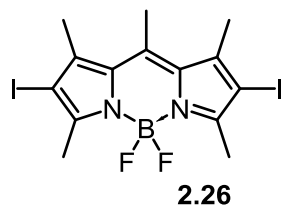<smiles></smiles>

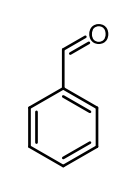

2.31a<smiles>COc1ccc(C=O)cc1</smiles>

2.31b<smiles>COc1cc(C=O)cc(OC)c1OC</smiles><smiles>O=Cc1ccc([N+](=O)[O-])cc1</smiles><smiles></smiles>

2.27<smiles></smiles>

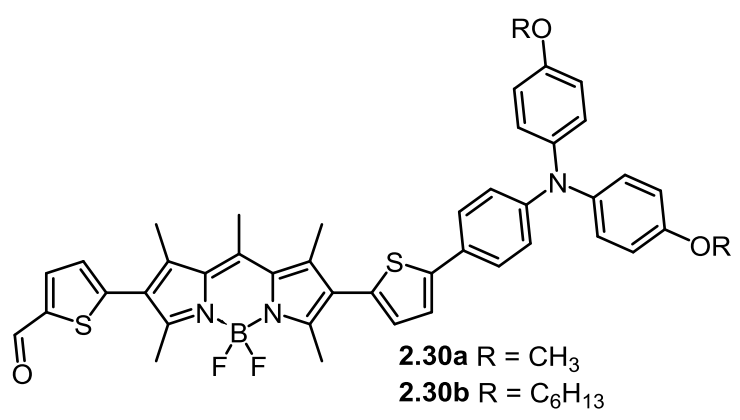

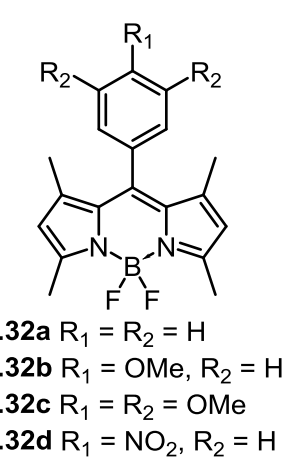

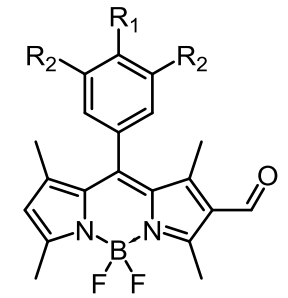

2.33a $R_{1}=R_{2}=H$ 2.33b R $\mathrm{R}_{1}=\mathrm{OMe}, \mathrm{R}_{2}=\mathrm{H}$ 2.33c $\mathrm{R}_{1}=\mathrm{R}_{2}=\mathrm{OMe}$ 2.33d $\mathrm{R}_{1}=\mathrm{NO}_{2}, \mathrm{R}_{2}=\mathrm{H}$

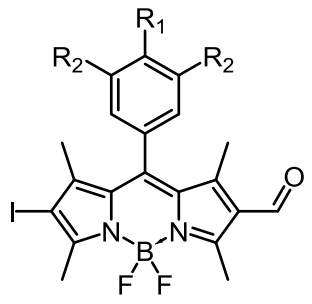

2.34a $R_{1}=R_{2}=H$ 2.34b $\mathrm{R}_{1}=\mathrm{OMe}, \mathrm{R}_{2}=\mathrm{H}$ 2.34c $R_{1}=R_{2}=O M e$ 2.34d $R_{1}=\mathrm{NO}_{2}, \mathrm{R}_{2}=\mathrm{H}$ 

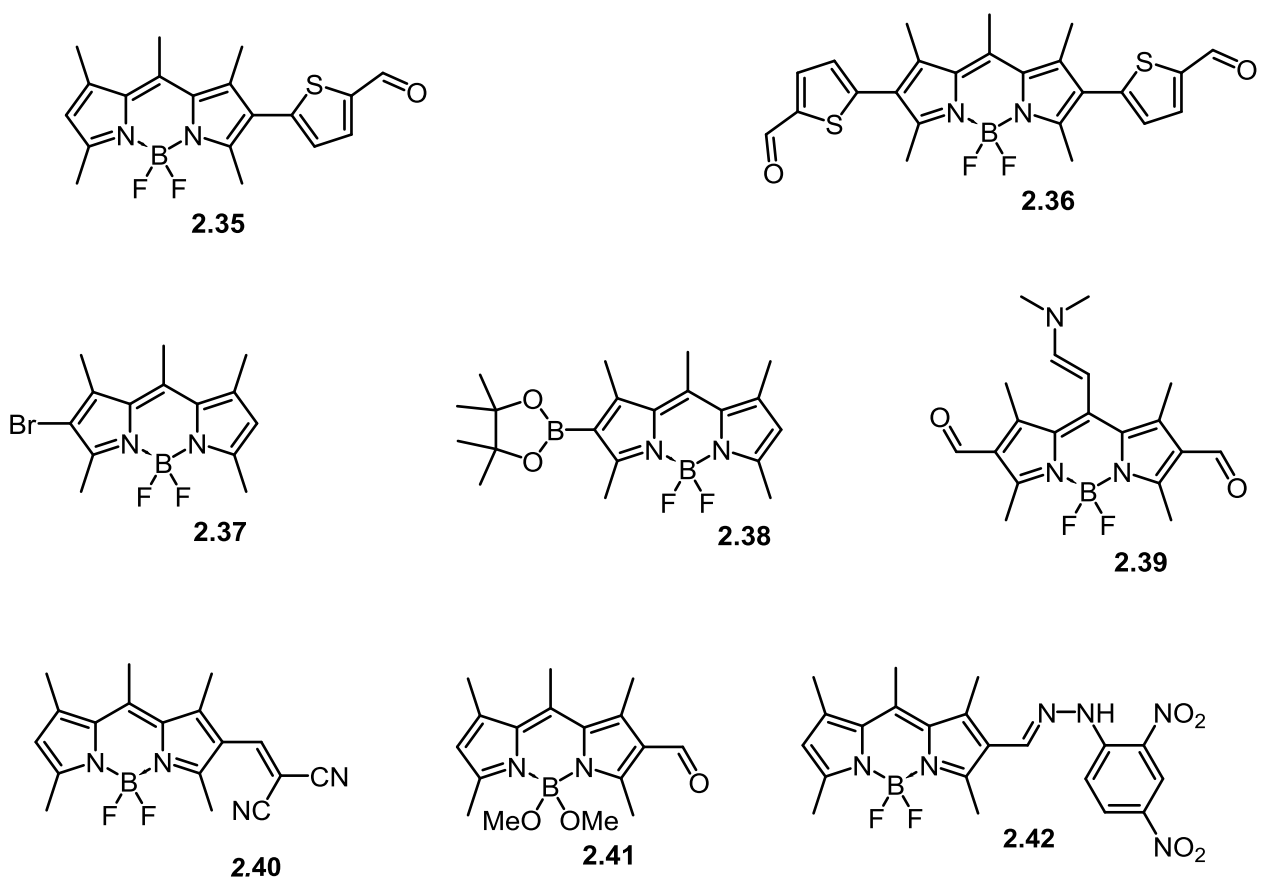


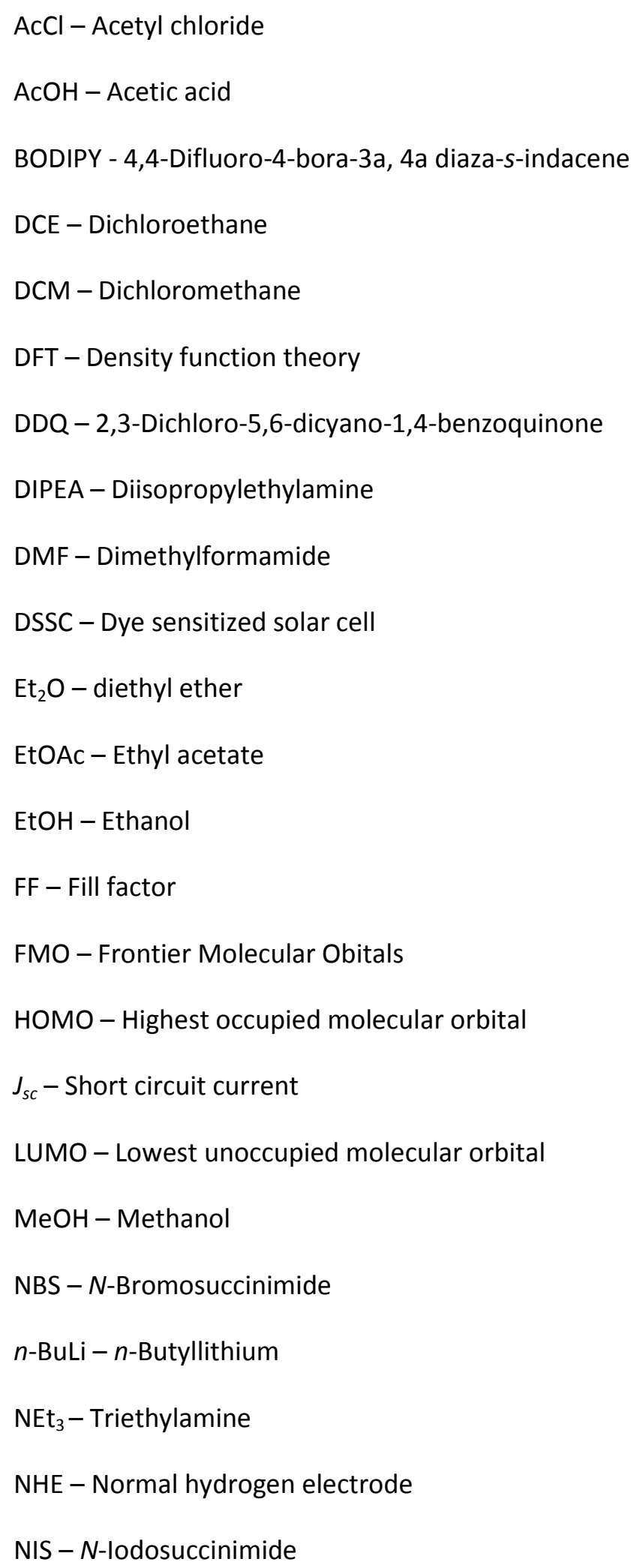


OPV - Organic photovoltatics

ORTEP - Oak Ridge thermal ellipsoid plot

PCC - Pyridinium chlorochromate

$\mathrm{Pd} / \mathrm{C}$ - Palladium on carbon

1, 10 Phen - 1, 10-Phenanthroline

PV - Photovoltaic

TD-DFT - Time dependent density functional theory

TFA - Trifluoroacetic acid

THF - Tetrahydrofuran

TPA - Triphenylamine

$p$-TsOH $-p$-Toluenesulfonic acid

$V_{o c}$ - Open circuit voltage 


\section{INTRODUCTION}

\subsection{Energy on planet Earth}

Since the industrial revolution energy demands around the globe have increased dramatically. ${ }^{1}$ Our energy demand is constantly growing and disregarding the economic collapse in 2009, global energy demand has increased every year this century. ${ }^{2}$ Today, developing countries are requiring more energy as they strive to provide a greater standard of living for their inhabitants. ${ }^{3}$ Due to the low cost of fossil fuels (especially coal) carbonaceous energy sources have been employed to meet these energy demands. A consequence of this is a massive and well publicized increase in atmospheric $\mathrm{CO}_{2}$ levels in the past 50 years caused largely by the combustion of fossil fuels. ${ }^{4}$ This has led to a rapid climate change of our planet causing 2012 to be the hottest year ever recorded in the USA. ${ }^{5}$

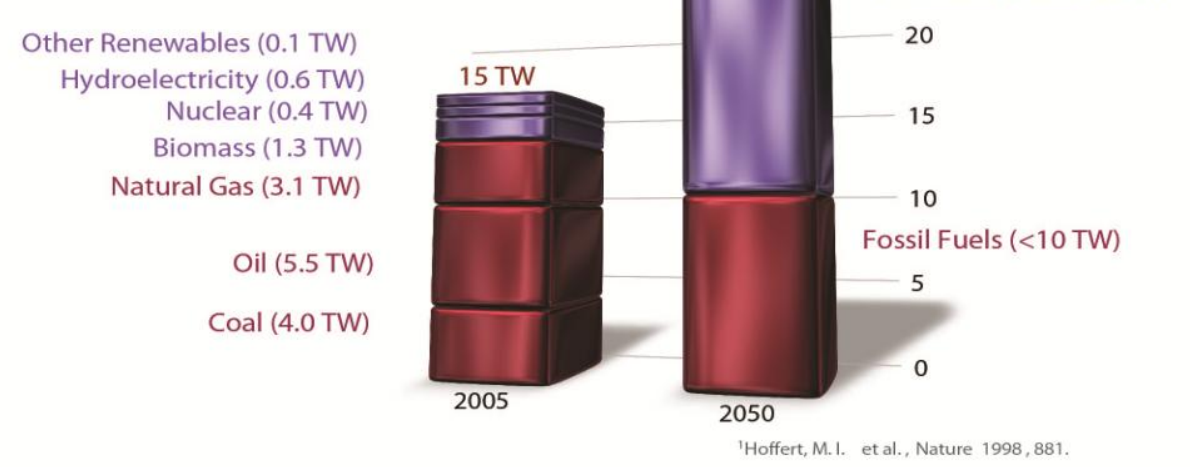

Figure 1.1 Total predicted future energy demand and feasible energy sources

In 1998 Hoffert and co-workers predicted that by 2050 global energy demand would grow to 30 TW. ${ }^{6}$ Furthermore, this study also states that two thirds of this future energy will need to come from renewable sources or there will be severe environmental, economic and social consequences caused by irreversible damage done to the planet. ${ }^{7}$ Alternative energy sources need to be explored to reduce the environmental strain caused by increasing $\mathrm{CO}_{2}$ levels. Two of the largest non-carbonaceous energy sources come from biomass and nuclear energy. ${ }^{8,9}$ Biomass requires the combustion of fast growing 
crops which is a carbon neutral; however, it requires large portions of agricultural land which could otherwise be used to feed the growing population. Nuclear energy also produces no $\mathrm{CO}_{2}$ but requires long term storage of dangerous waste and is also unpopular in public opinion due to recent nuclear disasters. Considering these issues with nuclear fission, solar energy has the highest potential to accommodate the expected drastic increase in energy consumption. ${ }^{10}$

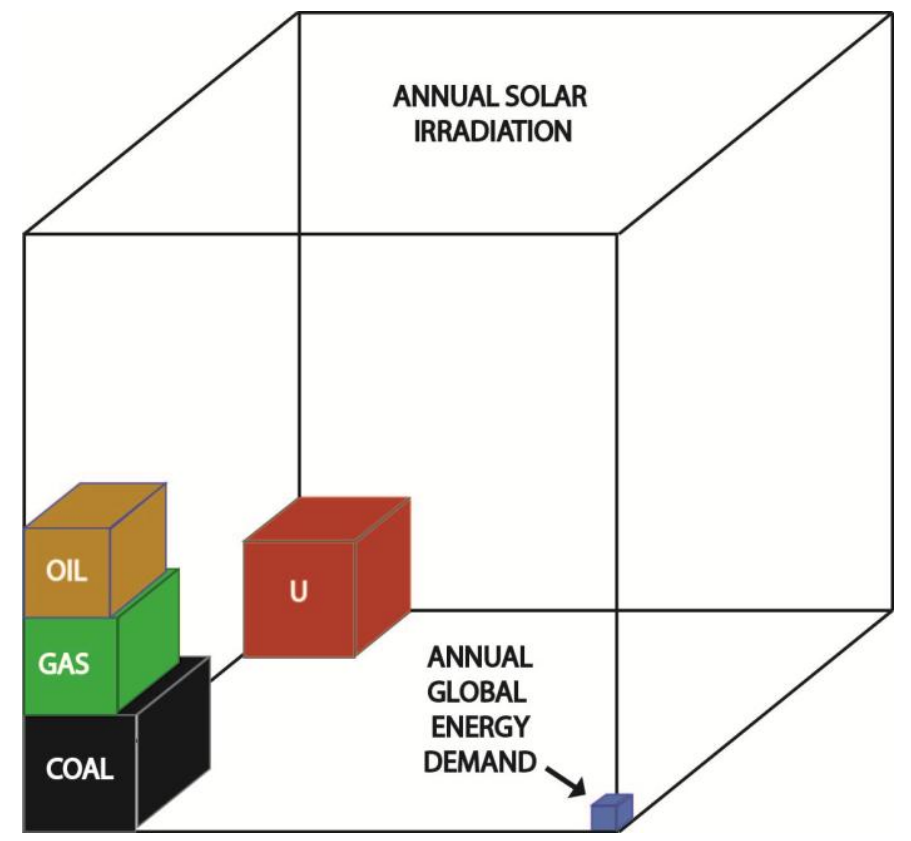

Figure 1.2 Total energy reserves of fossil fuels and uranium compared to total annual solar irradiance

In fact, the sun provides the earth with 175,000 TW of energy, meaning that in approximately 50 minutes, the sun has provided the Earth with enough energy to last for an entire year. ${ }^{10,11}$ It is projected that 600 TW is feasible solar energy target, and that 10\% efficiency solar panels would provide 60 TW, which is more than double the projected demand. ${ }^{11}$ Silicon-based photovoltaic (PV) devices (solar cells) are already able to achieve efficiencies upwards of $20 \%{ }^{12}$ however, these PVs are incredibly costly to produce, which makes the current technologies uncompetitive when compared against fossil fuels. As such a plethora of research has been performed examining alternative PV technologies. As shown in Figure 1.3, second generation thin film photovoltaics have excellent efficiencies but there are environmental concerns over a possible release of heavy metals into the environment. ${ }^{13}$ 


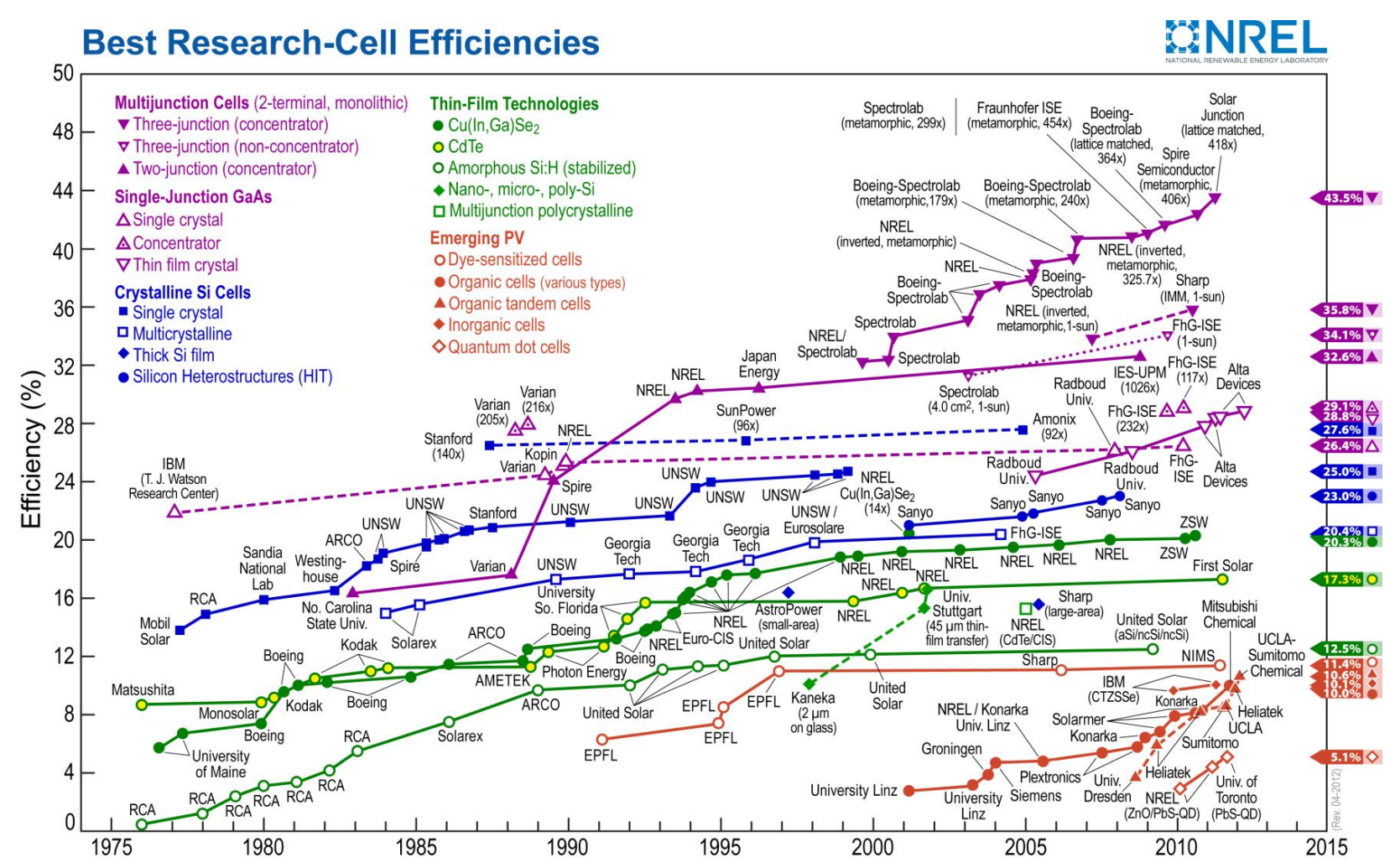

Figure 1.3 Efficiencies of current and emerging photovoltaic technologies ${ }^{14}$

Currently emerging photovoltaic technologies including quantum dot cells and organic photovoltaics (OPVs) are being extensively studied. The most efficient next generation PV technology is the dye sensitized solar cell which, has a current record efficiency of $15.0 \%{ }^{15}$

\subsection{The dye sensitized solar cell (DSSC)}

The dye sensitized solar cell (DSSC) is a promising next generation PV technology. These devices may be easily fabricated, can be optically transparent and are potentially far cheaper per Watt output as compared to $\mathrm{SiO}_{2}$ based photovoltaics. Figure 1.4 represents the anatomy of the DSSC, which is comprised of a transparent photoanode made from a conducting material such as indium doped tin oxide (ITO) or fluorine doped tin oxide (FTO). ${ }^{11} \mathrm{~A}$ thin layer of a mesoporous semiconductor, typically titania $\left(\mathrm{TiO}_{2}\right)$ is sputtered onto the anode which is soaked in a solution containing a dye molecule which covalently binds the die molecules to the semiconductor surface. ${ }^{16}$ A counter electrode made of a similar conducting glass material as the photoanode, is covered with a thin layer of Pt to catalyze redox reactions of the electrolyte and sandwiched on top of the anode. Finally a liquid electrolyte is added to fill the void between the electrodes and mediate the redox reactions taking place in the device. 


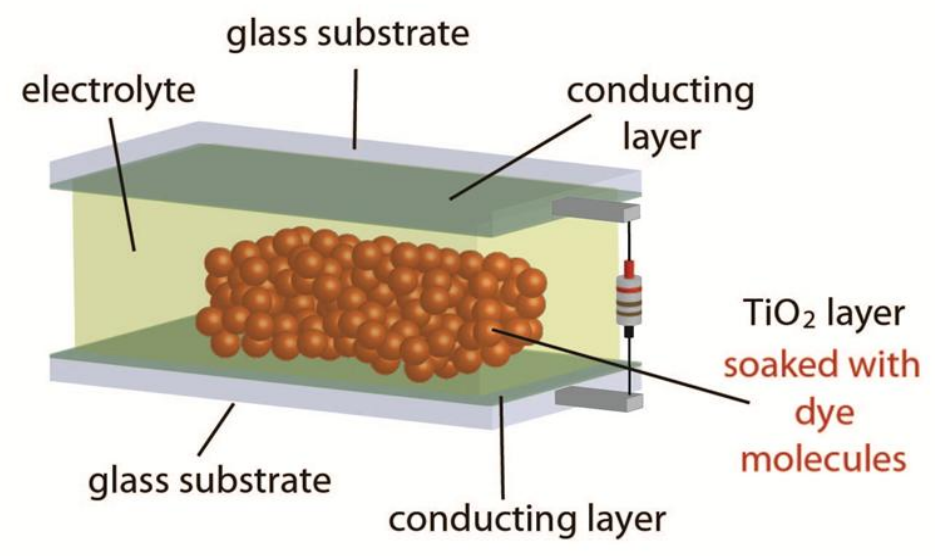

Figure 1.4 Schematic representation of a DSSC

All of the components mentioned can be tuned to improve device stability and performance. As this is a molecular based PV device there are several thermodynamic barriers that need to be overcome to ensure efficient devices.

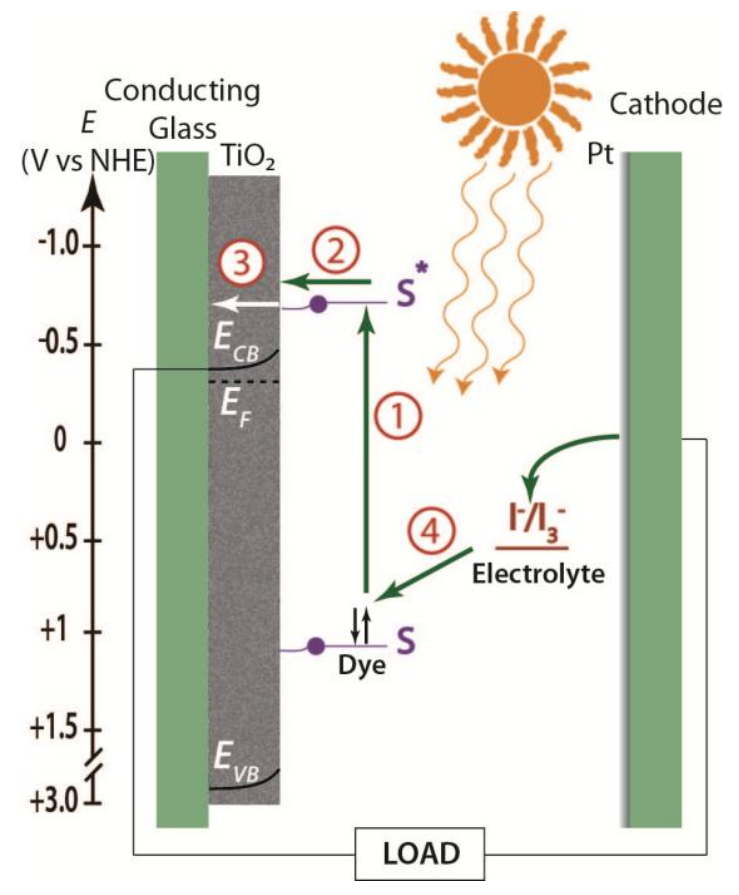

Figure 1.5 Thermodynamic transitions in a DSSC. 
Figure 1.5 shows the working principle of the DSSC; ${ }^{17}$ (1) a photon of sufficient energy strikes the dye molecule which causes a photoexcitation of an electron from the ground state (S) to the excited state $\left(S^{*}\right)$. The $S^{*}$ energy level must be of sufficient energy that there exists a thermodynamic driving force for charge injection from the $S^{*}$ to the conduction band of the semiconductor (2). The electron percolates through the semiconductor to an external load and then the redox electrolyte (3). The redox couple of the electrolyte that regenerates the dye must be at a sufficient energy that it is energetically favourable for the dye molecule to be reduced back to the ground state (4). ${ }^{18}$ This represents the ideal thermodynamic pathway for the DSSC to operate however there exist other thermodynamically favourable pathways that would result in a short circuit of the DSSC. ${ }^{11}$ The kinetic rates at which each one of these processes occurs becomes greatly important for the proper operation and thus efficiency of a DSSC device. Figure 1.6 shows the kinetic competitions that are present in the DSSC, after photoexcitation the desirable process injection (d) must compete with relaxation (b) and a short circuit by which the excited electron is transferred to the electrolyte solution (c). Upon charge injection to the conduction band of the $\mathrm{TiO}_{2}$ there are two processes that compete with electron transfer to the external circuit. First, if the ground state of the dye molecule is not regenerated by the electrolyte (h), there exists a recombination pathway from the conduction band $(\mathbf{g}) .^{19}$

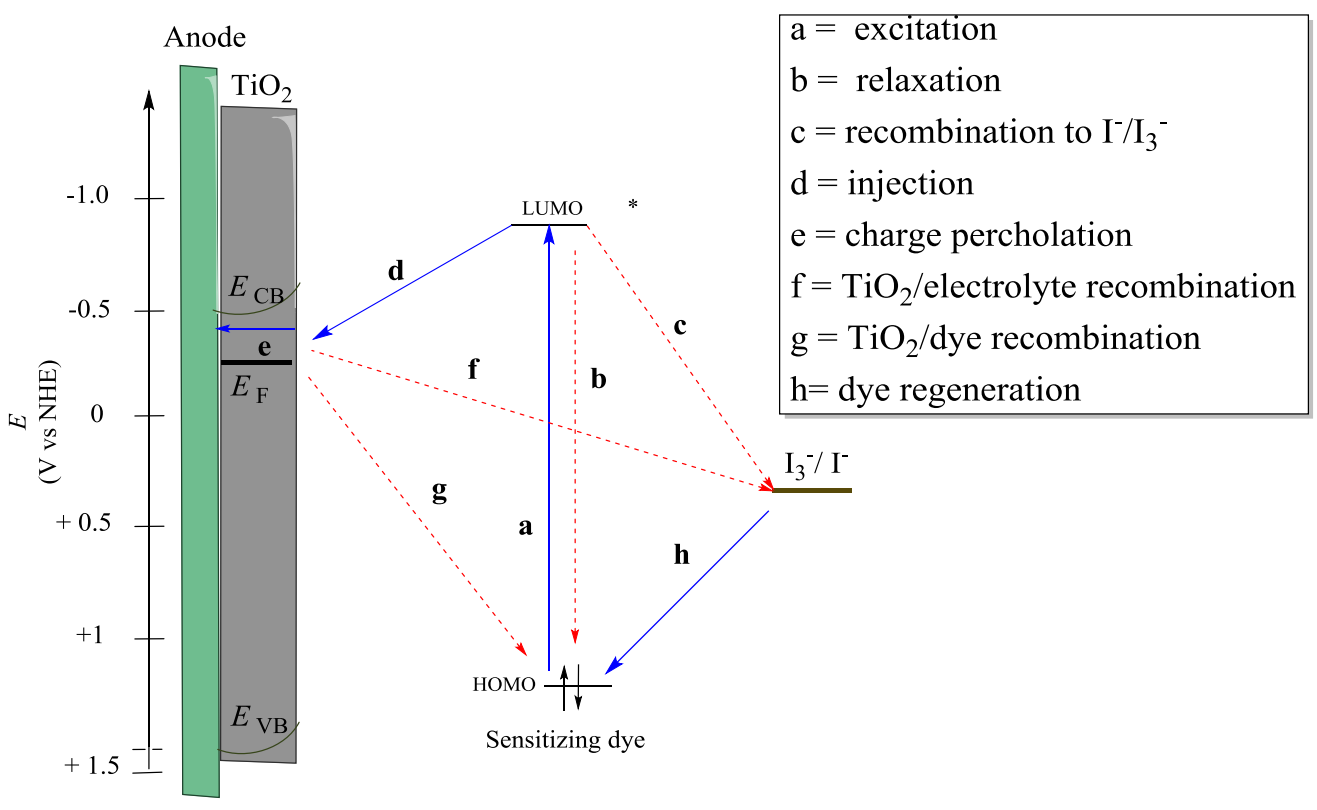

Figure 1.6 Favourable and unfavourable kinetic processes in a DSSC 
However, the most problematic recombination pathway is (f) whereby the electron injected to the conduction band recombines with the electrolyte redox couple. ${ }^{20}$ This recombination has been a large problem for the development of new electrolyte materials for DSSC devices. Nevertheless, this recombination pathway can be somewhat mitigated through surface passivation by the addition of coabsorbents to the $\mathrm{TiO}_{2}$ nanoparticles. ${ }^{21}$ Similarly, bulky alkyl chains can be added to the periphery of DSSC dye molecules to block the electrolyte dye interface in an attempt to reduce this process. ${ }^{22}$ The DSSC is a complex device that relies on multiple thermodynamic and kinetic pathways to convert solar to electrical energy. All components of the DSSC are currently under study to maximize the efficiency of these devices. ${ }^{11}$ The component of the device of interest to our group is the dye molecule itself which acts as the devices power house and is responsible for photon absorption.

\subsection{How molecules absorb light}

When designing dyes for DSSC applications it is important to first understand how molecules absorb light. It is paramount that dyes absorb as much visible and infra red light as possible. Typically, these molecules possess a redox-active donor tethered to a strong electron acceptor and upon photon absorption significant charge separation occurs between the ground and excited state. Because this absorption is quantized, electron density goes directly from the HOMO to LUMO and is never inbetween. The molecules propensity to absorb light can be measured by UV-vis spectroscopy by examining the absorption envelope of the molecule and the extinction coefficient $(\varepsilon)$ which is the intensity of the absorption. The wavelength of absorption corresponds (to a first approximation) to the length of conjugation within the dye molecule. Conjugated molecules obey the 1D particle-in-a-box model, and therefore extension of the box (conjugated system) leads to a decrease in the HOMO-LUMO gap and a more red-shifted absorption. ${ }^{23}$ The molar extinction coefficient relates two physical quantities: (1) optical cross-section and (2) the probability of absorption.

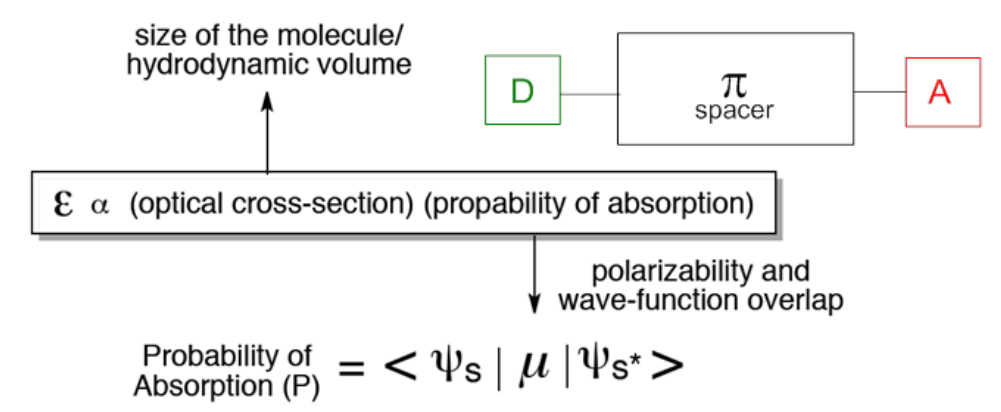

Figure 1.7 Factors affecting the extinction coefficient $\varepsilon$, and the Donor- $\pi$-acceptor motif 
The optical cross-section is proportional to the actual size of the molecule, while the probability directly relates to quantum mechanics. The most probable absorption ( $S$ to $S^{*}$ ) corresponds to a transition between the two electronic states with the best wave function overlap (Frank-Condon Principle). ${ }^{24}$ The dichotomy here pertains to the polarizability $(\mu)$ operator (transition dipole moment). Polarizability represents a molecules propensity to undergo charge redistribution upon photon absorption. However, with greater charge distribution, then there is necessarily less wave function overlap between ground and excited states which reduces extinction coefficient. $\varepsilon$ can be predicted by time dependant density functional theory (TD-DFT) and as such TD-DFT was performed on all target compounds.

\subsection{Designing dye molecules}

Since the dye molecule is responsible for light harvesting dye molecules will need to be synthesized and tuned to harvest as much solar energy as possible. The solar spectrum and photon flux diagrams are shown in Figure 1.8 and provide insight into how many photons of a given wavelength are striking the earth's surface during broad daylight.

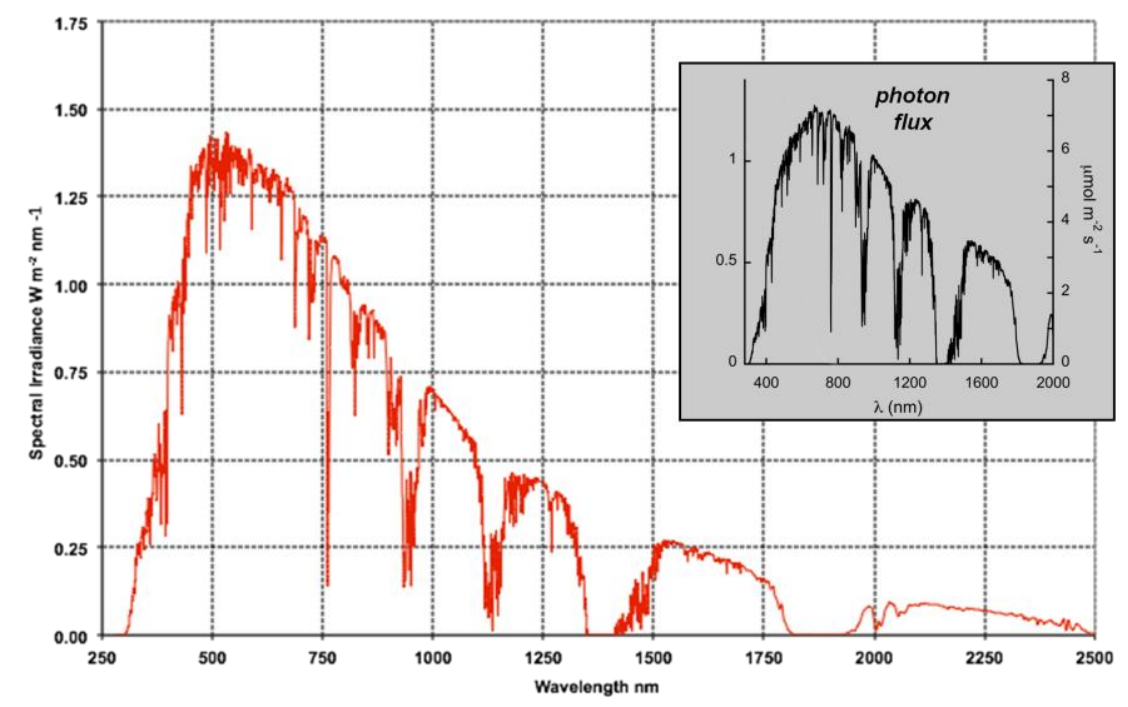

Figure 1.8 Solar irradiance and inset of photon flux

As shown in Figure 1.8 there is very little photon flux in the UV region of the electromagnetic spectrum due to the filtering effect of the ozone layer. With limited high energy photons to absorb it is crucial that dyes for DSSC applications have a broad absorption envelope that includes most of the visible light 
region all the way down to near infrared (NIR) light. ${ }^{25}$ As stated in chapter 1.3 chromophores can be systematically tuned by modifying electronic properties and conjugation length of molecules.

\subsection{Components of DSSC dyes}

DSSC dyes are comprised of three main components that permit the tuning of frontier energy levels and have an effect on extinction coefficients, absorption profile and electron transfer rates. There is a redoxactive donor, a $\pi$-bridge and an acceptor that is capable of binding to the $\mathrm{TiO}_{2}$ semiconductor anode. The redox active chromophore acts as an electron donor group. A photon is absorbed by the donor (HOMO), and is transferred to the acceptor/anchor (LUMO). Donor moieties usually consist of electronrich moieties designed to increase HOMO energy level which lowers the energy gap of the molecule and bathochromically shifts the absorption envelope. It is also hypothesized that strong electron donating characteristics favor the stability of the photo-oxidized donor species and reduce electron relaxation back to the ground state, thus increasing the efficiency of the device. ${ }^{26}$

The conjugated $\pi$-spacer/bridge (black, Figure 1.9) connects the donor/chromophore and the anchor/acceptor. Their length and constitution have varied enormously over the past decade in an attempt to harvest ideal wavelengths of light while achieving high extinction coefficients. ${ }^{27}$ In particular thiophene based $\pi$-spacers have received large interest due to their exceptional electron transport properties.

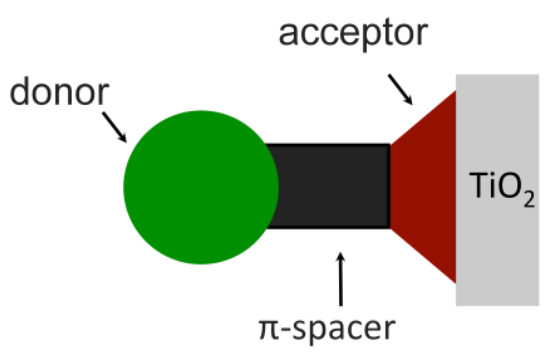

Figure 1.9 Donor $\pi$-spacer acceptor motif present in DSSC dyes 
The anchor/acceptor moiety of the dye (red, Figure 1.9) molecule also is capable of binding to the dye molecule to the semiconductor. Anchor groups are amongst the least studied DSSC components owing to the requirement of the anchor forming a covalent bond to the $\mathrm{TiO}_{2}$. Electron deficient anchor groups such as $\mathrm{COOH}, \mathrm{COO}^{-}$and $\mathrm{HSO}_{3}$ have been investigated but currently cyanoacetic acid groups are the anchor of choice due to their stronger electron withdrawing effect and electron transport properties. ${ }^{28}$

\subsection{Metal containing DSSC dyes}

The DSSC was first reported in 1991 by O'Regan and Gratzel using a Ru based sensitizer. ${ }^{29}$ Two years later the Gratzel group reported the first ever "Champion" DSSC dye (1.1) with an efficiency of $11.03 \%{ }^{16}$ This dye and its many champion derivatives, sensitize $\mathrm{TiO}_{2}$ by employing metal to ligand charge transfer (MLCT) from the Ru core to the bipyridyl groups which contain a $\mathrm{COOH}$ anchoring group to bind the dye molecule to the titania. ${ }^{30}$ As such there exists an electron rich donor part of the molecule comprised of the Ru centre and the NCS ligands (the donor). The $\pi$ - spacer consists of the bipyridyl ligands and an electron deficient accepting part of the molecule comprised of the electron deficient carboxylic acid groups. $^{31}$

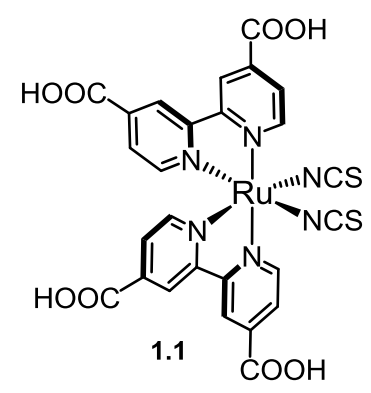

Figure 1.10 The first champion DSSC dye 


\subsection{Hybrid Organic-inorganic DSSC dyes.}

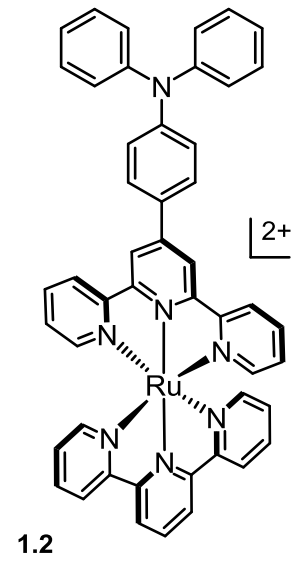

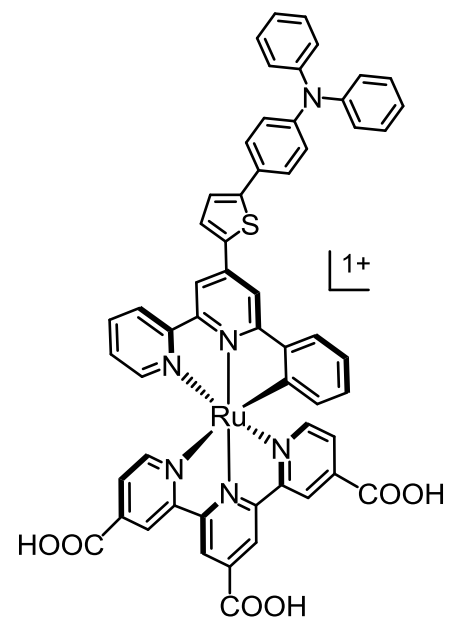

1.3

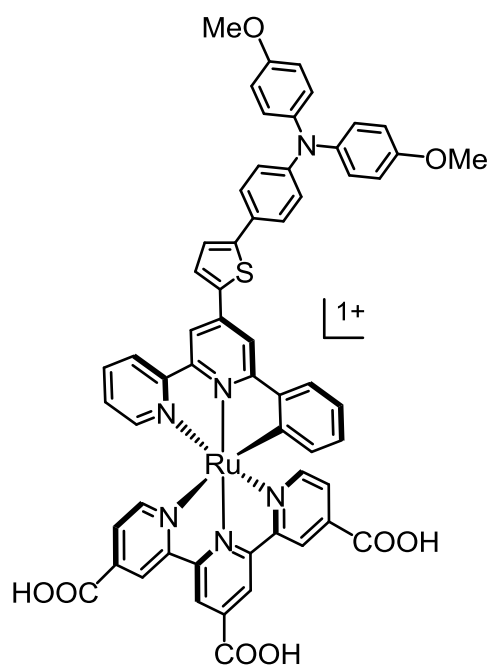

1.4

Figure 1.11 Organic/inorganic hybrid DSSC dyes

In an attempt to achieve greater efficiencies through a greater tunability in DSSC devices organic frameworks were added to the ruthenium metal core. The addition of an organic electron donor creates two possible photoexcitations, that could each expand the absorption profile of a device. ${ }^{32}$ The HOMO of the molecule would still reside on the Ru metal centre of the molecule and the LUMO would be localized on the carboxylic anchor groups as expected for a metal-based DSSC dye. However, the addition of an electron rich triphenylamine (TPA) to the periphery of one of the ligands allows for a HOMO-1 energy level to be present on the organic frame work which can also provide electrons to the LUMO excited state creating a broader absorption envelope and possibly increasing device efficiency. ${ }^{33}$ Of the dyes presented in Figure 1.111 .4 was able to show a peak efficiency of $8.02 \%$ which is quite impressive for a thiocyanate free DSSC dye. ${ }^{34}$ However, despite the promise of this work and the tunability of the organic TPA fragment DSSC dye research began to shift away from Ru based sensitizers due to the high cost of the metal centre and the overall global supply of ruthenium being too scarce for mainstream implementation. ${ }^{35}$

\subsection{Metal free organic dyes}

While most "champion" DSSC dyes contain a Ru metal centre, there is intense research interest on metal free dye molecules for DSSC applications. Organic dyes have the advantage of readily available syntheses from more abundant elemental sources (i.e., carbon) with devices that are cheaper to 
prepare and fabricate. Furthermore the energy levels of organic molecules is readily tuned and the entire organic chemistry toolbox can be utilized to make the most efficient dyes possible. ${ }^{36}$ Similar to their metal containing relatives organic based DSSC dyes contain the same donor, $\pi$-spacer, acceptor motif with the greatest difference present in the donor component.

In metal containing DSSC dyes the energy transfer relies on a MLCT, to move electron density from the middle of the molecule to the periphery where it can be injected to the $\mathrm{TiO}_{2}$. Since organic molecules are metal free there is no MLCT and the dye must rely on a $\pi$ to $\pi^{*}$ transition. Generally this organic transition fits a narrow absorption profile and is of high energy which make organic molecules challenging for DSSC applications. However, using the information presented in Chapter 1.3, organic DSSC dyes have begun to rival Ru based dyes in term of overall efficiency. The donor portion of an organic dye is typically constructed of an electron rich aromatic system; originally these were benzopyran ${ }^{37}$ or imidazole derivatives. ${ }^{38}$ More recently, substituted triphenylamines (TPA) have been utilized due to their strong electron donating ability and their large hydrodynamic volume which reduces dye aggregation. ${ }^{39,40}$ Similarly, TPAs can be easily substituted to change their electronic properties or to steric bulk of the molecule to passivate the surface of $\mathrm{TiO}_{2}$. $\pi$-spacers in organic dyes typically are comprised of a conjugated organic linker where five membered aromatic rings being the most prevalent. These rings have a distinct advantage over six member rings because they allow molecules to sit more planar maximizing electronic communication. ${ }^{41}$ As with metal containing dyes the anchor acceptor group must be strongly electron withdrawing and there is little deviation in the literature from $-\mathrm{COOH}$ and cyanoacetic acid anchor groups in organic DSSC dyes. ${ }^{42,43}$

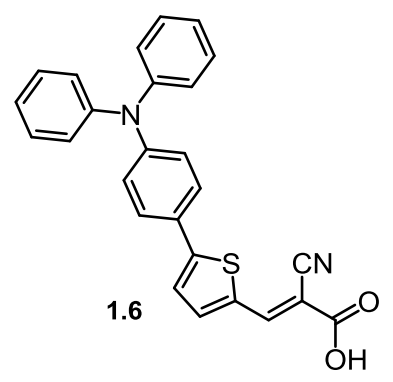

Figure 1.12 The Sun dye, a benchmark for efficiency. 
A significant breakthrough in organic DSSC dyes occurred in 2007 when the Sun group published 1.6. ${ }^{44}$ This dye contained a TPA donor, thiophene $\pi$-spacer and a cyanoacetic acid anchor group, all of which are now used as benchmarks in organic dye synthesis. While this dye originally was only $2.75 \%$ efficient it has since been optimized to over $5.2 \%{ }^{45}$ Table 1.1 along with Figure 1.13 show the effect of modifying the $\pi$-spacer in a DSSC dye. The benchmark compound $\mathbf{1 . 6}$ can be compared to $\mathbf{1 . 5}$ as the only modification is removal of the thiophene spacer. As expected the reduced conjugation length blueshifts the absorption from 494 to $400 \mathrm{~nm}$, this causes a reduction in the amount of photons that are of sufficient energy to excite the dye so the current drops dramatically. The ultimate effect is that $\mathbf{1 . 5}$ has less than half the efficiency of $\mathbf{1 . 6 .}$

Table 1.1 Dye performance of dyes utilizing TPA as the electron donor

\begin{tabular}{|c|c|c|c|c|c|}
\hline Compound & $J_{s c}\left(\mathrm{~mA} / \mathrm{cm}^{2}\right)$ & $V_{\text {oc }}(\mathrm{V})$ & FF & $\eta(\%)$ & $\begin{array}{c}\varepsilon / \lambda_{\max } \\
\left(10^{4} \mathrm{M}^{-1} \mathrm{~cm}^{-1}\right) /(\mathrm{nm})\end{array}$ \\
\hline $1.5^{46}$ & 6.1 & 0.60 & 0.68 & 2.5 & $1.5 / 400$ \\
\hline $1.6^{47}$ & 12.8 & 0.62 & 0.66 & 5.2 & $2.5 / 494$ \\
\hline $1.7^{44}$ & 12 & 0.69 & 0.72 & 5.9 & $3.3 / 537$ \\
\hline $1.8^{48}$ & 18.3 & 0.76 & 0.74 & 10.2 & $2.7 / 470$ \\
\hline $1.9^{26,49}$ & 17.9 & 0.77 & 0.73 & $10.1(8.9 *)$ & $5.7 / 493$ \\
\hline
\end{tabular}


In $\mathbf{1 . 7}$ there is an increase conjugation length due to the addition of a trans alkene to the $\pi$-spacer component of the molecule. This causes a bathochromic shift in the absorption, but there was only a minor increase in efficiency as compared to the benchmark compound 1.6. Dye 1.8, contains a benzothiadiazole $\pi$-spacer that is asymmetrically flanked by a thiophene and a slightly less electron rich phenyl substituent. This leads to excellent electron density transport towards the anchor group of the molecule. This molecule also contains large alkyl side chains which block/passivate the titania electrolyte interface minimizing recombination. This gives $\mathbf{1 . 8}$ an overall efficiency of $10.2 \%$ making it the current record holder for organic dye efficiency. ${ }^{48}$ The previous organic record holder was 1.9 with an efficiency of $10.1 \%$ however, it should be noted that this dye still holds the record efficiency of $8.9 \%$ using an alternative to the $\mathrm{I}^{-} / \mathrm{I}_{3}{ }^{-}$electrolyte. The hexyl and iso-octyl side chains provide excellent surface passivation and the fused 3 ring $\pi$-spacer provides an increased conjugation leading to a superb efficiency. $^{50}$

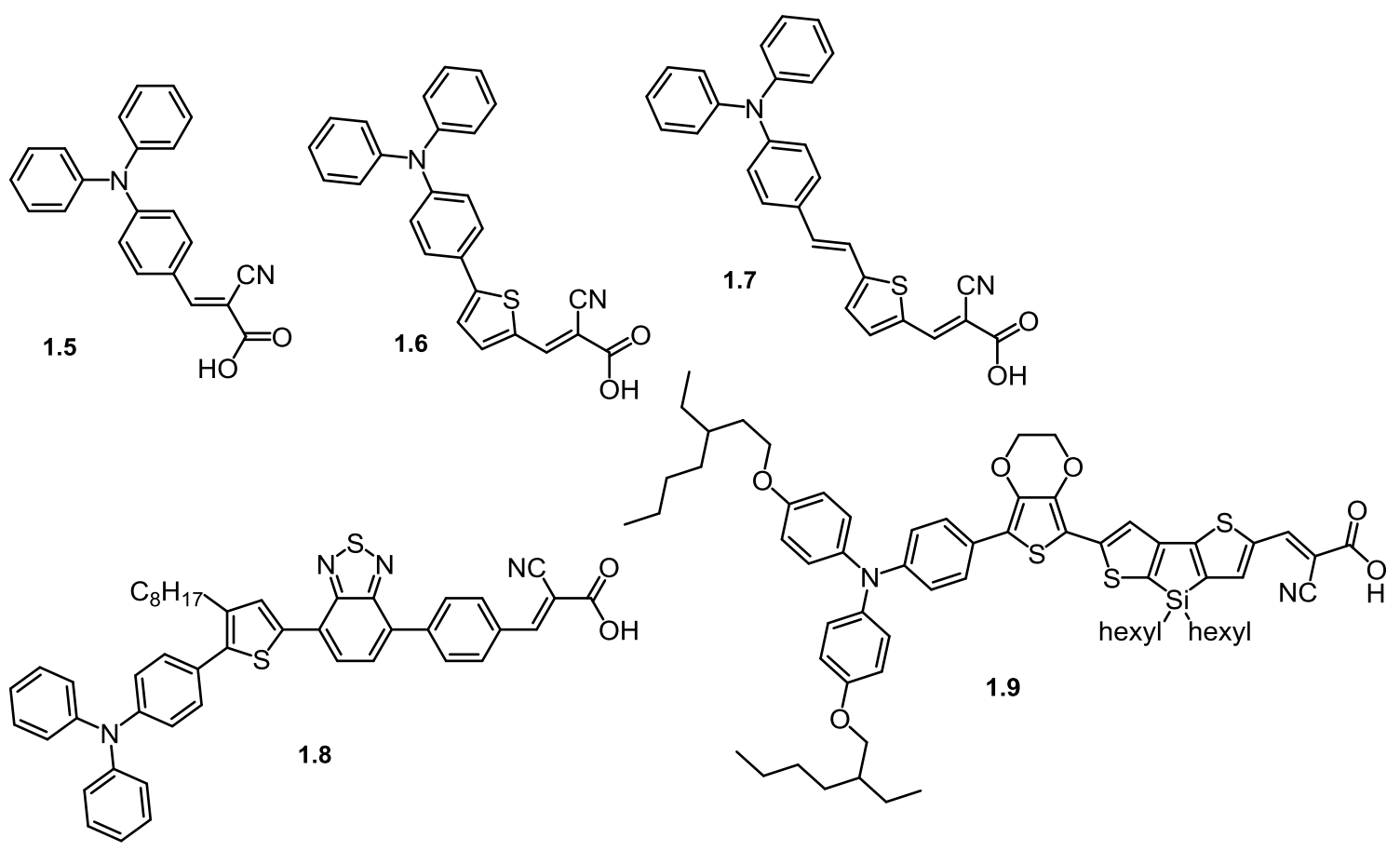

Figure 1.13 TPA based DSSC dyes based on $\mathbf{1 . 6}$ 


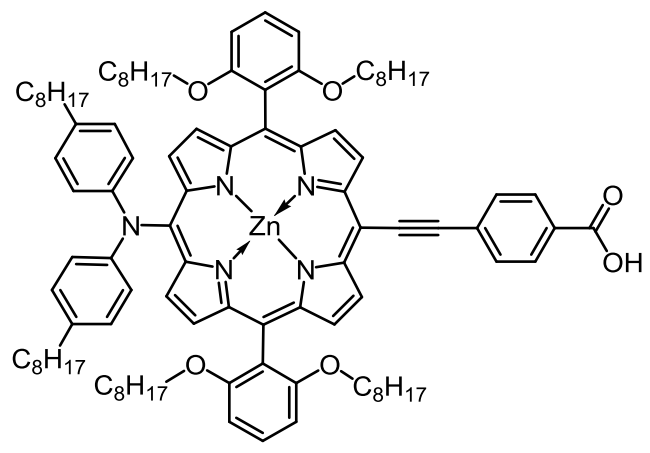

1.10

Figure 1.14 Porphyrin based dye with a record efficiency of $15 \%$

The current overall record DSSC dye efficiency is $15 \%$ for the zinc-porphyrin molecule shown in Figure $1.14{ }^{51}$ This molecule like the other organic molecules uses long alkyl chains to passivate the surface of $\mathrm{TiO}_{2}$; in this molecule however they are actually alkoxy chains which have a more significant impact on the electronics of the molecule. While this molecule contains a metallic Zn centre, the zinc acts largely as a spectator ion, it hold the porphyrin core planar but does not exhibit MLCT. ${ }^{52}$ The sensitization occurs entirely in the $\pi$-system ( $a$ to $\pi^{*}$ ) which is identical to the organic dye mode of sensitization. The studies of champion dyes $\mathbf{1 . 9}$ and $\mathbf{1 . 1 0}$ led us to a potential optimal $\pi$-spacer, BODIPY.

\subsection{BODIPY: An attractive $\pi$-spacer for DSSC applications}

The champion organic dye reported by Wang and the record efficiency dye reported by Gratzel both contain a rigid organic framework to harvest light energy. First discovered by Triebs in 1968, 4,4difluoro-4-bora-3a,4a-diaza-s-indacene (BODIPY) based molecules are very prevalent in the literature. ${ }^{53}$ They are used to label proteins in the body due to their fluorescent characteristics and have more recently begun to appear in a myriad of materials applications. ${ }^{54,55}$ 


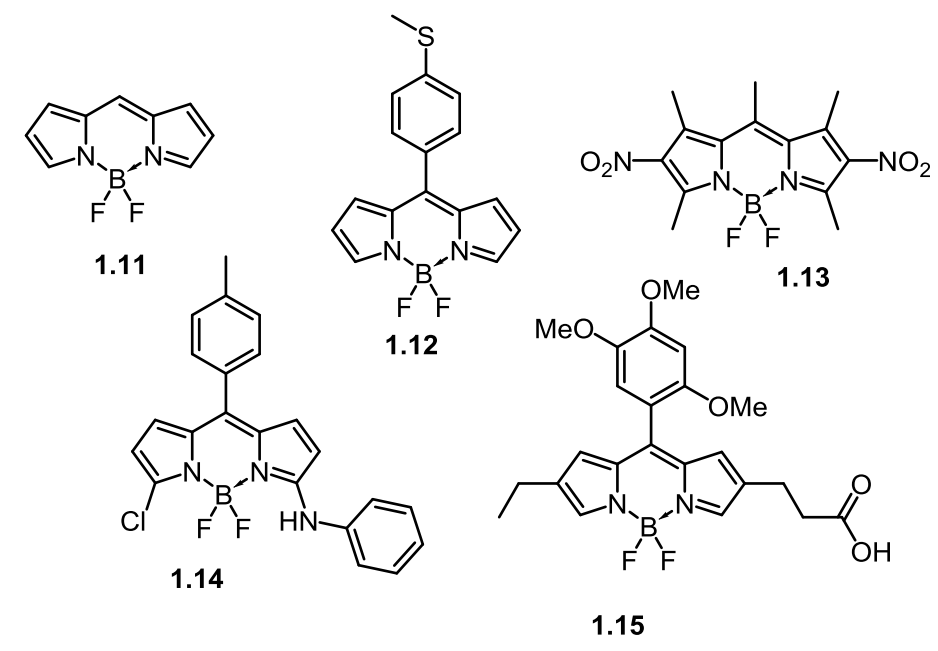

Figure 1.15 BODIPY compounds

As shown in Figure 1.15, there are a plethora of different BODIPY based compounds both symmetric and asymmetric that have been synthetically prepared..$^{56} 1.11$ has never been reported in the literature due to its low stability. ${ }^{53}$ However modified BODIPYs also shown in Figure 1.15 have been known to be stable to UV-light, $\mathrm{pH}$ and even physiological conditions inside the BODIPY. ${ }^{57}$ The ability for these molecules to be tuned synthetically, their robust nature and their synthetic versatility make BODIPYs excellent target molecules for implementation into DSSC devices. 


\subsection{BODIPY in DSSC dyes}

Boron-dipyrrin dyes have been explored as components in many material applications owing to their tunability and photostability under a wide range of conditions. ${ }^{58}$ Despite this, BODIPY-based dyes have not been effective sensitizers in DSSC applications thus far. ${ }^{59-61}$ Akkaya and coworkers have recently investigated a set of BODIPY dyes possessing Type I and II (Figure 1.16) D-A motifs. ${ }^{59,60}$ In general, energy transfer through the BODIPY core tends to be less efficient in these types of motifs because substitution to the meso-position typically exhibits poor electronic communication; i.e. there is poor conjugation between the BODIPY core. As a result, energy-transfer "cassettes" are observed ${ }^{58}$ Conversely, extremely fast energy transfer is seen when transition moments are aligned in the Type III architecture. ${ }^{58}$ This can be seen when exploring the efficiencies of previously reported BODIPY dyes shown in Figure 1.17 as well as Table 1.2 .

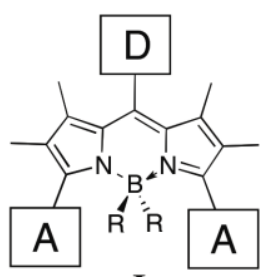

I

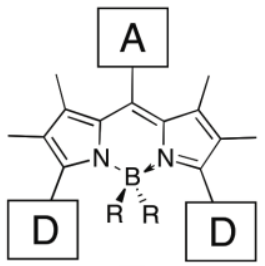

II

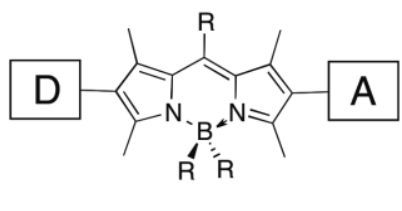

III

Figure 1.16 BODIPY motifs in DSSC dyes 

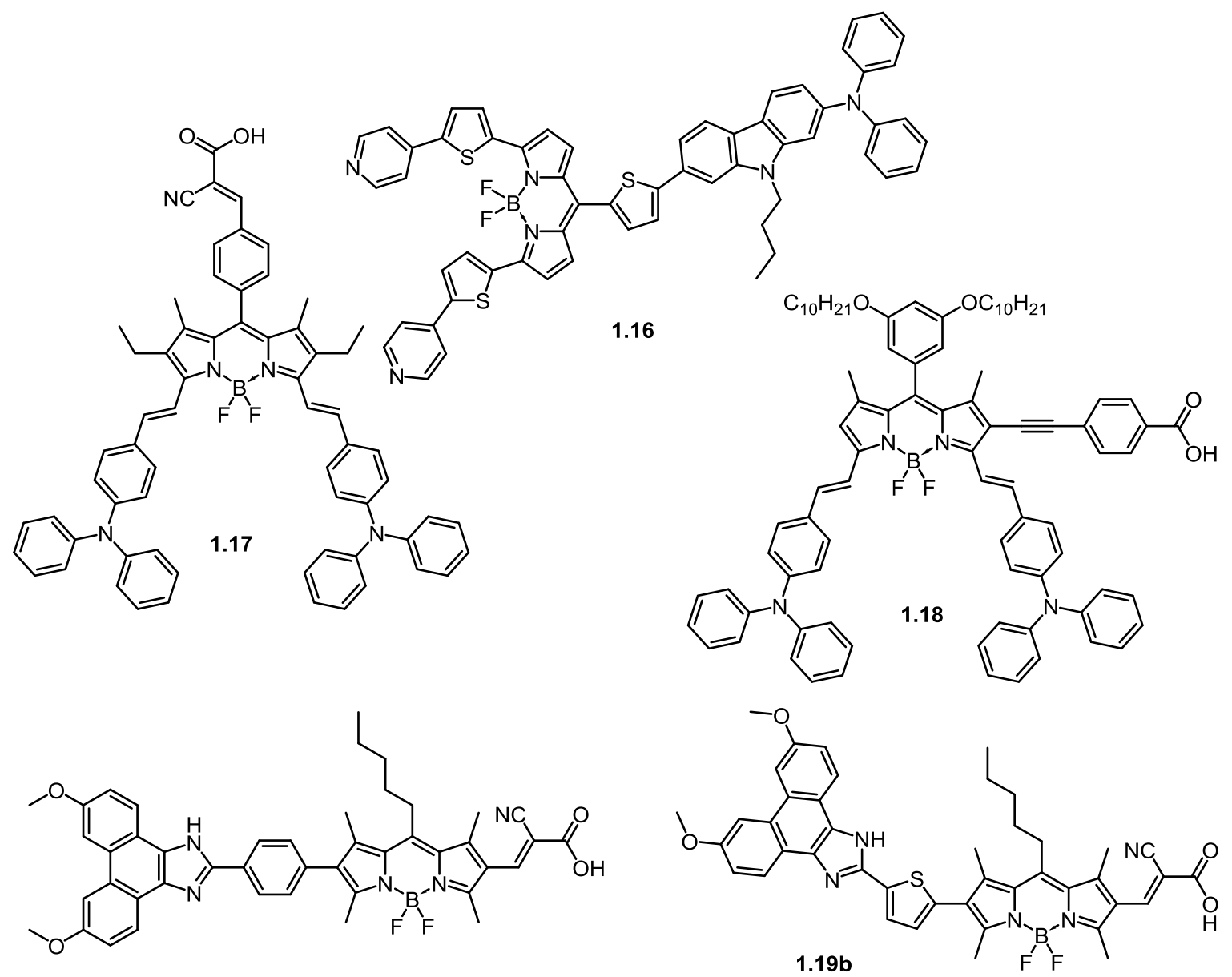

$1.19 a$

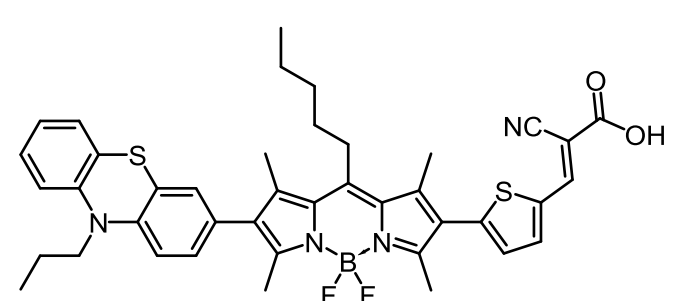

1.20

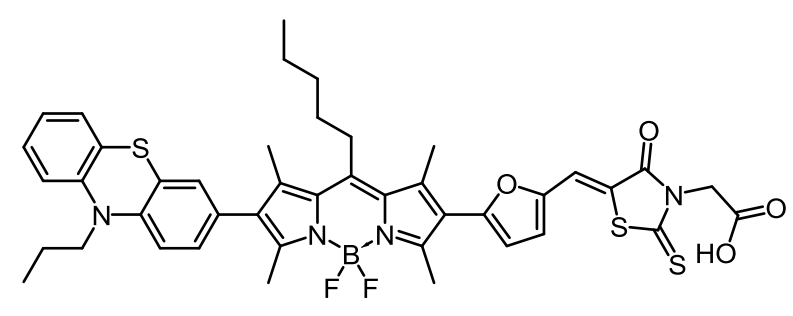

1.22

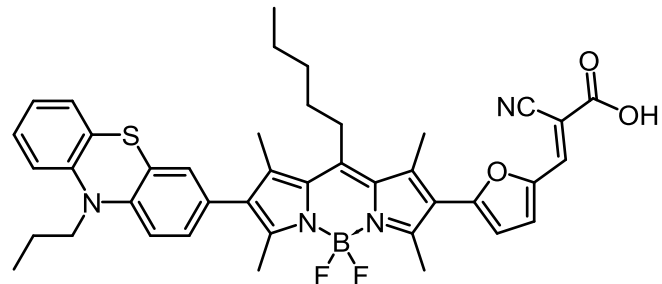

1.21

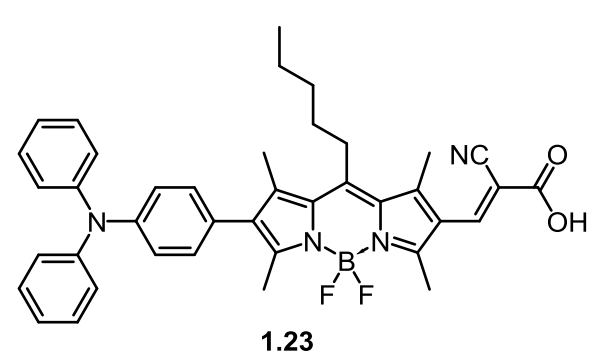

Figure 1.17 Previously reported BODIPY DSSC dyes 
Table 1.2 Device efficiencies of BODIPY DSSC dyes

\begin{tabular}{|c|c|c|c|c|c|}
\hline Compounds & $J_{s c}\left(\mathrm{~mA} / \mathrm{cm}^{2}\right)$ & $V_{\text {oc }}(\mathrm{V})$ & $\mathrm{FF}$ & $\eta(\%)$ & $\varepsilon / \lambda_{\max }$ \\
\hline $1.16^{62}$ & 1.85 & 0.20 & 0.67 & 0.39 & $8.1 / 673$ \\
\hline $1.17^{59}$ & 4.03 & 0.56 & 0.74 & 1.66 & $7.0 / 700$ \\
\hline $1.18^{60}$ & 3.74 & 0.52 & 0.71 & 1.40 & $7.1 / 707$ \\
\hline $1.19 a^{61}$ & 2.64 & 0.54 & 0.64 & 0.92 & $8.7 / 532$ \\
\hline $1.19 b^{61}$ & 5.10 & 0.61 & 0.72 & 2.26 & $8.0 / 532$ \\
\hline $1.20^{63}$ & 11.85 & 0.58 & 0.67 & 4.61 & $7.2 / 536$ \\
\hline $1.21^{63}$ & 13.64 & 0.59 & 0.66 & 5.31 & $7.6 / 553$ \\
\hline $1.22^{63}$ & 3.60 & 0.49 & 0.70 & 1.23 & $5.6 / 556$ \\
\hline $1.23^{64}$ & 4.38 & 0.58 & 0.72 & 1.83 & $7.4 / 534$ \\
\hline
\end{tabular}

1.16 contains a triarylamine (TAA) donor connected to an extented conjugated system including a BODIPY core leading to a red shifted absorbtion at almost $700 \mathrm{~nm}$. However, there is no strong electron withdrawing groups (EWG) to pull electron density towards the $\mathrm{TiO}_{2}$ semiconductor which limits device current and thus overall efficiency. Dyes 1.17 and 1.18 have a strong red shifted absorbance but suffer from poor electronic communication through the BODIPY core as explained previously. 1.19ab take advantage of the type III motif but still have an underwhelming efficiency due to the absence of a strong electron donating group (EDG). This issue is remedied somewhat by the inclusion of the phenothiazine electron donating group in $\mathbf{1 . 2 0}$ and $\mathbf{1 . 2 1}$ which is to the best of our knowledge the most efficient BODIPY DSSC dye. A noteworthy observation occurs when comparing 1.21 to $\mathbf{1 . 2 2}$ as the cyanoacetic acid is replaced by a rhodanine-3-acetic acid anchor group causing a massive decrease in efficiency. ${ }^{64}$

Finally, a TPA containing 2,6 modified BODIPY dye is presented in 1.23, while the efficiency is far from ideal this molecule has a large opportunity for functionalization. One of the major thesis' objectives is to detail how BODIPYs behave as non-innocent $\pi$-spacers and to examine how subtle changes in conjugation are necessary in order for these dyes candidates to exhibit the appropriate optical and electrochemical properties for light-harvesting. 


\subsection{Thesis objectives:}

Since the Gratzel group reported a porphyrin DSSC with 15\% efficiency BODIPY compounds have been under intense study due to the similarities between the two moieties. Rather than focus on overall efficiency data this project aims to explore the tunability of a BODIPY core for different materials applications. We aim to explore the structure property relationships guiding DSSC research in this field and use the physicochemical data gathered to further dye design. The current materials study of BODIPY has recently begun to lack systematic investigation of physicochemical properties of molecules in favour of rapid dye synthesis. Therefore, the goals of this work are to first synthesize a complete family of BODIPY based DSSC dyes as shown in Figure 1.18. We will systematically investigate the use of BODIPY as a $\pi$-spacer in 2,6 modified systems. Thiophene subunits will be added to the BODIPY core to modify/improve conjugation between the donor and BODIPY spacer.
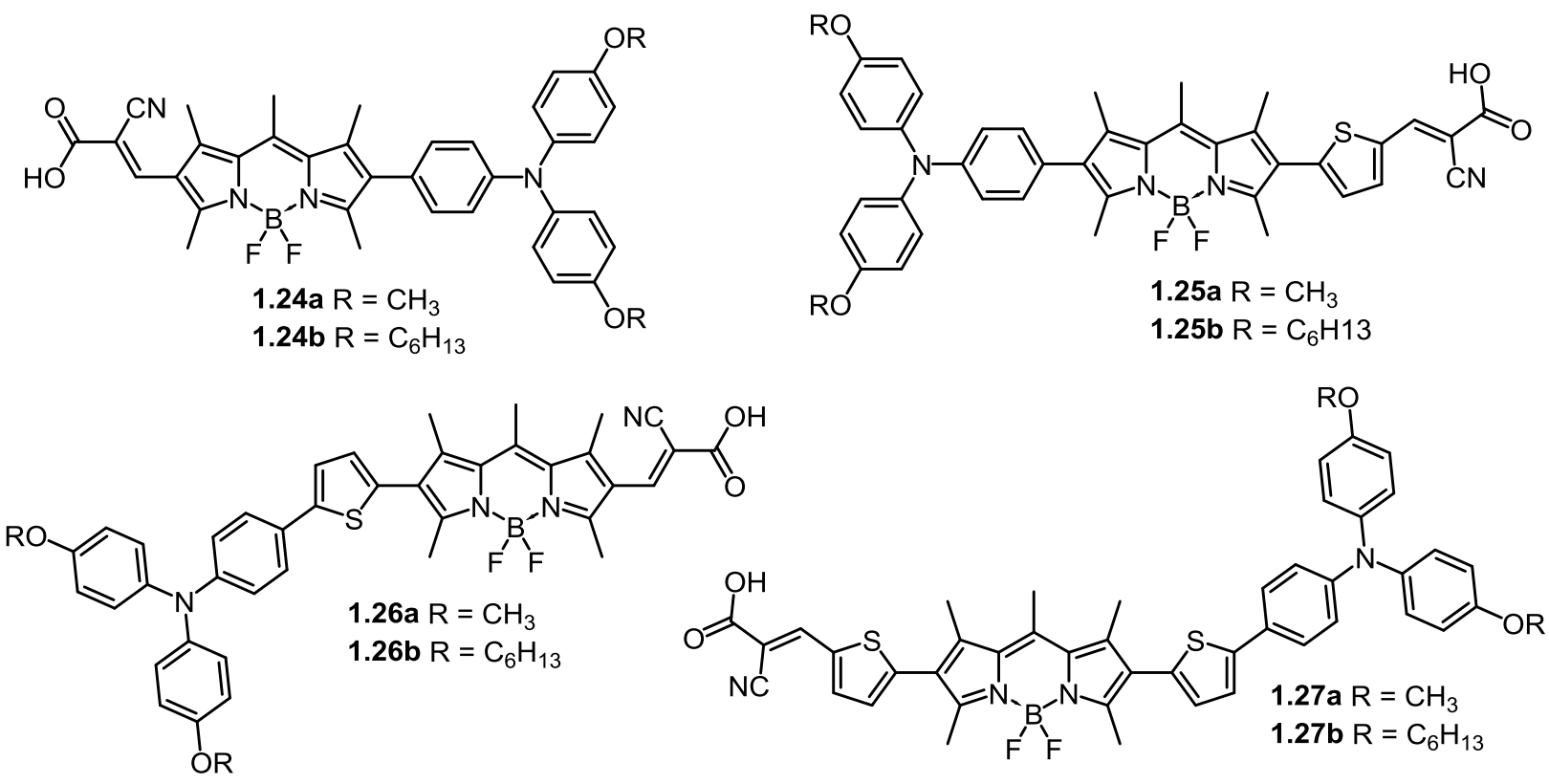

Figure 1.18 Family of target BODIPY dyes

Molecules 1.24 ab to 1.27 ab will also be thoroughly examined for their physicochemical properties using theoretical calculations, UV-vis spectroscopy and electrochemistry to further appreciate structure property relationships. Finally, DSSC devices will be fabricated and tested to determine which thermodynamic pathways can be tuned to further improve device efficiencies. 
The second objective of this thesis is to employ the data received through preliminary device testing (vide infra) and explore the design of second generation BODIPY DSSC dyes. Preliminary device data shows an insufficient LUMO energy level on our fully conjugated dye $\mathbf{1 . 2 7 b}$ to promote charge injection. As such this project explores modification of the BODIPY core in an attempt to reposition the frontier molecular orbitals and maximize device efficiency. As such, the synthesis and physicochemical properties of a series of novel BODIPY dyes are discussed, with the intention of being able to optimize frontier molecular energy levels. It is also intended that the syntheses will begin on these BODIPY cores so that future dye molecules can be more readily prepared.

Finally, this project also involves the synthesis of push-pull BODIPY core systems that have unique electronic properties. Examining how modification to a BODIPYs periphery can change the favourable energy transitions within a molecule. To this context previously unreported BODIPY building blocks have been synthesized to aid in the preparation of novel BODIPY molecules in the future.

The overall aim of this thesis is to provide a complete and comprehensive study of BODIPY analogs for future materials chemistry applications. 


\section{SYNTHESIS AND CHARACTERIZATION}

This work presents the use of new $\pi$-spacer moieties coupled to previously reported donor groups and secondary $\pi$-spacers to yield novel organic DSSC dyes, vide supra. To efficiently synthesize these compounds, convergent synthesis pathways were chosen to maximize overall conversion efficiencies.

\subsection{The synthesis of triphenylamine donors}

Triphenylamine (TPA) derivatives were chosen as electron donors for our novel dye molecules due to their redox stability and prevalence in the literature. ${ }^{65,66}$ In addition, the oxidation potential of TPA can be tuned systematically. By changing the substituents attached to the TPA core, the HOMO level can be adjusted. Specifically, the HOMO can be destabilized by introducing electron donating alkoxy chains to the para position of the TPA. Longer alkyl chains (such as $n$-hexyl) have the added advantage of surface passivation, due to steric screening at the $\mathrm{TiO}_{2}$ /electrolyte interface. Scheme 2.1 shows the synthesis of two alkoxy TPA Suzuki reagents used for the synthesis of our dye families. While the synthesis of these molecules is well reported the Ullmann synthesis of $\mathbf{2 . 3}$ proved difficult to reproduce.

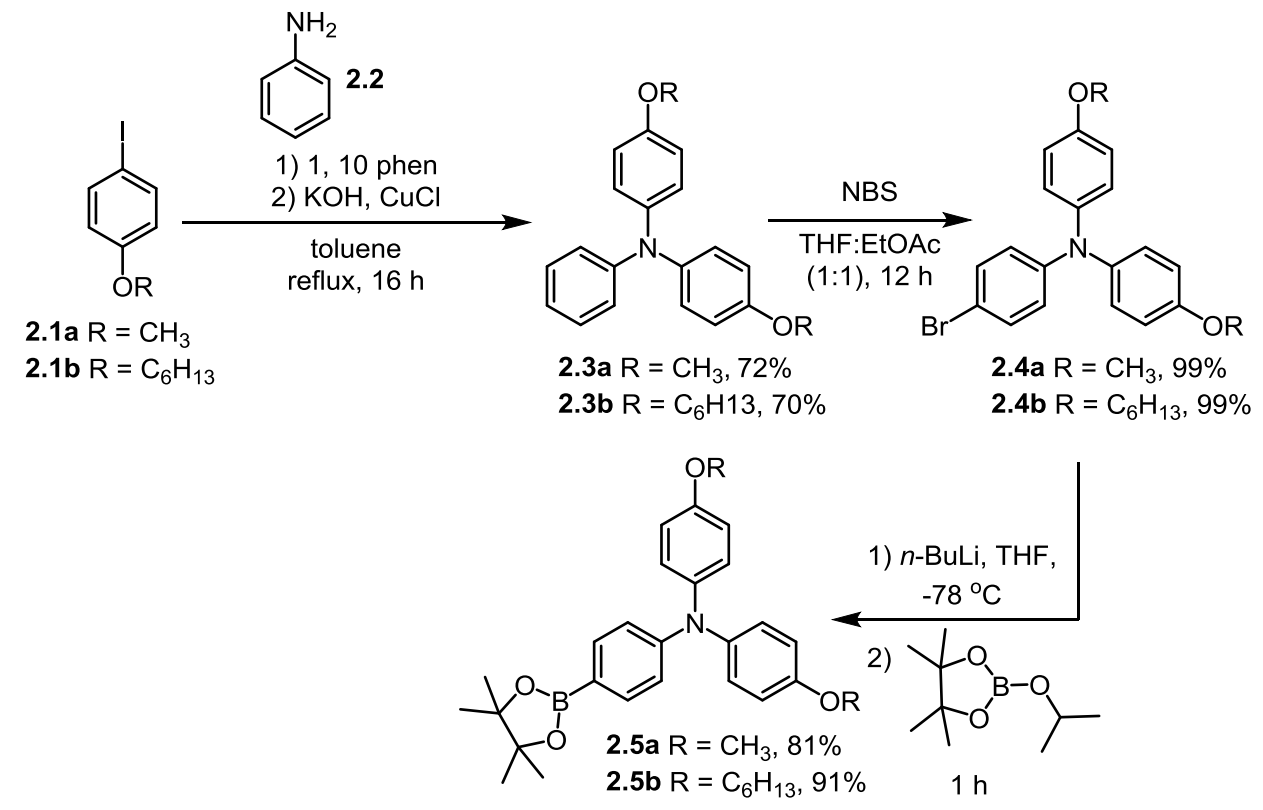

Scheme 2.1: The synthesis of TPA donor moieties for organic DSSC dyes

Commercially available iodo-anisole (2.1a) or readily prepared para-hexoxy, iodo-benzene (2.1b) was dissolved in toluene and reacted in two consecutive Ullmann couplings with aniline (2.2) to yield the 
desired alkoxy TPA derivatives in reasonable yields (2.3a and 2.3b, respectively). This was followed by mono-bromination with one equivalent of NBS nearly quantitatively to yield $\mathbf{2 . 4 a}$ and $\mathbf{2 . 4 \mathbf { b }}$. The bromide was lithiated with $n$-BuLi and quenched with a boronic ester to yield the Suzuki reagents 2.5a and $\mathbf{2 . 5 b}$ in $81 \%$ and $91 \%$, yields respectively.

\subsection{The synthesis of thiophene Suzuki reactants}

In DSSC dyes, specifically organic dyes, it is imperative to tune the conjugation length of the dye molecule to achieve maximum light absorption and thus photo-conversion efficiency, (vide supra, Chapter 1.3). There are several pathways to extend the conjugation of our molecules including benzene rings and trans alkenes. While both of these subgroups have been widely utilized in DSSC dyes, they have pragmatic limitations that make them undesirable choices for DSSC dye applications. Benzene rings due to their 6 carbon ring structure, twist out of plane when coupled to a BODIPY backbone disrupting conjugation, electronic communication and thus the $J_{s c}$. Trans-alkenes alleviate the steric issue disrupting communication but have a high reactivity that can make further dye modification challenging synthetically. Thiophene due to its desirable electronic properties and robust aromatic structure is an ideal candidate for extending conjugation in DSSC dyes. The five-membered ring of thiophene has bond angles that are less sterically hindered when adjacent to the BODIPY core (as shown by DFT, vide infra). Secondly, the thiophene boronic ester (2.16), is readily prepared in excellent yields through a two step synthesis from commercially available thiophene.

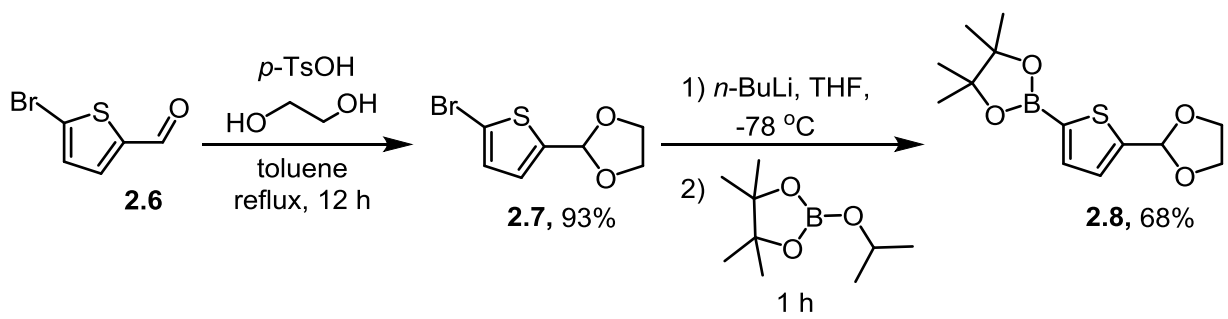

Scheme 2.2: The synthesis of a protected aldehyde $\pi$-spacer for DSSC applications

Some syntheses required the formyl group to be coupled to the thiophene prior to coupling to our BODIPY core. This required a slightly more complicated synthesis due to the carbonyl group needing protection to avoid an unwanted side reaction during lithiation. As shown in Scheme 2.2, 2-bromo-5thiophene carbaldehye (2.6), the carbonyl group is converted to an acetal group using ethylene glycol in the presence of an acid catalyst. $\mathbf{2 . 7}$ was purified in $\mathbf{9 3 \%}$ yield but required great care to handle because 
both water and acid could force the reverse reaction back to the starting material (2.6). The protected aldehyde was lithiated and then quenched with a boronic ester to yield the thiophene aldehyde Suzuki reagent in a $68 \%$ yield. After coupling to BODIPY the acetal group on the thiophene can be deprotected back to the aldehyde for Knovenagel condensation.

\subsection{The synthesis of pentamethyl BODIPY}

The idea of a redox-active "non-innocent" $\pi$-spacer, vide supra is an exciting possibility for improving the efficiency of organic DSSC dyes. Using a $\pi$-spacer that has an extinction coefficient approaching $10^{5} \mathrm{M}^{-1}$ $\mathrm{cm}^{-1}$ and can be photo-oxidized provides enormous potential as a component for a DSSC dye. BODIPY, due to its strong light absorption properties, redox stability and synthetic pervasiveness in the literature make it an excellent candidate for DSSCs. Previous reported, pentamethyl BODIPY (2.12) is commercially available, however, it is far more expensive to purchase then to prepare synthetically. ${ }^{67}$ The synthetic pathway for this compound can be performed as shown in Figure 2.3.

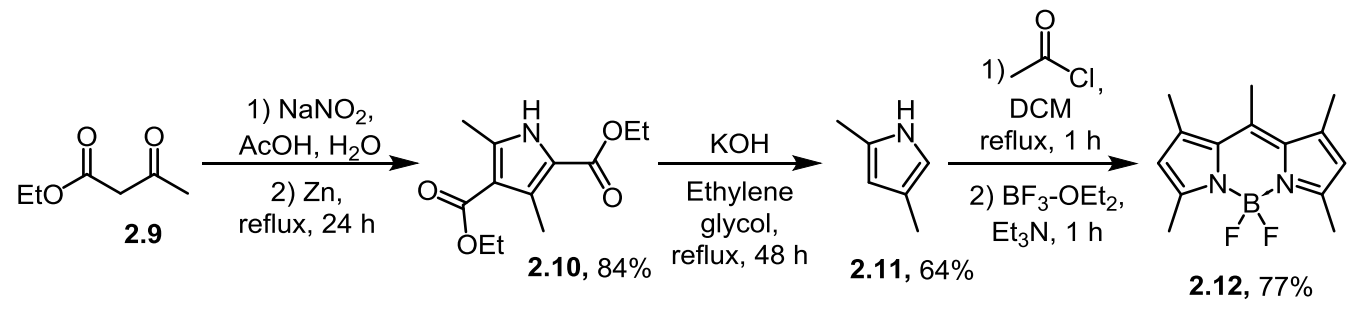

Scheme 2.3: The synthesis of a pentamethyl BODIPY for use as a non-innocent $\pi$-spacer for organic DSSCS

Ethyl acetoacetate (2.9) undergoes a Paal-Knorr pyrrole synthesis to yield the carboxylated pyrrole (2.10) in a respectable yield. The diester (2.10) undergoes two sequential decarboxylation reactions in the presence of base to achieve the desired 2,4 dimethyl pyrrole (2.11). Commercially available acetyl chloride is added to the pyrrole resulting in two successive electrophilic aromatic substitution reactions, which upon oxidation, forms the free ligand to which a boron is added to achieve the desired BODIPY (2.12) in a $42 \%$ total overall yield.

\subsection{The synthesis of a benchmark BODIPY DSSC dye}


After the synthesis of our dye components shown above a convergent synthetic pathway to our first dye family is shown below (Scheme 2.4) The first such dyes 1.24a and 1.24b (Figure 2.4) were synthesized utilizing BODIPY as the only $\pi$-spacer with no additional conjugation added to the backbone. These dyes serve as excellent benchmarks to show the effects of adding additional $\pi$-spacers as is the case in the rest of the first generation dye family.
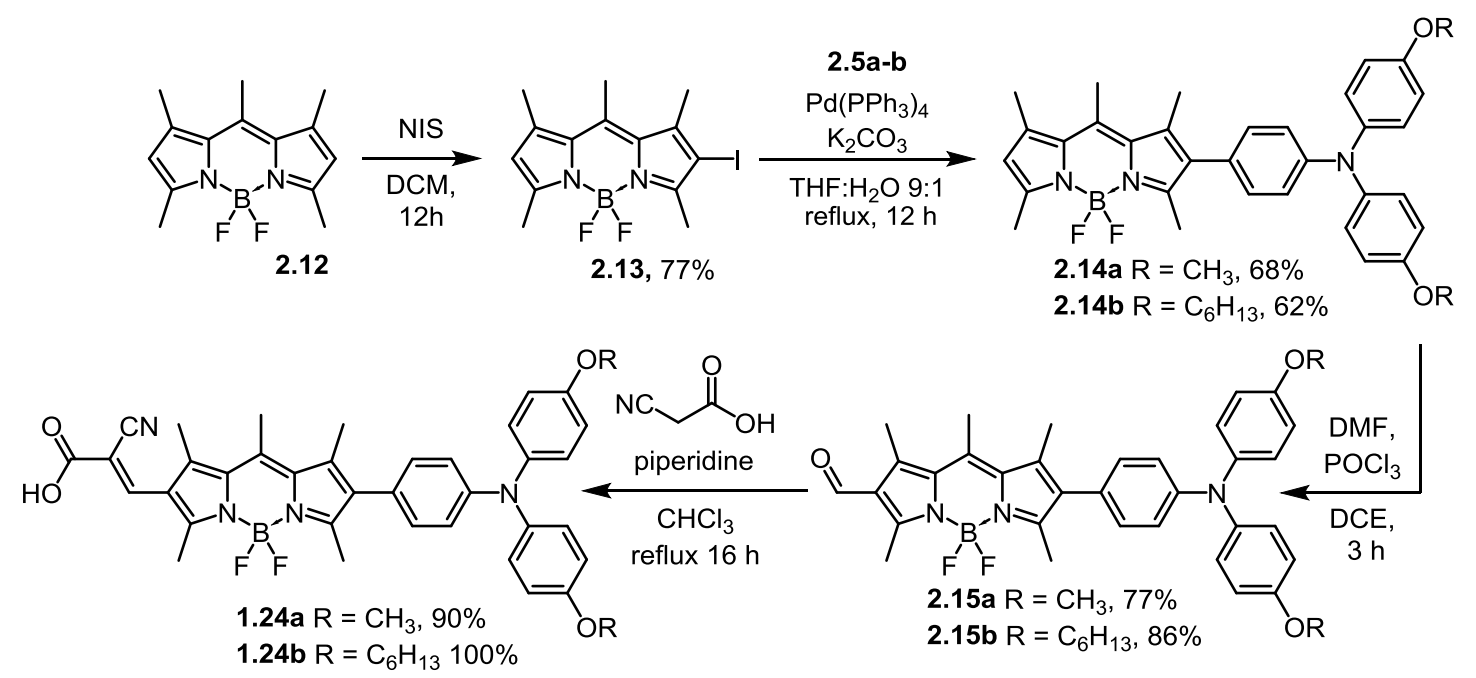

Scheme 2.4: The synthesis of an organic DSSC dye with a 2,6 modified BODIPY $\pi$-spacer

BODIPY (2.12) undergoes an iodination with NIS to yield a monoiodo-BODIPY (2.13). The alkoxy TPAs (2.5a and 2.5b) are coupled to the BODIPY through a Suzuki cross-coupling reaction to achieve 2.14a and 2.14b. The 6-position of the BODIPY is then formylated via the Vilsmeier-Haack reaction to yield the formylated BODIPY derivatives (2.15a and 2.15b). A Knoevenagel condensation was employed to couple on the cyanoacetic acid anchor group to give the desired dyes 1.24a and 1.24b.

\subsection{The synthesis of a BODIPY dye with extended conjugation between BODIPY and the anchor}

As stated above the conjugation length between the donor and acceptor of an organic DSSC dye plays an important role in the short circuit current and thus the overall efficiency of a dye molecule. Therefore, placing a thiophene spacer between the BODIPY and the cyanoacetic acid anchor may red shift the absorption creating a more efficient DSSC dye. 


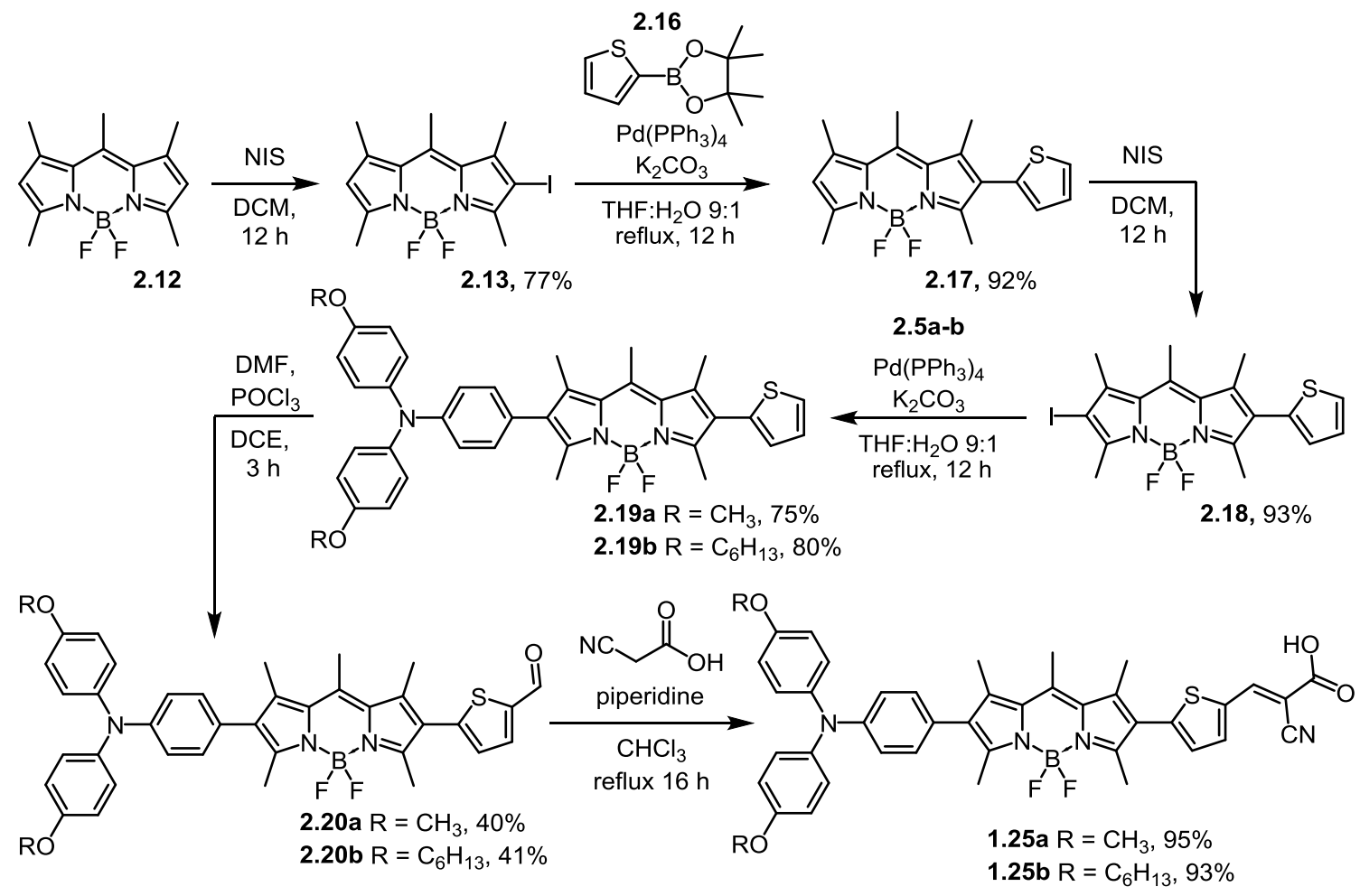

Scheme 2.5: The synthesis of a BODIPY dye with extended conjugation near the electron acceptor

BODIPY (2.12) underwent an iodination with NIS to yield a monoiodo-BODIPY (2.13). Thiophene boronic ester (2.16) was then coupled to $\mathbf{2 . 1 3}$ through a Suzuki cross-coupling reaction to give the BODIPY, thiophene $\pi$-spacer (2.17) in excellent yield. 2.17 was iodinated with NIS to yield 2.18 for a Suzuki coupling with $\mathbf{2 . 5 a}$ and $\mathbf{2 . 5 b}$ to yield $\mathbf{2 . 1 9 a}$ and $\mathbf{2 . 1 9 b}$, respectively. These compounds underwent the Vilsmeier-Haack formylation to give $2.20 \mathrm{a}$ and $\mathbf{2 . 2 0 b}$ in manageable yields. To complete the dyes a Knoevenagel condensation was employed to couple on the cyanoacetic acid groups yielding dyes $\mathbf{1 . 2 5 a}$ in $95 \%$ yield and $\mathbf{1 . 2 5 b}$ in $93 \%$ yield.

\subsection{The synthesis of a BODIPY dye with a thiophene spacer adjacent to the TPA donor}

While red shifting the absorption can be achieved by placing the thiophene spacer on either side of the BODIPY, placing the spacer in between the TPA donor and the BODIPY provides a secondary advantage. Owing to the redox activity of BODIPY and TPA, placing the thiophene between these species increases conjugation and lowers the oxidation potential of both species; vide infra, (Chapter 3 ). Synthesis of these dye molecules is shown in Figure 2.6. 


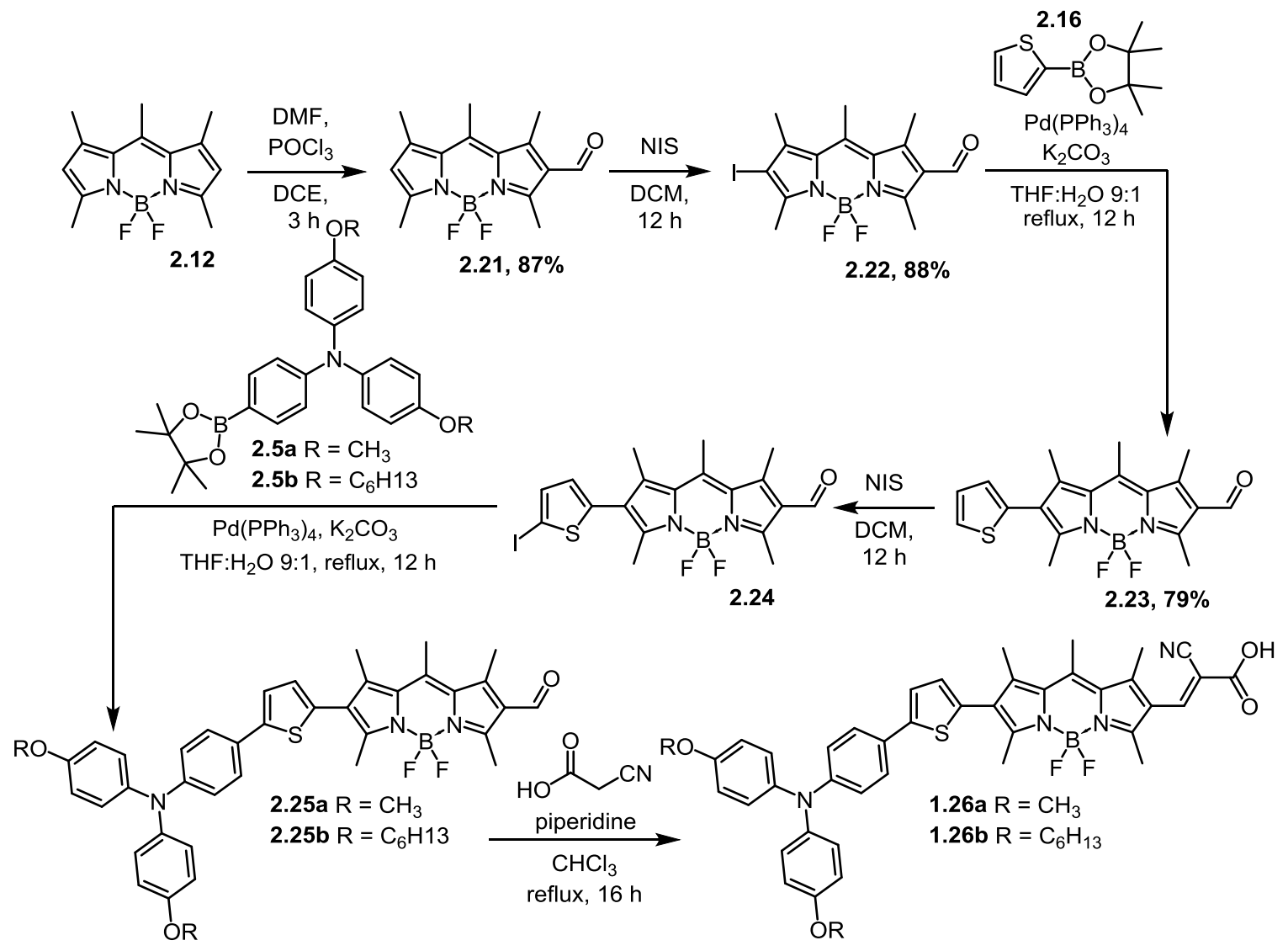

Scheme 2.6: The synthesis of BODIPY with extended conjugation near the electron donor

BODIPY (2.12) was formylated using the Vilsmeier-Haack reaction to give BODIPY aldehyde (2.21) which was iodinated with NIS to give iodo-formyl BODIPY (2.22). lodo-formyl BODIPY (2.22), underwent a Suzuki coupling in the presence of $\mathbf{2 . 1 6}$ to give the thiophene BODIPY aldehyde (2.23). 2.23 was iodinated with NIS to yield $\mathbf{2 . 2 4}$ for a second Suzuki coupling. However, standard Suzuki conditions were

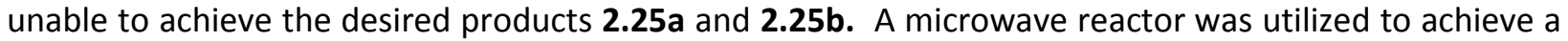
temperature of $150{ }^{\circ} \mathrm{C}$ to successfully couple $\mathbf{2 . 2 4}$ to $2.5 \mathrm{a}$ and $\mathbf{2 . 5 b}$ to give the products $\mathbf{2 . 2 5 a}$ and $\mathbf{2 . 2 5 b}$ in moderate yields, respectively. These compounds smoothly underwent a Knoevenagel condensation with cyanoacetic acid to give the desired dye molecules $\mathbf{1 . 2 6 a}$ and $\mathbf{1 . 2 6 b .}$

2.7. The synthesis of BODIPY with two thiophene spacers for maximum conjugation 
The addition of a thiophene to one side of the BODIPY backbone provides a moderate increase in conjugation and theoretically higher power conversion efficiency. It is also possible to add thiophene spacers to both sides of the BODIPY core to extend the conjugation to an even greater extent. Further red shifting the absorption envelope of our DSSC dyes allows even more photons to be harvested and thus may increase overall device performance. The synthesis of dyes $1.27 \mathrm{a}$ and $1.27 \mathrm{~b}$ is presented in Scheme 2.7 and despite the molecules large size relies on the same toolbox of reactions presented previously.

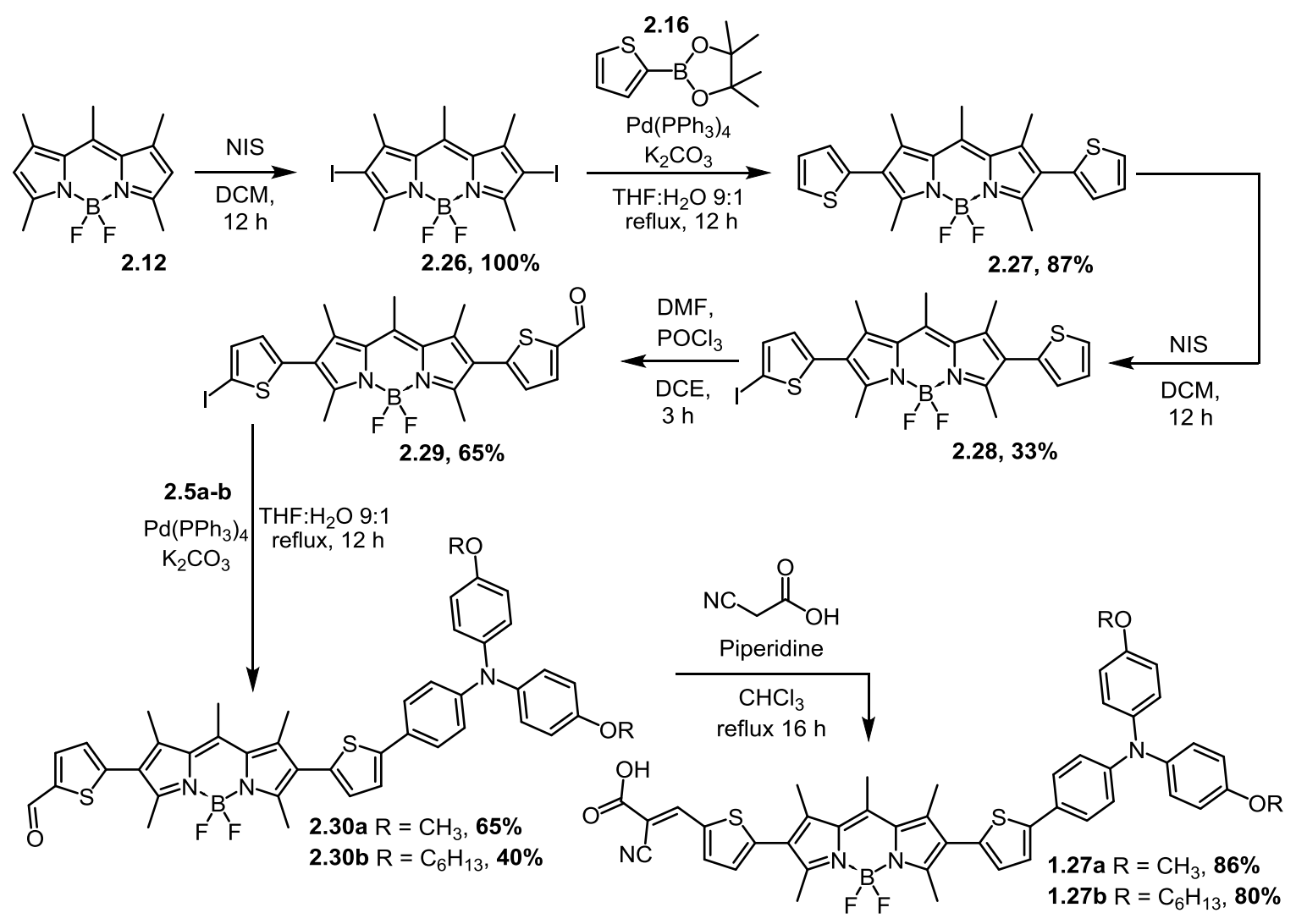

Scheme 2.7: The synthesis of a BODIPY dye with extended conjugation on the 2 and the 6 position

BODIPY (2.12) underwent a diiodonation in the presence of excess NIS to quantitatively synthesize diiodo BODIPY (2.26). A Suzuki coupling was then performed between 2.16 on 2.26 to add both thiophenes in one step to the BODIPY framework giving dithiophene BODIPY (2.27). 2.27 was iodinated NIS to give $\mathbf{2 . 2 8}$ in a poor yield due to almost no selectivity between the monoiodinated and diiodinated 
product. $\mathbf{2 . 2 8}$ underwent a Vilsmeier-Haack reaction to give $\mathbf{2 . 2 9}$ which was then reacted with $\mathbf{2 . 5 a}$ and 2.5b by way of a Suzuki coupling to give the formylated dye precursors $2.30 \mathrm{a}$ and $2.30 \mathrm{~b}$ respectively. These compounds were submitted to Knoevenagel condensation conditions to afford the desired dyes 1.27a and 1.27b.

\section{8. meso-substituted BODIPY building blocks for DSSC applications}

Based on preliminary device data obtain from first generation (vide infra, Chapter 3.1.4) BODIPY DSSC dyes, second generation BODIPY molecules were synthesized to be more electron rich. The mesoposition was chosen as an ideal location to modify the BODIPY core electronics. Benzene, anisole and trimethoxy benzene were chosen as potential replacements of the meso methyl group for this family of dyes. The introduction of the substituted phenyl ring, permits the tunable increase or decrease of the HOMO and LUMO energy levels, depending on the nature of the substituents. For example, it would be expected that a strong EWG would pull electron density away from the BODIPY core, Stabilizing the LUMO. Due to the high electron density present on the new meso substituents an alternate BODIPY synthesis pathway was chosen for these novel materials. Figure 2.8 outlines the synthesis pathway of this meso substituted photovoltaic material precursors. 


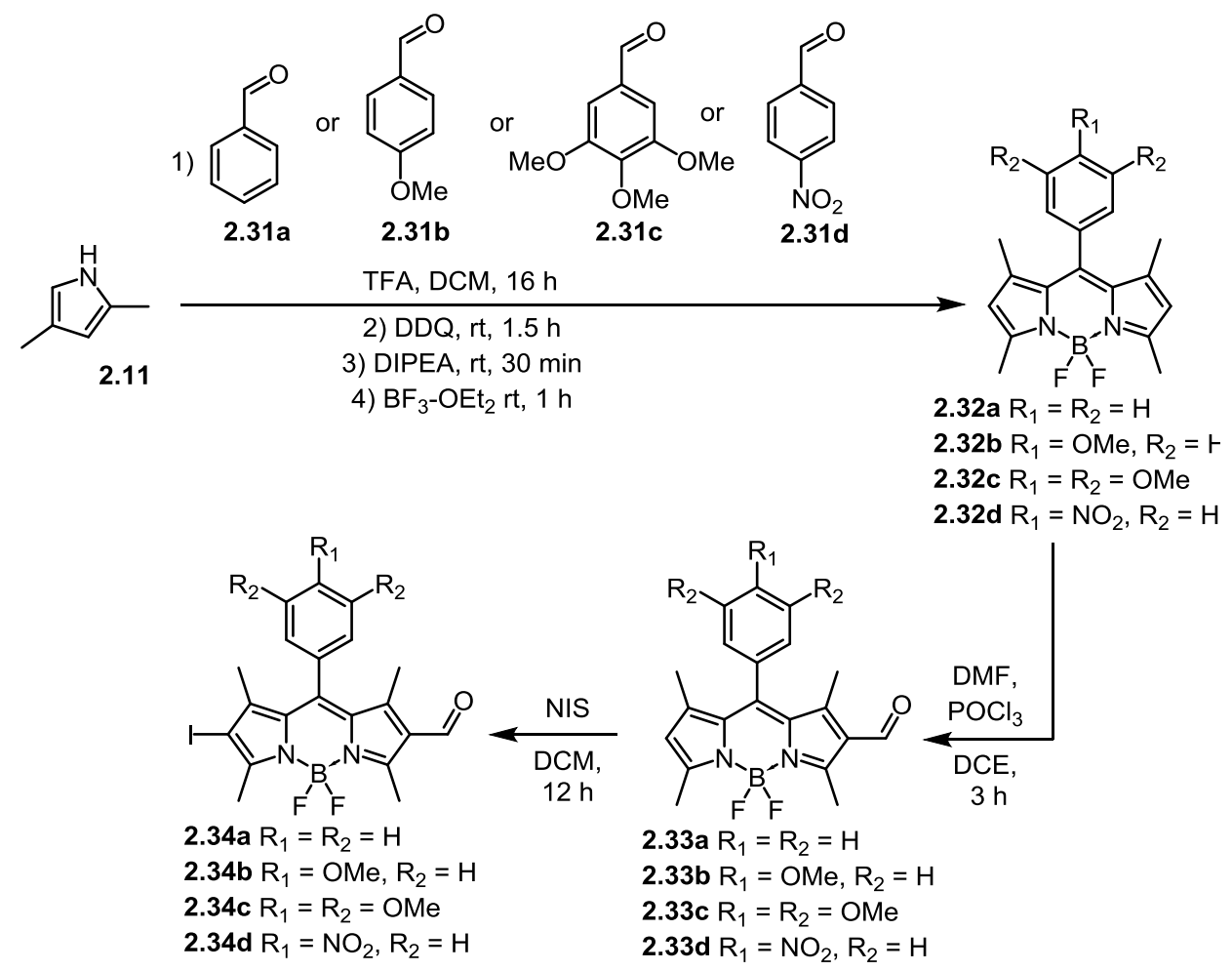

Scheme 2.8: The synthesis of electron rich BODIPY dyes through modification of the meso-position

2,4-dimethyl pyrrole 2.11 was coupled through two sequential electrophilic aromatic substitution reactions to benzaldehyde (2.31a), p-methoxy benzaldehyde (2.31b), 3,4,5 trimethoxy benzaldehyde (2.31c) and nitro benzaldehyde to yield three BODIPY $\pi$-spacers (2.32a-d). These $\pi$-spacers were then formylated via the Vilsmeier-Haack reaction to give the monoformyl derivatives (2.33a-d). All three BODIPYs were iodinated with NIS to achieve the formyl iodo derivatives $2.34 a, 2.34 b, 2.34 c$ and $2.34 d$ which, were the characterized physiochemically

\subsection{The synthesis of BODIPY molecules with push-pull characteristics}

Several modifications to the BODIPY backbone (2.12) were explored with varying success. BODIPY was coupled to a variety of electron withdrawing groups and changes in electronic properties were observed. 


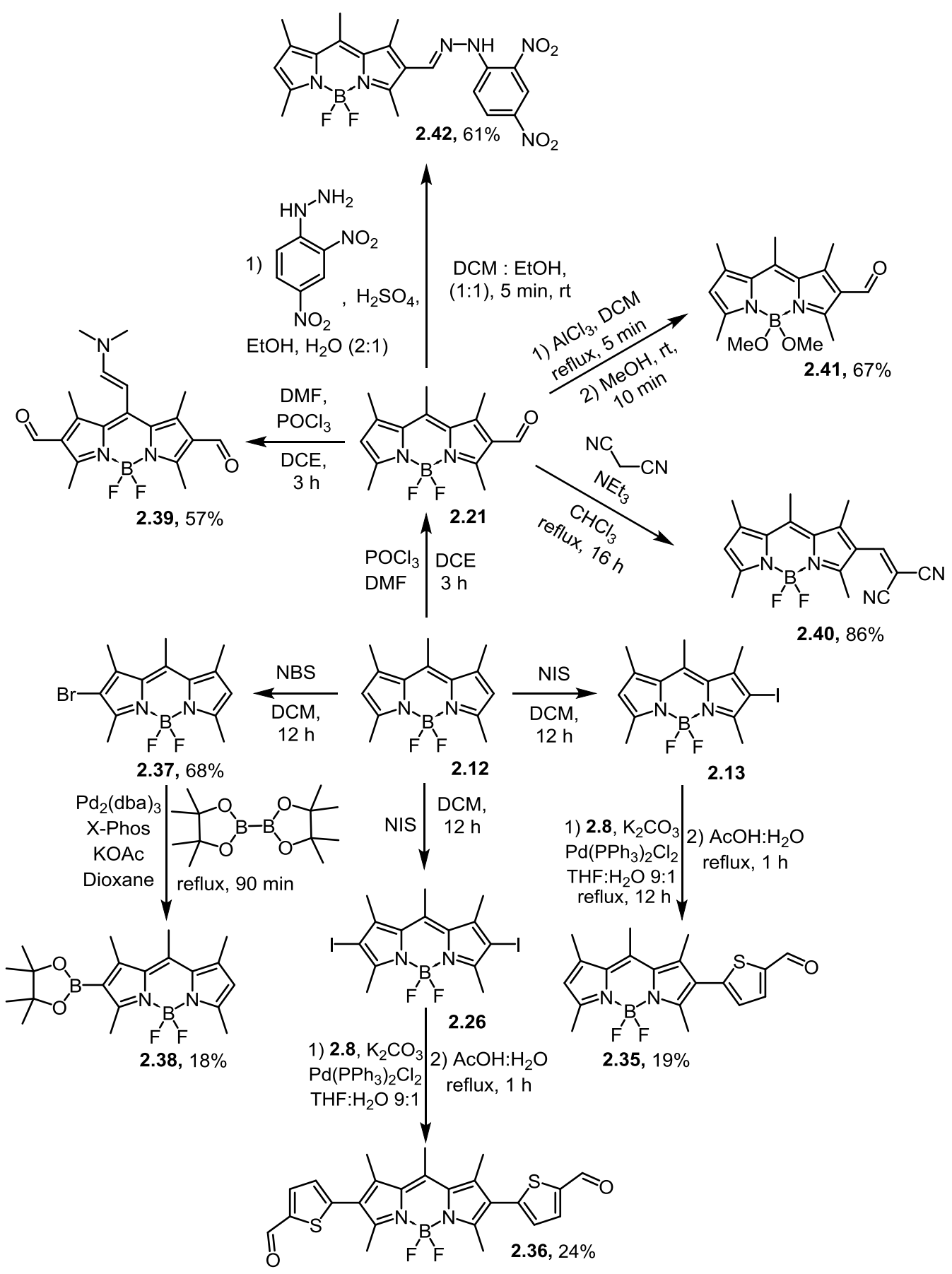

Scheme 2.9: Synthesis of BODIPY precursors for photovoltaic applications 
Starting from BODIPY several different paths were followed to arrive at a plethora of novel molecules. 2.12 was monoiodinated to give $\mathbf{2 . 1 3}$, which was then coupled to $\mathbf{2 . 8}$, the acetal group was deprotected to the aldehyde yielding $\mathbf{2 . 3 5}$. Similarly $\mathbf{2 . 1 2}$ could be diiodinated to $\mathbf{2 . 2 6}$ which could then be coupled to 2 equivalents of 2.8, the acetal groups were both deprotected to give 2.36. BODIPY (2.12) can also be brominated with NBS to give $\mathbf{2 . 3 7}$ in a respectable yield. $\mathbf{2 . 3 7}$ can then undergo a Pd catalyzed Miyaura borylation to give the Suzuki reagent of BODIPY (2.38). As shown above, BODIPY (2.12) can also be formylated to give BODIPY aldehyde (2.21). From the aldehyde (2.21) 3 exciting molecules were synthesized. First, a second Vilsmeier-Haack formylation was done to yield the surprising product 2.39, where not only was a second formyl group added but also a meso trans enamine. Next 2.21 was used in a Knoevenagel condensation with malononitrile to afford 2.40. 2.21 can also be reacted with a stoichiometric amount of $\mathrm{AlCl}_{3}$ and quenched with $\mathrm{MeOH}$ to give 2.41. The desired product is achieved as proven by the absence of a ${ }^{19} \mathrm{~F}$ signal in fluorine NMR. Finally, through a century old reaction BODIPY aldehyde (2.21) was reacted with Brady's reagent to couple BODIPY to 2,4 dinitrophenyl hydrazine (2.42).

\subsection{Characterization of $\mathbf{2 . 3 9}$ and a possible synthetic mechanism}

The synthesis of $\mathbf{2 . 3 9}$ occurred when standard Vilsmeier-Haack conditions were applied to 2.21. The predicted product of a diformylated BODPIY was not achieved but red crystals were isolated from the reaction mixture. As shown in the crystal structure ORTEP (Figure 2.1), a trans dimethylenamine has replaced a normally robust methyl group. Activation of any BODIPY methyl group is rare and the meso protons were thought to be particularly stable as Mulliken-charge analysis typically shows high electron density on the meso carbon further reducing the acidity of the protons. ${ }^{68}$ 


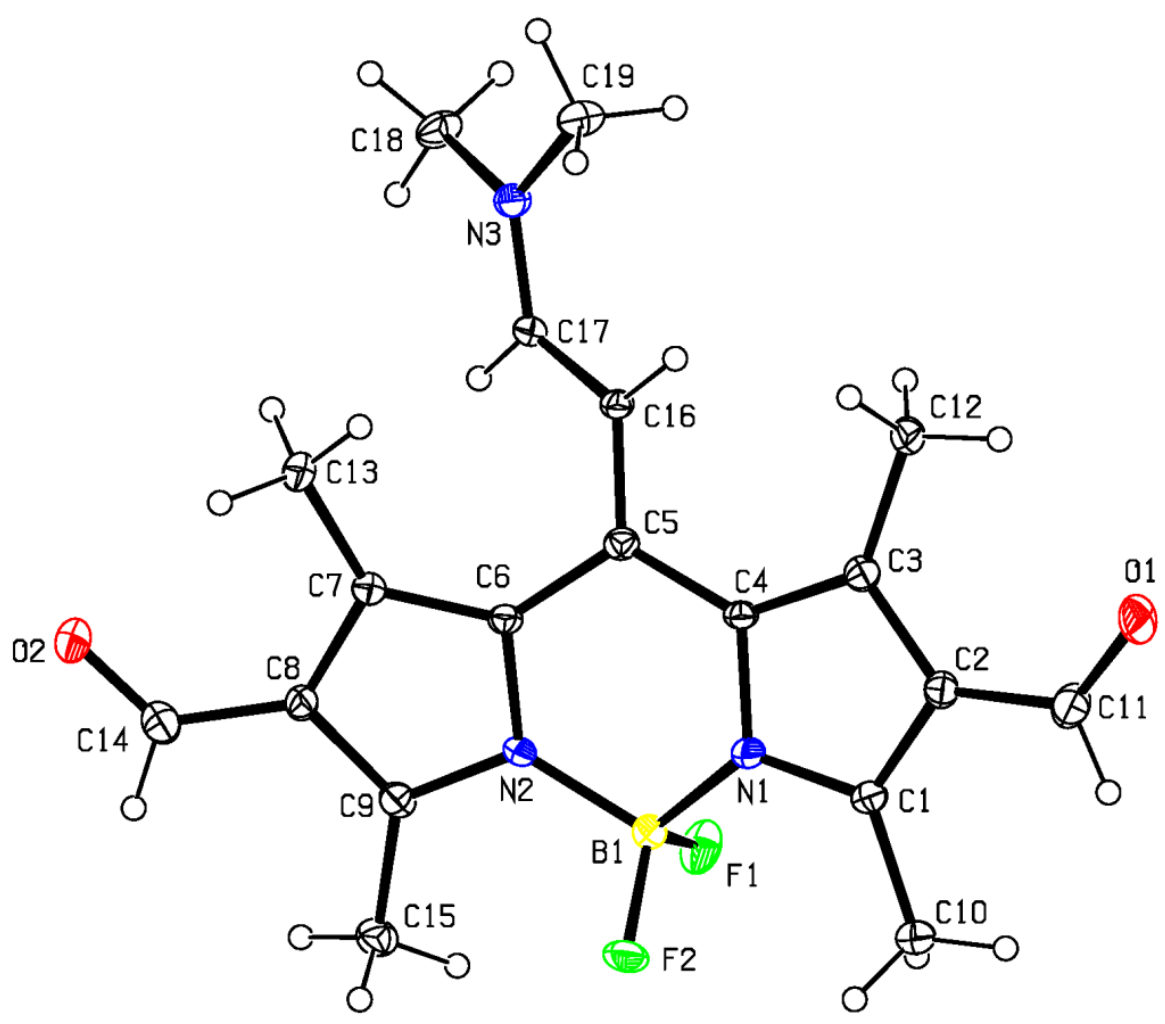

Figure 2.1 ORTEP diagram of the molecular structure of $\mathbf{2 . 3 9}$

Chattopadhyay and coworkers attributed this activation to steric strain on the meso hydrogens due to their neighboring methyl protons. ${ }^{68}$ However, this rationale does not explain why we only see activation of this position under Vilsmeier-Haack conditions. We propose that the increased acidity of the meso protons is caused by resonance stabilization owing to the presence of the cationic Vilsmeier reagent present on the 2-position of the BODIPY core as shown in Figure 2.2. 

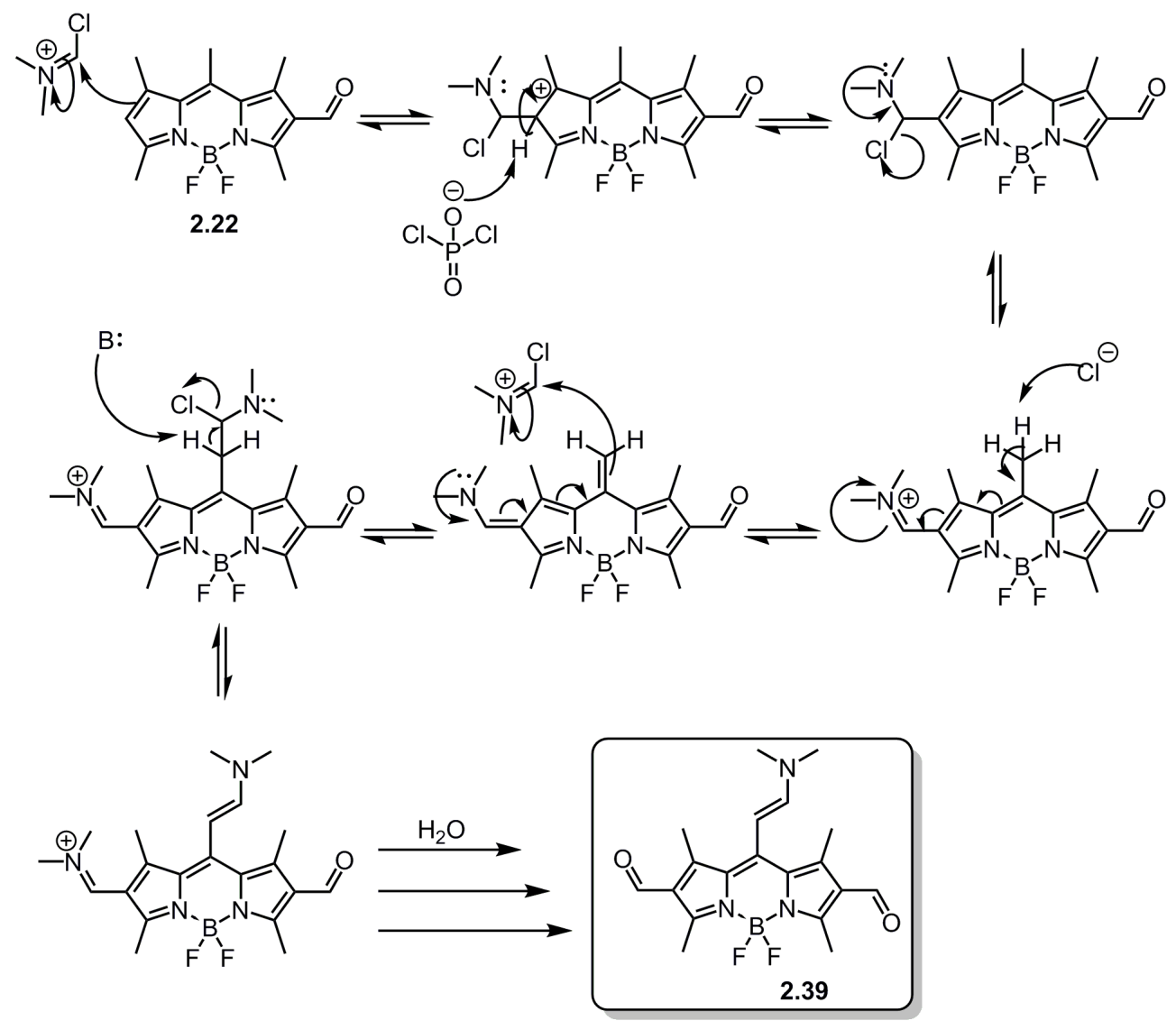

Figure 2.2 Proposed mechanism of compound 2.39

The increased acidity of the meso proton allows for a second deprotonation leading to the coupling of a second equivalent of the Vilsmeier-Haack reagent. The BODIPY core re-aromatizes to stabilize the dimethylamine and the addition of water allows a standard hydrolysis to occur yielding 2.39. While this molecule was not an original target compound, the electron rich amine conjugated to an electron deficient BODIPY should make for a molecule with interesting physicochemical properties. 


\section{RESULTS AND DISCUSSION}

The molecules synthesized above have potential applications in a wide range of materials. After all the synthesis was completed the physicochemical properties of these molecules were examined largely through UV-Vis spectroscopy and electrochemistry. The meso-substituted BODIPY cores were likewise studied by DFT prior to synthesis, which was followed by physicochemical characterization. This process was repeated a final time with the final set of BODIPY compounds $(2.35-\mathbf{2 . 4 2})$ and the results of all experiments provide invaluable info for next generation BODIPY DSSC Dyes

\subsection{Physicochemical properties of BODIPY DSSC dyes (1.24a-b-1.27a-b)}

In this section the physicochemical properties of the 8 BODIPY DSSC dyes will be explored. Generally, only dyes $1.24 a-1.27$ a will be examined to reduce the computing power necessary for DFT and then to maintain consistency through the rest of the section.

\subsubsection{Density Functional Theory (DFT) Calculations of Dyes 1.24a-1.27a}

All theoretical calculations were performed using the Gaussian software suite. ${ }^{69,70}$ The ground state of all molecules was optimized utilizing the hybrid functional B3LYP and the 6-31G (d,p) basis set. Optimized structures were used to ensure that there was significant delocalization between ground state and excited energy levels. It is imperative in DSSC dyes that not only there be a delocalization of electron upon excitation but also that electron density in the $\mathrm{LUMO}$ is spatially close to the $\mathrm{TiO}_{2}$ semiconductor. Next, the optimized structure was subjected to time dependant density functional theory (TD-DFT) to find a calculated UV-Vis spectra based on the optimized B3LYP ground states. All calculations were performed in the gas phase as similar calculations have been previously shown to adequately describe the electronic and optical properties of similar push-pull dyes. The result of the DFT optimization is shown in Figure 3.1; Electron densities for the HOMO -1, HOMO, LUMO and LUMO+1 for all 4 molecules displays a clear trend. The HOMO for all molecules is as expected located on the electron rich triphenylamine (TPA) donor. The HOMO-1 is located on the next most electron rich group, the BODIPY core itself. LUMO +1 electron density presides largely over the BODIPY core as well as the electron deficient cyano acetic acid anchor. 


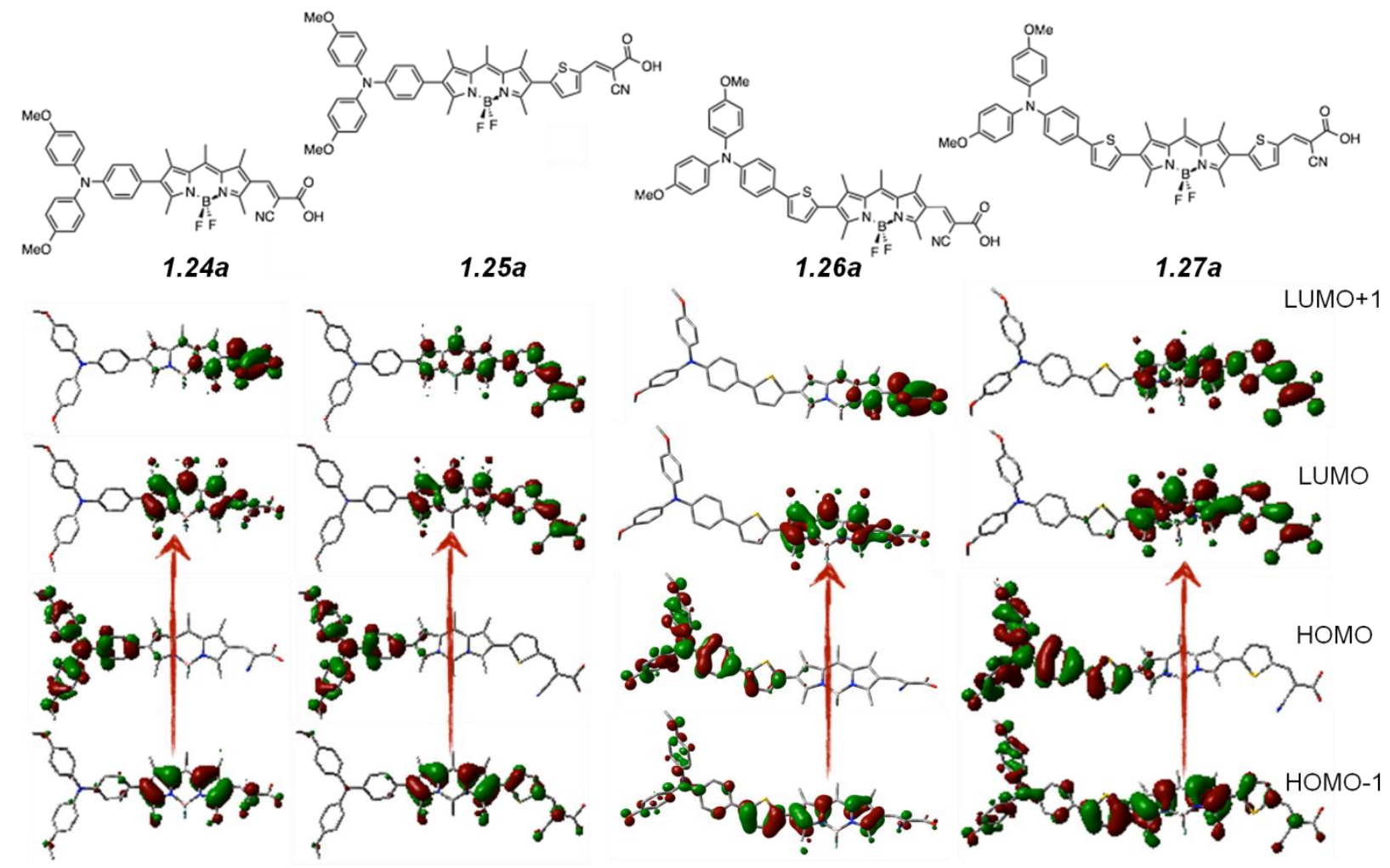

Figure 3.1 DFT calculations of the frontier molecular orbitals (FMO) of BODIPY DSSC dyes as calculated by B3LYP 6-31G Basis set. Red arrow indicates the dominant transition as predicted by TD-DFT.

Electron density in the LUMO is similarly localized to the $\pi$-spacer and the anchor group, which is crucial for DSSC performance. Kasha's rule implies that internal conversion from a higher singlet excited states happens rapidly, and therefore emission or electron injection should originate from the lowest excited state (the LUMO). ${ }^{71}$ The dyes presented in Figure 3.1 all show electron density as spatially close as possible to the $\mathrm{TiO}_{2}$ semiconductor in the lowest energy excited state (LUMO). Furthermore TD-DFT provides valuable information as to the nature of the transitions occurring in these molecules. The red arrows in Figure 3.1 show the most favoured energy transition as predicted by DFT. As shown in Figure 3.2, the HOMO - LUMO transition (1), which is always the lowest energy transition has a weak predicted oscillator strength near $750 \mathrm{~nm}$. Conversely the dominant transition of HOMO-1 to LUMO (2) is a much stronger transition and is largely responsible for the predicted absorption maxima of these dyes. 


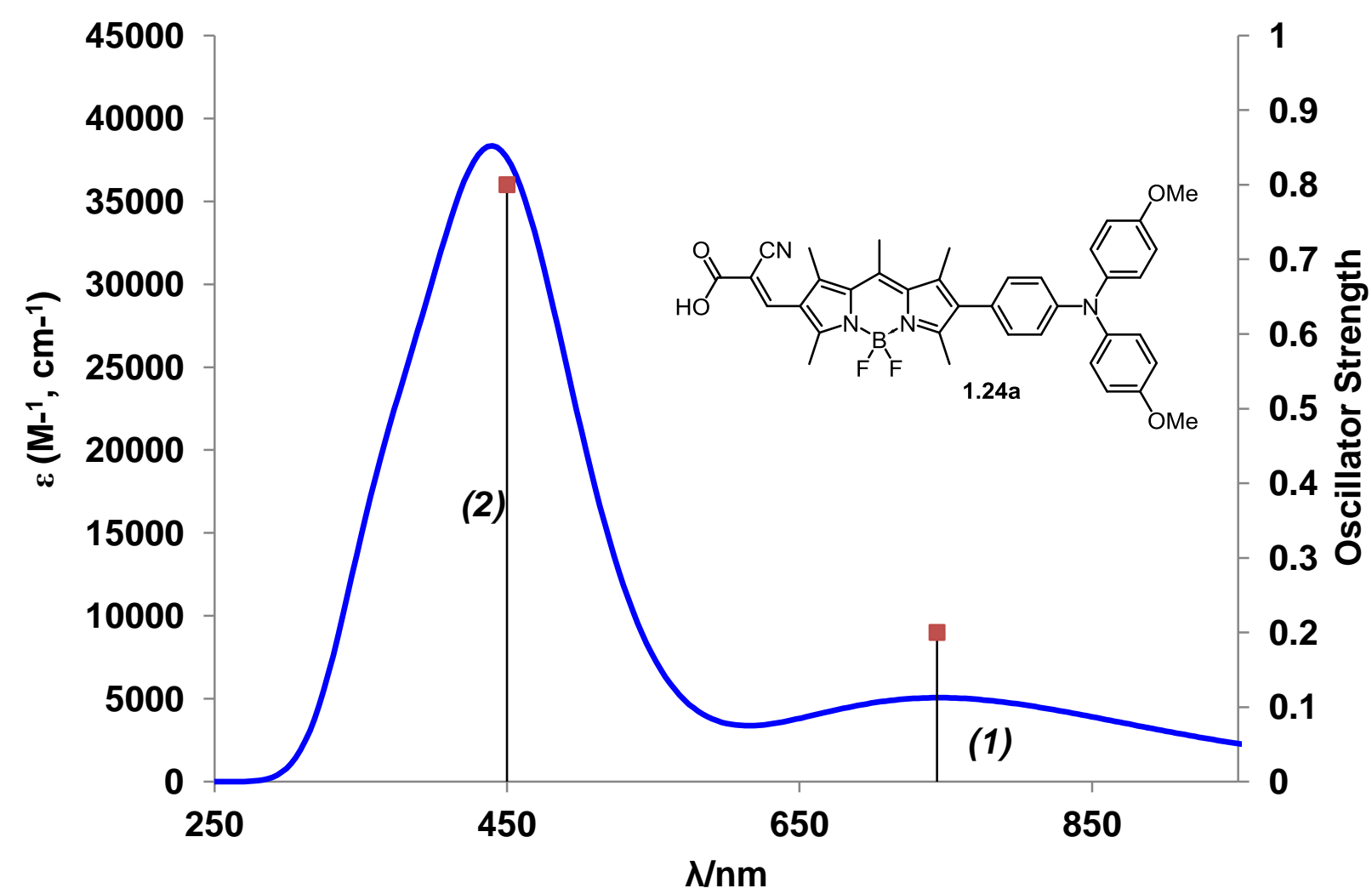

Figure 3.2 UV-Vis of Dye 1.24a as predicted with TD-DFT. (1) The HOMO-LUMO transition, (2) the HOMO-1 to LUMO transition.

DFT calculations were not performed on the OHexyl (1.24b -1.27b) derivatives of these dyes because of the additional computing power required. Additionally no major changes in physicochemical properties are expected by modifying alkyl chain length at the para position of the TPA in these molecules.

\subsubsection{UV-Vis Spectroscopy of dyes 1.24 - 1.27}

In order to maximize efficiency, DSSC dyes are required to have high molar extinction coefficients $(\varepsilon)$, and panchromatic absorption so that devices can harness as much light as possible. To measure the $\varepsilon$ values of our dyes (1.24 to 1.27) we performed solution based UV-Vis spectroscopy on all of our target molecules. Figure 3.3 shows the results of this experiment as well as a comparison to the pentamethyl BODIPY starting material 2.12. As shown below the BODIPY starting material has a very large $\varepsilon$ value over $8 * 10^{4} \mathrm{M}^{-1} \mathrm{~cm}^{-1}$, however, this is a relatively high energy transition when compared to our synthesized DSSC dyes. It is imperative that DSSC dyes be able to harvest low energy photons ideally to 
the red or even IR wavelengths to maximize device efficiency vide supra (Chapter 1 ). The addition of thiophene spacers to our BODIPY molecules was performed because extending the conjugation length of a molecule leads to a bathchromic shift in the molecules absorbance. As shown in Figure 3.3, all of our potential DSSC dyes have a red-shifted absorption as well as a wider absorption envelope than the standard BODIPY 2.12.

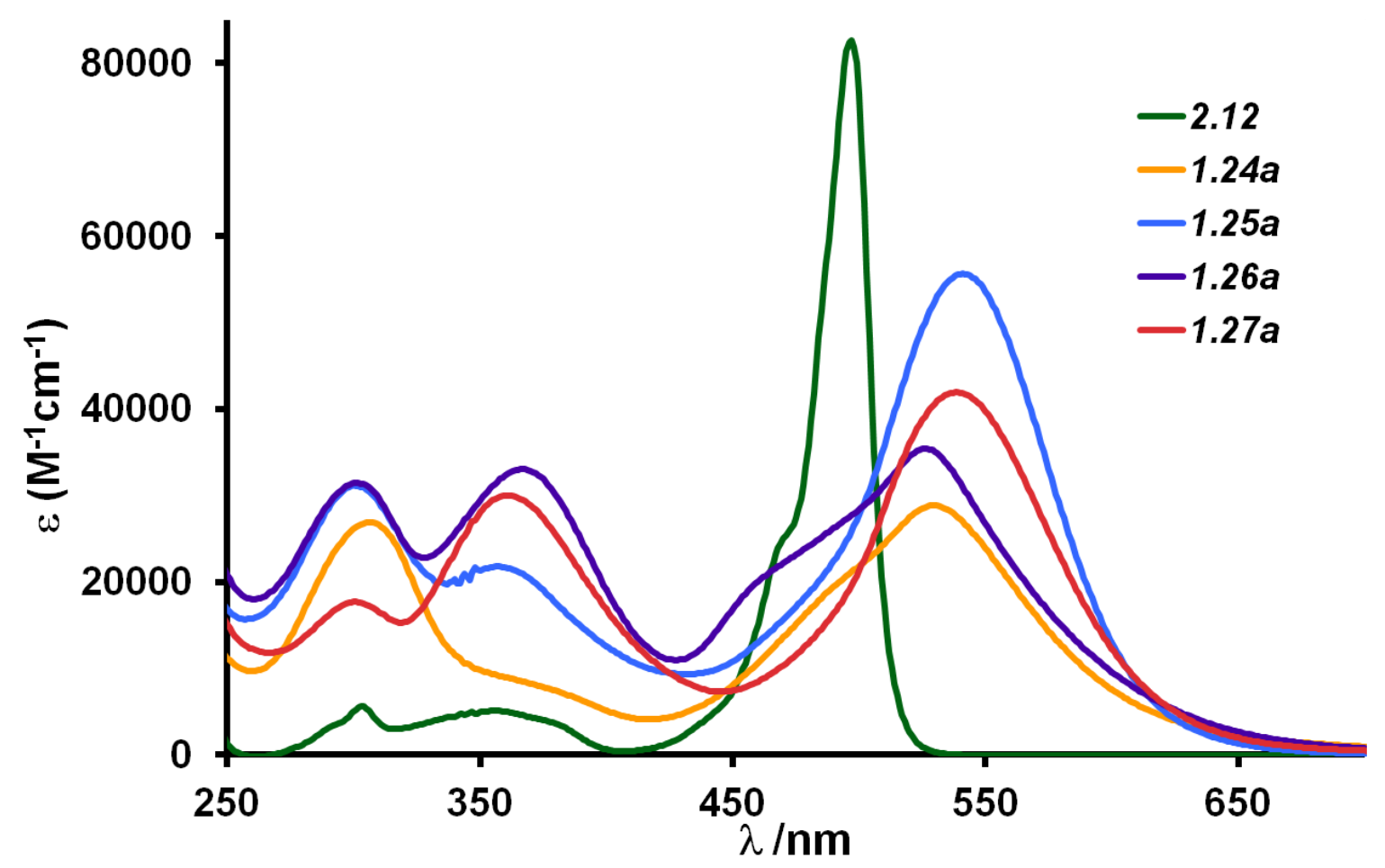

Figure 3.3 UV-Vis data of 2.12 and BODIPY Dyes 1.24a to 1.27a. Data Collected In DCM Solutions

It was predicted that 1.27a with thiophene spacers on both sides of the BODIPY would have the most red shifted absorption, However 1.25a with only one thiophene spacer between the BODIPY and the cyanoacetic acid anchor group has a slightly lower energy absorption maximum. Similarly while 1.26a was expected to have a more bathochromic absorption then 1.24a solution phase UV-Vis shows the absorption maxima of $\mathbf{1 . 2 6 a}$ to be slightly blue shifted as compared to the dye with no thiophene spacers. A possible explanation for these results could be attributed to the thiophene between the BODIPY and the anchor group allows for better planarity and thus electronic communication. Having the cyanoacetic acid group directly attached to the BODIPY causes a disruption in planarity and thus blue shifts the absorption. 
UV-vis experiments were performed on all synthesized dye molecules and as expected the absorption maxima for the methoxy (a) and hexoxy (b) derivatives of each dye are at very similar wavelengths as shown in Table 3.1.

Table 3.1 Physicochemical properties for Dyes 1.24a-b to $1.27 a-b$

\begin{tabular}{|c|c|c|c|c|}
\hline \multirow{2}{*}{ Compound } & \multirow{2}{*}{ UV-vis Absorbance Data $(\mathrm{nm}):{ }^{a} \lambda_{\max }\left(\varepsilon \times 10^{3} \mathrm{M}^{-1} \cdot \mathrm{cm}^{-1}\right)$} & \multicolumn{3}{|c|}{$E_{1 / 2}{ }^{0 x}$ (V vs NHE) ${ }^{*}$} \\
\hline & & BODIPY/BODIPY ${ }^{\circ}$ & $\mathrm{TPA}^{\circ} / \mathrm{TPA}$ & BODIPY $^{\circ} /$ BODIPY $^{\circ}$ \\
\hline $2.3 a$ & $299(21.2)$ & - & 1.02 & - \\
\hline 2.12 & 497 (82.6), $356(5.1), 303(5.7)$ & -1.05 & - & 1.50 \\
\hline $1.24 a$ & $529(28.8), 360^{s h}(9.0), 306(26.9)$ & -0.87 & 1.02 & 1.63 \\
\hline $1.24 b$ & $530(37.4), 360^{\text {sh }}(9.0), 307(29.9)$ & -0.87 & 1.00 & 1.63 \\
\hline $1.25 \mathrm{a}$ & $541(55.6), 357(21.8), 300$ (31.2) & -0.90 & 1.01 & 1.58 \\
\hline $1.25 \mathrm{~b}$ & 540 (56.6), 357 (21.6), 302 (30.7) & -0.89 & 0.99 & 1.57 \\
\hline $1.26 a$ & $526(35.5), 367(33.1), 301(31.2)$ & -0.86 & 0.98 & 1.39 \\
\hline $1.26 \mathrm{~b}$ & $528(43.2) 359(45.9) 299(405)$ & -0.86 & 0.96 & 1.36 \\
\hline $1.27 a$ & $538(41.9), 361(30.0), 300(17.7)$ & -0.82 & 0.97 & 1.32 \\
\hline $1.27 \mathrm{~b}$ & $538(57.3), 361(40.8), 300$ (22.7) & -0.82 & 0.95 & 1.32 \\
\hline
\end{tabular}

*all data collected in $\mathrm{CH}_{2} \mathrm{Cl}_{2}$ using $0.1 \mathrm{M}\left[n \mathrm{Bu}_{4} \mathrm{~N}\right]\left[\mathrm{PF}_{6}\right]$ at $100 \mathrm{mV} / \mathrm{s}$ and referenced to a $[\mathrm{Fc}] /[\mathrm{Fc}]^{+}$internal standard $\left(+765 \mathrm{mV}\right.$ vs. $\mathrm{NHE}$ in $\left.\mathrm{CH}_{2} \mathrm{Cl}_{2}\right)$

With a difference of $2 \mathrm{~nm} \mathrm{1.26a}$ and $\mathbf{1 . 2 6 \mathrm { b }}$ had the largest $\lambda$ max variance and secondary absorption maxima were also within $2 \mathrm{~nm}$ when comparing OMe and OHexyl side chains. The UV-Vis experiments showed that all dyes have broad absorptions in the visible region of the electromagnetic spectrum which makes them excellent candidates for DSSC applications.

\subsubsection{Electrochemistry of dye molecules $1.24 a, b$ to $1.27 a, b$}

Electrochemistry was performed on molecules $1.24 a, b$ to $1.27 a, b$ to provide insight to the energy levels of the frontier molecular orbital's in each dye. The energy level of the HOMO must be significantly lower the redox couple of the electrolyte to ensure there is sufficient thermodynamic driving force to regenerate the dye following electron injection. Similarly the energetic location of the LUMO is crucial to ensure there is proper thermodynamic driving force to inject electrons from the excited state of the dye to the conduction band of the semiconductor.

Figure 3.4 Cyclic voltammogram of dye 1.26a as recorded in a solution of DCM. Data collected in $\mathrm{CH}_{2} \mathrm{Cl}_{2}$ using $0.1 \mathrm{M}\left[n \mathrm{Bu}_{4} \mathrm{~N}\right]\left[\mathrm{PF}_{6}\right]$ at $100 \mathrm{mV} / \mathrm{s}$ and referenced to a $[\mathrm{Fc}] /[\mathrm{Fc}]^{+}$internal standard $(+765 \mathrm{mV}$ vs. NHE in $\mathrm{CH}_{2} \mathrm{Cl}_{2}$ ) 


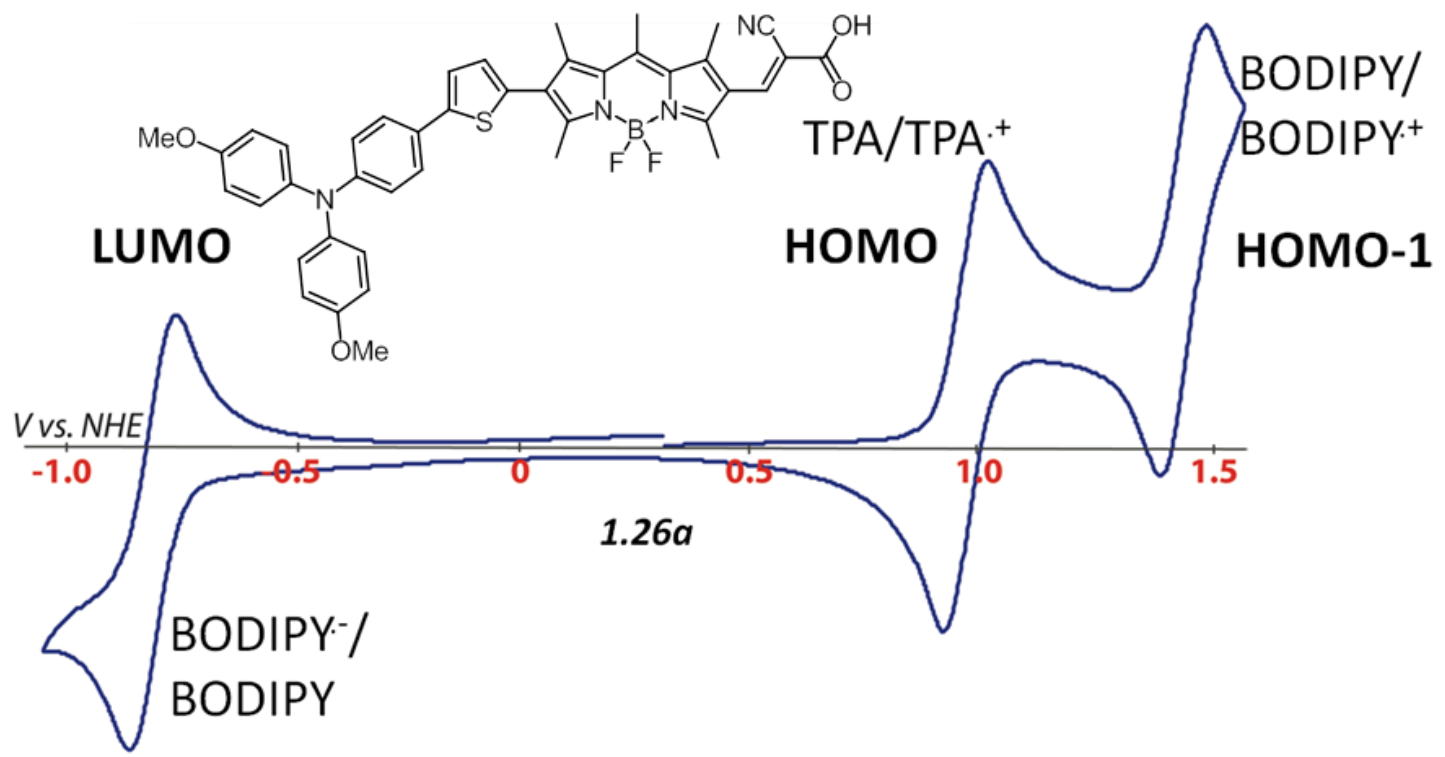

While CV does not provide identical energy levels as those present in devices due to the change of state ( $\mathrm{CV}$ is performed in solution, in a device the dyes are adsorbed to solid TiO2) it is very useful as a tool for examining the trends in these molecules. All of the BODIPY based dyes experienced two oxidations as shown in Table 3.1 and specifically to dye 1.26a in Figure 3.4. The first oxidation at approximately $1 \mathrm{eV}$, is the TPA core being oxidized. There is a trend of reduced oxidation potential as conjugation is increased as expected with the $\mathbf{1 . 2 4}$ dyes having higher TPA oxidation potentials than the dyes with extended conjugations. This trend is reinforced by what is observed in the second oxidation, the oxidation of the BODIPY core. While there is a slight difference between dyes $\mathbf{1 . 2 4}$ and $\mathbf{1 . 2 5}$ there is a drastic change in this second oxidation potential after the addition of a thiophene spacer between the TPA and BODIPY moieties. The spatial separation of these groups allows for much lower second oxidation potentials as shown in Table 3.1. Dyes 1.24 to 1.27 all show a completely reversible reduction as shown in Table 3.1. The previously unreported 1.26ab dyes confirmed that the thiophene between the BODIPY and the TPA was the major driving force in dropping the BODIPY oxidation potential in 1.27ab. It is imperative that this second oxidation which may strongly reflect the HOMO-1 energy level is as accessible as possible because as the DFT in Chapter 3.1.1 showed, The HOMO-1 to LUMO is the dominant energy transition in these dye molecules.

\subsubsection{Preliminary testing of device $\mathbf{1 . 2 7 b}$}

Due to geographical and financial constraints dyes 1.24 -1.27 have not yet been systematically tested in DSSC devices. However, through collaboration with the Berlinguette group at the University of Calgary one dye was examined for preliminary device performance. $1.27 \mathrm{~b}$ was selected as the optimum 
candidate due to the OHexyl chains being present on the periphery of the dye, which is important for surface passivation.

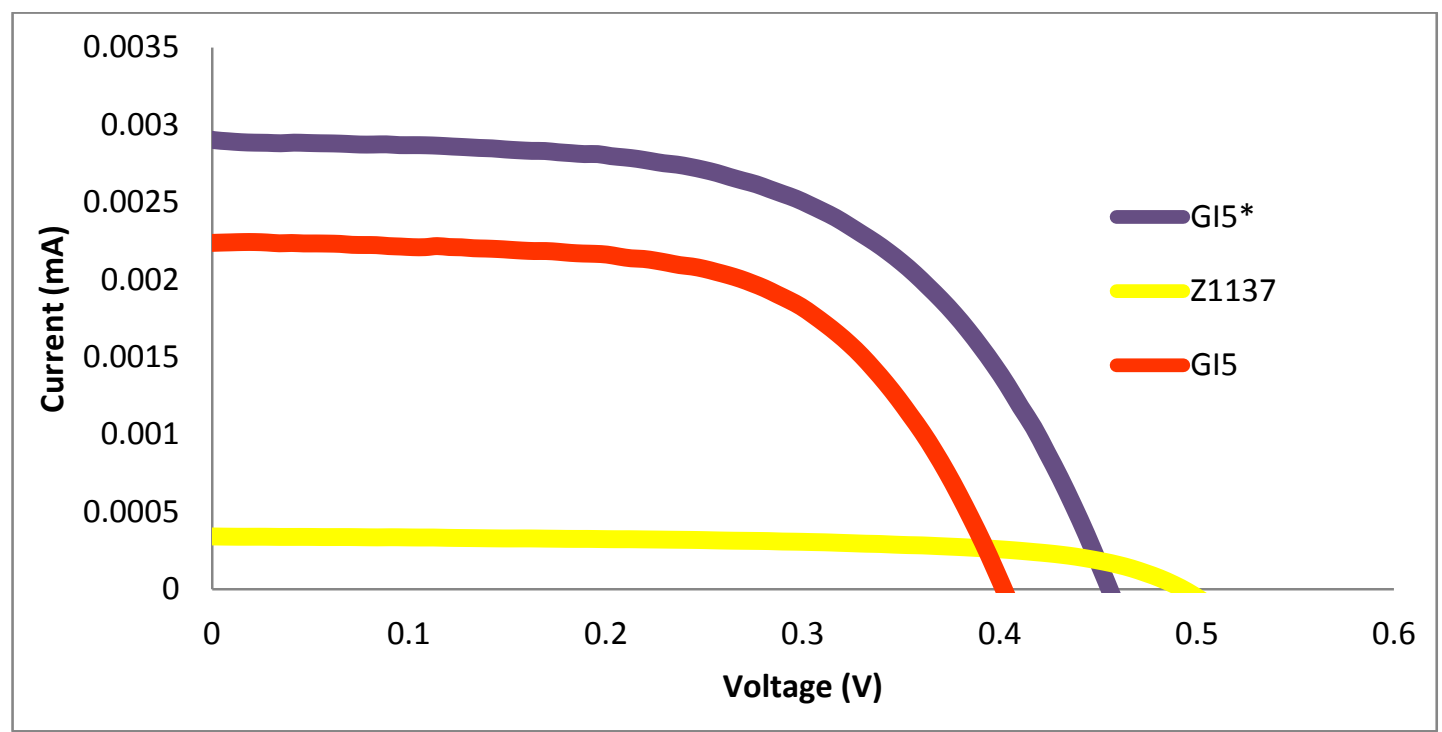

Figure 3.5 Preliminary device data of dye $1.27 \mathrm{~b}$. GI5* represents the same device as GI5 after 80 minutes of light soaking.

Secondly, it had the smallest HOMO LUMO gap of any dye which suggested it may be the most efficient device in our family of dyes. The current voltage (JV) curve showing the performance of $\mathbf{1 . 2 7 b}$ is shown in Figure 3.5 and there is a clear difference between the GI5 and the Z1137 electrolyte. Table 3.2 shows that the GI5 electrolyte shows over a 10 fold increase in current over Z1137. The reason for this is that even though both electrolytes are based on the $\mathrm{I}^{2} / \mathrm{I}_{3}^{-}$redox couple, GI5 contains a large amount of $\mathrm{Li}^{+}$ which causes the conduction band of $\mathrm{TiO}_{2}$ to decrease in energy thus promoting charge injection. ${ }^{72}$

Table 3.2 Comparing the GI5 and Z1137 Electrolyte in 1.27b DSSC Device

\begin{tabular}{|c|c|c|c|c|c|}
\hline Electrolyte & Voc (V) & Isc (A) & Jsc (mA/cm $\left.{ }^{2}\right)$ & Fill Factor & Efficiency (\%) \\
\hline Z1137 & 0.48 & 0.00031 & 1.20 & 0.60 & 0.35 \\
\hline GI5 & 0.40 & 0.0022 & 8.60 & 0.61 & 2.11 \\
\hline GI5* & 0.41 & 0.0032 & 12.21 & 0.55 & 2.93 \\
\hline
\end{tabular}


GI5* is the same device as electrolyte GI5 but efficiency was recorded after 80 minutes of light soaking

While changing electrolytes provided improved efficiency, light soaking was also employed to maximize the efficiency of this device. Light soaking is a process by which the device is exposed to simulated direct sunlight for a period of time (80 minutes in this case) before solar efficiency data is recorded. This process allows electrons that are injected into the $\mathrm{TiO}_{2}$ to "fill up" the trap states in the semiconductor prior to device testing. This led to a then BODIPY based DSSC dye record efficiency of $2.93 \%$. However, lowering the conduction band of the semiconductor reduces the maximum voltage that can be produced by the DSSC device, limiting overall efficiency. To address this issue a novel series of BODIPY building blocks with higher energy LUMO's must be designed to maximize the voltage and thus efficiency of future generation DSSC dyes.

\subsection{Physicochemical properties of meso-substituted BODIPY cores}

To this end, the first approach investigated to raise the LUMO energy level of these dyes was to modify the meso position of the BODIPY core. Through the synthesis pathway shown in Chapter 2.8, four new BOPIDY cores were prepared with different physicochemical properties. The choice to modify the meso position was pragmatic, as it permits the adjustment of the LUMO level without affecting the TPA or anchor moieties. While there was not enough time to finish the synthesis of dye targets with these new BODIPY cores, the following study focuses on the structure property relationships of exclusively mesofunctionalized BODIPYs.

In inclusion of a phenyl ring at the meso position (2.32a), permits the substitution of resonance donor or withdrawing groups. In an attempt to further increase electron density on the BODIPY to destabilize the

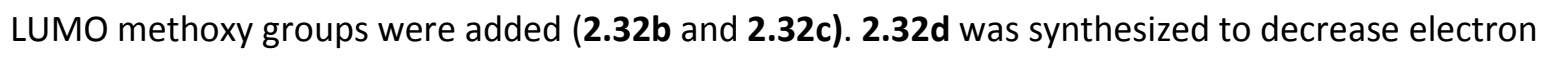
density on the BODIPY backbone and as such, a nitro group was employed at the para position of the BODIPY building block. 


\subsubsection{DFT calculations of BODIPY cores $2.32 a$ to $\mathbf{2 . 3 2 d}$}

To test this hypothesis, DFT calculations were performed on $\mathbf{2 . 3 2 a}$ to $\mathbf{2 . 3 2} \mathrm{d}$ as shown in Figure 3.6 the HOMOs and LUMOs of these molecules are distributed across most of the BODIPY core. The exception

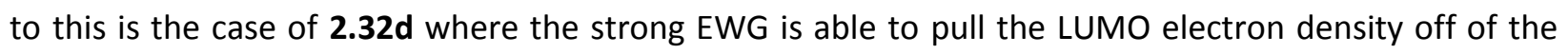
BODIPY and onto the nitro containing phenyl ring.

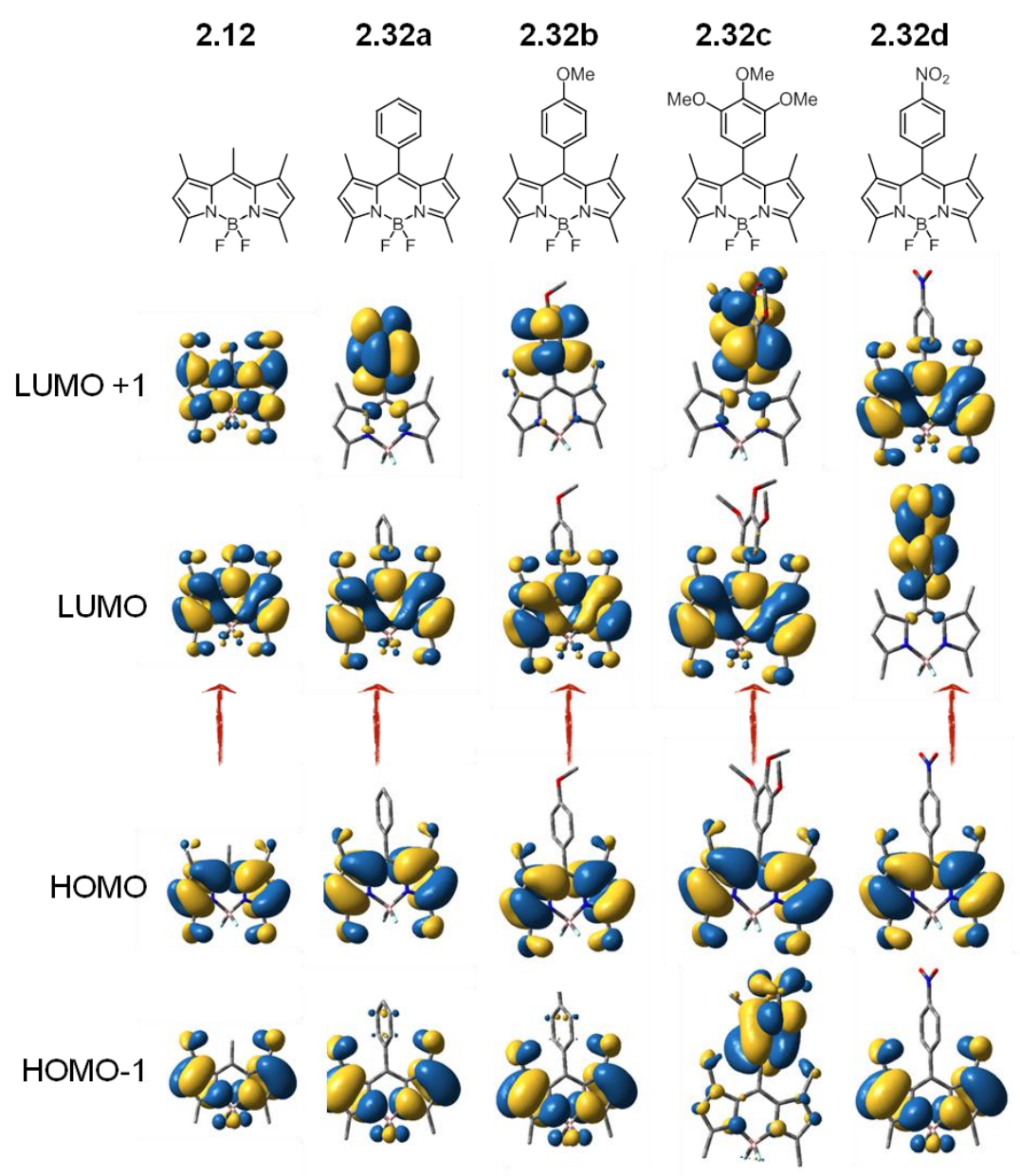

Figure 3.6 Predicted energy density diagrams of BODIPYs 2.32a to 2.32d 
However, despite the electronic differences, all of these molecules showed HOMO to LUMO as the most favored electron excitation. By DFT the only filled orbital with electron density present on the nitro phenyl ring was the HOMO-3 orbital which did show a contribution to the predicted UV-Vis as shown in Figure 3.7. 2.32a to 2.32c showed almost a sinusoidal UV-Vis spectrum by DFT, the HOMO-LUMO absorption is slightly red-shifted from the absorption maxima due to other electronic transitions being of higher energy but not very favourable.

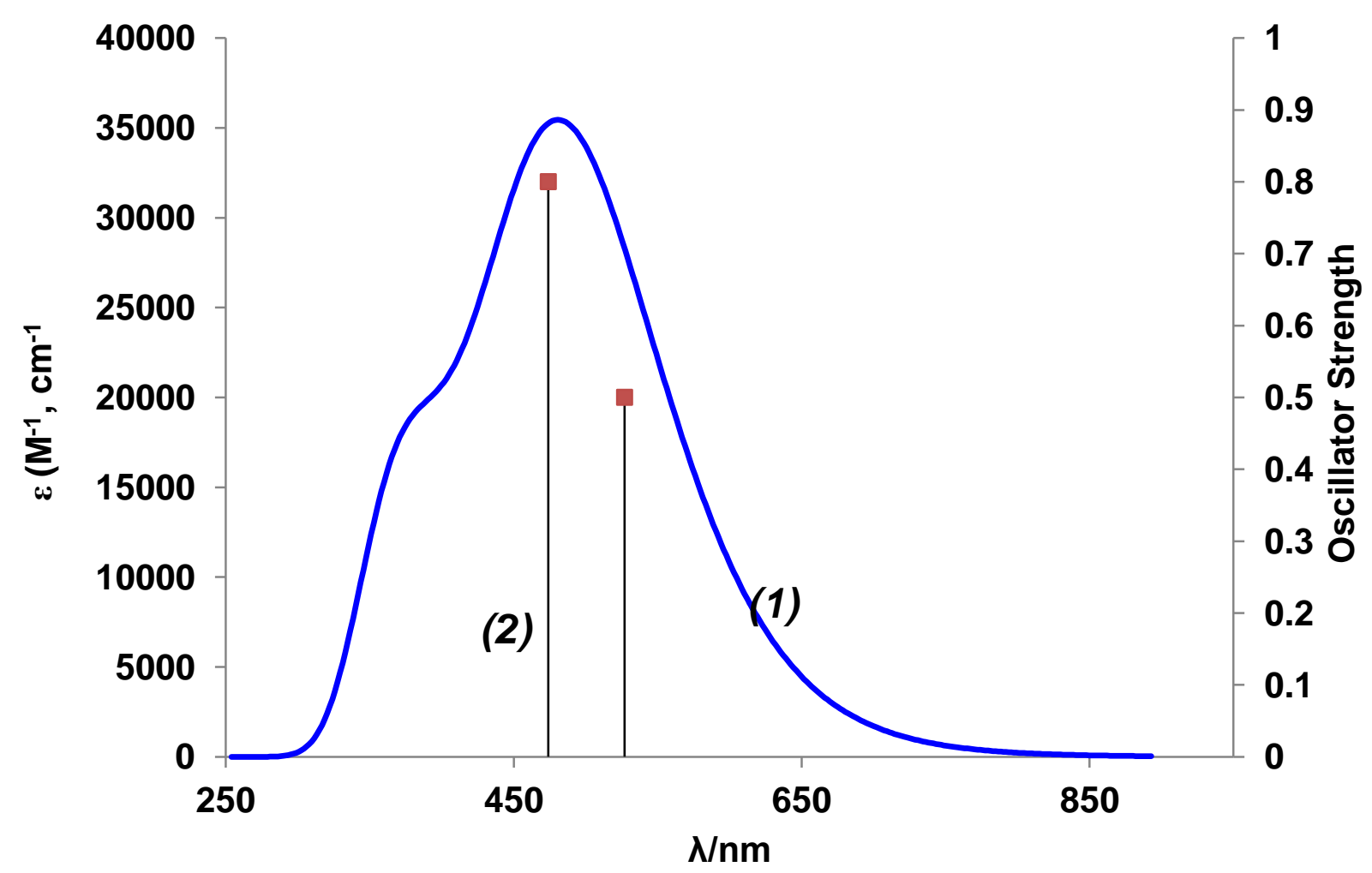

Figure 3.7 The Predicted UV-Vis Spectrum of 2.32d. (1) is the HOMO to LUMO transition and (2) is the HOMO-3 to LUMO transition

The predicted relative energies of these molecules was also explored and compared to our benchmark BODIPY 2.12. While these calculations are performed in the gas phase and are not absolute DFT has shown promise predicting relative energy levels of similar molecules. ${ }^{73,74}$ Table 3.3 DFT calculated energy levels in BODIPY cores shows the predicted relative energy levels of 2.32a-d including the HOMO-LUMO gap which is imperative for maintaining a high current in DSSC devices. As expected the 
LUMO energy level in more electron rich BODIPYs (2.32a-2.32c) shows an increase in energy, which could increase the thermodynamic driving force for charge injection in a DSSC dye. These molecules also show a stabilization of the HOMO resulting in a similar HOMO-LUMO gap as the benchmark BODIPY

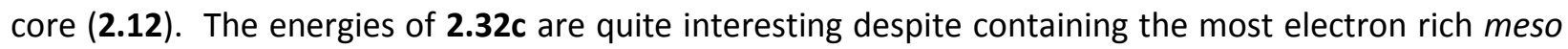
substituent, it provided less destabilization of the LUMO than $\mathbf{2 . 3 2}$ a and $\mathbf{2 . 3 2}$. A possible explanation for this is the methoxy groups at the meta positions to the BODIPY are too bulky and do not allow the meso phenyl ring to sit planer with the BODIPY core. This would disrupt electronic communication and thus limit the effect of any substituents present at the meso position.

Table 3.3 DFT calculated energy levels in BODIPY cores (all energies reported in Hartrees)

\begin{tabular}{|c|c|c|c|}
\hline Compound & HOMO & LUMO & Gap \\
\hline $\mathbf{2 . 1 2}$ & -0.20224 & -0.08808 & -0.11416 \\
\hline $\mathbf{2 . 3 2 a}$ & -0.19282 & -0.07542 & -0.1174 \\
\hline $\mathbf{2 . 3 2 b}$ & -0.19292 & -0.0756 & -0.11732 \\
\hline $\mathbf{2 . 3 2 c}$ & -0.19778 & -0.0858 & -0.11198 \\
\hline $\mathbf{2 . 3 2 d}$ & -0.21171 & -0.10948 & -0.10223 \\
\hline
\end{tabular}

*Found using the hybrid functional B3LYP and the 6-31G $(d, p)$ basis set.

The nitro derivative $\mathbf{2 . 3 2} \mathrm{d}$, acts in the opposite way as the other three modified BODIPYs. The strong EWG stabilizes both the HOMO and the LUMO with the more intense decrease in energy occurring with the LUMO. The lowering of the LUMO energy means it would not be suitable for the dye molecules with extended conjugation but $\mathbf{1 . 2 4}$ may be an ideal candidate for this BODIPY in future dye synthesis due to the drastically reduced HOMO-LUMO gap. As DFT calculations confirmed our initial hypothesis BODIPY cores 2.32a-d were synthesized. 


\subsubsection{UV-Vis spectroscopy of BODIPY cores 2.32a to $\mathbf{2 . 3 2 d}$}

The UV-Vis spectroscopy data of $\mathbf{2 . 3 2 a}$ to $\mathbf{2 . 3 2 d}$ was compared to that of our benchmark BODIPY 2.12. Ideally these molecules should have the same or greater $\lambda$ max than the benchmark compound so that as many photons as possible can be harvested after dye synthesis. $2.32 \mathrm{a}$ and $\mathbf{2 . 3 2} \mathbf{b}$ were expected to have a slightly blue-shifted absorption maxima due to the slightly larger HOMO LUMO gap predicted by DFT. However, as shown in Figure 3.8 UV-Vis spectra of 2.32a to $2.32 \mathrm{~d}$ in DCM both these molecules actually show a slight bathochromic shift in their absorption profiles as compared to $\mathbf{2 . 1 2}$. While this is inconsistent with DFT it is supported by the theory that adding electron density destabilizes the HOMO to a greater effect LUMO.

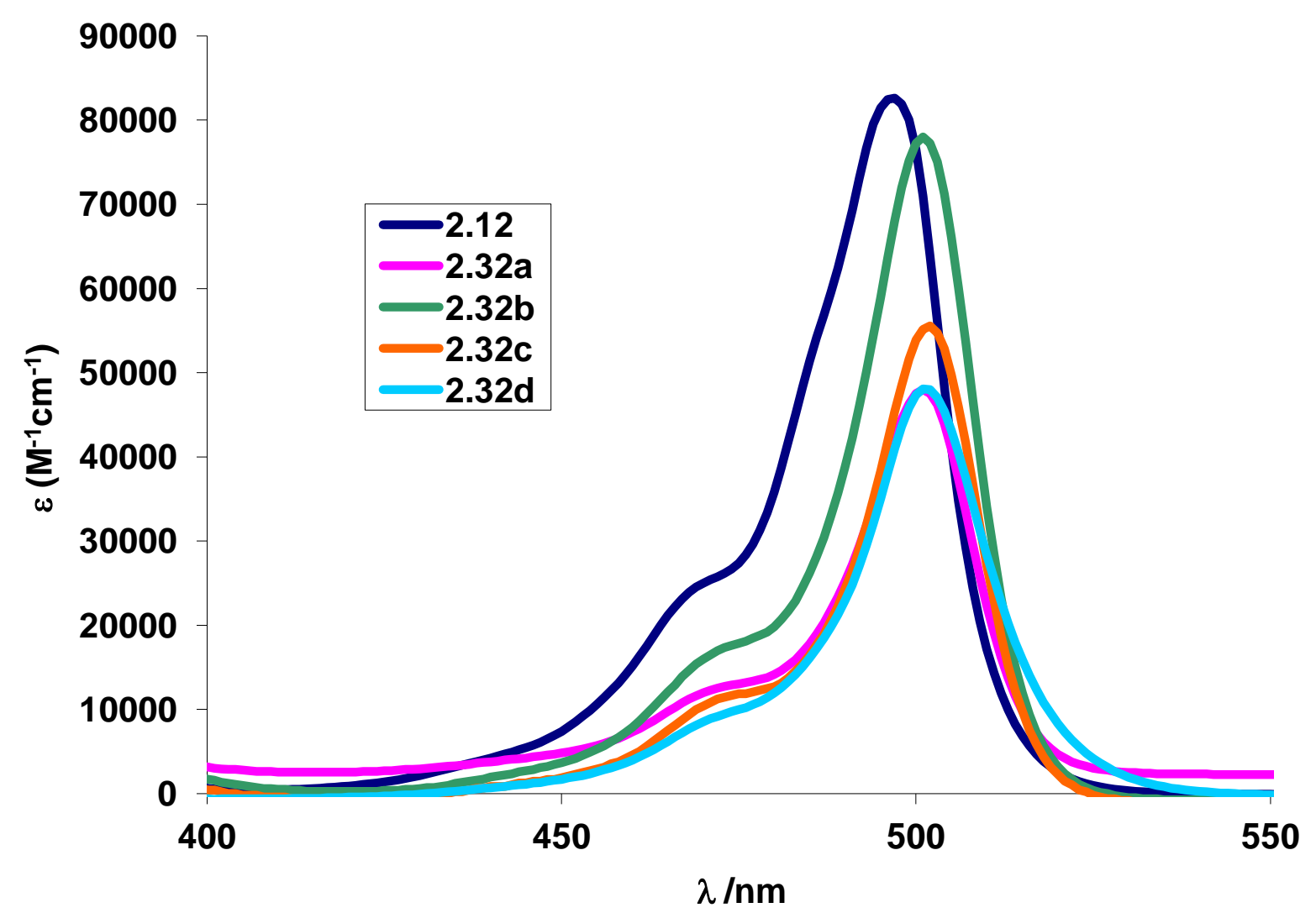

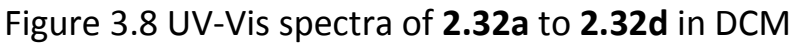

2.32c is in the most agreement with DFT as the small decrease in predicted HOMO LUMO gap translates to a small red-shift of the $\lambda$ max. $\mathbf{2 . 3 2} \mathrm{d}$ shows a peculiar maximum absorption as despite having the smallest energy gap by DFT it shows no bathochromic shift in its absorption envelope as compared to 
the other meso substituted BODIPY cores. Table 3.4 shows the physical and chemical properties of 2.32a to $\mathbf{2 . 3 2} \mathrm{d}$ and appears to support the DFT evidence in the HOMO LUMO gap of molecule $\mathbf{2 . 3 2} \mathrm{d}$.

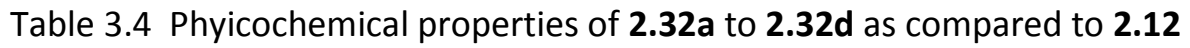

\begin{tabular}{|c|c|c|c|c|}
\hline \multirow{2}{*}{ Compound } & \multirow{2}{*}{$\lambda \mathrm{nm},\left(\varepsilon \mathrm{M}^{-1} \mathrm{~cm}^{-1}\right)$} & \multicolumn{2}{|c|}{$E_{1 / 2}{ }^{\text {ox }}(\mathrm{V} \text { vs NHE })^{b}$} & \\
\cline { 3 - 5 } & & BODIPY/BODIPY & BODIPY & \\
\hline $\mathbf{2 . 1 2}$ & $497(82600)$ & -1.05 & 1.50 & 2.55 \\
\hline $\mathbf{2 . 3 2 a}$ & $501(48000)$ & -0.957 & 1.52 & 2.48 \\
\hline $\mathbf{2 . 3 2 b}$ & $501(78000)$ & -0.977 & 1.54 & 2.52 \\
\hline $\mathbf{2 . 3 2 c}$ & $502(55000)$ & - & 1.58 & - \\
\hline $\mathbf{2 . 3 2 d}$ & $501(49000)$ & -0.726 & 1.62 & 2.35 \\
\hline
\end{tabular}

*all data collected in $\mathrm{CH}_{2} \mathrm{Cl}_{2}$ using $0.1 \mathrm{M}\left[n \mathrm{Bu}_{4} \mathrm{~N}\right]\left[\mathrm{PF}_{6}\right]$ at $100 \mathrm{mV} / \mathrm{s}$ and referenced to a $[\mathrm{Fc}] /[\mathrm{Fc}]^{+}$internal standard $\left(+765 \mathrm{mV}\right.$ vs. $\mathrm{NHE}$ in $\left.\mathrm{CH}_{2} \mathrm{Cl}_{2}\right)$

\subsubsection{Electrochemistry of BODIPY cores 2.32a to $2.32 d$}

The nitro derivative 3.23d has by far the smallest reduction potential and thus the lowest energy LUMO level as compared to the other BODIPY cores. There is a slight increase in oxidation potential as

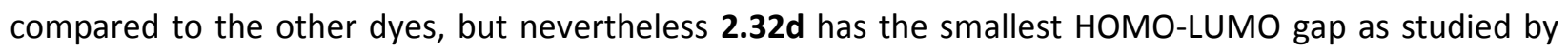
cyclic voltammetry. A possibility for the discrepancy between the UV-Vis and CV data is that there are other dominant transitions in this molecule that blue shift the UV-Vis $\lambda$ max but these transitions do not affect the electrochemistry because there is no condition of orbital overlap. 


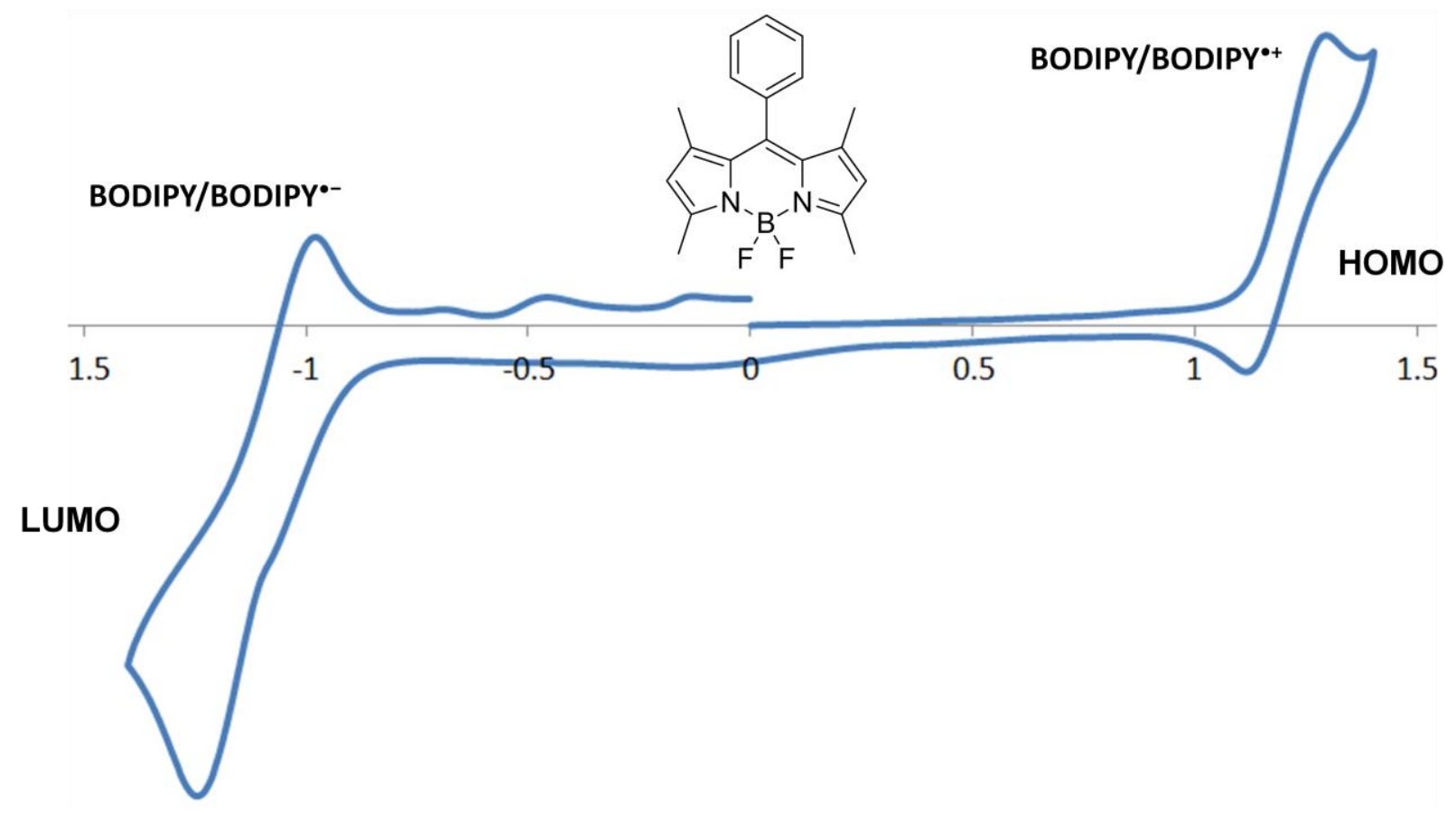

Figure $3.9 \mathrm{CV}$ of 2.32a showing a reversible reduction and oxidation. Data collected in $\mathrm{CH}_{2} \mathrm{Cl}_{2}$ using $0.1 \mathrm{M}$ $\left[n \mathrm{Bu}_{4} \mathrm{~N}\right]\left[\mathrm{PF}_{6}\right]$ at $100 \mathrm{mV} / \mathrm{s}$ and referenced to a $[\mathrm{Fc}] /[\mathrm{Fc}]^{+}$internal standard (+ $765 \mathrm{mV}$ vs. $\mathrm{NHE}$ in $\mathrm{CH}_{2} \mathrm{Cl}_{2}$ )

2.32a (Figure 3.9) and 2.32b showed expected results, both molecules show increased reduction potentials as compared to $\mathbf{2 . 1 2}$. 2.32b has a slightly elevated LUMO (reduction potential) energy as

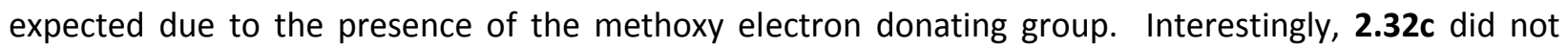
show a reduction potential by electrochemistry which could be an indication of a destabilization of the BODIPY core with the increased electron density of the trimethoxy phenyl ring. Regardless of a potential

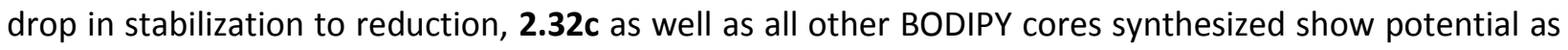
candidates for second generation BODIPY dye synthesis. To ensure the chemical stability of these

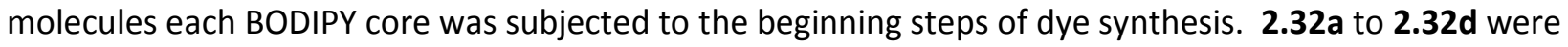
all successfully formylated and iodinated and can now be modified with relative ease.

\subsection{The physicochemical properties of push pull BODIPY molecules and dye precursors}

Throughout the course of this project we were also interested in how to modify the push pull properties of BODIPY as well as to modify the BODIPY core to increase the ease of synthesis when utilizing BODIPY in materials applications 


\subsubsection{The synthesis of BODIPY containing dye precursors}

Several new BODIPY compounds were synthesized beginning with the thiophene aldehyde derivatives 2.35 and 2.36. These molecules could undergo polymerization reactions or Knoevenagel condensation reactions to make novel BODIPY materials. Next, the somewhat surprisingly unreported $\mathbf{2 . 3 7}$ was utilized to synthesize the Miyaura reagent $2.38 .^{75}$ The synthesis of a $\mathbf{2 . 3 8}$ is exciting as it now allows for Suzuki coupling to be performed without the need of borylating secondary aromatic structures. 2.35 to 2.37 have a large potential for future synthesis of BODIPY based materials. Furthermore, to explore the potential of $\mathbf{2 . 1 2}$ to be tuned for different materials properties, a variety of EWG and EDG were coupled to the BODIPY core to give $\mathbf{2 . 3 9}$ to $\mathbf{2 . 4 2}$; the physicochemical properties of these molecules are discussed below.

\subsubsection{The DFT of push pull dye precursors}

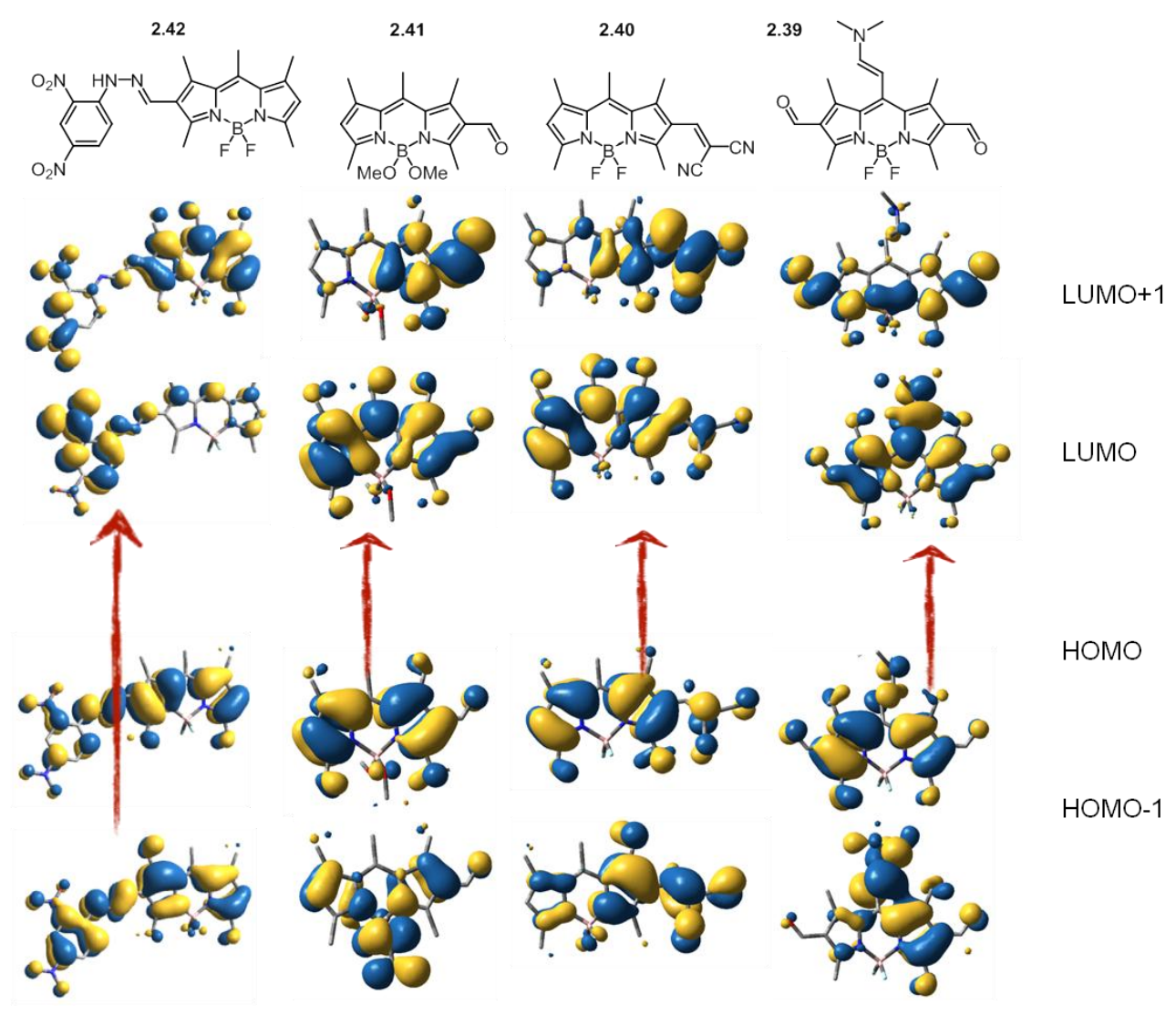

Figure 3.10 Predicted optical transitions in molecules 2.39-2.42 
As with all molecules studied, DFT calculations were performed on 2.39 to 2.42 to determine the electronic effects of the substituents attached to the BODIPY core. For $\mathbf{2 . 3 9}$ the symmetric aldehyde groups do little to pull electron density from the BODIPY core in the ground state; as such the dominant transition is that of HOMO to LUMO. However there is a distinct absence of electron density at the electron rich amine position of the molecule in the LUMO+1 energy state.

For the BODIPY substituted with a malononitrile, 2.40, there is little effect of the electron withdrawing group seen except for in the LUMO+1 energy level. As expected the dominant transition is that of HOMO to LUMO. In $\mathbf{2 . 4 1}$ the fluorine atoms on the boron atom are replaced with less inductively electron-withdrawing methoxy groups. This effect is only seen in the HOMO-1 energy level and the excellent orbital overlap between HOMO and LUMO provides the dominant transition for this molecule.

2.42 was the exception to the trend for this set of molecules, as the additional separation between the EWG and the BODIPY core pulled a large portion of LUMO electron density to the dinitrophenyl hydrazine (DPH) portion of the molecule. This causes the HOMO-1 to LUMO transition and even the HOMO-1 to LUMO +1 transition to dominate (Figure 3.11) due to good orbital overlap.

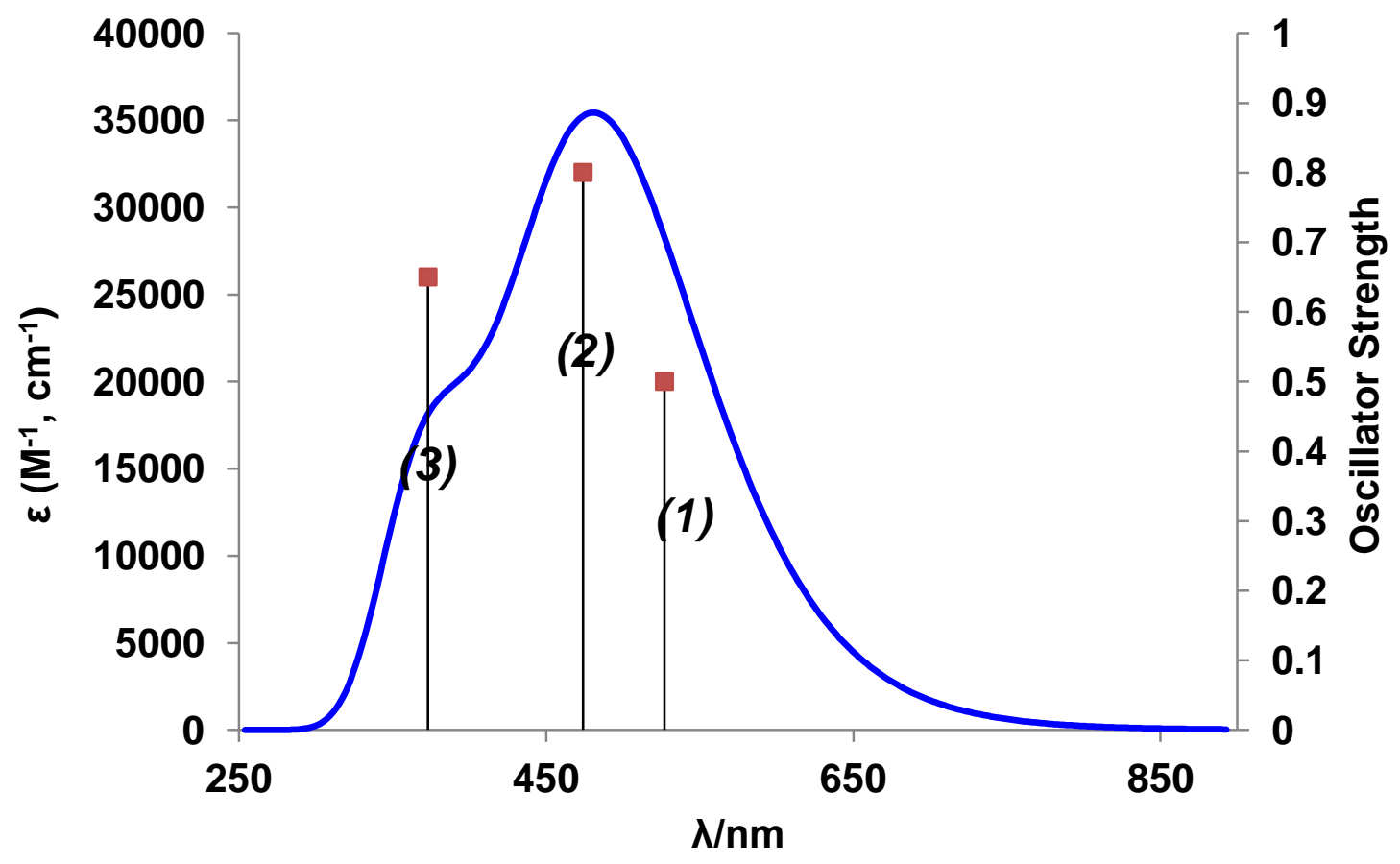

Figure 3.11 Predicted UV-Vis spectrum of 2.42. (1) HOMO - LUMO transition (2) HOMO - LUMO+1 transition and (3) HOMO-1 to LUMO transition 


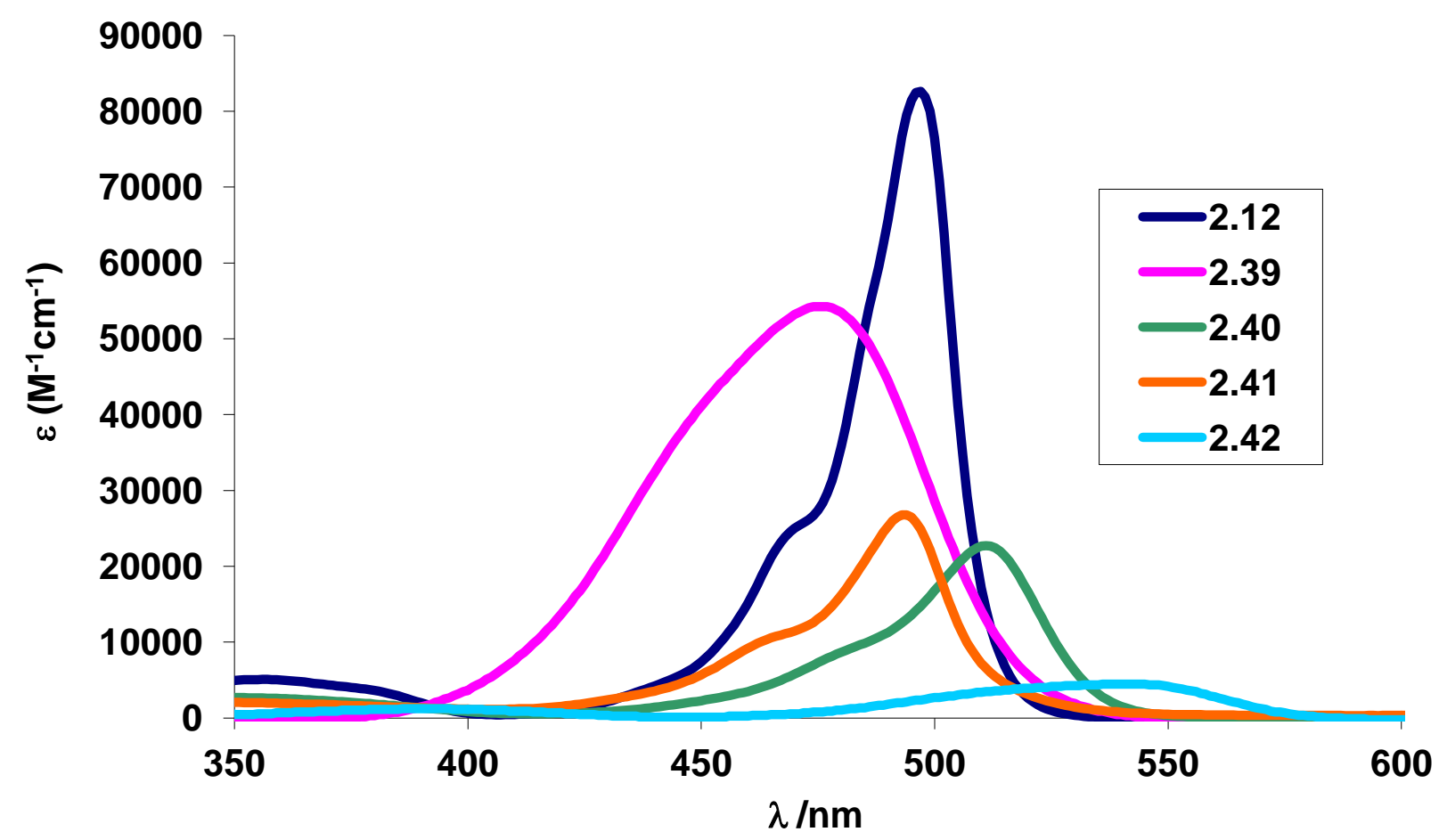

Figure 3.12 The Uv-vis spectra of molecules 2.39 to 2.42 in DCM

Following DFT calculations all molecules were synthesized and their physicochemical properties were explored. 2.39 showed the benefit of coupling EWG and EDG on the same molecule by having the broadest absorption envelope among the molecules studied. It is surprising to see absorption maxima blue shifted as compared to $\mathbf{2 . 2 2}$ but nevertheless $\mathbf{2 . 3 9}$ would be able to harvest a large number of photons. 2.40's electron withdrawing malononitrile drives down the LUMO energy of the molecule shrinking the energy gap which red-shifts the absorption as shown in Figure 3.12. The methoxy groups on the boron of $\mathbf{2 . 4 1}$ do not seem to have an appreciable effect on the absorption envelope of the molecule nor does the aldehyde substituent: $\mathbf{2 . 4 1}$ has a very similar absorption profile as $\mathbf{2 . 2 2}$. The absorption data of $\mathbf{2 . 4 2}$ is somewhat unreliable as solubility issues prevented an ideal UV-vis spectrum from being collected. 


\subsubsection{Electrochemistry of BODIPY containing building blocks}

The electrochemical data of these compounds was quite difficult to obtain. Somewhat disappointingly 2.42 was too insoluble to obtain reliable redox potentials. There was another issue presented by the addition of the aldehyde group to $\mathbf{2 . 4 0}$ and 2.39. The aldehyde acted as an EWG group as expected in both cases but either the aldehyde was not stable to oxidation or the EWG pushed the oxidation potential of each molecule too high which caused degradation of the BODIPY core. Evidence seems to support the first proposal as $\mathbf{2 . 4 1}$ did show a pseudo reversible reduction at $1.62 \mathrm{~V}$ vs NHE. In conclusion molecules $\mathbf{2 . 3 9}$ to $\mathbf{2 . 4 2}$ were successfully synthesized and show interesting physicochemical properties. This combined with the originally synthesized BODIPY material precursors $\mathbf{2 . 3 5}$ to $\mathbf{2 . 3 7}$ have demonstrated the versatility of the BODIPY core and have opened doors to future materials.

Table 3.5 The solvent based physicochemical properties of $\mathbf{2 . 3 9}$ to $\mathbf{2 . 4 2}$

\begin{tabular}{|c|c|c|c|}
\hline & \multirow{2}{*}{$\lambda \mathrm{nm},\left(\varepsilon \mathrm{M}^{-1} \mathrm{~cm}^{-1}\right)$} & \multicolumn{2}{|c|}{$E_{1 / 2}{ }^{o x}(\text { V vs NHE) })^{b}$} \\
\hline & & BODIPY/BODIPY॰- & $\mathrm{BODIPY}^{\circ+} / \mathrm{BODIPY}$ \\
\hline 2.12 & $497(82600)$ & -1.05 & 1.50 \\
\hline 2.39 & $475(54000)$ & -0.80 & - \\
\hline 2.40 & $511(23000)$ & -0.94 & - \\
\hline 2.41 & 494 (27000) & 0.74 & 1.62 \\
\hline 2.42 & $545(6000)$ & - & - \\
\hline
\end{tabular}

*all data collected in $\mathrm{CH}_{2} \mathrm{Cl}_{2}$ using $0.1 \mathrm{M}\left[n \mathrm{nu}_{4} \mathrm{~N}\right]\left[\mathrm{PF}_{6}\right]$ at $100 \mathrm{mV} / \mathrm{s}$ and referenced to a $[\mathrm{Fc}] /[\mathrm{Fc}]^{+}$internal standard $\left(+765 \mathrm{mV}\right.$ vs. $\mathrm{NHE}$ in $\left.\mathrm{CH}_{2} \mathrm{Cl}{ }_{2}\right)$ 


\section{CONCLUSIONS AND FUTURE WORK}

The objectives of this project were achieved with varying success. A novel family of BODIPY dyes was synthesized with modified $\pi$-spacers to extend conjugation lengths and tune optical properties. 1.24a,b to $1.27 \mathrm{a}, \mathrm{b}$ had their physicochemical properties studied and $1.27 \mathrm{~b}$ underwent preliminary device testing for DSSC applications. From the information gathered a series of BODIPY cores were synthesized and their physicochemical properties were explored. The goal was to find a BODIPY core with an increased LUMO energy to further promote charge injection. However, apart from perhaps $2.32 \mathrm{c}$ all synthesized BODIPYs had a lower reduction potential than the standard pentamethyl BODIPY 2.12. Finally, a group of BODIPY molecules with interesting push pull characteristics were synthesized that have potential in photovoltaic applications (Figure 4.1).

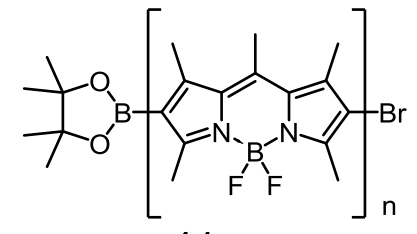

4.1

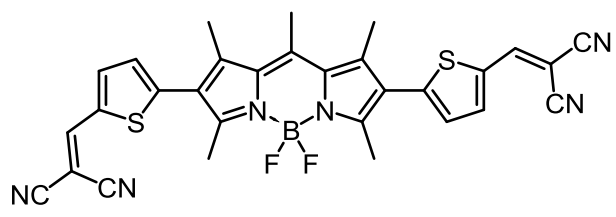

4.2

Figure 4.1 Possible BODIPY based polymer (4.1) or OPV material (4.2)

This research has provided a foundation for BODIPY based photovoltaic materials and has provided invaluable knowledge for the design of future BODIPY dyes. The completion of this systematic study requires compounds $\mathbf{1 . 2 4} \mathbf{- 1 . 2 7}$ to be fabricated into DSSC devices to determine their efficiencies. The substituted BODIPY cores may not have increased LUMO energy limiting their potential in DSSC applications but may allow for greater light harvesting in smaller organic molecules such as organic photovoltaics. To conclude the molecules synthesized above can be easily tuned for different materials applications and this thesis explores some of BODIPY's potential in photovoltaic materials. 


\section{EXPERIMENTAL}

\subsection{General Synthetic Methods}

All reagents were purchased from Aldrich except $\mathrm{Pd}\left(\mathrm{PPh}_{3}\right)_{4}$ and $\mathrm{Pd}\left(\mathrm{PPh}_{3}\right)_{2} \mathrm{Cl}_{2} \quad$ (Pressure Chemical Co., Pittsburgh, PA). Purification by column chromatography was carried out using silica (Silicycle: ultrapure flash silica). Analytical thin-layer chromatography was performed on aluminum-backed sheets precoated with silica 60 F254 adsorbent (0.25 mm thick; Silicycle) and visualized under UV light. Melting points were determined using a Perkin Elmer Diamond Differential Scanning Calorimeter. UV-Vis spectroscopy was performed on a Agilent Cary series UV-Vis-NIR spectrophotometer. Electrochemistry experiments were carried out using a $\mu$ Autolab Type II potentiostat/galvanostat. Routine ${ }^{1} \mathrm{H}$, and ${ }^{13} \mathrm{C}\left\{{ }^{1} \mathrm{H}\right\},{ }^{11} \mathrm{~B}\left\{{ }^{1} \mathrm{H}\right\}$ and ${ }^{19} \mathrm{~F}\left\{{ }^{1} \mathrm{H}\right\}$ were recorded at $400 \mathrm{MHz}, 100 \mathrm{MHz}, 128 \mathrm{MHz}$ and $376 \mathrm{MH}$ respectively, on a Bruker AV 400 instrument at ambient temperature. Chemical shifts $(\delta)$ are reported in parts per million (ppm) from low to high field and referenced to a residual nondeuterated solvent $\left(\mathrm{CHCl}_{3}\right)$ for ${ }^{1} \mathrm{H}$ and ${ }^{13} \mathrm{C}$ nuclei. Standard abbreviations indicating multiplicity are used as follows: $\mathrm{s}=$ singlet; $\mathrm{d}=$ doublet; $\mathrm{m}=$ multiplet.

\subsection{Experimental details}

1-n-(hexyloxy)-4-iodobenzene (2.1b). p-iodophenol (10.0 g, $45 \mathrm{mmol}$ ), 1-bromohexane (9.6 mL, 68

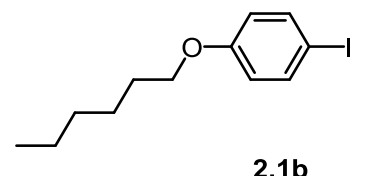
$\mathrm{mmol}$ ) and $\mathrm{K}_{2} \mathrm{CO}_{3}(6.3 \mathrm{~g}, 45 \mathrm{mmol})$ were combined in a flask and $150 \mathrm{~mL}$ of EtOH were added. The mixture was refluxed overnight and after cooling to room temperature, solids were filtered and discarded. Volatiles from the filtrate were removed in vacuo, affording an off-white oil and white solids. The crude product was purified via column chromatography over silica using hexanes as eluent $\left(R_{f}=0.4\right)$ affording the desired product as a colorless oil (13.35 g, 97\%). ${ }^{1} \mathrm{H}$ NMR is consistent with previously reported. ${ }^{76}$

4-methoxy-N-(4-methoxyphenyl)-N-phenylaniline. $p$-iodoanisole(6.35 g, $27 \mathrm{mmol})$, aniline (1.0 mL, 11<smiles>COc1ccc(N(c2ccccc2)c2ccc(OC)cc2)cc1</smiles>
mmol) and 1,10-phenanthroline $(0.39 \mathrm{~g}, 2.2 \mathrm{mmol})$ were dissolved in $20 \mathrm{~mL}$ of toluene. The solution was heated at $100^{\circ} \mathrm{C}$ and was added $\mathrm{CuCl}(0.22 \mathrm{~g}, 2.2 \mathrm{mmol})$ followed by $\mathrm{KOH}(4.9 \mathrm{~g}, 87 \mathrm{mmol})$. The mixture was refluxed overnight and after being cooled at room temperature, $3 \mathrm{~mL}$ of glacial $\mathrm{AcOH}$ and $15 \mathrm{~mL}$ of toluene were added. The mixture was washed with $\mathrm{H}_{2} \mathrm{O}$ once and extracted with toluene. The combined organic layers were dried over $\mathrm{MgSO}_{4}$, filtered and volatiles were removed in vacuo. The crude product was purified via column chromatography over 
silica using hexanes:EtOAc 9:1 as the eluent $\left(R_{f}=0.6, p\right.$-iodoanisole; $R_{f}=0.5$, desired product $)$, affording the desired product as a yellow solid $(2.40 \mathrm{~g}, 72 \%) .{ }^{1} \mathrm{H}$ NMR is consistent with previously reported. ${ }^{77}$

4-(hexyloxy)- $\mathbf{N}$-(4-(hexyloxy)phenyl)- $\mathbf{N}$-phenylaniline. Under an atmosphere of $\mathrm{N}_{2}, 1-n$-hexyloxy-4-

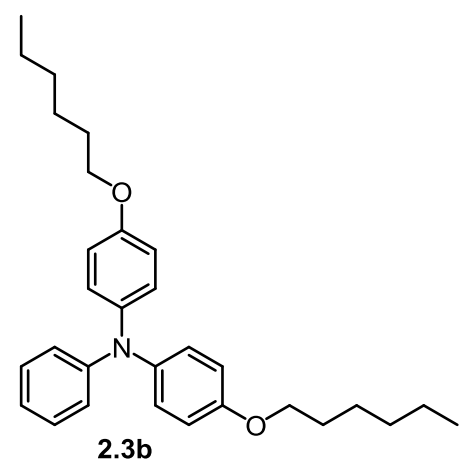
iodobenzene $(8.25 \mathrm{~g}, 27 \mathrm{mmol})$, aniline $(1.0 \mathrm{~mL}, 11 \mathrm{mmol})$ and 1,10phenanthroline $(0.39 \mathrm{~g}, 2.2 \mathrm{mmol})$ were dissolved in $20 \mathrm{~mL}$ of toluene. The solution was heated at $100^{\circ} \mathrm{C}$ and $\mathrm{CuCl}(0.22 \mathrm{~g}, 2.2 \mathrm{mmol})$ was added followed by $\mathrm{KOH}(4.9 \mathrm{~g}, 87 \mathrm{mmol})$. The mixture was refluxed overnight and after being cooled at room temperature, $3 \mathrm{~mL}$ of glacial $\mathrm{AcOH}$ and 15 $\mathrm{mL}$ of toluene were added. The mixture was washed with $\mathrm{H}_{2} \mathrm{O}$ once and extracted with toluene. The combined organic layers were dried over $\mathrm{MgSO}_{4}$, filtered and volatiles were removed in vacuo. The crude product was purified via column chromatography over silica using a gradient, starting with hexanes, eluting 1-n-hexyloxy-4-iodobenzene, followed by hexanes:EtOAc 1:1 to elute the desired product, as a yellow oil $(7.60 \mathrm{~g}, 70 \%) .{ }^{1} \mathrm{H}$ NMR is consistent with previously reported. ${ }^{78}$

4-bromo-N,N-bis(4-methoxyphenyl)aniline. Under an atmosphere of $\mathrm{N}_{2}$, 4-methoxy- $\mathrm{N}$-(4-<smiles>COc1ccc(N(c2ccc(Br)cc2)c2ccc(OC)cc2)cc1</smilesmethoxyphenyl)- $N$-phenylaniline $(6.3 \mathrm{~g}, 21 \mathrm{mmol})$ was dissolved in $150 \mathrm{~mL}$ of THF:EtOAc and $N$-bromosuccinimide $(4.1 \mathrm{~g}, 23 \mathrm{mmol})$ was added in one portion. The flask was covered with $\mathrm{Al}$ foil and the mixture was stirred overnight. Volatiles were removed in vacuo and the crude was purified via column chromatography over silica using hexanes:EtOAc 9:1 as the eluent $\left(R_{f}=0.5\right)$, affording the desired product as a yellowish solid $(7.86 \mathrm{~g}, 99 \%) .{ }^{1} \mathrm{H}$ NMR is consistent with previously reported. ${ }^{77}$

4-bromo-N-(4-(hexyloxy)phenyl)-N-(4-(hexyloxy)phenyl)aniline. Under an atmosphere of $\mathrm{N}_{2}, \mathrm{~N}, \mathrm{~N}$-bis(4-

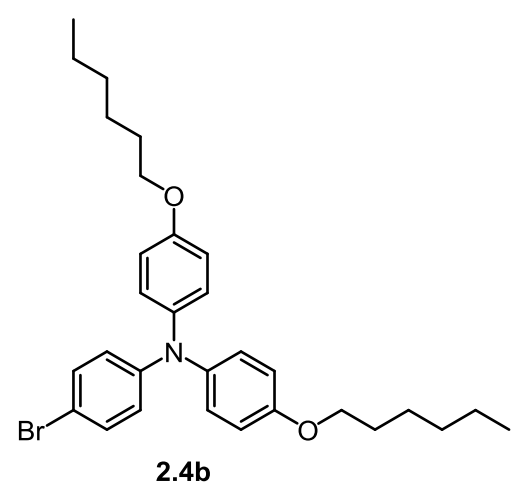
hexyloxyphenyl)aniline $(6.4 \mathrm{~g}, 14 \mathrm{mmol})$ was dissolved in $150 \mathrm{~mL}$ of THF:EtOAc and $N$-bromosuccinimide $(2.8 \mathrm{~g}, 16 \mathrm{mmol})$ was added in one portion. The flask was covered with Al foil and the mixture was stirred overnight. Volatiles were removed in vacuo and the crude was purified via column chromatography over silica using hexanes:EtOAc 9:1 as the eluent $\left(R_{f}=0.7\right)$, affording the desired product as a yellowish oil (7.80 g, 99\%). ${ }^{1} \mathrm{H}$ NMR is consistent with previously reported. ${ }^{79}$ 
(4-(4,4',5,5'-tetramethyl-1,3,2-dioxaborolan-2-yl)phenyl)-di-(4-methoxyphenyl)amine. Under an

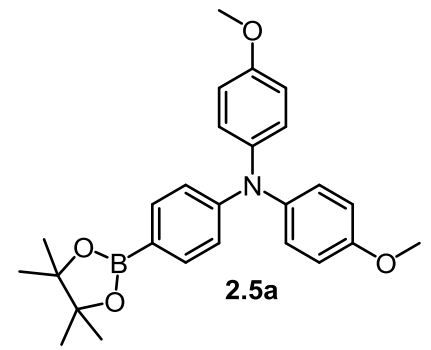

atmosphere of $\mathrm{N}_{2}$, 4-bromo- $\mathrm{N}, \mathrm{N}$-bis(4-methoxyphenyl)aniline (7.9 g, 20.5 $\mathrm{mmol}$ ) was dissolved in $75 \mathrm{~mL}$ of dry THF and the solution was cooled to $78^{\circ} \mathrm{C}$. nBuLi $(1.6 \mathrm{M}, 15.4 \mathrm{~mL}, 24.5 \mathrm{mmol})$ was added dropwise and the mixture was stirred $30 \mathrm{~min}$ at this temperature. 2-isopropoxy-4,4',5,5'tetramethyl-[1,3,2]-dioxaborolane $(6.1 \mathrm{~mL}, 31 \mathrm{mmol})$ was added in one portion and the mixture was stirred $30 \mathrm{~min}$ at $-78^{\circ} \mathrm{C}$ and was allowed to warm to room temperature overnight. $5 \mathrm{~mL}$ of $\mathrm{MeOH}$ were added and volatiles were removed in vacuo. The crude product was purified via column chromatography over silica using hexanes:EtOAc 9:1 as the eluent, affording the desired product as an off-white solid $(7.11 \mathrm{~g}$, $81 \%) .{ }^{1} \mathrm{H} N \mathrm{NM}$ is consistent with previously reported. ${ }^{80}$

4,4',5'5,-tetramethyl-2-(4-(N,N-bis(4-hexyloxyphenyl)amino) phenyl)-1,3,2-dioxaborolane Under an

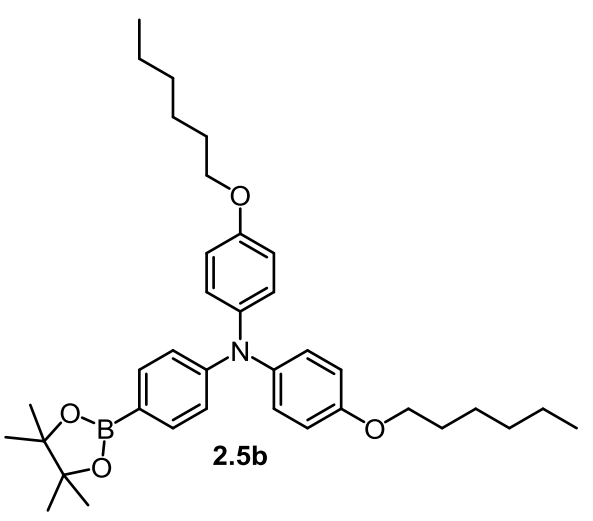
atmosphere of $\mathrm{N}_{2}$, 4-bromo- $\mathrm{N}, \mathrm{N}$-bis(4-hexoxylphenyl)aniline (7.8 $\mathrm{g}, 15 \mathrm{mmol}$ ) was dissolved in $75 \mathrm{~mL}$ of dry THF and the solution was cooled to $-78^{\circ} \mathrm{C}$. $n$ BuLi $(1.6 \mathrm{M}, 11 \mathrm{~mL}, 17.5 \mathrm{mmol})$ was added dropwise and the mixture was stirred $30 \mathrm{~min}$ at this temperature. 2-isopropoxy-4, $4^{\prime}, 5,5^{\prime}$-tetramethyl-[1,3,2]dioxaborolane ( $4.4 \mathrm{~mL}, 22 \mathrm{mmol}$ ) was added in one portion and the mixture was stirred $30 \mathrm{~min}$ at $-78^{\circ} \mathrm{C}$ and was allowed to warm to room temperature overnight. $5 \mathrm{~mL}$ of $\mathrm{MeOH}$ were added and volatiles were removed in vacuo. The crude product was purified via column chromatography over silica using hexanes:EtOAc 9:1 as the eluent, affording the desired product as a yellow oil (7.77 g, 91\%). ${ }^{1} \mathrm{H}$ NMR is consistent with previously reported. ${ }^{78}$

2-(5-bromothiophen-2-yl)-1,3-dioxolane. 5-bromothiophene-2-carbaldehyde $(5.0 \mathrm{~g}, 26 \mathrm{mmol})$ and<smiles></smiles>
ethylene glycol (10 mL, $183 \mathrm{mmol}$ ) were dissolved in $175 \mathrm{~mL}$ of toluene and $p$ toluenesulfonic acid $(0.135 \mathrm{~g}, 0.8 \mathrm{mmol})$ was added. The flask was equipped with a Dean-Stark trap and the mixture was refluxed overnight. After being cooled to room temperature, the mixture was neutralized with aqueous $\mathrm{Na}_{2} \mathrm{CO}_{3}$ and the organic layer was separated and dried over $\mathrm{MgSO}_{4}$. After removal of volatiles in vacuo, the crude material was purified via column chromatography over silica using $\mathrm{CH}_{2} \mathrm{Cl}_{2}$ :hexanes $1: 1$ as the eluent $\left(\mathrm{R}_{\mathrm{f}}=0.45\right)$, affording the desired product as a dark yellow oil $(5.70 \mathrm{~g}, 93 \%) .{ }^{1} \mathrm{H}$ NMR is consistent with previously reported. ${ }^{81}$ 
2-(5-[1,3]dioxolan-2-yl-thien-2-yl)-4,4',5,5'-tetramethyl-[1,3,2]-dioxaborolane. Under an atmosphere

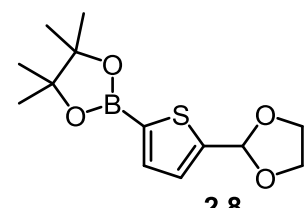

2.8 of $\mathrm{N}_{2}$, 2-(5-bromothiophen-2-yl)-1,3-dioxolane $(5.7 \mathrm{~g}, 30 \mathrm{mmol}$ ) was dissolved in 60 $\mathrm{mL}$ of dry THF and the solution was cooled to $-78^{\circ} \mathrm{C}$. nBuLi $(1.6 \mathrm{M}, 22.4 \mathrm{~mL}, 36$ $\mathrm{mmol}$ ) was added dropwise and the mixture was stirred at this temperature for 45 min. 2-isopropoxy-4,4',5,5'-tetramethyl-[1,3,2]-dioxaborolane (8.3 $\mathrm{mL}, 45 \mathrm{mmol})$ was added in one portion and the mixture stirred at $-78^{\circ} \mathrm{C}$ for $30 \mathrm{~min}$ and allowed to warm to room temperature overnight. $5 \mathrm{~mL}$ of $\mathrm{MeOH}$ were added and volatiles were removed in vacuo. The crude product was purified via column chromatography over silica using $\mathrm{CH}_{2} \mathrm{Cl}_{2}$ :EtOAc 9:1 as the eluent $\left(R_{f}=0.85\right)$ affording a yellowish solid $(4.31 \mathrm{~g}, 68 \%) .{ }^{1} \mathrm{H}$ NMR is consistent with previously reported. $^{82}$

diethyl 3,5-dimethyl-1H-pyrrole-2,4-dicarboxylate. Ethyl acetoacetate (19.5 mL, $154 \mathrm{mmol}$ ) was added to<smiles>CCOC(=O)c1[nH]c(C)c(C(=O)OCC)c1C</smiles>
$70 \mathrm{~mL}$ of glacial $\mathrm{AcOH}$ and the solution was cooled in an ice bath. In another flask, a solution of $\mathrm{NaNO}_{2}(12.2 \mathrm{~g}, 177 \mathrm{mmol})$ in $20 \mathrm{~mL}$ of $\mathrm{H}_{2} \mathrm{O}$ was cooled in an ice bath and added dropwise to the first mixture, maintaining an internal temperature between 6 $10^{\circ} \mathrm{C}$. The resulting yellow solution was stirred at room temperature overnight and ethyl acetoacetate $(22.5 \mathrm{~mL}, 178 \mathrm{mmol})$ was added to the mixture. Zinc powder $(22.6 \mathrm{~g}, 344 \mathrm{mmol})$ was obtained and a minimum amount was added in small portions to increase the internal temperature of the mixture to $65^{\circ} \mathrm{C}$. The mixture was then cooled to $0^{\circ} \mathrm{C}$ and the ice bath was removed. Zinc powder was added in small portions to increase the internal temperature of the mixture to $70^{\circ} \mathrm{C}$ and the remaining was added, maintaining the internal temperature between $60-80^{\circ} \mathrm{C}$. After the last addition of zinc powder, the mixture was refluxed $24 \mathrm{hr}$ and poured onto ice. The solids were filtered and washed with $\mathrm{H}_{2} \mathrm{O}$. The crude material was recystallized from hot $\mathrm{EtOH}$, affording the desired product as flesh coloured solid $(15.48 \mathrm{~g}, 84 \%){ }^{1} \mathrm{H}$ NMR is consistent with previously reported. ${ }^{83}$

2,4-dimethyl-1H-pyrrole. In a $250 \mathrm{~mL}$ Schlenk flask, under an atmosphere of $\mathrm{N}_{2}$, diethyl-3,5-dimethyl-1HH pyrrole-2,4-dicarboxylate $(15.0 \mathrm{~g}, 63 \mathrm{mmol})$ was dissolved in ethylene glycol $(75 \mathrm{~mL})$ and $\mathrm{KOH}$ $(11.7 \mathrm{~g}, 157 \mathrm{mmol})$ was slowly added. The mixture was heated to $160^{\circ} \mathrm{C}$ for $3 \mathrm{hr}$. After being cooled to room temperature, the product was distilled off under vacuum, affording the desired

2.11 product as an oxygen sensitive dark oil (3.755 g, 63\%). ${ }^{1} \mathrm{H}$ NMR is consistent with previously reported. ${ }^{84}$

5,5-difluoro-1,3,7,9,10-pentamethyl-5H-4/4,5/4-dipyrrolo[1,2-c:2',1'-f][1,3,2]diazaborinine. In a 250mL<smiles>[Z12]Cc1cc(C)c2c(C)c(C)c(C)cn12</smiles>
Schlenk flask, under an atmosphere of $\mathrm{N}_{2}$, acetyl chloride $(4.35 \mathrm{ml}, 60.70 \mathrm{mmol})$, was added dropwise at room temperature over $30 \mathrm{~min}$ to a solution of 2,4-dimethyl pyrrole $(2.5 \mathrm{~g}, 26 \mathrm{mmol})$, in $10 \mathrm{~mL}$ of dry DCM. The mixture was refluxed for $1 \mathrm{~h}$ and after cooling 2.12 to room temperature, $50 \mathrm{~mL}$ of hexanes was added to the mixture. Volatiles (azeotroped 
hexane and access acetyl chloride) were removed in vacuo and $120 \mathrm{~mL}$ of dry DCM were added. $\mathrm{NEt}_{3}$ $(10.4 \mathrm{~mL}, 75 \mathrm{mmol})$ was added and the mixture stirred for $10 \mathrm{~min} . \mathrm{BF}_{3}(13.6 \mathrm{~mL}, 113 \mathrm{mmol}$ ) was added dropwise and stirred for $1 \mathrm{~h}$ at room temperature. The mixture was washed with aqueous saturated $\mathrm{NaHCO}_{3}$ and the organic layer was dried over $\mathrm{MgSO}_{4}$, filtered and volatiles were removed in vacuo. The oily residue was chromatographed using $\operatorname{DCM}\left(R_{f}=0.92\right)$ and the fluorescent yellow band collected. After removing the volatiles the resulting residue was recrystallized from $\mathrm{EtOH}(2.65 \mathrm{~g}, 77 \%) .{ }^{1} \mathrm{H} \mathrm{NMR}$ is consistent with previously reported. ${ }^{85}$

5,5-difluoro-2-iodo-1,3,7,9,10-pentamethyl-5H-4/4,5/4-dipyrrolo[1,2-c:2',1'-f][1,3,2]diazaborinine. 2.12

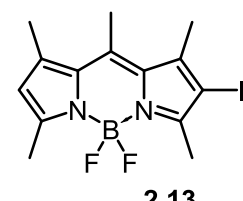

$(1.0 \mathrm{~g}, 3.8 \mathrm{mmol})$ was dissolved in a minimum amount of $\mathrm{CH}_{2} \mathrm{Cl}_{2}$ and NIS $(0.86 \mathrm{~g}, 3.8$ $\mathrm{mmol}$ ) was added in one portion. The mixture was stirred $12 \mathrm{~h}$ with the flask covered with Al foil. Volatiles were removed in vacuo and the crude material was purified via column chromatography using hexanes: $\mathrm{CH} 2 \mathrm{Cl} 21: 1$ as the eluent, affording $1.13 \mathrm{~g}$ of desired compound as an orange solid (77\%), $52 \mathrm{mg}$ of starting material $\mathbf{2 . 1 2}$ and 112 $\mathrm{mg}$ of the corresponding diiodo derivative $2.26 .{ }^{1} \mathrm{H}$ NMR is consistent with previously reported. ${ }^{86}$

4-(5,5-difluoro-1,3,7,9,10-pentamethyl-5H-4/4,5/4-dipyrrolo[1,2-c:2',1'-f][1,3,2]diazaborinin-2-yl)-N,N-

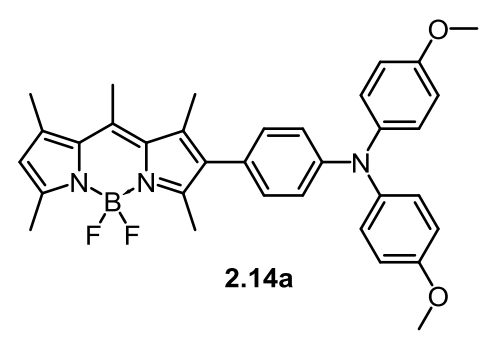
bis(4-methoxyphenyl)aniline. $\mathbf{2 . 1 3}(110 \mathrm{mg}, 0.28 \mathrm{mmol}$ ) and $2.5 \mathrm{a}$ (182 $\mathrm{mg}, 0.42 \mathrm{mmol}$ ) were dissolved in $110 \mathrm{~mL}$ of $\mathrm{THF}: \mathrm{H}_{2} \mathrm{O} 9: 1$ and the solution was sparged 10 min with $\mathrm{N}_{2} . \mathrm{K}_{2} \mathrm{CO}_{3}(196 \mathrm{mg}, 1.4 \mathrm{mmol})$ and $\mathrm{Pd}\left(\mathrm{PPh}_{3}\right)_{4}$ (32 $\mathrm{mg}, 0.028 \mathrm{mmol}$ ) were added and the mixture was refluxed $12 \mathrm{~h}$ under an atmosphere of $\mathrm{N}_{2}$. After being cooled to room temperature, $50 \mathrm{~mL}$ of $\mathrm{H}_{2} \mathrm{O}$ were added and the organic layer was separated. The aqueous layer was extracted with $\mathrm{Et}_{2} \mathrm{O}(3 \times 25 \mathrm{~mL})$ and the combined organic layers were dried over $\mathrm{MgSO}_{4}$, filtered and volatiles were removed in vacuo. The crude material was purified via column chromatography using hexanes: $\mathrm{CH}_{2} \mathrm{Cl}_{2} \quad 1: 1$ as the eluent, affording the desired product as a pink solid (108 mg, $68 \%$ ). ${ }^{1} \mathrm{H}$ NMR is consistent with previously reported. $^{87}$

4-(5,5-difluoro-1,3,7,9,10-pentamethyl-5H-4/4,5/4-dipyrrolo[1,2-c:2',1'-f][1,3,2]diazaborinin-2-yl)-N,Nbis(4-(hexyloxy)phenyl)aniline. 2.13 (55 $\mathrm{mg}, 0.14 \mathrm{mmol}$ ) and 2.5b (121 mg, $0.21 \mathrm{mmol}$ ) were dissolved in $55 \mathrm{~mL}$ of THF: $\mathrm{H}_{2} \mathrm{O}$ 9:1 and the solution was sparged 10 min with $\mathrm{N}_{2} . \mathrm{K}_{2} \mathrm{CO}_{3}(97 \mathrm{mg}$, $0.71 \mathrm{mmol})$ and $\mathrm{Pd}\left(\mathrm{PPh}_{3}\right)_{4}(16 \mathrm{mg}, 0.014 \mathrm{mmol})$ were added and the mixture was refluxed $12 \mathrm{~h}$ under an atmosphere of $\mathrm{N}_{2}$. After being cooled to room temperature, $25 \mathrm{~mL}$ of $\mathrm{H}_{2} \mathrm{O}$ were added and the organic layer was separated. The aqueous layer was extracted with $\mathrm{Et}_{2} \mathrm{O}(3 \times 25 \mathrm{~mL})$ and the combined organic 
layers were dried over $\mathrm{MgSO}_{4}$, filtered and volatiles were removed in vacuo. The crude material was purified via column chromatography using hexanes: $\mathrm{CH}_{2} \mathrm{Cl}_{2}$ 1:1 as the eluent, affording the desired product as a pink solid (61 mg, $62 \%$ ). ${ }^{1} \mathrm{H}$ NMR is consistent with previously reported. ${ }^{87}$

\section{8-(4-(bis(4-methoxyphenyl)amino)phenyl)-5,5-difluoro-1,3,7,9,10-pentamethyl-5H-5I4,6I4-}

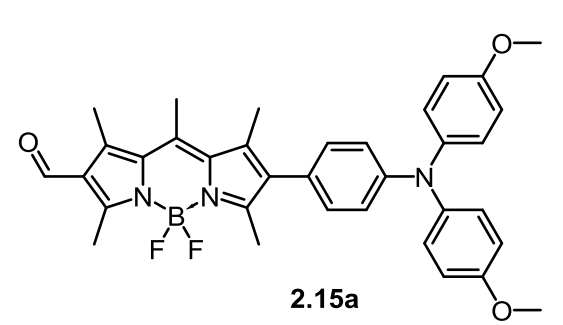
dipyrrolo[1,2-c:2',1'-f][1,3,2]diazaborinine-2-carbaldehyde. A solution of $0.5 \mathrm{~mL}$ of dry DMF in $5 \mathrm{~mL}$ of dry 1,2-dichloroethane was cooled in an ice bath and $0.6 \mathrm{~mL}$ of $\mathrm{POCl}_{3}$ was added dropwise. The mixture was warmed to room temperature and stirred $30 \mathrm{~min}$. 2.14a (26 mg, $0.05 \mathrm{mmol}$ ) dissolved in $6 \mathrm{~mL}$ of dry 1,2dichloroethane was added in one portion and the mixture was stirred $2 \mathrm{~h}$. The mixture was neutralized in $30 \mathrm{~mL}$ of saturated aqueous $\mathrm{NaHCO}_{3}$ cooled to $0{ }^{\circ} \mathrm{C}$ and the mixture was stirred $30 \mathrm{~min}$. at room temperature. The organic layer was separated and the aqueous layer was extracted with $\mathrm{CH}_{2} \mathrm{Cl}_{2}(3 \times 25 \mathrm{~mL})$. The combined organic layers were dried over $\mathrm{MgSO}_{4}$, filtered and volatiles were removed in vacuo. The crude material was purified via column chromatography using $\mathrm{CH}_{2} \mathrm{Cl}_{2}$ as the eluent, affording the desired product as a purple solid (21 mg, 77\%). ${ }^{1} \mathrm{H}$ NMR is consistent with previously reported. ${ }^{87}$

\section{8-(4-(bis(4-(hexyloxy)phenyl)amino)phenyl)-5,5-difluoro-1,3,7,9,10-pentamethyl-5H-5I4,614-}

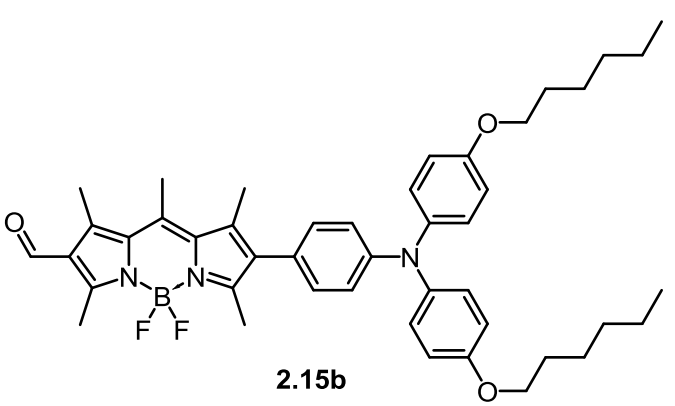

dipyrrolo[1,2-c:2',1'-f][1,3,2]diazaborinine-2-

carbaldehyde. A solution of $1.0 \mathrm{~mL}$ of dry DMF in $10 \mathrm{~mL}$ of dry 1,2-dichloroethane was cooled in an ice bath and 1.2 $\mathrm{mL}$ of $\mathrm{POCl}_{3}$ was added dropwise. The mixture was warmed to room temperature and stirred $30 \mathrm{~min}$. 2.14b $(61 \mathrm{mg}$, $0.09 \mathrm{mmol}$ ) dissolved in $12 \mathrm{~mL}$ of dry 1,2-dichloroethane was added in one portion and the mixture was stirred $2 \mathrm{hr}$. The mixture was neutralized in $30 \mathrm{~mL}$ of saturated aqueous $\mathrm{NaHCO}_{3}$ cooled to $0{ }^{\circ} \mathrm{C}$ and the mixture was stirred $30 \mathrm{~min}$. at room temperature. The organic layer was separated and the aqueous layer was extracted with $\mathrm{CH}_{2} \mathrm{Cl}_{2}(3 \times 25 \mathrm{~mL})$. The combined organic layers were dried over $\mathrm{MgSO}_{4}$, filtered and volatiles were removed in vacuo. The crude material was purified via column chromatography using $\mathrm{CH}_{2} \mathrm{Cl}_{2}$ as the eluent, affording the desired product as a purple solid (54 mg, 86\%). ${ }^{1} \mathrm{H}$ NMR is consistent with previously reported. ${ }^{87}$ 
(E)-3-(8-(4-(bis(4-methoxyphenyl)amino)phenyl)-5,5-difluoro-1,3,7,9,10-pentamethyl-5H-5I4,6l4-

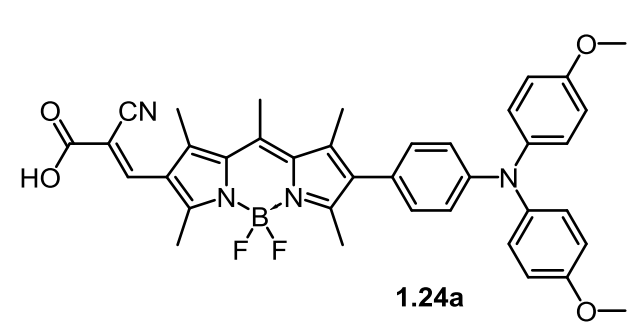

\%). ${ }^{1} \mathrm{H}$ NMR is consistent with previously reported. ${ }^{87}$

\section{dipyrrolo[1,2-c:2',1'-f][1,3,2]diazaborinin-2-yl)-2-cyanoacrylic} acid. 2.15a (48 $\mathrm{mg}, 0.081 \mathrm{mmol}$ ) was dissolved in $25 \mathrm{~mL}$ of $\mathrm{MeCN}: \mathrm{CHCl}_{3}$ 1:1 and cyanoacetic acid (14 $\mathrm{mg}, 0.17 \mathrm{mmol}$ ) was added, followed by piperidine $(2 \mu \mathrm{L}, 0.02 \mathrm{mmol})$. The organic layer was dried over $\mathrm{MgSO}_{4}$, filtered and volatiles were removed in vacuo. The crude product was recrystallized from hexanes: $\mathrm{CH}_{2} \mathrm{Cl}_{2}$ 3:1, affording a dark purple solid (48 mg, 90

(E)-3-(8-(4-(bis(4-(hexyloxy)phenyl)amino)phenyl)-5,5-difluoro-1,3,7,9,10-pentamethyl-5H-5I4,6I4-

dipyrrolo[1,2-c:2',1'-f][1,3,2]diazaborinin-2-yl)-2cyanoacrylic acid. $2.15 \mathrm{~b}(50 \mathrm{mg}, 0.07 \mathrm{mmol}$ ) was dissolved in $25 \mathrm{~mL}$ of $\mathrm{MeCN}: \mathrm{CHCl}^{3} 1: 1$ and cyanoacetic acid (12 $\mathrm{mg}, 0.14 \mathrm{mmol}$ ) was added, followed by piperidine $(2 \mu \mathrm{L}, 0.02 \mathrm{mmol})$. The mixture was refluxed $24 \mathrm{hr}$ and after being cooled at room temperature, the organic layer was washed with $\mathrm{HCl}$ $1 \mathrm{~N}(3 \times 25 \mathrm{~mL})$. The organic layer was dried over $\mathrm{MgSO}_{4}$, filtered and volatiles were removed in vacuo. The crude product was recrystallized from hexanes:MeOH 3:1, affording a dark purple solid (55 mg, quantitative). ${ }^{1} \mathrm{H}$ NMR is consistent with previously reported. $^{87}$

4,4,5,5-tetramethyl-2-(thiophen-2-yl)-1,3,2-dioxaborolane. Under an atmosphere of $\mathrm{N}_{2}$, of thiophene

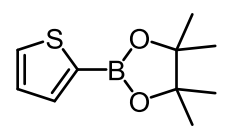

2.16

$(8.41 \mathrm{~g}, 10 \mathrm{mmol})$ was dissolved in $20 \mathrm{~mL}$ of dry THF and the solution was cooled to $78^{\circ} \mathrm{C}$. $n$ BuLi $(1.6 \mathrm{M}, 6.25 \mathrm{~mL}, 10 \mathrm{mmol})$ was added dropwise and after the last addition, the mixture was warmed to room temperature and stirred $30 \mathrm{~min}$. The mixture was cooled to $-78^{\circ} \mathrm{C}$ and 2-isopropoxy-4,4',5,5'-tetramethyldioxoborolane (1.86 g, $10 \mathrm{mmol}$ ) was added. The mixture was warmed to room temperature and stirred $20 \mathrm{~min}$. Volatiles were removed in vacuo and the residue was dissolved in a minimum amount of $\mathrm{CHCl}_{3}$. Under vigorous stirring, $20 \mathrm{~mL}$ of $5 \mathrm{M} \mathrm{HCl}$ was added and the organic layer was separated and dried over $\mathrm{MgSO}_{4}$. Volatiles were removed in vacuo and the crude material was recrystallized from hexanes or purified via column chromatography over silica using $\mathrm{CH}_{2} \mathrm{Cl}_{2}$ :hexanes $1: 1$ as eluent $\left(\mathrm{R}_{\mathrm{f}}=0.3\right)$, affording the desired product as an off-white solid (1.51 $\mathrm{g}, 72 \%) .{ }^{1} \mathrm{H}$ NMR is consistent with previously reported. ${ }^{88}$ 


\section{5,5-difluoro-1,3,7,9,10-pentamethyl-2-(thiophen-2-yl)-5H-4I4,5/4-dipyrrolo[1,2-c:2',1'}

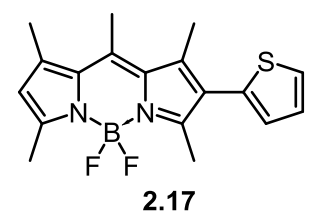

f][1,3,2]diazaborinine. 2.13 (450 $\mathrm{mg}, 1.17 \mathrm{mmol}$ ) and 2.16 (488 $\mathrm{mg}, 1.74 \mathrm{mmol}$ ) were dissolved in $330 \mathrm{~mL}$ of THF: $\mathrm{H}_{2} \mathrm{O} 9: 1$ and the solution was sparged $10 \mathrm{~min}$ with $\mathrm{N}_{2} . \mathrm{K}_{2} \mathrm{CO}_{3}(807 \mathrm{mg}, 5.85 \mathrm{mmol})$ and $\mathrm{Pd}\left(\mathrm{PPh}_{3}\right)_{4}(135 \mathrm{mg}, 0.12 \mathrm{mmol})$ were added and the mixture was refluxed $12 \mathrm{~h}$ under an atmosphere of $\mathrm{N}_{2}$. After being cooled to room temperature, $100 \mathrm{~mL}$ of $\mathrm{H}_{2} \mathrm{O}$ were added and the organic layer was separated. The aqueous layer was extracted with $\mathrm{Et}_{2} \mathrm{O}(3 \times 75 \mathrm{~mL})$ and the combined organic layers were dried over $\mathrm{MgSO}_{4}$, filtered and volatiles were removed in vacuo. The crude material was purified via column chromatography using hexanes: $\mathrm{CH}_{2} \mathrm{Cl}_{2}$ 1:1 as the eluent, affording the desired product as an orange solid (372 mg, $92 \%$ ). ${ }^{1} \mathrm{H}$ NMR is consistent with previously reported. ${ }^{87}$

\section{5,5-difluoro-2-iodo-1,3,7,9,10-pentamethyl-8-(thiophen-2-yl)-5H-5/4,614-dipyrrolo[1,2-c:2',1'-}

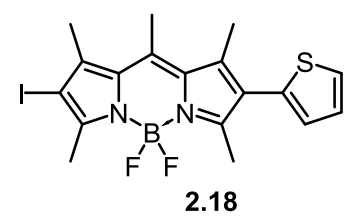

f][1,3,2]diazaborinine. 2.17 (200 $\mathrm{mg}, 0.58 \mathrm{mmol}$ ) was dissolved in a minimum amount of $\mathrm{CH}_{2} \mathrm{Cl}_{2}$ and NIS (150 mg, $0.67 \mathrm{mmol}$ ) was added in one portion. The mixture was stirred $12 \mathrm{~h}$ with the flask covered with Al foil. Volatiles were removed in vacuo and the crude material was purified via column chromatography using hexanes: $\mathrm{CH}_{2} \mathrm{Cl}_{2}$ 1:1 as the eluent, affording the desired product as an orange solid ( $253 \mathrm{mg}, 93 \%) .{ }^{1} \mathrm{H}$ NMR is consistent with previously reported. ${ }^{87}$

\section{4-(5,5-difluoro-1,3,7,9,10-pentamethyl-8-(thiophen-2-yl)-5H-5I4,6I4-dipyrrolo[1,2-c:2',1'-}

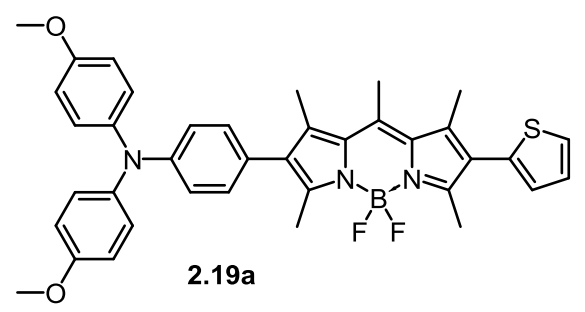

f][1,3,2]diazaborinin-2-yl)-N,N-bis(4-methoxyphenyl)aniline. 2.18 (96 mg, $0.20 \mathrm{mmol}$ ) and 2.5a (129 mg, $0.30 \mathrm{mmol}$ ) were dissolved in $110 \mathrm{~mL}$ of THF: $\mathrm{H}_{2} \mathrm{O} 9: 1$ and the solution was sparged 10 min with $\mathrm{N}_{2} . \mathrm{K}_{2} \mathrm{CO}_{3}(138 \mathrm{mg}, 1.0 \mathrm{mmol})$ and $\mathrm{Pd}\left(\mathrm{PPh}_{3}\right)_{4}(23 \mathrm{mg}$, $0.020 \mathrm{mmol}$ ) were added and the mixture was refluxed $12 \mathrm{~h}$ under an atmosphere of $\mathrm{N}_{2}$. After being cooled to room

temperature, $50 \mathrm{~mL}$ of $\mathrm{H}_{2} \mathrm{O}$ were added and the organic layer was separated. The aqueous layer was extracted with $\mathrm{Et}_{2} \mathrm{O}(3 \times 50 \mathrm{~mL})$ and the combined organic layers were dried over $\mathrm{MgSO}_{4}$, filtered and volatiles were removed in vacuo. The crude material was purified via column chromatography using hexanes: $\mathrm{CH}_{2} \mathrm{Cl}_{2}$ 1:1 as the eluent, affording the desired product as a purple solid (97 $\left.\mathrm{mg}, 75 \%\right) .{ }^{1} \mathrm{H} \mathrm{NMR}$ is consistent with previously reported. ${ }^{87}$ 
4-(5,5-difluoro-1,3,7,9,10-pentamethyl-8-(thiophen-2-yl)-5H-5I4,614-dipyrrolo[1,2-c:2',1'-

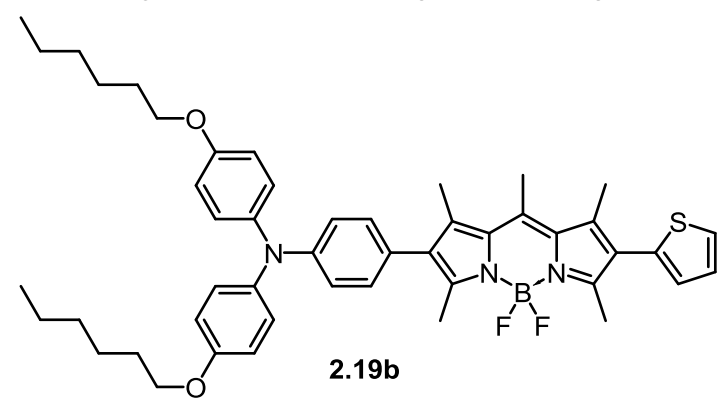

f][1,3,2]diazaborinin-2-yl)-N,N-bis(4(hexyloxy)phenyl)aniline. 2.18 (51 $\mathrm{mg}, 0.11 \mathrm{mmol}$ ) and 2.5b (94 mg, $0.17 \mathrm{mmol}$ ) were dissolved in $55 \mathrm{~mL}$ of THF: $\mathrm{H}_{2} \mathrm{O} 9: 1$ and the solution was sparged $10 \mathrm{~min}$ with $\mathrm{N}_{2} . \mathrm{K}_{2} \mathrm{CO}_{3}(76 \mathrm{mg}, 0.55 \mathrm{mmol})$ and $\mathrm{Pd}\left(\mathrm{PPh}_{3}\right)_{4}(13 \mathrm{mg}$, $0.011 \mathrm{mmol}$ ) were added and the mixture was refluxed $12 \mathrm{~h}$ under an atmosphere of $\mathrm{N}_{2}$. After being cooled to room temperature, $25 \mathrm{~mL}$ of $\mathrm{H}_{2} \mathrm{O}$ were added and the organic layer was separated. The aqueous layer was extracted with $\mathrm{Et}_{2} \mathrm{O}(3 \times 25 \mathrm{~mL})$ and the combined organic layers were dried over $\mathrm{MgSO}_{4}$, filtered and volatiles were removed in vacuo. The crude material was purified via column chromatography using hexanes: $\mathrm{CH}_{2} \mathrm{Cl}_{2} 1: 1$ as the eluent, affording the desired product as a purple solid (69 mg, $80 \%$ ). ${ }^{1} \mathrm{H}$ NMR is consistent with previously reported. ${ }^{87}$

\section{5-(8-(4-(bis(4-methoxyphenyl)amino)phenyl)-5,5-difluoro-1,3,7,9,10-pentamethyl-5H-4I4,5/4-}

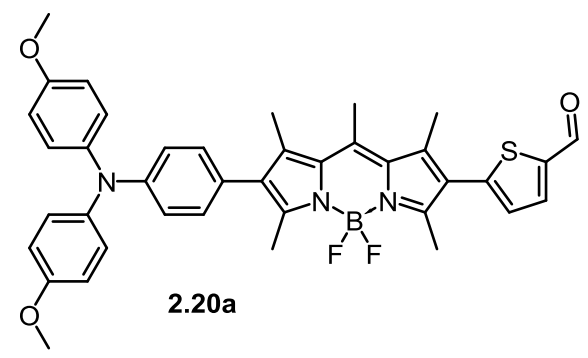
dipyrrolo[1,2-c:2',1'-f][1,3,2]diazaborinin-2-yl)thiophene-2carbaldehyde. A solution of $1.0 \mathrm{~mL}$ of dry DMF in $10 \mathrm{~mL}$ of dry 1,2-dichloroethane was cooled in an ice bath and $1.2 \mathrm{~mL}$ of $\mathrm{POCl}_{3}$ was added dropwise. The mixture was warmed to room temperature and stirred $30 \mathrm{~min} .19 \mathrm{a}(70 \mathrm{mg}, 0.11 \mathrm{mmol})$ dissolved in $12 \mathrm{~mL}$ of dry 1,2-dichloroethane was added in one portion and the mixture was stirred $16 \mathrm{hr}$. The mixture was neutralized in $30 \mathrm{~mL}$ of saturated aqueous $\mathrm{NaHCO}_{3}$ cooled to $0^{\circ} \mathrm{C}$ and the mixture was stirred $30 \mathrm{~min}$. at room temperature. The organic layer was separated and the aqueous layer was extracted with $\mathrm{CH}_{2} \mathrm{Cl}_{2}(3$ $\times 25 \mathrm{~mL}$ ). The combined organic layers were dried over $\mathrm{MgSO}_{4}$, filtered and volatiles were removed in vacuo. The crude material was purified via column chromatography using $\mathrm{CH}_{2} \mathrm{Cl}_{2}$ as the eluent, affording the desired product as a purple solid (30 mg, $40 \%$ ). ${ }^{1} \mathrm{H}$ NMR is consistent with previously reported. ${ }^{87}$

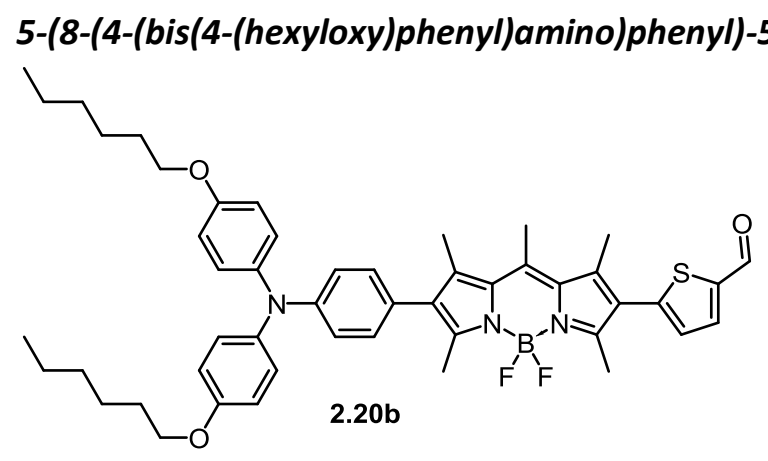
dipyrrolo[1,2-c:2',1'-f][1,3,2]diazaborinin-2yl)thiophene-2-carbaldehyde. A solution of $1.0 \mathrm{~mL}$ of dry DMF in $10 \mathrm{~mL}$ of dry 1,2-dichloroethane was cooled in an ice bath and $1.2 \mathrm{~mL}$ of $\mathrm{POCl}_{3}$ was added dropwise. The mixture was warmed to room temperature and stirred $30 \mathrm{~min} . \mathbf{2 . 1 9 b}(70 \mathrm{mg}, 0.089$ $\mathrm{mmol}$ ) dissolved in $12 \mathrm{~mL}$ of dry 1,2-dichloroethane was added in one portion and the mixture was stirred

$16 \mathrm{hr}$. The mixture was neutralized in $30 \mathrm{~mL}$ of saturated aqueous $\mathrm{NaHCO}_{3}$ cooled to $0{ }^{\circ} \mathrm{C}$ and the mixture was stirred $30 \mathrm{~min}$. at room temperature. The organic layer was separated and the aqueous layer was extracted with $\mathrm{CH}_{2} \mathrm{Cl}_{2}(3 \times 25 \mathrm{~mL})$. The combined organic layers were dried over $\mathrm{MgSO}_{4}$, 
filtered and volatiles were removed in vacuo. The crude material was purified via column chromatography using $\mathrm{CH}_{2} \mathrm{Cl}_{2}$ as the eluent, affording the desired product as a purple solid ( $30 \mathrm{mg}, 41 \%$ ). ${ }^{1} \mathrm{H}$ NMR is consistent with previously reported. ${ }^{87}$

(E)-3-(5-(8-(4-(bis(4-methoxyphenyl)amino)phenyl)-5,5-difluoro-1,3,7,9,10-pentamethyl-5H-4I4,5/4-

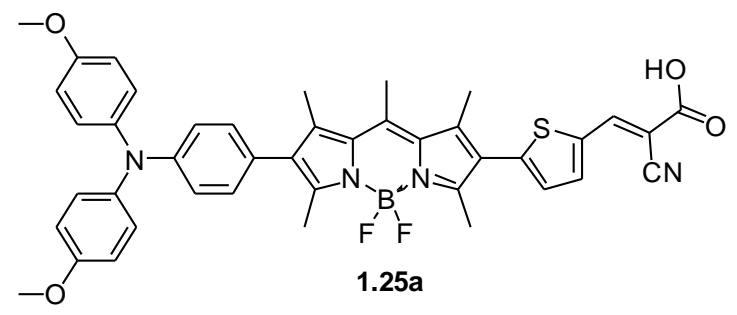
dipyrrolo[1,2-c:2',1'-f][1,3,2]diazaborinin-2yl)thiophen-2-yl)-2-cyanoacrylic acid. 2.20a (46 mg, $0.068 \mathrm{mmol}$ ) was dissolved in $25 \mathrm{~mL}$ of $\mathrm{MeCN}: \mathrm{CHCl} 3$ 1:1 and cyanoacetic acid (12 mg, $0.14 \mathrm{mmol}$ ) was added, followed by piperidine $(2 \mu \mathrm{L}, 0.02 \mathrm{mmol})$. The mixture was refluxed $24 \mathrm{hr}$ and after being cooled at room temperature, the organic layer was washed with $\mathrm{HCl} 1 \mathrm{~N}(3 \times 25 \mathrm{~mL})$. The organic layer was dried over $\mathrm{MgSO}_{4}$, filtered and volatiles were removed in vacuo. The crude product was recrystallized from hexanes: $\mathrm{CH}_{2} \mathrm{Cl}_{2}$ 3:1, affording a dark purple solid (48 mg, $95 \%$ ). ${ }^{1} \mathrm{H}$ NMR is consistent with previously reported. ${ }^{87}$

(E)-3-(5-(8-(4-(bis(4-(hexyloxy)phenyl)amino)phenyl)-5,5-difluoro-1,3,7,9,10-pentamethyl-5H-4I4,5/4-

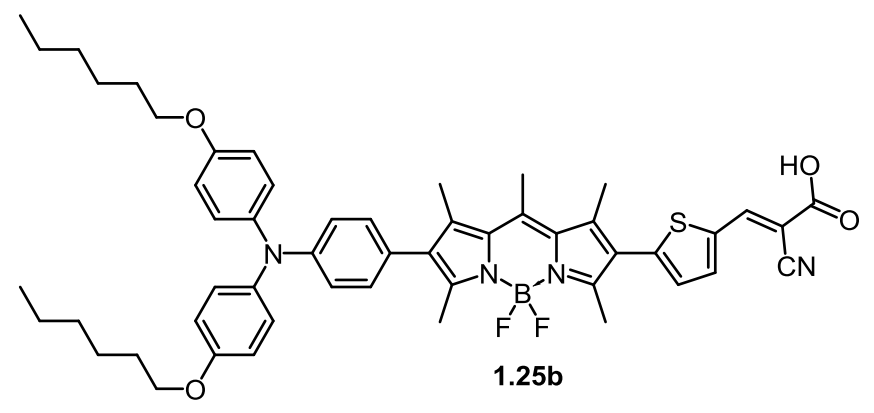

dipyrrolo[1,2-c:2',1'-f][1,3,2]diazaborinin-2yl)thiophen-2-yl)-2-cyanoacrylic acid. 2.20b (50 mg, $0.061 \mathrm{mmol}$ ) was dissolved in $25 \mathrm{~mL}$ of $\mathrm{MeCN}: \mathrm{CHCl}_{3}$ 1:1 and cyanoacetic acid $(10 \mathrm{mg}$, $0.12 \mathrm{mmol}$ ) was added, followed by piperidine ( $2 \mu \mathrm{L}, 0.02 \mathrm{mmol})$. The mixture was refluxed 24 $\mathrm{hr}$ and after being cooled at room temperature, the organic layer was washed with $\mathrm{HCl} 1 \mathrm{~N}(3 \times 25 \mathrm{~mL})$. The organic layer was dried over $\mathrm{MgSO}_{4}$, filtered and volatiles were removed in vacuo. The crude product was recrystallized from hexanes: $\mathrm{MeOH} 3: 1$, affording a dark purple solid (50 $\mathrm{mg}, 93 \%) .{ }^{1} \mathrm{H}$ NMR is consistent with previously reported..$^{87}$

\section{5,5-difluoro-1,3,7,9-tetramethyl-5H-4I4,5/4-dipyrrolo[1,2-c:2',1'-f][1,3,2]diazaborinine-2-carbaldehyde}

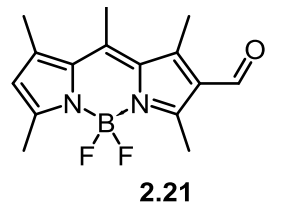

An oven dried Schlenk flask was charged with DMF $(10 \mathrm{~mL})$, and DCE $(30 \mathrm{~mL})$. The solution was cooled to $0{ }^{\circ} \mathrm{C}$ and $\mathrm{POCl}_{3}(12 \mathrm{~mL})$ was added over 5 minutes. The solution was stirred an additional 5 minutes before being warmed to room temperature. After 30 minutes stirring at room temperature, a solution of $\mathbf{2 . 1 2}(0.26$ $\mathrm{g}, 1 \mathrm{mmol}$ ) in $30 \mathrm{~mL}$ of DCE was added in one portion. The reaction was stirred for 3 hours at room temperature and monitored by TLC for consumption of starting material 2.12. The solution was slowly poured onto $400 \mathrm{~mL}$ of saturated aqueous $\mathrm{NaHCO}_{3}$ at $0{ }^{\circ} \mathrm{C}$ then warmed to room temperature overnight. The organic layer was extracted with DCM and solvents were removed in vacuo. 
The residue was purified by column chromatography using DCM as eluent. $R_{\mathrm{f}}=0.4$ yielding $\mathbf{2 . 2 1}$ as an orange solid $(0.25 \mathrm{~g}, 87 \%) .{ }^{1} \mathrm{H}$ NMR is consistent with previously reported. ${ }^{64}$

5,5-difluoro-8-iodo-1,3,7,9,10-pentamethyl-5H-4l4,5/4-dipyrrolo[1,2-c:2',1'-f][1,3,2]diazaborinine-2-

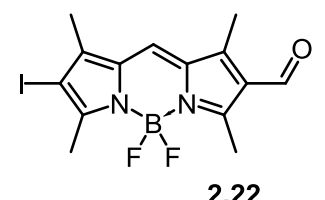

carbaldehyde. 2.21 (100 mg, $0.34 \mathrm{mmol}$ ) was dissolved in $35 \mathrm{~mL}$ of $\mathrm{CH}_{2} \mathrm{Cl}_{2}$ and NIS ( $81 \mathrm{mg}, 0.36 \mathrm{mmol}$ ) was added. The mixture was stirred at room temperature $12 \mathrm{~h}$ with the flask covered with Al foil. Volatiles were removed in vacuo and the crude material was purified via column chromatography using $\mathrm{CH}_{2} \mathrm{Cl}_{2}$ as the eluent, affording the desired product as an orange solid (125 mg, 88\%). ${ }^{1} \mathrm{H}$ NMR is consistent with previously reported. ${ }^{64}$

\section{5,5-difluoro-1,3,7,9,10-pentamethyl-8-(thiophen-2-yl)-5H-4l4,5I4-dipyrrolo[1,2-c:2',1'-}

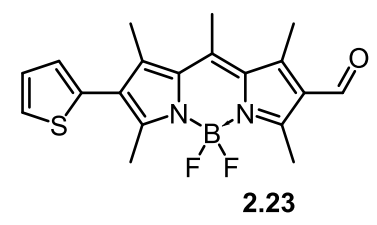

f][1,3,2]diazaborinine-2-carbaldehyde. In a $20 \mathrm{~mL}$ microwave vial, 2.22 (120 $\mathrm{mg}, 0.29 \mathrm{mmol}), 2.16(244 \mathrm{mg}, 1.16 \mathrm{mmol})$ and $\mathrm{Pd}\left(\mathrm{PPh}_{3}\right)_{4}(35 \mathrm{mg}, 0.03 \mathrm{mmol})$ were added to $16 \mathrm{~mL}$ of THF and the mixture was sparged 10 min with $\mathrm{N}_{2}$. The vial was capped and $\mathrm{K}_{2} \mathrm{CO}_{3}\left(1 \mathrm{M}\right.$ solution in $\mathrm{H}_{2} \mathrm{O} ; 1.45 \mathrm{~mL}, 1.45 \mathrm{mmol}$ ), freshly sparged with $\mathrm{N}_{2}$, was added via syringe. The mixture was stirred $30 \mathrm{sec}$ at room temperature and subjected to microwave irradiation during $4 \mathrm{~min}$ at $150^{\circ} \mathrm{C}$. After being cooled to room temperature, volatiles were removed in vacuo and the crude material was purified via column chromatography using $\mathrm{CH}_{2} \mathrm{Cl}_{2}$ as eluent, affording the desired product as a red solid (86 mg, 79\%). ${ }^{1} \mathrm{H}$ $\operatorname{NMR}\left(\mathrm{CDCl}_{3}, 400 \mathrm{MHz}\right): \delta=10.12(\mathrm{~s}, 1 \mathrm{H}), 7.45\left(\mathrm{~d},{ }^{3} \mathrm{~J}_{\mathrm{HH}}=3.6 \mathrm{~Hz}, 1 \mathrm{H}\right), 7.15(\mathrm{dd}, 1 \mathrm{H}), 6.94\left(\mathrm{~d},{ }^{3} \mathrm{~J}_{\mathrm{HH}}=2.6 \mathrm{~Hz}\right.$, $1 \mathrm{H}), 2.80(\mathrm{~s}, 3 \mathrm{H}), 2.76(\mathrm{~s}, 3 \mathrm{H}), 2.75(\mathrm{~s}, 3 \mathrm{H}), 2.58(\mathrm{~s}, 3 \mathrm{H}), 2.45(\mathrm{~s}, 3 \mathrm{H}) \cdot{ }^{13} \mathrm{C}\left\{{ }^{1} \mathrm{H}\right\} \mathrm{NMR}\left(\mathrm{CDCl}_{3}, 100 \mathrm{MHz}\right): \delta=$ 186.2, 159.0, 155.9, 144.4, 142.2, 141.0, 134.5, 133.1, 131.4, 129.0, 128.7, 127.6, 127.0, 126.2, 17.8, $16.2,14.3,14.0\left(\mathrm{t}, \mathrm{J}_{\mathrm{CF}}=2.6 \mathrm{~Hz}\right), 13.9\left(\mathrm{t}, \mathrm{J}_{\mathrm{CF}}=2.7 \mathrm{~Hz}\right) .{ }^{11} \mathrm{~B}\left\{{ }^{1} \mathrm{H}\right\} \mathrm{NMR}\left(\mathrm{CDCl}_{3}, 128 \mathrm{MHz}\right): \delta=0.59\left(\mathrm{t},{ }^{1} \mathrm{~J}_{\mathrm{BF}}=32\right.$ $\mathrm{Hz}) .{ }^{19} \mathrm{~F} \mathrm{NMR}\left(\mathrm{CDCl}_{3}, 376 \mathrm{MHz}\right): \delta=-144.8$ (q). HRMS: *

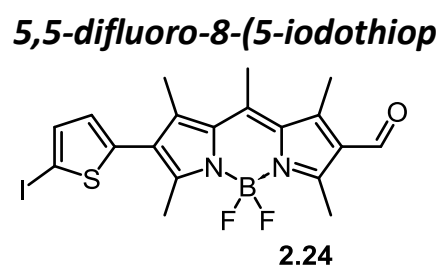

f][1,3,2]diazaborinine-2-carbaldehyde. 2.23 (132 $\mathrm{mg}, 0.35 \mathrm{mmol})$ was dissolved in a minimum amount of $\mathrm{CH}_{2} \mathrm{Cl}_{2}$ and NIS (94 $\mathrm{mg}, 0.42 \mathrm{mmol}$ ) was added in one portion. The mixture was stirred with the flask covered with $\mathrm{Al}$ foil and the disappearance of the starting material was monitored via TLC. After complete consumption of the starting material, volatiles were removed in vacuo and the crude material was purified via column chromatography using $\mathrm{CH}_{2} \mathrm{Cl}_{2}$ as the eluent, affording the desired compound as a dark red solid (168 mg, 96\%). ${ }^{1} \mathrm{H} \mathrm{NMR}\left(\mathrm{CDCl}_{3}, 400 \mathrm{MHz}\right): \delta=$ $10.13(\mathrm{~s}, 1 \mathrm{H}), 7.29\left(\mathrm{~d}, 1 \mathrm{H},{ }^{3} \mathrm{~J}_{\mathrm{HH}}=3.6 \mathrm{~Hz}\right), 6.62(\mathrm{~d}, 1 \mathrm{H}), 2.80(\mathrm{~s}, 3 \mathrm{H}), 2.77(\mathrm{~s}, 3 \mathrm{H}), 2.76(\mathrm{~s}, 3 \mathrm{H}), 2.57(\mathrm{~s}, 3 \mathrm{H})$, $2.44(\mathrm{~s}, 3 \mathrm{H}) .{ }^{13} \mathrm{C}\left\{{ }^{1} \mathrm{H}\right\} \mathrm{NMR}\left(\mathrm{CDCl}_{3}, 100 \mathrm{MHz}\right): \delta=186.2,158.3,156.5,144.9,142.1,141.8,139.6,137.6$, 
134.4, 131.6, 130.3, 128.4, 127.8, 126.5, 17.9, 16.1, 14.4, 13.8 (t, $\left.\mathrm{J}_{\mathrm{CF}}=2.7 \mathrm{~Hz}\right), 12.9$ (br). ${ }^{11} \mathrm{~B}\left\{{ }^{1} \mathrm{H}\right\} \mathrm{NMR}$ $\left(\mathrm{CDCl}_{3}, 128 \mathrm{MHz}\right): \delta=0.56\left(\mathrm{t},{ }^{1} \mathrm{~J}_{\mathrm{BF}}=31 \mathrm{~Hz}\right) .{ }^{19} \mathrm{~F} \mathrm{NMR}\left(\mathrm{CDCl}_{3}, 376 \mathrm{MHz}\right): \delta=-144.9$ (q).

8-(5-(4-(bis(4-methoxyphenyl)amino)phenyl)thiophen-2-yl)-5,5-difluoro-1,3,7,9,10-pentamethyl-5H-

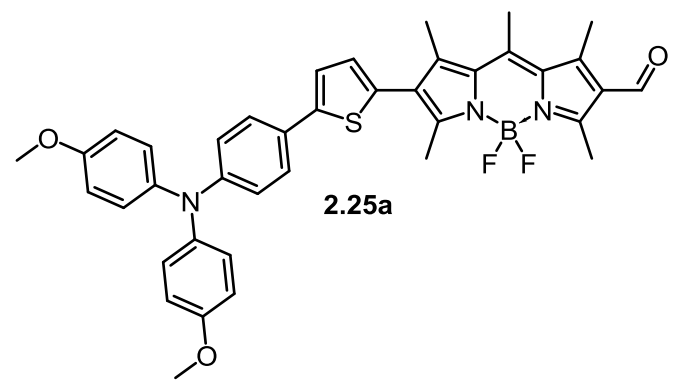
4I4,5I4-dipyrrolo[1,2-c:2',1'-f][1,3,2]diazaborinine-2carbaldehyde. In a $20 \mathrm{~mL}$ microwave vial, 2.24 (50 mg, 0.10 $\mathrm{mmol})$, 2.5a (173 mg, $0.40 \mathrm{mmol})$ and $\mathrm{Pd}\left(\mathrm{PPh}_{3}\right)_{4}(0.012 \mathrm{mg}$, $0.01 \mathrm{mmol}$ ) were added to $4 \mathrm{~mL}$ of THF and the mixture was sparged 10 min with $\mathrm{N}_{2}$. The vial was capped and $\mathrm{K}_{2} \mathrm{CO}_{3}$ (1M solution in $\mathrm{H}_{2} \mathrm{O} ; 0.5 \mathrm{~mL}$ ), freshly sparged with $\mathrm{N}_{2}$, was added via syringe. The mixture was stirred $30 \mathrm{sec}$ at room temperature and subjected to microwave irradiation during $4 \mathrm{~min}$ at $150^{\circ} \mathrm{C}$. After being cooled to room temperature, volatiles were removed in vacuo and the crude material was purified via column chromatography using $\mathrm{CH}_{2} \mathrm{Cl}_{2}$ as eluent, affording the desired product as a red solid (47 mg, 75\%). ${ }^{1} \mathrm{H}$ NMR $\left(\mathrm{CDCl}_{3}, 400 \mathrm{MHz}\right): \delta=10.13(\mathrm{~s}, 1 \mathrm{H}), 7.41\left(\mathrm{~d}, 2 \mathrm{H},{ }^{3} \mathrm{~J}_{\mathrm{HH}}=8.6 \mathrm{~Hz}\right), 7.20$ $\left(\mathrm{d}, 1 \mathrm{H},{ }^{3} \mathrm{~J}_{\mathrm{HH}}=3.6 \mathrm{~Hz}\right), 7.08\left(\mathrm{~d}, 4 \mathrm{H},{ }^{3} \mathrm{~J}_{\mathrm{HH}}=8.8 \mathrm{~Hz}\right), 6.93(\mathrm{~d}, 2 \mathrm{H}), 6.86(\mathrm{~m}, 5 \mathrm{H}), 3.80(\mathrm{~s}, 6 \mathrm{H}), 2.81(\mathrm{~s}, 3 \mathrm{H}), 2.77$ (s, 6H), $2.64(\mathrm{~s}, 3 \mathrm{H}), 2.50(\mathrm{~s}, 3 \mathrm{H}) .{ }^{13} \mathrm{C}\left\{{ }^{1} \mathrm{H}\right\} \mathrm{NMR}\left(\mathrm{CDCl}_{3}, 100 \mathrm{MHz}\right): \delta=186.2,159.3,156.2,155.9,148.7$, $146.3,144.2,141.9,140.8,140.7,134.7,131.5,130.9,129.7,127.2,126.9,126.5,126.2,126.1,122.0$, 120.6, 114.9, 55.7, 17.9, 16.3, 14.3, $14.1\left(\mathrm{t}, \mathrm{J}_{\mathrm{CF}}=2.7 \mathrm{~Hz}\right), 12.8\left(\mathrm{t}, \mathrm{J}_{\mathrm{CF}}=2.9 \mathrm{~Hz}\right) .{ }^{11} \mathrm{~B}\left\{{ }^{1} \mathrm{H}\right\} \mathrm{NMR}\left(\mathrm{CDCl}_{3}, 128\right.$ $\mathrm{MHz}): \delta=0.60\left(\mathrm{t},{ }^{1} \mathrm{~J}_{\mathrm{BF}}=32 \mathrm{~Hz}\right) .{ }^{19} \mathrm{~F} \mathrm{NMR}\left(\mathrm{CDCl}_{3}, 376 \mathrm{MHz}\right): \delta=-144.9$ (q).

8-(5-(4-(bis(4-(hexyloxy)phenyl)amino)phenyl)thiophen-2-yl)-5,5-difluoro-1,3,7,9,10-pentamethyl-5H-

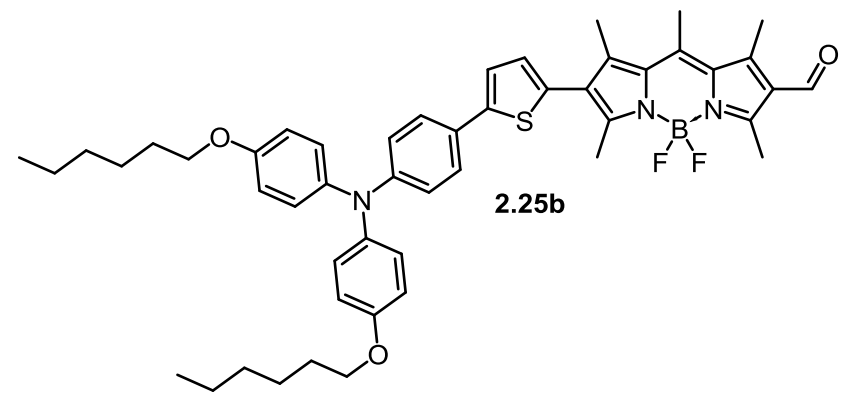

4/4,5/4-dipyrrolo[1,2-c:2',1'$f][1,3,2]$ diazaborinine-2-carbaldehyde. In a 20 $\mathrm{mL}$ microwave vial, 2.24 (116 $\mathrm{mg}, 0.23 \mathrm{mmol}$ ), 2.5b (532 mg, $0.93 \mathrm{mmol})$ and $\mathrm{Pd}\left(\mathrm{PPh}_{3}\right)_{4}(27 \mathrm{mg}$, $0.023 \mathrm{mmol}$ ) were added to $18 \mathrm{~mL}$ of THF and the mixture was sparged 10 min with $\mathrm{N}_{2}$. The vial was capped and $\mathrm{K}_{2} \mathrm{CO}_{3}$ (1M solution in $\mathrm{H}_{2} \mathrm{O} ; 1.15$ $\mathrm{mL}$ ), freshly sparged with $\mathrm{N}_{2}$, was added via syringe. The mixture was stirred $30 \mathrm{sec}$ at room temperature and subjected to microwave irradiation during $6 \mathrm{~min}$ at $150^{\circ} \mathrm{C}$. After being cooled to room temperature, volatiles were removed in vacuo and the crude material was purified via column chromatography using $\mathrm{CH}_{2} \mathrm{Cl}_{2}$ as eluent, affording the desired product as a red-brown solid (43 mg, 23\%). ${ }^{1} \mathrm{H} \mathrm{NMR}\left(\mathrm{CDCl}_{3}, 400 \mathrm{MHz}\right): \delta=10.13(\mathrm{~s}, 1 \mathrm{H}), 7.40\left(\mathrm{~d}, 2 \mathrm{H},{ }^{3} \mathrm{~J}_{\mathrm{HH}}\right.$ $=8.6 \mathrm{~Hz}), 7.20\left(\mathrm{~d}, 1 \mathrm{H},{ }^{3} \mathrm{~J}_{\mathrm{HH}}=3.6 \mathrm{~Hz}\right), 7.06\left(\mathrm{~d}, 4 \mathrm{H},{ }^{3} \mathrm{~J}_{\mathrm{HH}}=8.8 \mathrm{~Hz}\right), 6.93(\mathrm{~d}, 2 \mathrm{H}), 6.86(\mathrm{~d}, 1 \mathrm{H}), 6.83(\mathrm{~d}, 4 \mathrm{H})$, $3.94\left(\mathrm{t}, 4 \mathrm{H},{ }^{3} \mathrm{~J}_{\mathrm{HH}}=6.5 \mathrm{~Hz}\right), 2.80(\mathrm{~s}, 3 \mathrm{H}), 2.76(\mathrm{~s}, 6 \mathrm{H}), 2.64(\mathrm{~s}, 3 \mathrm{H}), 2.50(\mathrm{~s}, 3 \mathrm{H}), 1.78(\mathrm{~m}, 4 \mathrm{H}), 1.46(\mathrm{~m}, 4 \mathrm{H})$, $1.35(\mathrm{~m}, 8 \mathrm{H}), 0.91\left(\mathrm{t}, 6 \mathrm{H},{ }^{3} \mathrm{~J}_{\mathrm{HH}}=6.8 \mathrm{~Hz}\right) .{ }^{13} \mathrm{C}\left\{{ }^{1} \mathrm{H}\right\} \mathrm{NMR}\left(\mathrm{CDCl}_{3}, 100 \mathrm{MHz}\right): \delta=186.2,159.3,155.9,155.8$, $148.8,146.3,144.2,141.9,140.8,140.5,134.7,131.4,130.9,129.7,129.3,126.9,126.5,126.2,125.9$, 
$122.0,120.5,115.5,68.4,31.8,29.5,25.9,22.8,17.9,16.3,14.3,14.2,14.1\left(\mathrm{t}, \mathrm{J}_{\mathrm{CF}}=4.0 \mathrm{~Hz}\right), 12.8\left(\mathrm{t}, \mathrm{J}_{\mathrm{CF}}=\right.$ $2.9 \mathrm{~Hz}) .{ }^{11} \mathrm{~B}\left\{{ }^{1} \mathrm{H}\right\} \operatorname{NMR}\left(\mathrm{CDCl}_{3}, 128 \mathrm{MHz}\right): \delta=0.60\left(\mathrm{t},{ }^{1} \mathrm{~J}_{\mathrm{BF}}=31 \mathrm{~Hz}\right) .{ }^{19} \mathrm{~F} \mathrm{NMR}\left(\mathrm{CDCl}_{3}, 376 \mathrm{MHz}\right): \delta=-144.9$ (q).

(E)-3-(8-(5-(4-(bis(4-(hexyloxy)phenyl)amino)phenyl)thiophen-2-yl)-5,5-difluoro-1,3,7,9,10-

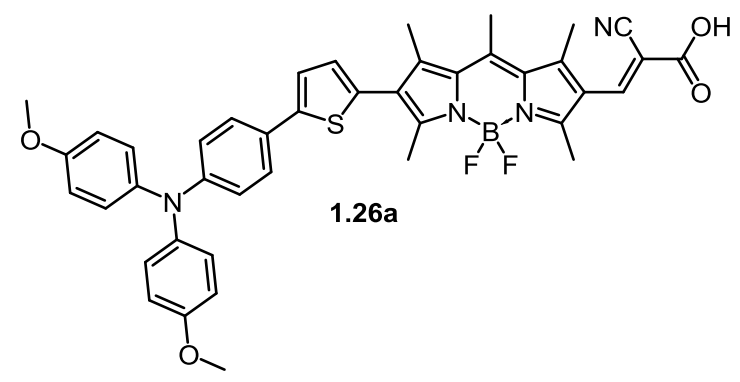

pentamethyl-5H-4|4,5|4-dipyrrolo[1,2-c:2',1'f][1,3,2]diazaborinin-2-yl)-2-cyanoacrylic acid. 2.25a (47 mg, $0.070 \mathrm{mmol}$ ) was dissolved in $25 \mathrm{~mL}$ of MeCN: $\mathrm{CHCl}_{3} \quad 1: 1$ and cyanoacetic acid $(12 \mathrm{mg}, 0.14$ mmol) was added, followed by piperidine $(2 \mu \mathrm{L}, 0.02$ $\mathrm{mmol})$. The mixture was refluxed $24 \mathrm{hr}$ and after being cooled at room temperature, the organic layer was

washed with $\mathrm{HCl} 1 \mathrm{~N}(3 \times 25 \mathrm{~mL})$. The organic layer was dried over $\mathrm{MgSO}_{4}$, filtered and volatiles were removed in vacuo. The crude product was purified via column chromatography using $\mathrm{CH}_{2} \mathrm{Cl}_{2}$ : $\mathrm{MeOH}, 7: 1$ as eluent, affording a dark purple solid (23 mg, 44\%). ): $\delta=8.31(\mathrm{~s}, 1 \mathrm{H}), 7.41\left(\mathrm{~d},{ }^{3} \mathrm{~J}_{\mathrm{HH}}=4.1 \mathrm{~Hz}, 2 \mathrm{H}\right), 7.19$ $(\mathrm{m}, 1 \mathrm{H}),, 7.10(\mathrm{~m}, 4 \mathrm{H}), 6.93\left(\mathrm{~d},{ }^{3} \mathrm{~J}_{\mathrm{HH}}=4.1 \mathrm{~Hz}, 2 \mathrm{H}\right), 6.83(\mathrm{~m}, 5 \mathrm{H}), 3.79(\mathrm{~s}, 6 \mathrm{H}), 2.75(\mathrm{~s}, 3 \mathrm{H}), 2.63(\mathrm{~s}, 6 \mathrm{H}), 2.52$ $(\mathrm{s}, 3 \mathrm{H}), 2.49(\mathrm{~s}, 3 \mathrm{H}) \cdot{ }^{11} \mathrm{~B}\left\{{ }^{1} \mathrm{H}\right\} \mathrm{NMR}\left(\mathrm{CDCl}_{3}, 128 \mathrm{MHz}\right): \delta=0.58\left(\mathrm{t},{ }^{1} \mathrm{~J}_{\mathrm{BF}}=29 \mathrm{~Hz}\right) \cdot{ }^{19} \mathrm{~F} \mathrm{NMR}\left(\mathrm{CDCl}_{3}, 376 \mathrm{MHz}\right): \delta$ $=-145.5(q)$.

(E)-3-(8-(5-(4-(bis(4-(hexyloxy)phenyl)amino)phenyl)thiophen-2-yl)-5,5-difluoro-1,3,7,9,10-

pentamethyl-5H-4|4,5|4-dipyrrolo[1,2-

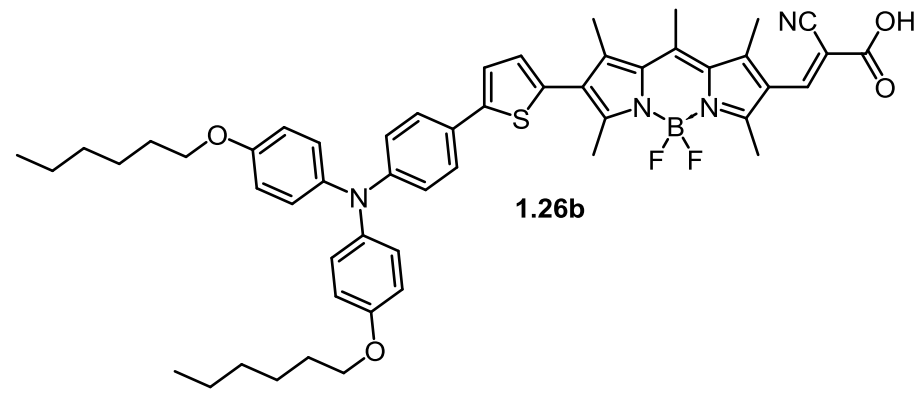
$c: 2 ', 1 '-f][1,3,2] d i a z a b o r i n i n-2-y l)-2-$ cyanoacrylic acid. $2.25 \mathrm{~b}(48 \mathrm{mg}, 0.063$ mmol) was dissolved in $25 \mathrm{~mL}$ of $\mathrm{MeCN}: \mathrm{CHCl}_{3}$ 1:1 and cyanoacetic acid (11 $\mathrm{mg}, 0.13 \mathrm{mmol}$ ) was added, followed by piperidine $(2 \mu \mathrm{L}, 0.02 \mathrm{mmol})$. The mixture was refluxed $24 \mathrm{hr}$ and after being cooled at room temperature, the organic layer was washed with $\mathrm{HCl} 1 \mathrm{~N}(3 \times 25 \mathrm{~mL})$. The organic layer was dried over $\mathrm{MgSO}_{4}$, filtered and volatiles were removed in vacuo. The crude product was recrystallized from $\mathrm{CH}_{2} \mathrm{Cl}_{2}: \mathrm{MeOH} 2: 1$, affording a dark purple solid $(37 \mathrm{mg}, 67 \%) . \delta=8.29(\mathrm{~s}, 1 \mathrm{H}), 7.40\left(\mathrm{~d}, 2 \mathrm{H},{ }^{3} \mathrm{~J}_{\mathrm{HH}}=8.2 \mathrm{~Hz}\right), 7.18\left(\mathrm{~d}, 1 \mathrm{H},{ }^{3} \mathrm{~J}_{\mathrm{HH}}=3.4 \mathrm{~Hz}\right), 7.06\left(\mathrm{~d}, 4 \mathrm{H},{ }^{3} \mathrm{~J}_{\mathrm{HH}}\right.$ $=8.8 \mathrm{~Hz}), 6.92\left(\mathrm{~d},{ }^{3} \mathrm{~J}_{\mathrm{HH}}=8.2 \mathrm{~Hz}, 2 \mathrm{H}\right), 6.83\left(\mathrm{dd},{ }^{3} \mathrm{~J}_{\mathrm{HH}}=8.2 \mathrm{~Hz},{ }^{3} \mathrm{~J}_{\mathrm{HH}}=3.4 \mathrm{~Hz}, 5 \mathrm{H}\right), 3.94\left(\mathrm{t}, 4 \mathrm{H},{ }^{3} \mathrm{~J}_{\mathrm{HH}}=6.4 \mathrm{~Hz}\right)$, $2.73(\mathrm{~s}, 3 \mathrm{H}), 2.63(\mathrm{~s}, 6 \mathrm{H}), 2.50(\mathrm{~s}, 3 \mathrm{H}), 2.48(\mathrm{~s}, 3 \mathrm{H}), 1.78(\mathrm{~m}, 4 \mathrm{H}), 1.46(\mathrm{~m}, 4 \mathrm{H}), 1.35(\mathrm{~m}, 8 \mathrm{H}), 0.91(\mathrm{t}, 6 \mathrm{H}$, $\left.{ }^{3} \mathrm{~J}_{\mathrm{HH}}=6.8 \mathrm{~Hz}\right) .{ }^{13} \mathrm{C} \mathrm{NMR}\left(100 \mathrm{MHz}, \mathrm{CDCl}_{3}\right) \delta 155.65,140.17,126.71,120.36,115.30,68.27,31.60,29.32,25.76$, 22.62, 14.05. Peaks absent due to solubility issues. ${ }^{11} \mathrm{~B}\left\{{ }^{1} \mathrm{H}\right\} \mathrm{NMR}(\mathrm{CDCl}, 128 \mathrm{MHz}): \delta=0.56\left(\mathrm{t},{ }^{1} \mathrm{~J}_{\mathrm{BF}}=27 \mathrm{~Hz}\right){ }^{19} \mathrm{~F}$ $\operatorname{NMR}\left(\mathrm{CDCl}_{3}, 376 \mathrm{MHz}\right): \delta=145.5$ 
5,5-difluoro-2,8-diiodo-1,3,7,9,10-pentamethyl-5H-4/4,5/4-dipyrrolo[1,2-c:2',1'-f][1,3,2]diazaborinine.

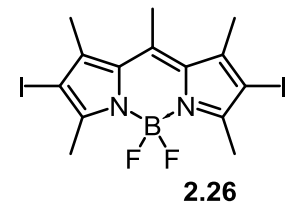

NIS (680 mg, $3.04 \mathrm{mmol}$ ) was added to a solution of 2.12 (199 $\mathrm{mg}, 0.76 \mathrm{mmol}$ ) in 35 $\mathrm{mL}$ of $\mathrm{CH}_{2} \mathrm{Cl}_{2}$. The mixture was stirred $12 \mathrm{~h}$ at room temperature and volatiles were removed in vacuo. The crude material was purified through column chromatography using $\mathrm{CH}_{2} \mathrm{Cl}_{2}$ as the eluent to afford the title compound as an orange solid (quantitative). ${ }^{1} \mathrm{H}$ NMR is consistent with previously reported. ${ }^{86}$

\section{5,5-difluoro-1,3,7,9,10-pentamethyl-2,8-di(thiophen-2-yl)-5H-4l4,5/4-dipyrrolo[1,2-c:2',1'-}

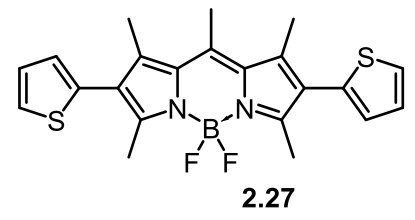

f][1,3,2]diazaborinine. 2.26 (0.881 g, $1.76 \mathrm{mmol}$ ) and $2.16(0.887 \mathrm{~g}, 4.22$ mmol) were dissolved in $75 \mathrm{~mL}$ of THF: $\mathrm{H}_{2} \mathrm{O} 9: 1$ and the solution was sparged 10 min with $\mathrm{N}_{2} . \mathrm{K}_{2} \mathrm{CO}_{3}(0.822 \mathrm{~g}, 17.6 \mathrm{mmol})$ and $\mathrm{Pd}\left(\mathrm{PPh}_{3}\right)_{4}(139 \mathrm{mg}, 0.35$ $\mathrm{mmol}$ ) were added and the mixture was refluxed $12 \mathrm{~h}$ under an atmosphere of $\mathrm{N}_{2}$. After being cooled to room temperature, $25 \mathrm{~mL}$ of $\mathrm{H}_{2} \mathrm{O}$ were added and the organic layer was separated. The aqueous layer was extracted with $\mathrm{Et}_{2} \mathrm{O}(3 \times 50 \mathrm{~mL})$ and the combined organic layers were dried over $\mathrm{MgSO}_{4}$, filtered and volatiles were removed in vacuo. The crude material was purified via column chromatography using hexanes: $\mathrm{CH}_{2} \mathrm{Cl}_{2}$ 1:1 as the eluent, affording the desired product as a dark red solid (0.652 g, $87 \%$ ). ${ }^{1} \mathrm{H}$ NMR is consistent with previously reported. ${ }^{87}$

\section{5,5-difluoro-2-(5-iodothiophen-2-yl)-1,3,7,9,10-pentamethyl-8-(thiophen-2-yl)-5H-5I4,6I4-}

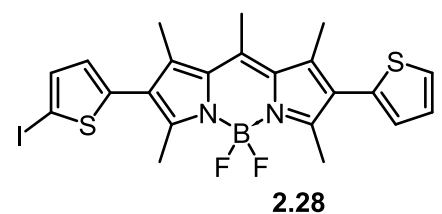

dipyrrolo[1,2-c:2',1'-f][1,3,2]diazaborinine. 2.27 (500 mg, $1.17 \mathrm{mmol}$ ) was dissolved in $75 \mathrm{~mL}$ of $\mathrm{CH}_{2} \mathrm{Cl}_{2}$ and $\mathrm{N}$-iodosuccinimide (263 mg, $1.17 \mathrm{mmol}$ ) was added. The mixture was stirred at room temperature $12 \mathrm{~h}$ with the flask covered with Al foil. Volatiles were removed in vacuo and the crude mixture was purified through column chromatography using $\mathrm{CH}_{2} \mathrm{Cl}_{2}$ :hexanes 1:1 as the eluent, affording the desired compound as a dark red solid (215 $\mathrm{mg}, 33 \%$ ) and $200 \mathrm{mg}$ of starting material $12 .{ }^{1} \mathrm{H}$ NMR is consistent with previously reported. ${ }^{87}$

\section{5-(5,5-difluoro-8-(5-iodothiophen-2-yl)-1,3,7,9,10-pentamethyl-5H-4/4,5/4-dipyrrolo[1,2-c:2',1'-}

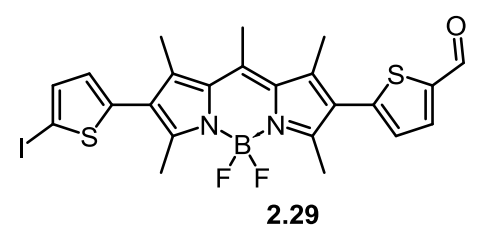

2.29

f][1,3,2]diazaborinin-2-yl)thiophene-2-carbaldehyde. A solution of 2.0 $\mathrm{mL}$ of dry DMF in $10 \mathrm{~mL}$ of dry 1,2-dichloroethane was cooled in an ice bath and $2.5 \mathrm{~mL}$ of $\mathrm{POCl}_{3}$ was added drop wise. The mixture was warmed to room temperature and stirred $30 \mathrm{~min} .2 .28(26 \mathrm{mg}, 0.05$

$\mathrm{mmol}$ ) dissolved in $15 \mathrm{~mL}$ of dry 1,2-dichloroethane was added in one portion and the mixture was stirred $16 \mathrm{~h}$ at room temperature. The mixture was neutralized in $60 \mathrm{~mL}$ of saturated aqueous $\mathrm{NaHCO}_{3}$ cooled to $0^{\circ} \mathrm{C}$ and the mixture was stirred $30 \mathrm{~min}$. at room temperature. The organic layer was separated and the aqueous layer was extracted with $\mathrm{CH}_{2} \mathrm{Cl}_{2}(3 \times 50 \mathrm{~mL})$. The combined 
organic layers were dried over $\mathrm{MgSO}_{4}$, filtered and volatiles were removed in vacuo. The crude material was purified via column chromatography using $\mathrm{CH}_{2} \mathrm{Cl}_{2}$ as the eluent, affording the desired product as a dark purple solid (60 mg, 65\%). ${ }^{1} \mathrm{H}$ NMR is consistent with previously reported. ${ }^{87}$

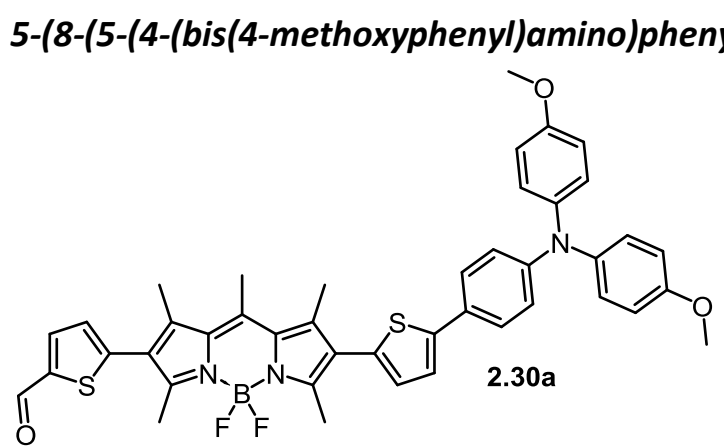

- 2-yl)-5,5-difluoro-1,3,7,9,10-pentamethyl-5H 4/4,5/4-dipyrrolo[1,2-c:2',1'-f][1,3,2]diazaborinin-2yl)thiophene-2-carbaldehyde. 2.29 (80 mg, $0.14 \mathrm{mmol})$ and 2.5 a ( $80 \mathrm{mg}, 0.18 \mathrm{mmol}$ ) were dissolved in $55 \mathrm{~mL}$ of THF: $\mathrm{H}_{2} \mathrm{O} 9: 1$ and the solution was sparged $10 \mathrm{~min}$ with $\mathrm{N}_{2} . \mathrm{K}_{2} \mathrm{CO}_{3}(100 \mathrm{mg}, 0.70 \mathrm{mmol})$ and $\mathrm{Pd}\left(\mathrm{PPh}_{3}\right)_{4}(16 \mathrm{mg}$, $0.014 \mathrm{mmol}$ ) were added and the mixture was refluxed $12 \mathrm{~h}$ under an atmosphere of $\mathrm{N}_{2}$. After being cooled to room temperature, $25 \mathrm{~mL}$ of $\mathrm{H}_{2} \mathrm{O}$ were added and the organic layer was separated. The aqueous layer was extracted with $\mathrm{Et}_{2} \mathrm{O}(3 \times 25 \mathrm{~mL})$ and the combined organic layers were dried over $\mathrm{MgSO}_{4}$, filtered and volatiles were removed in vacuo. The crude material was purified via column chromatography using $\mathrm{CH}_{2} \mathrm{Cl}_{2}$ as the eluent, affording the desired product as a dark purple solid (69 mg, 65\%). ${ }^{1} \mathrm{H}$ NMR is consistent with previously reported. ${ }^{87}$

5-(8-(5-(4-(bis(4-(hexyloxy)phenyl)amino)phenyl)thiophen-2-yl)-5,5-difluoro-1,3,7,9,10-pentamethyl-

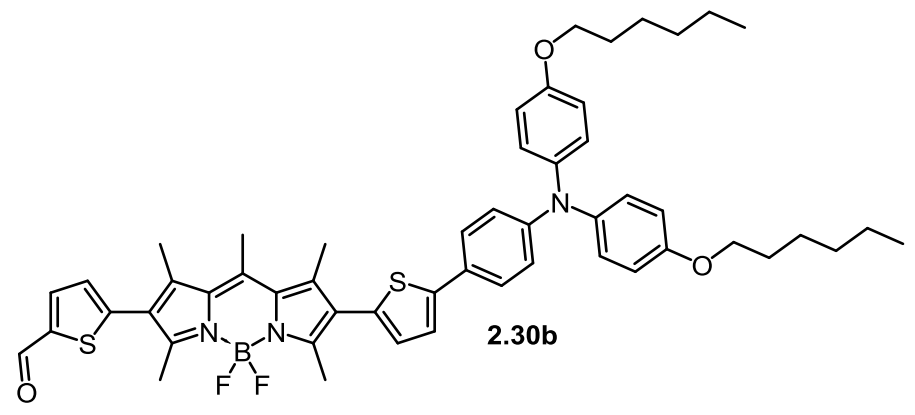

5H-4I4,5/4-dipyrrolo[1,2-c:2',1'f][1,3,2]diazaborinin-2-yl)thiophene-2carbaldehyde. 2.29 ( $80 \mathrm{mg}, 0.14 \mathrm{mmol})$ and 2.5b (103 $\mathrm{mg}, 0.18 \mathrm{mmol}$ ) were dissolved in $55 \mathrm{~mL}$ of THF: $\mathrm{H}_{2} \mathrm{O} 9: 1$ and the solution was sparged 10 min with $\mathrm{N}_{2} . \mathrm{K}_{2} \mathrm{CO}_{3}(100 \mathrm{mg}, 0.70$ $\mathrm{mmol})$ and $\mathrm{Pd}\left(\mathrm{PPh}_{3}\right)_{4}(16 \mathrm{mg}, 0.014 \mathrm{mmol})$ were added and the mixture was refluxed

$12 \mathrm{~h}$ under an atmosphere of $\mathrm{N}_{2}$. After being cooled to room temperature, $25 \mathrm{~mL}$ of $\mathrm{H}_{2} \mathrm{O}$ were added and the organic layer was separated. The aqueous layer was extracted with $\mathrm{Et}_{2} \mathrm{O}(3 \times 25 \mathrm{~mL})$ and the combined organic layers were dried over $\mathrm{MgSO}_{4}$, filtered and volatiles were removed in vacuo. The crude material was purified via column chromatography using $\mathrm{CH}_{2} \mathrm{Cl}_{2}$ as the eluent, affording the desired product as a dark purple solid (50 mg, 40\%). ${ }^{1} \mathrm{H}$ NMR is consistent with previously reported. ${ }^{87}$ 
(E)-3-(5-(8-(5-(4-(bis(4-methoxyphenyl)amino)phenyl)thiophen-2-yl)-5,5-difluoro-1,3,7,9,10-

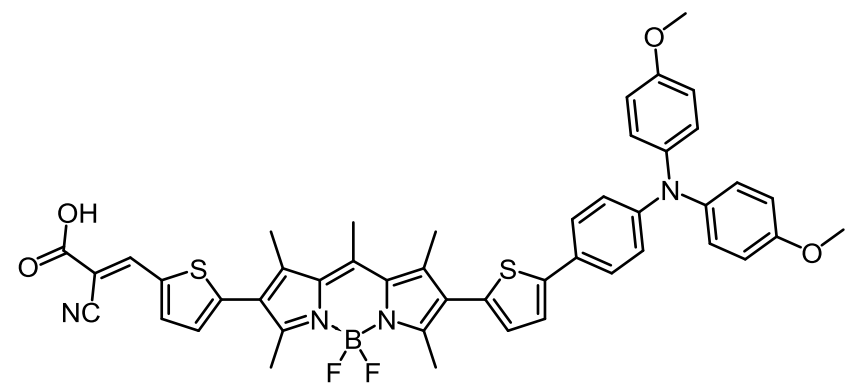

pentamethyl-5H-4I4,5/4-dipyrrolo[1,2-c:2',1'f][1,3,2]diazaborinin-2-yl)thiophen-2-yl)-2cyanoacrylic acid. 2.30a (47 mg, $0.065 \mathrm{mmol})$ was dissolved in $25 \mathrm{~mL}$ of $\mathrm{MeCN}: \mathrm{CHCl}_{3} 1: 1$ and cyanoacetic acid (11 mg, $0.13 \mathrm{mmol}$ ) was added, followed by piperidine $(2 \mu \mathrm{L}, 0.02 \mathrm{mmol})$. The mixture was refluxed $24 \mathrm{hr}$ and after being cooled at room temperature, the organic layer was washed with $\mathrm{HCl} 1 \mathrm{~N}(3 \times 25 \mathrm{~mL})$. The organic layer was dried over $\mathrm{MgSO}_{4}$, filtered and volatiles were removed in vacuo. The crude product was recrystallized from hexanes: $\mathrm{CH}_{2} \mathrm{Cl}_{2}$ 3:1, affording a dark purple solid (46 mg, $86 \%$ ). ${ }^{1} \mathrm{H}$ NMR is consistent with previously reported. ${ }^{87}$

\section{(E)-3-(5-(8-(5-(4-(bis(4-(hexyloxy)phenyl)amino)phenyl)thiophen-2-yl)-5,5-difluoro-1,3,7,9,10-}

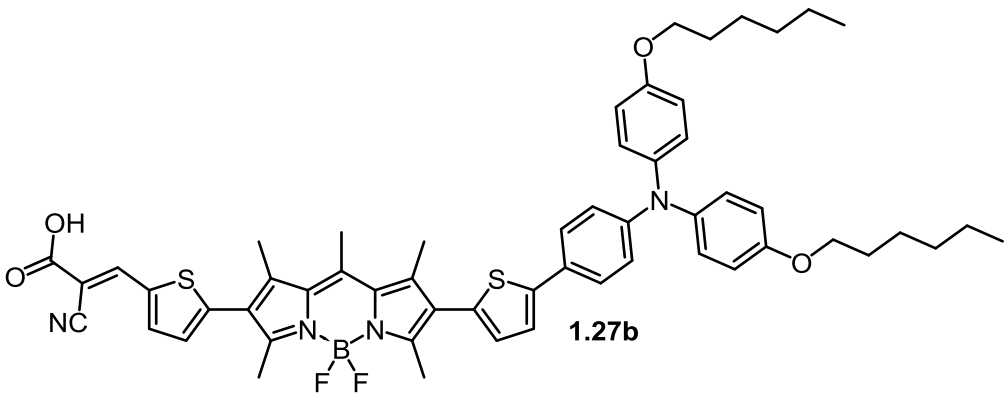

pentamethyl-5H-414,5/4-

dipyrrolo[1,2-c:2',1'f][1,3,2]diazaborinin-2-yl)thiophen2-yl)-2-cyanoacrylic acid. 2.30b (50 $\mathrm{mg}, 0.056 \mathrm{mmol}$ ) was dissolved in 25 $\mathrm{mL}$ of $\mathrm{MeCN}: \mathrm{CHCl}_{3} \quad 1: 1$ and cyanoacetic acid (10 $\mathrm{mg}, 0.11 \mathrm{mmol})$ was added, followed by piperidine ( 2 $\mu \mathrm{L}, 0.02 \mathrm{mmol}$ ). The mixture was refluxed $24 \mathrm{~h}$ and after being cooled at room temperature, the organic layer was washed with $\mathrm{HCl} 1 \mathrm{~N}(3 \times 25 \mathrm{~mL})$. The organic layer was dried over $\mathrm{MgSO}_{4}$, filtered and volatiles were removed in vacuo. The crude product was recrystallized from hexanes:MeOH 3:1, affording a dark purple solid (43 mg, $80 \%) .{ }^{1} \mathrm{H}$ NMR is consistent with previously reported. ${ }^{87}$

5,5-difluoro-1,3,7,9-tetramethyl-10-phenyl-5H-4l4,5/4-dipyrrolo[1,2-c:2',1'-f][1,3,2]diazaborinine. To a<smiles>Cc1cc(C)n(P)c1-c1c(C)cc(C)n1P(F)F</smiles>
solution of 2.11 (0.46 g, $4.83 \mathrm{mmol})$ in dry DCM (70mL) benzaldehyde (2.31a) $(0.26 \mathrm{~g}$, $2.42 \mathrm{mmol}$ ) was added followed by a catalytic amount of trifluoroacetic acid (TFA). The mixture was stirred overnight, then 2,3-dichloro-5,6-dicyanobenzoquinone (DDQ, $0.65 \mathrm{~g}$, $2.9 \mathrm{mmol}$ ) was added and the mixture allowed to stir for $1 \mathrm{~h}$. Disappearance of the aldehyde was monitored by TLC, and if still present, an additional 0.5 eq of DDQ were 2.32a added. Following the complete disappearance of the aldehyde, $\mathrm{N}, \mathrm{N}$ diisopropylethylamine (DIPEA, $3 \mathrm{~mL}, 17.2 \mathrm{mmol}$ ) was added before stirring for $30 \mathrm{~min}$. $\mathrm{BF}_{3} \mathrm{OEt}_{2}(3.5 \mathrm{~mL}$, $28.4 \mathrm{mmol}$ ) was then added and stirred for $1 \mathrm{~h}$. The mixture was washed with $\mathrm{HCl}$. The water layer was extracted with EtOAc and the combined organic layers dried with $\mathrm{MgSO}_{4}$, filtered and the solvent removed in vacuo. The crude material was purified via column chromatography, using hexanes: $\mathrm{CH}_{2} \mathrm{Cl}_{2} 1$ 
: 1 as eluent, affording the desired product as a brown powder $(0.17 \mathrm{~g} 21 \%) .{ }^{1} \mathrm{H}$ NMR is consistent with previously reported. ${ }^{89}$

\section{5,5-difluoro-10-(4-methoxyphenyl)-1,3,7,9-tetramethyl-5H-4I4,5I4-dipyrrolo[1,2-c:2',1'-}

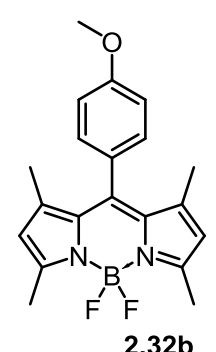

f][1,3,2]diazaborinine. To a solution of $2.11(0.5 \mathrm{~mL}, 0.46 \mathrm{~g}, 4.83 \mathrm{mmol})$ in dry DCM (70mL) p-anisaldehyde (2.31b) (1.29 mL $0.143 \mathrm{~g}, 1.05 \mathrm{mmol})$ was added followed by a catalytic amount of trifluoroacetic acid (TFA). The mixture was stirred overnight, then 2,3-dichloro-5,6-dicyanobenzoquinone ( $D D Q, 0.36 \mathrm{~g}, 1.58 \mathrm{mmol}$ ) was added and the mixture allowed to stir for $1 \mathrm{~h}$. Disappearance of the aldehyde was monitored by TLC, and if still present, an additional 0.5 eq of DDQ were added. Following the complete 2.32b disappearance of the aldehyde, $\mathrm{N}, \mathrm{N}$-diisopropylethylamine (DIPEA, $0.8 \mathrm{~mL}, 4.50 \mathrm{mmol}$ ) was added before stirring for 30 min. $\mathrm{BF}_{3} \mathrm{OEt}_{2}(1.04 \mathrm{~mL}, 1.2 \mathrm{~g} 8.41 \mathrm{mmol})$ was then added and stirred for $1 \mathrm{~h}$. The mixture was washed with $\mathrm{HCl}$. The water layer was extracted with $\mathrm{DCM}$ and the combined organic layers dried with $\mathrm{MgSO}_{4}$, filtered and the solvent removed in vacuo. The crude material was purified via column chromatography, using $\mathrm{CHCl}_{2}$ : hexanes $1: 1$ as eluent, affording the desired product as a red powder $(0.096 \mathrm{~g}, 26 \%) .{ }^{1} \mathrm{H}$ NMR is consistent with previously reported. ${ }^{90}$

\section{5,5-difluoro-1,3,7,9-tetramethyl-10-(3,4,5-trimethoxyphenyl)-5H-4/4,5/4-dipyrrolo[1,2-c:2',1'-}

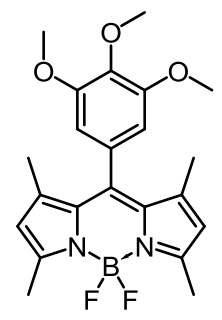

f][1,3,2]diazaborinine. To a solution of $2.11(0.5 \mathrm{~mL}, 0.46 \mathrm{~g}, 4.83 \mathrm{mmol})$ in dry DCM (70mL) 3, 4, 5-trimethoxybenzaldehyde (2.31c) ( $0.43 \mathrm{~g}, 2.42 \mathrm{mmol}$ ) was added followed by a catalytic amount of trifluoroacetic acid (TFA). The mixture was stirred overnight, then 2,3-dichloro-5,6-dicyanobenzoquinone (DDQ, $0.65 \mathrm{~g}, 2.9 \mathrm{mmol}$ ) was added and the mixture allowed to stir for $1 \mathrm{~h}$. Disappearance of the aldehyde was monitored by TLC, and if still present, an additional 0.5 eq of DDQ were added. Following the complete

2.32c disappearance of the aldehyde, $\mathrm{N}, \mathrm{N}$-diisopropylethylamine (DIPEA, $3 \mathrm{~mL}, 17.2 \mathrm{mmol}$ ) was added before stirring for $30 \mathrm{~min} . \mathrm{BF}_{3} \mathrm{OEt}_{2}(3.5 \mathrm{~mL}, 28.4 \mathrm{mmol}$ ) was then added and stirred for $1 \mathrm{~h}$. The mixture was washed with $\mathrm{HCl}$. The water layer was extracted with $\mathrm{DCM}$ and the combined organic layers dried with $\mathrm{MgSO}_{4}$, filtered and the solvent removed in vacuo. The crude material was purified via column chromatography, using hexanes ethyl acetate 8:2 as eluent, affording the desired product as a red powder (0.56 g 56\%). ${ }^{1} \mathrm{H}$ NMR is consistent with previously reported. ${ }^{91}$ 


\section{5,5-difluoro-1,3,7,9-tetramethyl-10-(4-nitrophenyl)-5H-4I4,5/4-dipyrrolo[1,2-c:2',1'-}

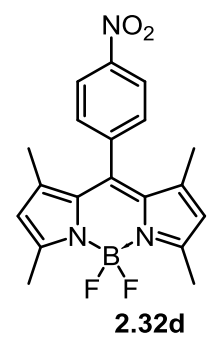

f][1,3,2]diazaborinine. To a solution of 2.11 (0.46 g, $4.83 \mathrm{mmol})$ in dry DCM (70mL) nitrobenzaldehyde (2.31d) $(0.37 \mathrm{~g}, 2.42 \mathrm{mmol}$ ) was added followed by a catalytic amount of trifluoroacetic acid (TFA). The mixture was stirred overnight, then 2,3-dichloro-5,6dicyanobenzoquinone (DDQ, $0.66 \mathrm{~g}, 2.9 \mathrm{mmol}$ ) was added and the mixture allowed to stir for $1 \mathrm{~h}$. Disappearance of the aldehyde was monitored by TLC, and if still present, an additional 0.5 eq of DDQ were added. Following the complete disappearance of the aldehyde, N,N-diisopropylethylamine (DIPEA, $3 \mathrm{~mL}, 17.2 \mathrm{mmol}$ ) was added before stirring for $30 \mathrm{~min} . \mathrm{BF}_{3} \mathrm{OEt}_{2}(3.5 \mathrm{~mL}, 28.4 \mathrm{mmol}$ ) was then added and stirred for $1 \mathrm{~h}$. The mixture was washed with $\mathrm{HCl}$. The water layer was extracted with EtOAc and the combined organic layers dried with $\mathrm{MgSO}_{4}$, filtered and the solvent removed in vacuo. The crude material was purified via column chromatography, using hexanes $\mathrm{CH}_{2} \mathrm{Cl}_{2}$ as eluent, affording the desired product as red needles $(0.20 \mathrm{~g} 22 \%)$. ${ }^{1} \mathrm{H} \mathrm{NMR}$ is consistent with previously reported. ${ }^{90}$

\section{5,5-difluoro-1,3,7,9-tetramethyl-10-phenyl-5H-4/4,5/4-dipyrrolo[1,2-c:2',1'-f][1,3,2]diazaborinine-2-}

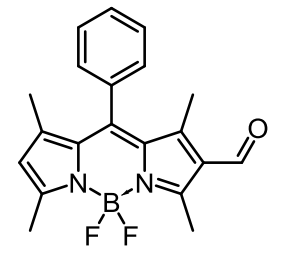

2.33a

carbaldehyde. A solution of dry DMF $(10 \mathrm{~mL})$ and $\mathrm{POCl}_{3}(12 \mathrm{~mL})$ in $30 \mathrm{~mL}$ of dry DCE (dichloroethane) was stirred for $5 \mathrm{~min}$ at $0^{\circ} \mathrm{C}$ under nitrogen. After being warmed at room temperature, the mixture was stirred for another $30 \mathrm{~min}$. To this mixture was added $2.32 \mathrm{a}(0.20 \mathrm{~g}, 0.62 \mathrm{mmol})$ in $30 \mathrm{~mL}$ of 1,2 -dichloroethane and the mixture was stirred 3 hours and was monitored by TLC at $25{ }^{\circ} \mathrm{C}$. The solution was slowly poured onto $300 \mathrm{~mL}$ of saturated $\mathrm{NaHCO}_{3}$ and ice and was allowed to come to room temperature overnight. The organic layer was washed with water, dried with $\mathrm{MgSO}_{4}$. Solvent was removed in vacuo and the crude product was purified via column chromatography using $\mathrm{CH}_{2} \mathrm{Cl}_{2}$ as an eluent, affording the desired product as bright red solid $(0.165 \mathrm{~g}, 80 \%){ }^{1} \mathrm{H}$ NMR is consistent with previously reported. ${ }^{64}$

\section{5,5-difluoro-10-(4-methoxyphenyl)-1,3,7,9-tetramethyl-5H-4I4,5l4-dipyrrolo[1,2-c:2',1'-}

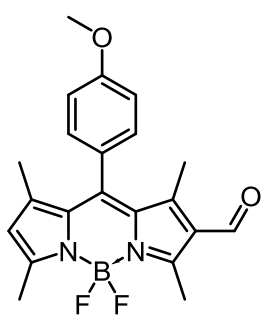

2.33b

$f][1,3,2]$ diazaborinine-2-carbaldehyde. A solution of dry DMF $(10 \mathrm{~mL})$ and $\mathrm{POCl}_{3}(12$ $\mathrm{mL}$ ) in $30 \mathrm{~mL}$ of dry DCE was stirred for $5 \mathrm{~min}$ at $0^{\circ} \mathrm{C}$ under nitrogen. After being warmed at room temperature, the mixture was stirred for another $30 \mathrm{~min}$. To this mixture was added $2.32 \mathrm{~b}(0.355 \mathrm{~g}, 1.00 \mathrm{mmol})$ in $30 \mathrm{~mL}$ of 1,2-dichloroethane and the mixture was stirred 3 hours and was monitored by TLC room temperature. The solution was slowly poured onto $300 \mathrm{~mL}$ of saturated $\mathrm{NaHCO}_{3}$ and ice and was allowed to come to room temperature overnight. The organic layer was washed with water, dried with $\mathrm{MgSO}_{4}$. Solvent was removed in vacuo and the crude product was purified via column chromatography using $\mathrm{CH}_{2} \mathrm{Cl}_{2}$ as an eluent, affording the desired product as bright red solid $(0.163 \mathrm{~g}$, $43 \%) .{ }^{1} \mathrm{H}$ NMR is consistent with previously reported. ${ }^{92}$ 


\section{5,5-difluoro-1,3,7,9-tetramethyl-10-(3,4,5-trimethoxyphenyl)-5H-4l4,5/4-dipyrrolo[1,2-c:2',1'-}

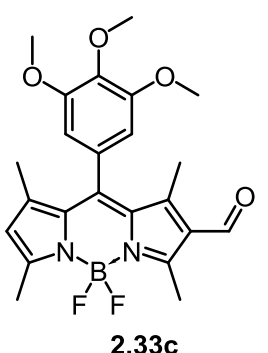

f][1,3,2]diazaborinine-2-carbaldehyde. A solution of dry DMF $(10 \mathrm{~mL})$ and $\mathrm{POCl}_{3}(12$ $\mathrm{mL}$ ) in $30 \mathrm{~mL}$ of dry DCE (dichloroethane) was stirred for $5 \mathrm{~min}$ at $0^{\circ} \mathrm{C}$ under nitrogen. After being warmed at room temperature, the mixture was stirred for another 30 min. To this mixture was added $2.32 \mathrm{c}(0.075 \mathrm{~g}, 0.18 \mathrm{mmol})$ in $30 \mathrm{~mL}$ of 1,2 dichloroethane and the mixture was stirred 3 hours and was monitored by TLC at 25 ${ }^{\circ} \mathrm{C}$. The solution was slowly poured onto $200 \mathrm{~mL}$ of saturated $\mathrm{NaHCO}_{3}$ and ice and was allowed to come to room temperature overnight. The organic layer was washed with water, dried with $\mathrm{MgSO}_{4}$. Solvent was removed in vacuo and the crude product was purified via column chromatography using $\mathrm{CH}_{2} \mathrm{Cl}_{2}$ as an eluent, affording the desired product as bright red solid (0.075 g, 93\%). ${ }^{1} \mathrm{H} \mathrm{NMR}\left(\mathrm{CDCl}_{3}, 400 \mathrm{MHz}\right): \delta=10.04(\mathrm{~s}, 1 \mathrm{H}), 6.50(\mathrm{~s}, 2 \mathrm{H}) 3.94(\mathrm{~s}, 3 \mathrm{H}), 3.84(\mathrm{~s}, 6 \mathrm{H}), 2.83(\mathrm{~s}$, $3 \mathrm{H}), 2.70(\mathrm{~s}, 3 \mathrm{H}), 1.82(\mathrm{~s}, 3 \mathrm{H}), 1.60(\mathrm{~s}, 3 \mathrm{H})$.

\section{5,5-difluoro-1,3,7,9-tetramethyl-10-(4-nitrophenyl)-5H-4I4,5/4-dipyrrolo[1,2-c:2',1'-}

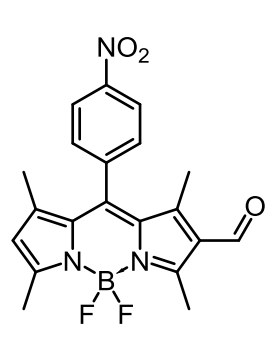

2.33d

f][1,3,2]diazaborinine-2-carbaldehyde. . A solution of dry DMF $(10 \mathrm{~mL})$ and $\mathrm{POCl}_{3}(12$ $\mathrm{mL}$ ) in $30 \mathrm{~mL}$ of dry DCE (dichloroethane) was stirred for $5 \mathrm{~min}$ at $0^{\circ} \mathrm{C}$ under nitrogen. After being warmed at room temperature, the mixture was stirred for another 30 min. To this mixture was added $2.32 \mathrm{~d}(0.20 \mathrm{~g}, 0.54 \mathrm{mmol})$ in $30 \mathrm{~mL}$ of 1,2 dichloroethane and the mixture was stirred 3 hours and was monitored by TLC at 25 ${ }^{\circ} \mathrm{C}$. The solution was slowly poured onto $300 \mathrm{~mL}$ of saturated $\mathrm{NaHCO}_{3}$ and ice and was allowed to come to room temperature overnight. The organic layer was washed with water, dried with $\mathrm{MgSO}_{4}$. Solvent was removed in vacuo and the crude product was purified via column chromatography using $\mathrm{CH}_{2} \mathrm{Cl}_{2}$ as an eluent, affording the desired product as purple flakes $(0.20$ g, 95\%). ${ }^{1} \mathrm{H}$ NMR is consistent with previously reported. ${ }^{90}$

\section{5,5-difluoro-8-iodo-1,3,7,9-tetramethyl-10-phenyl-5H-4I4,5/4-dipyrrolo[1,2-c:2',1'-}

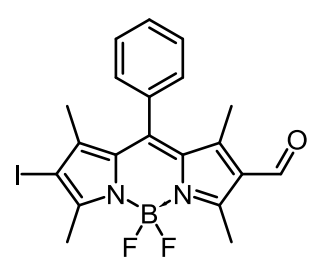

2.34a

f][1,3,2]diazaborinine-2-carbaldehyde. In a $100 \mathrm{~mL}$ RBF (2.33a) (140 mg, 0.39 $\mathrm{mmol})$, and NIS (90 mg, $40 \mathrm{mmol})$, were dissolved in DCM $(40 \mathrm{~mL})$. The flask was covered in $\mathrm{Al}$ foil and stirred at room temperature, under $\mathrm{N}_{2}$ overnight. Solvent was removed in vacuo and the residue was purified through column chromatography using DCM : Hexanes, 1:1 as the eluent yielding a brown powder. (140 mg 91\% yield). ${ }^{1} \mathrm{H}$ NMR is consistent with previously reported. ${ }^{64}$ 


\section{5,5-difluoro-8-iodo-10-(4-methoxyphenyl)-1,3,7,9-tetramethyl-5H-4|4,5I4-dipyrrolo[1,2-c:2',1'-}

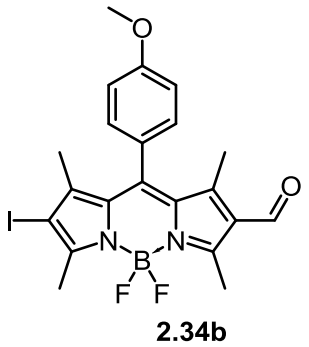

f][1,3,2]diazaborinine-2-carbaldehyde. In a $100 \mathrm{~mL}$ RBF (2.33b) (141 mg, 0.34 $\mathrm{mmol})$, and NIS (92 $\mathrm{mg}, 41 \mathrm{mmol})$, were dissolved in DCM (40 mL). The flask was covered in Al foil and stirred at room temperature, under $\mathrm{N}_{2}$ overnight. Solvent was removed in vacuo and the residue was purified through column chromatography using $\mathrm{CHCl}_{2}$ as the eluent yielding a bright red powder. (167 mg $96 \%$ yield). ${ }^{1} \mathrm{H}$ NMR is consistent with previously reported. ${ }^{93}$

\section{5,5-difluoro-8-iodo-1,3,7,9-tetramethyl-10-(3,4,5-trimethoxyphenyl)-5H-4I4,5/4-dipyrrolo[1,2-c:2',1'-}

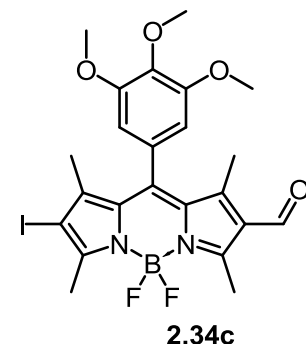

f][1,3,2]diazaborinine-2-carbaldehyde. In a $100 \mathrm{~mL}$ RBF (2.33c) (140 mg, 0.39 $\mathrm{mmol})$, and NIS (90 mg, $40 \mathrm{mmol})$, were dissolved in DCM $(40 \mathrm{~mL})$. The flask was covered in Al foil and stirred at room temperature, under $\mathrm{N}_{2}$ overnight. Solvent was removed in vacuo and the residue was purified through column chromatography using DCM : Hexanes, $1: 1$ as the eluent yielding a brown powder. (140 mg 91\% yield). ${ }^{1} \mathrm{H}$ NMR (400 MHz, $\left.\mathrm{CDCl}_{3}\right): \delta=10.03(\mathrm{~s}, 1 \mathrm{H}), 6.49(\mathrm{~s}, 2 \mathrm{H}), 3.93$ $(\mathrm{s}, 3 \mathrm{H}), 3.84(\mathrm{~s}, 6 \mathrm{H}), 2.82(\mathrm{~s}, 3 \mathrm{H}), 2.70(\mathrm{~s}, 3 \mathrm{H}), 1.82(\mathrm{~s}, 3 \mathrm{H}), 1.60(\mathrm{~s}, 3 \mathrm{H}) .{ }^{13} \mathrm{C}\left\{{ }^{1} \mathrm{H}\right\} \mathrm{NMR}$

$\left(\mathrm{CDCl}_{3}, 100 \mathrm{MHz}\right): \delta=185.7,171.1,160.8,158.0,154.7,147.8,145.1,143.4,139.4,133.4,129.9,129.0$, $127.0,104.8,61.4,60.4,56.5,21.0,17.3,16.38,14.2,13.3,11.8 .{ }^{11} \mathrm{~B}\left\{{ }^{1} \mathrm{H}\right\} N M R\left(\mathrm{CDCl}_{3}, 128 \mathrm{MHz}\right): \delta=0.60$ $\left(\mathrm{t},{ }^{1} \mathrm{~J}_{\mathrm{BF}}=32 \mathrm{~Hz}\right) .{ }^{19} \mathrm{~F} \mathrm{NMR}\left(\mathrm{CDCl}_{3}, 376 \mathrm{MHz}\right): \delta=-144.5$ (q). HRMS: (HREI) m/z 568.0832 (M+), calculated for ${ }^{12} \mathrm{C}_{23}{ }^{1} \mathrm{H}_{24}{ }^{11} \mathrm{~B}^{19} \mathrm{~F}_{2}{ }^{127} \mathrm{I}^{14} \mathrm{~N}_{2}{ }^{16} \mathrm{O}_{4}{ }^{+}: \mathrm{m} / \mathrm{z} 568.0842$

\section{5,5-difluoro-8-iodo-1,3,7,9-tetramethyl-10-(4-nitrophenyl)-5H-4I4,5/4-dipyrrolo[1,2-c:2',1'-}

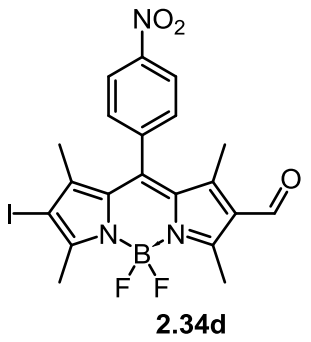

f][1,3,2]diazaborinine-2-carbaldehyde In a $100 \mathrm{~mL} R B F$ (2.33d) (160 mg, 0.40 $\mathrm{mmol})$, and NIS (96 mg, $43 \mathrm{mmol})$, were dissolved in DCM (40 mL). The flask was covered in Al foil and stirred at room temperature, under $\mathrm{N}_{2}$ overnight. Solvent was removed in vacuo and the residue was purified through column chromatography using DCM : Hexanes, $1: 1$ as the eluent yielding a shiny brown powder. (73 mg 35\% yield). ${ }^{1} \mathrm{H}$ NMR $\left(400 \mathrm{MHz}, \mathrm{CDCl}_{3}\right): \delta=10.02(\mathrm{~s}, 1 \mathrm{H}), 8.45(\mathrm{~m}$, $2 \mathrm{H}), 7.56(\mathrm{~m}, 2 \mathrm{H}), 2.83(\mathrm{~s}, 3 \mathrm{H}), 2.72(\mathrm{~s}, 3 \mathrm{H}), 1.65(\mathrm{~s}, 3 \mathrm{H}), 1.42(\mathrm{~s}, 3 \mathrm{H}) .{ }^{13} \mathrm{C}$ NMR $(100$ $\left.\mathrm{MHz}, \mathrm{CDCl}_{3}\right) \delta 186.34,184.64,162.11,158.87,140.89,132.78,130.29,130.22,129.17,128.63,128.56$, $125.70,125.65,123.96,18.36,17.08,12.86,11.57 .{ }^{11} \mathrm{~B}\left\{{ }^{1} \mathrm{H}\right\} \mathrm{NMR}\left(\mathrm{CDCl}_{3}, 128 \mathrm{MHz}\right): \delta=0.58\left(\mathrm{t},{ }^{1} \mathrm{~J}_{\mathrm{BF}}=32\right.$ Hz). ${ }^{19} \mathrm{~F} \mathrm{NMR}\left(\mathrm{CDCl}_{3}, 376 \mathrm{MHz}\right): \delta=-144.3(\mathrm{q})$. 
5-(5,5-difluoro-1,3,7,9,10-pentamethyl-5H-5/4,6l4-dipyrrolo[1,2-c:2',1'-f][1,3,2]diazaborinin-2-

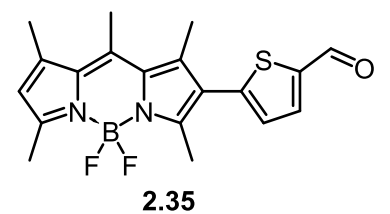

yl)thiophene-2-carbaldehyde An oven dried Schlenk flask was charged with 2.13 (0.3 g, $0.77 \mathrm{mmol})$, and 2.8 (0.65 g, $2.31 \mathrm{mmol})$, in THF( $90 \mathrm{~mL}) \mathrm{H}_{2} \mathrm{O}(10$ $\mathrm{mL}$ ). The flask was sparged with $\mathrm{N}_{2}$ gas for 10 minutes prior to the addition of $\mathrm{K}_{2} \mathrm{CO}_{3}(0.53 \mathrm{~g}, 3.86 \mathrm{mmol})$, and $\mathrm{Pd}\left(\mathrm{PPh}_{3}\right)_{4}(89 \mathrm{mg}, 0.077 \mathrm{mmol})$. The reaction was refluxed overnight and organics were extracted using DCM. Solvents were removed in vacuo and the residue was taken in $180 \mathrm{~mL}$ of 2:1 $\mathrm{AcOH}: \mathrm{H}_{2} \mathrm{O}$ and refluxed for $1.5 \mathrm{~h}$. Organics were separated using DCM as the eluent and solvents were removed in vacuo. The residue was purified through column chromatography using DCM as the eluent to yield as an orange-red powder (0.055 g, 19\%). ${ }^{1} \mathrm{H}$ NMR (400 MHz, $\left.\mathrm{CDCl}_{3}\right): \delta=9.91(\mathrm{~s}, 1 \mathrm{H}), 7.78(\mathrm{~m}, 1 \mathrm{H}), 7.00(\mathrm{~m}, 1 \mathrm{H}), 6.15(\mathrm{~s}, 1 \mathrm{H}), 2.66$ $(\mathrm{s}, 3 \mathrm{H}), 2.56(\mathrm{~s}, 6 \mathrm{H}), 2.46(\mathrm{~s}, 3 \mathrm{H}), 2.44(\mathrm{~s}, 3 \mathrm{H})$. HRMS (ESI): $\mathrm{m} / \mathrm{z} 373.13482(\mathrm{M}+\mathrm{H}+)$, calculated for ${ }^{12} \mathrm{C}_{19}{ }^{1} \mathrm{H}_{20}{ }^{11} \mathrm{~B}^{19} \mathrm{~F}_{2}{ }^{14} \mathrm{~N}_{2}{ }^{16} \mathrm{O}^{32} \mathrm{~S}^{+}: \mathrm{m} / \mathrm{z} 373.12520$.

\section{5,5'-(5,5-difluoro-1,3,7,9,10-pentamethyl-5H-4|4,5/4-dipyrrolo[1,2-c:2',1'-f][1,3,2]diazaborinine-2,8-}

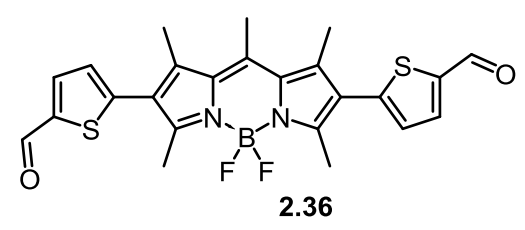
diyl)bis(thiophene-2-carbaldehyde). An oven dried Schlenk flask was charged with 2.26 (0.3 g, $0.58 \mathrm{mmol})$, and 2.8 (0.49 g, $1.75 \mathrm{mmol})$, in $\operatorname{THF}(90 \mathrm{~mL}) \mathrm{H}_{2} \mathrm{O}(10 \mathrm{~mL})$. The flask was sparged with $\mathrm{N}_{2}$ gas for 10 minutes prior to the addition of $\mathrm{K}_{2} \mathrm{CO}_{3}(0.81 \mathrm{~g}, 5.84 \mathrm{mmol})$, and $\mathrm{Pd}\left(\mathrm{PPh}_{3}\right)_{4}(134 \mathrm{mg}, 0.12 \mathrm{mmol})$. The reaction was refluxed overnight and organics were extracted with DCM. Solvents were removed in vacuo and the residue was taken in $180 \mathrm{~mL}$ of 2:1 AcOH : $\mathrm{H}_{2} \mathrm{O}$ and refluxed for $1.5 \mathrm{~h}$. Organics were separated using DCM as the eluent and solvents were removed in vacuo. The residue was purified through column chromatography using a gradient of eluents from DCM, to 9:1, DCM : EtOAc; to yield an orange-red powder $(0.070 \mathrm{~g}, 24 \%) .{ }^{1} \mathrm{H}$ $\operatorname{NMR}\left(400 \mathrm{MHz}, \mathrm{CDCl}_{3}\right): \delta=9.93(\mathrm{~s}, 2 \mathrm{H}), 7.80\left(\mathrm{~d},{ }^{3} \mathrm{~J}_{\mathrm{HH}}=3.8 \mathrm{~Hz}, 2 \mathrm{H}\right), 7.04\left(\mathrm{~d},{ }^{3} \mathrm{~J}_{\mathrm{HH}}=3.8 \mathrm{~Hz}, 2 \mathrm{H}\right), 2.75(\mathrm{~s}, 3 \mathrm{H})$, $2.60(\mathrm{~s}, 6 \mathrm{H}), 2.48(\mathrm{~s}, 6 \mathrm{H}) .{ }^{13} \mathrm{C}\left\{{ }^{1} \mathrm{H}\right\} \mathrm{NMR}\left(\mathrm{CDCl}_{3}, 100 \mathrm{MHz}\right): \delta=182.7,153.5,144.9,144.1,143.6,139.1$, 136.6, 132.7, 129.2, 29.7, 17.7, 15.7, 13.5. ${ }^{11} \mathrm{~B}\left\{{ }^{1} \mathrm{H}\right\} \quad \mathrm{NMR}\left(\mathrm{CDCl}_{3}, 128 \mathrm{MHz}\right) \delta=0.65\left(\mathrm{t},{ }^{1} J_{\mathrm{BF}}=32 \mathrm{~Hz}\right.$, ${ }^{19} \mathrm{~F}$ NMR $\left(\mathrm{CDCl}_{3}, 376 \mathrm{MHz}\right) \delta=-145.8$ (q). HRMS (EI) $m / z \quad 482.1119(\mathrm{M}+)$, calculated for ${ }^{12} \mathrm{C}_{24}{ }^{1} \mathrm{H}_{21}{ }^{11} \mathrm{~B}^{19} \mathrm{~F}_{2}{ }^{14} \mathrm{~N}_{2}{ }^{16} \mathrm{O}_{2}{ }^{32} \mathrm{~S}_{2}: \mathrm{m} / \mathrm{z} 482.1106$. 
2-bromo-5,5-difluoro-1,3,7,9,10-pentamethyl-5H-4l4,5/4-dipyrrolo[1,2-c:2',1'-f][1,3,2]diazaborinine. In

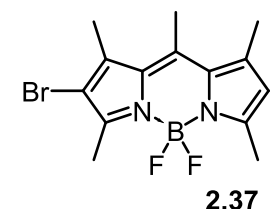

2.37

a $250 \mathrm{~mL} \operatorname{RBF}(\mathbf{2 . 1 2})(500 \mathrm{mg}, 1.91 \mathrm{mmol})$, and NBS (373 mg, $2.10 \mathrm{mmol})$, were dissolved in DCM (100 mL). The flask was covered in Al foil and stirred at room temperature, under $\mathrm{N}_{2}$ overnight. Solvent was removed in vacuo and the residue was purified through column chromatography. $\mathrm{DCM}$ : Hexanes, $1: 1$ as the eluent, $\mathrm{Rf}=$ 0.5 to yield a bright orange powder. (440 mg 68\% yield). ${ }^{1} \mathrm{H} \mathrm{NMR}\left(400 \mathrm{MHz}, \mathrm{CDCl}_{3}\right): \delta$ $=\delta=6.11(\mathrm{~s}, 1 \mathrm{H}), 2.61(\mathrm{~s}, 3 \mathrm{H}), 2.56(\mathrm{~s}, 3 \mathrm{H}), 2.53(\mathrm{~s}, 3 \mathrm{H}), 2.43(\mathrm{~s}, 6 \mathrm{H}) .{ }^{13} \mathrm{C}\left\{{ }^{1} \mathrm{H}\right\} \mathrm{NMR}\left(\mathrm{CDCl}_{3}, 100 \mathrm{MHz}\right): \delta=$ $156.1,149.6,143.0,141.6,136.4,132.7,130.6,122.3,110.4,17.5,16.8,16.1,14.6,13.39 .{ }^{11} \mathrm{~B}\left\{{ }^{1} \mathrm{H}\right\} \mathrm{NMR}$ $\left.\left(\mathrm{CDCl}_{3}, 128 \mathrm{MHz}\right): \delta=0.46\left(\mathrm{t},{ }^{1} \mathrm{~J}_{\mathrm{BF}}=32 \mathrm{~Hz},\right)\right) \cdot{ }^{19} \mathrm{~F} \mathrm{NMR}\left(\mathrm{CDCl}_{3}, 376 \mathrm{MHz}\right): \delta=-146.4$ (q). HRMS: (HREI) $\mathrm{m} / \mathrm{z}$ $340.0570(\mathrm{M}+)$, calculated for ${ }^{12} \mathrm{C}_{14}{ }^{1} \mathrm{H}_{16}{ }^{11} \mathrm{~B}^{79} \mathrm{Br}^{19} \mathrm{~F}_{2}{ }^{14} \mathrm{~N}_{2}+: m / z 340.0558$

5,5-difluoro-1,3,7,9,10-pentamethyl-2-(4,4,5,5-tetramethyl-1,3,2-dioxaborolan-2-yl)-5H-4l4,5l4-

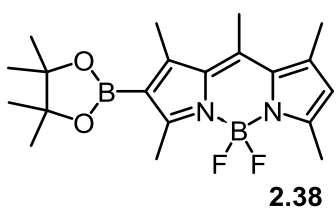

dipyrrolo[1,2-c:2',1'-f][1,3,2]diazaborinine. A microwave vial was charged with 2.37 (85 mg, $0.250 \mathrm{mmol}$ ), $\mathrm{Pd}_{2}(\mathrm{dba})_{3} \cdot \mathrm{CHCl}_{3}(3 \mathrm{mg}, 5.0 \mathrm{mmol}$ ), X-Phos (5 mg, 10 $\mathrm{mmol}$ ), bis(pinacolato)diboron (200 $\mathrm{mg}, 0.75 \mathrm{mmol}), \mathrm{KOAc}(80 \mathrm{mg}, 0.5$ mmol).The vial was capped with a rubber septum and then evacuated and backfilled with $\mathrm{N}_{2}$ (this sequence was carried out three times) prior to insertion into a glove box. 1,4-Dioxane $(4 \mathrm{~mL})$ was added via syringe and the vial was capped under $\mathrm{N}_{2}$. The reaction mixture was heated to $150{ }^{\circ} \mathrm{C}$ for 30 minutes after a 2 minute pre-stir. The reaction solution was then filtered through a thin pad of Celite and eluted with DCM. After removal of solvents in vacuo, the mixture was purified by column chromatography. DCM as the eluent $\mathrm{Rf}=0.5$ and eluent was removed in vacuo. The residue was triturated in hexanes to yield orange needles. (17 mg, 18\%) ${ }^{1} \mathrm{H}$ NMR $\left(400 \mathrm{MHz}, \mathrm{CDCl}_{3}\right): \delta=6.08(\mathrm{~s}, 1 \mathrm{H}), 2.71(\mathrm{~s}, 3 \mathrm{H}), 2.63(\mathrm{~s}, 3 \mathrm{H}), 2.62(\mathrm{~s}, 3 \mathrm{H}), 2.52(\mathrm{~s}, 3 \mathrm{H}), 2.42(\mathrm{~s}, 3 \mathrm{H}), 1.32(\mathrm{~s}$, 12H). ${ }^{13} \mathrm{C}$ NMR $\left(100 \mathrm{MHz}, \mathrm{CDCl}_{3}\right) \delta 187.13,185.46,153.92,152.11,150.43,133.52,129.51,125.65$, $125.43,100.59,99.01,16.54,15.27,13.99,12.82,11.53 .{ }^{11} \mathrm{~B}\left\{{ }^{1} \mathrm{H}\right\} \mathrm{NMR}\left(\mathrm{CDCl}_{3}, 128 \mathrm{MHz}\right): \delta=30.62,0.67$ $\left.\left(\mathrm{t},{ }^{1} \mathrm{~J}_{\mathrm{BF}}=32 \mathrm{~Hz},\right)\right) \cdot{ }^{19} \mathrm{~F} \mathrm{NMR}\left(\mathrm{CDCl}_{3}, 376 \mathrm{MHz}\right): \delta=-146.4$ (q). HRMS (EI) $\mathrm{m} / z 388.2296(\mathrm{M}+)$, calculated for ${ }^{12} \mathrm{C}_{20}{ }^{1} \mathrm{H}_{28}{ }^{11} \mathrm{~B}_{2}{ }^{19} \mathrm{~F}_{2}{ }^{14} \mathrm{~N}_{2}{ }^{16} \mathrm{O}_{2}{ }^{-}: m / z 388.2305$.

(E)-10-(2-(dimethylamino)vinyl)-5,5-difluoro-1,3,7,9-tetramethyl-5H-4I4,5/4-dipyrrolo[1,2-c:2',1'-

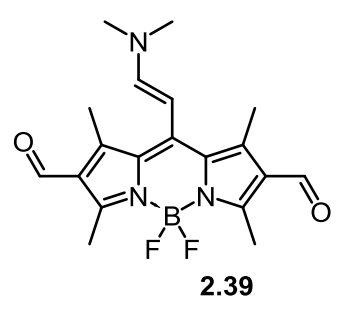

f][1,3,2]diazaborinine-2,8-dicarbaldehyde. A solution of $10 \mathrm{~mL}$ of dry DMF in dry 1,2-dichloroethane $(30 \mathrm{~mL})$ was cooled in an ice bath and $\mathrm{POCl}_{3}(12 \mathrm{~mL})$ was added dropwise. The mixture was warmed to room temperature and stirred 30 min. A solution of $\mathbf{2 . 2 1}$ (270 mg, $0.93 \mathrm{mmol})$ in dry 1,2-dichloroethane (30 mL) was added in one portion and the mixture was stirred $2 \mathrm{hr}$ at $40{ }^{\circ} \mathrm{C}$ while being monitored by TLC. The mixture was neutralized in $300 \mathrm{~mL}$ or saturated $\mathrm{NaHCO}_{3}$ at

$0{ }^{\circ} \mathrm{C}$ and allowed to warm to room temperature overnight. The organic layer was extracted with $\mathrm{CH}_{2} \mathrm{Cl}_{2}$ $(3 \times 25 \mathrm{~mL})$. The combined organic layers were dried over $\mathrm{MgSO}_{4}$, filtered and volatiles were removed in vacuo. The crude material was purified via column chromatography using $9: 1 \mathrm{CH}_{2} \mathrm{Cl}_{2}$ : $\mathrm{MeOH}$ as the eluent, affording the desired product as a red solid (170 mg, 57\%). $\left.{ }^{1} \mathrm{H} \mathrm{NMR} \mathrm{(400} \mathrm{MHz,} \mathrm{CDCl}_{3}\right): \delta=10.09$ 
$(\mathrm{s}, 2 \mathrm{H}), 7.33\left(\mathrm{~d},{ }^{3} \mathrm{H}_{\mathrm{HH}}=12 \mathrm{~Hz}, 1 \mathrm{H}\right), 6.16\left(\mathrm{~d},{ }^{3} J_{\mathrm{HH}}=12 \mathrm{~Hz}, 1 \mathrm{H}\right), 3.34(\mathrm{~m}, 6 \mathrm{H}), 2.77(\mathrm{~s}, 6 \mathrm{H}), 2.55(\mathrm{~s}, 6 \mathrm{H})$. ${ }^{13} \mathrm{C}\left\{{ }^{1} \mathrm{H}\right\} \mathrm{NMR}\left(\mathrm{CDCl}_{3}, 100 \mathrm{MHz}\right): \delta=186.3,160.8,152.2,150.5,133.6,129.5,125.6,99.8,29.7,14.6,12.2$, 12.1. ${ }^{11} \mathrm{~B}\left\{{ }^{1} \mathrm{H}\right\} \mathrm{NMR}\left(\mathrm{CDCl}_{3}, 128 \mathrm{MHz}\right): \delta=0.96\left(\mathrm{t},{ }^{1} J_{\mathrm{BF}}=32 \mathrm{~Hz},\right) .{ }^{19} \mathrm{~F} \mathrm{NMR}\left(\mathrm{CDCl}_{3}, 376 \mathrm{MHz}\right): \delta=-144.4$ (q).

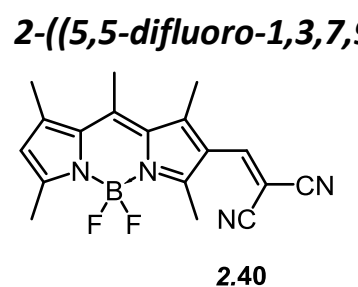

yl)methylene)malononitrile. $2.21(100 \mathrm{mg}, 0.35 \mathrm{mmol})$ and malononitrile $(0.057$ $\mathrm{g}, 0.86 \mathrm{mmol})$ were dissolved in $\mathrm{CHCl}_{3}(15 \mathrm{~mL})$. Four drops of $\mathrm{Et}_{3} \mathrm{~N}$ was added and the reaction was refluxed overnight. Solvent was removed in vacuo and the resulting residue was triturated in hot $\mathrm{MeOH}$ and washed with cold $\mathrm{MeOH}$ to yield 2.40 and an orange-red solid $(0.10 \mathrm{mg}, 86 \%) .{ }^{1} \mathrm{H} \mathrm{NMR}\left(400 \mathrm{MHz}, \mathrm{CDCl}_{3}\right): \delta$ $=7.79(\mathrm{~s}, 1 \mathrm{H}), 6.27(\mathrm{~s}, 1 \mathrm{H}), 2.69(\mathrm{~s}, 3 \mathrm{H}), 2.59(\mathrm{~s}, 6 \mathrm{H}), 2.49(\mathrm{~s}, 6 \mathrm{H}) .{ }^{13} \mathrm{C}\left\{{ }^{1} \mathrm{H}\right\} \mathrm{NMR}\left(\mathrm{CDCl}_{3}, 100 \mathrm{MHz}\right): \delta=$ $161.3,153.6,151.3,146.3,142.6,136.5,124.9,122.8,114.4,113.3,82.3,46.2,29.69,17.9,17.3,15.0$, 13.9, 8.6. ${ }^{11} \mathrm{~B}\left\{{ }^{1} \mathrm{H}\right\} \mathrm{NMR}\left(\mathrm{CDCl}_{3}, 128 \mathrm{MHz}\right): \delta=0.46\left(\mathrm{t},{ }^{1} \mathrm{~J}_{\mathrm{BF}}=32 \mathrm{~Hz},\right) \cdot{ }^{19} \mathrm{~F} \mathrm{NMR}\left(\mathrm{CDCl}_{3}, 376 \mathrm{MHz}\right): \delta=-144.4$ (q). HRMS: (HREI) $m / z 340.0570 \mathrm{M}+$, calculated for ${ }^{12} \mathrm{C}_{18}{ }^{1} \mathrm{H}_{17}{ }^{11} \mathrm{~B}^{19} \mathrm{~F}_{2}{ }^{14} \mathrm{~N}_{4}+: \mathrm{m} / \mathrm{z} 340.0558$.

\section{5,5-dimethoxy-1,3,7,9,10-pentamethyl-5H-4I4,5I4-dipyrrolo[1,2-c:2',1'-f][1,3,2]diazaborinine-2-}

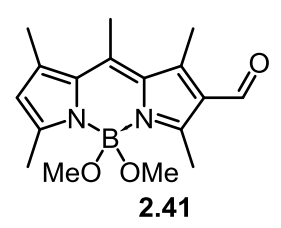

carbaldehyde. BODIPY (100 mg, $0.34 \mathrm{mmol}$ ) was dissolved in $10 \mathrm{~mL}$ of dry DCM, in the presence of $\mathrm{AlCl}_{3}(92 \mathrm{mg}, 69 \mathrm{mmol})$. The resulting mixture was refluxed for $5 \mathrm{~min}$ prior to the addition of $\mathrm{MeOH}(5 \mathrm{~mL})$ the reaction was stirred 10 mins at room temp. Solvents were removed in vacuo and products were isolated through column chromatography $19: 1 \mathrm{DCM}$ : $\mathrm{MeOH}$ to yield the desired product as a waxy brown solid (67\% $72 \mathrm{mg}) .{ }^{1} \mathrm{H}$ NMR $\left(400 \mathrm{MHz}, \mathrm{CDCl}_{3}\right): \delta=10.11(\mathrm{~s}, 1 \mathrm{H}), 6.23(\mathrm{~s}, 1 \mathrm{H}), 2.82(\mathrm{~s}, 6 \mathrm{H}), 2.77(\mathrm{~s}, 1 \mathrm{H})$, $2.76(\mathrm{~s}, 1 \mathrm{H}), 2.70(\mathrm{~s}, 1 \mathrm{H}), 2.49(\mathrm{~s}, 1 \mathrm{H}), 2.32(\mathrm{~s}, \mathrm{H} 1) .{ }^{13} \mathrm{C} \mathrm{NMR}\left(100 \mathrm{MHz}, \mathrm{CDCl}_{3}\right) \delta 186.44,160.90,160.28$, 155.56, 143.79, 143.08, 138.78, 136.59, 124.40, 49.02, 31.58, 22.64, 18.07, 17.35, 14.92, 14.24, 14.10, 12.16. ${ }^{11} \mathrm{~B}\left\{{ }^{1} \mathrm{H}\right\} \mathrm{NMR}\left(\mathrm{CDCl}_{3}, 128 \mathrm{MHz}\right): \delta=2.54 .{ }^{19} \mathrm{~F} \mathrm{NMR}\left(\mathrm{CDCl}_{3}, 376 \mathrm{MHz}\right): \delta=$ no signal.

\section{(E)-2-((2-(2,4-dinitrophenyl)hydrazono)methyl)-5,5-difluoro-1,3,7,9,10-pentamethyl-5H-4I4,5I4-}

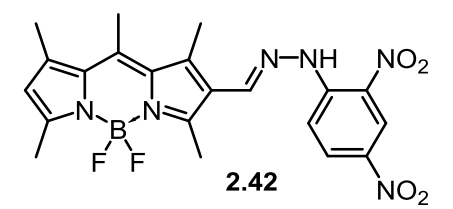
dipyrrolo[1,2-c:2',1'-f][1,3,2]diazaborinine. ) A $50 \mathrm{ml}$ RBF was charged with 2.21 ( $50 \mathrm{mg}, 0.18 \mathrm{mmol}$ ) in DCM $(10 \mathrm{~mL}$ ) of DCM $10 \mathrm{~mL}$ of Brady's Reagent ${ }^{94}$ was added in one portion at the reaction was stirred at room temperature for 15 minutes. The solution was filtered leaving dark purple crystals (50 mg, 61\%). ${ }^{1} \mathrm{H} \mathrm{NMR}\left(400 \mathrm{MHz}, \mathrm{CDCl}_{3}\right): \delta=11.24(\mathrm{~s}, 1 \mathrm{H}), 9.11(\mathrm{~s}, 1 \mathrm{H}), 8.36(\mathrm{~m}, 1 \mathrm{H}), 8.08\left(\mathrm{~d},{ }^{3} \mathrm{~J}_{\mathrm{HH}}\right.$ $=9.7 \mathrm{~Hz}, 1 \mathrm{H}), 7.69(\mathrm{~s}, 1 \mathrm{H}), 6.21(\mathrm{~s}, 1 \mathrm{H}), 2.68(\mathrm{~s}, 3 \mathrm{H}), 2.57(\mathrm{~s}, 3 \mathrm{H}), 2.51(\mathrm{~s}, 3 \mathrm{H}), 2.48(\mathrm{~s}, 3 \mathrm{H}), 2.38(\mathrm{~s}, 3 \mathrm{H})$. 
Carbon NMR was not obtained due to solubility issues. ${ }^{11} \mathrm{~B}\left\{{ }^{1} \mathrm{H}\right\} \mathrm{NMR}\left(\mathrm{CDCl}_{3}, 128 \mathrm{MHz}\right) \delta=0.56\left(\mathrm{t},{ }^{1} J_{\mathrm{BF}}=\right.$ $31.9 \mathrm{~Hz}$,) ${ }^{19} \mathrm{~F}$ NMR $\left(\mathrm{CDCl}_{3}, 376 \mathrm{MHz}\right) \delta=-146.41$ (q). HRMS (EI) $m / z 470.1697(\mathrm{M}+)$, calculated for ${ }^{12} \mathrm{C}_{21}{ }^{1} \mathrm{H}_{21}{ }^{11} \mathrm{~B}^{19} \mathrm{~F}_{2}{ }^{14} \mathrm{~N}_{6}{ }^{16} \mathrm{O}_{4}{ }^{-}: \mathrm{m} / \mathrm{z} 470.1685$. 


\section{APPENDIX A: CRYSTALOGRPHIC RESULTS}

Table A-1. Crystal data and structure refinement for $\mathbf{2 . 3 9}$

\begin{tabular}{|c|c|c|}
\hline Empirical formula & \multicolumn{2}{|l|}{$\mathrm{C}_{19} \mathrm{H}_{22} \mathrm{BF}_{2} \mathrm{~N}_{3} \mathrm{O}_{2}$} \\
\hline Formula weight & \multicolumn{2}{|l|}{373.20} \\
\hline Temperature & \multicolumn{2}{|l|}{$147(2) \mathrm{K}$} \\
\hline Wavelength & \multicolumn{2}{|l|}{$0.71073 \AA$} \\
\hline Crystal system & \multicolumn{2}{|l|}{ Orthorhombic } \\
\hline Space group & \multicolumn{2}{|l|}{ P n a 21} \\
\hline \multirow[t]{3}{*}{ Unit cell dimensions } & $a=21.7917(19) \AA$ & $a=90^{\circ}$. \\
\hline & $b=11.2285(10) \AA$ & $\mathrm{b}=90^{\circ}$. \\
\hline & $c=7.3897(6) \AA$ & $\mathrm{g}=90^{\circ}$. \\
\hline Volume & \multicolumn{2}{|l|}{$1808.2(3) \AA^{3}$} \\
\hline Z & \multicolumn{2}{|l|}{4} \\
\hline Density (calculated) & \multicolumn{2}{|l|}{$1.371 \mathrm{Mg} / \mathrm{m}^{3}$} \\
\hline Absorption coefficient & \multicolumn{2}{|l|}{$0.103 \mathrm{~mm}^{-1}$} \\
\hline$F(000)$ & \multicolumn{2}{|l|}{784} \\
\hline Crystal size & \multicolumn{2}{|c|}{$0.190 \times 0.120 \times 0.070 \mathrm{~mm}^{3}$} \\
\hline \multicolumn{3}{|l|}{ Difracctometer } \\
\hline Theta range for data collection & \multicolumn{2}{|l|}{2.040 to $27.504^{\circ}$} \\
\hline Index ranges & \multicolumn{2}{|c|}{$-28<=\mathrm{h}<=18,-13<=\mathrm{k}<=14,-9<=1<=9$} \\
\hline Reflections collected & \multicolumn{2}{|l|}{11348} \\
\hline Independent reflections & \multicolumn{2}{|c|}{$4098[R($ int $)=0.0602]$} \\
\hline Completeness to theta $=25.242^{\circ}$ & \multicolumn{2}{|l|}{$99.8 \%$} \\
\hline Absorption correction & \multicolumn{2}{|c|}{ Semi-empirical from equivalents } \\
\hline Max. and min. transmission & \multicolumn{2}{|l|}{0.7456 and 0.6423} \\
\hline Refinement method & \multicolumn{2}{|c|}{ Full-matrix least-squares on $\mathrm{F}^{2}$} \\
\hline Data / restraints / parameters & \multicolumn{2}{|l|}{4098 / 1 / 250} \\
\hline Goodness-of-fit on $F^{2}$ & \multicolumn{2}{|l|}{0.967} \\
\hline Final R indices [I>2sigma(I)] & \multicolumn{2}{|c|}{$\mathrm{R} 1=0.0492, \mathrm{wR} 2=0.0895$} \\
\hline $\mathrm{R}$ indices (all data) & \multicolumn{2}{|c|}{$\mathrm{R} 1=0.1199, \mathrm{wR} 2=0.1116$} \\
\hline Extinction coefficient & \multicolumn{2}{|l|}{$\mathrm{n} / \mathrm{a}$} \\
\hline Largest diff. peak and hole & \multicolumn{2}{|c|}{0.206 and -0.251 e. $\AA^{-3}$} \\
\hline
\end{tabular}


Table A-2. Atomic coordinates $\left(\times 10^{4}\right)$ and equivalent isotropic displacement parameters $\left(\AA^{2} \times 10^{3}\right)$ for 2.39. $U(\mathrm{eq})$ is defined as one third of the trace of the orthogonalized Uij tensor.

\begin{tabular}{|c|c|c|c|c|}
\hline & $x$ & $y$ & $z$ & $U(e q)$ \\
\hline$F(1)$ & $1541(1)$ & $7797(2)$ & $2352(3)$ & $38(1)$ \\
\hline$F(2)$ & $1378(1)$ & $8390(2)$ & $5240(4)$ & $40(1)$ \\
\hline$O(1)$ & $786(1)$ & $2629(2)$ & $5667(5)$ & $38(1)$ \\
\hline$O(2)$ & $4208(1)$ & $9973(3)$ & $5556(6)$ & $50(1)$ \\
\hline$N(1)$ & $1647(1)$ & $6344(3)$ & $4707(4)$ & $20(1)$ \\
\hline$N(2)$ & $2407(1)$ & $7954(3)$ & $4350(4)$ & $19(1)$ \\
\hline$N(3)$ & $4240(1)$ & $4637(3)$ & $3181(4)$ & $22(1)$ \\
\hline$C(1)$ & $1103(2)$ & $5779(3)$ & $4891(6)$ & $24(1)$ \\
\hline$C(2)$ & $1213(2)$ & $4550(3)$ & $5060(6)$ & $22(1)$ \\
\hline$C(3)$ & $1853(2)$ & $4363(3)$ & $4870(5)$ & $21(1)$ \\
\hline$C(4)$ & $2119(2)$ & $5493(3)$ & $4679(5)$ & $18(1)$ \\
\hline$C(5)$ & $2745(2)$ & $5868(3)$ & $4505(5)$ & $20(1)$ \\
\hline$C(6)$ & $2878(2)$ & $7123(3)$ & $4626(5)$ & 19(1) \\
\hline$C(7)$ & $3415(2)$ & $7743(3)$ & $5074(5)$ & $20(1)$ \\
\hline$C(8)$ & $3268(2)$ & $8974(3)$ & $4951(6)$ & $23(1)$ \\
\hline$C(9)$ & $2648(2)$ & $9062(3)$ & $4506(6)$ & $23(1)$ \\
\hline$C(10)$ & $499(2)$ & $6410(3)$ & $4788(7)$ & $34(1)$ \\
\hline$C(11)$ & $729(2)$ & $3700(4)$ & $5423(7)$ & $33(1)$ \\
\hline$C(12)$ & $2151(2)$ & $3166(3)$ & $4785(7)$ & $28(1)$ \\
\hline$C(13)$ & $4010(2)$ & $7283(4)$ & $5820(7)$ & $30(1)$ \\
\hline$C(14)$ & $3661(2)$ & $9994(4)$ & $5225(6)$ & $35(1)$ \\
\hline$C(15)$ & $2275(2)$ & 10167(3) & $4220(6)$ & $29(1)$ \\
\hline$C(16)$ & $3217(2)$ & $5040(3)$ & $4241(5)$ & 19(1) \\
\hline$C(17)$ & $3756(2)$ & $5340(3)$ & $3352(5)$ & 19(1) \\
\hline$C(18)$ & $4735(2)$ & 4943(4) & 1919(6) & $30(1)$ \\
\hline$C(19)$ & $4266(2)$ & $3457(4)$ & $4012(6)$ & $30(1)$ \\
\hline $\mathrm{B}(1)$ & $1725(2)$ & $7652(4)$ & $4147(7)$ & $22(1)$ \\
\hline
\end{tabular}


Table A-3. Bond lengths $[\AA ̊]$ and angles $\left[{ }^{\circ}\right]$ for $\mathbf{2 . 3 9}$.

\begin{tabular}{ll}
\hline$F(1)-B(1)$ & $1.395(5)$ \\
$F(2)-B(1)$ & $1.383(5)$ \\
$O(1)-C(11)$ & $1.222(5)$ \\
$O(2)-C(14)$ & $1.217(5)$ \\
$N(1)-C(1)$ & $1.351(5)$ \\
$N(1)-C(4)$ & $1.405(5)$ \\
$N(1)-B(1)$ & $1.535(5)$ \\
$N(2)-C(9)$ & $1.355(5)$ \\
$N(2)-C(6)$ & $1.402(5)$ \\
$N(2)-B(1)$ & $1.533(6)$ \\
$N(3)-C(17)$ & $1.322(4)$ \\
$N(3)-C(19)$ & $1.462(5)$ \\
$N(3)-C(18)$ & $1.466(5)$ \\
$C(1)-C(2)$ & $1.406(5)$ \\
$C(1)-C(10)$ & $1.498(5)$ \\
$C(2)-C(3)$ & $1.419(5)$ \\
$C(2)-C(11)$ & $1.446(6)$ \\
$C(3)-C(4)$ & $1.402(5)$ \\
$C(3)-C(12)$ & $1.494(5)$ \\
$C(4)-C(5)$ & $1.432(5)$ \\
$C(5)-C(16)$ & $1.400(5)$ \\
$C(5)-C(6)$ & $1.441(5)$ \\
$C(6)-C(7)$ & $1.402(5)$ \\
$C(7)-C(8)$ & $1.421(5)$ \\
$C(7)-C(13)$ & $1.501(5)$ \\
$C(8)-C(9)$ & $1.396(6)$ \\
$C(8)-C(14)$ & $1.445(5)$ \\
$C(9)-C(15)$ & $1.499(5)$ \\
$C(10)-H(10 A)-H(10 B)$ & 0.9800 \\
$C(10)$ & 0.9800 \\
$C(11 A)$ & 0.9800 \\
$C$ & \\
$C$ & \\
$C$ &
\end{tabular}




\begin{tabular}{|c|c|}
\hline$C(12)-H(12 B)$ & 0.9800 \\
\hline$C(12)-H(12 C)$ & 0.9800 \\
\hline$C(13)-H(13 A)$ & 0.9800 \\
\hline$C(13)-H(13 B)$ & 0.9800 \\
\hline$C(13)-H(13 C)$ & 0.9800 \\
\hline$C(14)-H(14 A)$ & 0.9500 \\
\hline$C(15)-H(15 A)$ & 0.9800 \\
\hline$C(15)-H(15 B)$ & 0.9800 \\
\hline$C(15)-H(15 C)$ & 0.9800 \\
\hline$C(16)-C(17)$ & $1.389(5)$ \\
\hline$C(16)-H(16 A)$ & 0.9500 \\
\hline$C(17)-H(17 A)$ & 0.9500 \\
\hline $\mathrm{C}(18)-\mathrm{H}(18 \mathrm{~A})$ & 0.9800 \\
\hline $\mathrm{C}(18)-\mathrm{H}(18 \mathrm{~B})$ & 0.9800 \\
\hline $\mathrm{C}(18)-\mathrm{H}(18 \mathrm{C})$ & 0.9800 \\
\hline$C(19)-H(19 A)$ & 0.9800 \\
\hline $\mathrm{C}(19)-\mathrm{H}(19 \mathrm{~B})$ & 0.9800 \\
\hline$C(19)-H(19 C)$ & 0.9800 \\
\hline$C(1)-N(1)-C(4)$ & $108.9(3)$ \\
\hline$C(1)-N(1)-B(1)$ & $125.0(3)$ \\
\hline$C(4)-N(1)-B(1)$ & $124.4(3)$ \\
\hline$C(9)-N(2)-C(6)$ & $108.4(3)$ \\
\hline$C(9)-N(2)-B(1)$ & $125.9(3)$ \\
\hline$C(6)-N(2)-B(1)$ & $125.2(3)$ \\
\hline$C(17)-N(3)-C(19)$ & $122.1(3)$ \\
\hline$C(17)-N(3)-C(18)$ & $120.4(3)$ \\
\hline$C(19)-N(3)-C(18)$ & $116.8(3)$ \\
\hline$N(1)-C(1)-C(2)$ & $108.8(3)$ \\
\hline$N(1)-C(1)-C(10)$ & $122.9(3)$ \\
\hline$C(2)-C(1)-C(10)$ & $128.2(4)$ \\
\hline$C(1)-C(2)-C(3)$ & 107.7(3) \\
\hline$C(1)-C(2)-C(11)$ & $122.7(4)$ \\
\hline$C(3)-C(2)-C(11)$ & $129.6(3)$ \\
\hline$C(4)-C(3)-C(2)$ & $106.4(3)$ \\
\hline
\end{tabular}




\begin{tabular}{|c|c|}
\hline$C(4)-C(3)-C(12)$ & $129.1(3)$ \\
\hline$C(2)-C(3)-C(12)$ & $124.4(3)$ \\
\hline$C(3)-C(4)-N(1)$ & $108.1(3)$ \\
\hline$C(3)-C(4)-C(5)$ & $131.9(3)$ \\
\hline$N(1)-C(4)-C(5)$ & $119.9(3)$ \\
\hline$C(16)-C(5)-C(4)$ & 121.1(3) \\
\hline$C(16)-C(5)-C(6)$ & $120.7(4)$ \\
\hline$C(4)-C(5)-C(6)$ & $118.2(3)$ \\
\hline$N(2)-C(6)-C(7)$ & $108.3(3)$ \\
\hline$N(2)-C(6)-C(5)$ & $119.6(3)$ \\
\hline$C(7)-C(6)-C(5)$ & $132.0(4)$ \\
\hline$C(6)-C(7)-C(8)$ & $106.3(3)$ \\
\hline$C(6)-C(7)-C(13)$ & $129.5(3)$ \\
\hline$C(8)-C(7)-C(13)$ & $123.6(3)$ \\
\hline$C(9)-C(8)-C(7)$ & $107.6(3)$ \\
\hline$C(9)-C(8)-C(14)$ & $123.4(4)$ \\
\hline$C(7)-C(8)-C(14)$ & $129.0(4)$ \\
\hline$N(2)-C(9)-C(8)$ & $109.2(3)$ \\
\hline$N(2)-C(9)-C(15)$ & $122.6(4)$ \\
\hline$C(8)-C(9)-C(15)$ & $128.2(4)$ \\
\hline$C(1)-C(10)-H(10 A)$ & 109.5 \\
\hline$C(1)-C(10)-H(10 B)$ & 109.5 \\
\hline$H(10 A)-C(10)-H(10 B)$ & 109.5 \\
\hline$C(1)-C(10)-H(10 C)$ & 109.5 \\
\hline$H(10 A)-C(10)-H(10 C)$ & 109.5 \\
\hline$H(10 B)-C(10)-H(10 C)$ & 109.5 \\
\hline $\mathrm{O}(1)-\mathrm{C}(11)-\mathrm{C}(2)$ & $127.1(4)$ \\
\hline $\mathrm{O}(1)-\mathrm{C}(11)-\mathrm{H}(11 \mathrm{~A})$ & 116.5 \\
\hline$C(2)-C(11)-H(11 A)$ & 116.5 \\
\hline$C(3)-C(12)-H(12 A)$ & 109.5 \\
\hline$C(3)-C(12)-H(12 B)$ & 109.5 \\
\hline$H(12 A)-C(12)-H(12 B)$ & 109.5 \\
\hline$C(3)-C(12)-H(12 C)$ & 109.5 \\
\hline$H(12 A)-C(12)-H(12 C)$ & 109.5 \\
\hline $\mathrm{H}(12 \mathrm{~B})-\mathrm{C}(12)-\mathrm{H}(12 \mathrm{C})$ & 109.5 \\
\hline
\end{tabular}




\begin{tabular}{|c|c|}
\hline$C(7)-C(13)-H(13 A)$ & 109.5 \\
\hline$C(7)-C(13)-H(13 B)$ & 109.5 \\
\hline$H(13 A)-C(13)-H(13 B)$ & 109.5 \\
\hline$C(7)-C(13)-H(13 C)$ & 109.5 \\
\hline$H(13 A)-C(13)-H(13 C)$ & 109.5 \\
\hline$H(13 B)-C(13)-H(13 C)$ & 109.5 \\
\hline$O(2)-C(14)-C(8)$ & $126.4(4)$ \\
\hline $\mathrm{O}(2)-\mathrm{C}(14)-\mathrm{H}(14 \mathrm{~A})$ & 116.8 \\
\hline$C(8)-C(14)-H(14 A)$ & 116.8 \\
\hline$C(9)-C(15)-H(15 A)$ & 109.5 \\
\hline$C(9)-C(15)-H(15 B)$ & 109.5 \\
\hline$H(15 A)-C(15)-H(15 B)$ & 109.5 \\
\hline$C(9)-C(15)-H(15 C)$ & 109.5 \\
\hline$H(15 A)-C(15)-H(15 C)$ & 109.5 \\
\hline$H(15 B)-C(15)-H(15 C)$ & 109.5 \\
\hline$C(17)-C(16)-C(5)$ & $121.8(4)$ \\
\hline$C(17)-C(16)-H(16 A)$ & 119.1 \\
\hline$C(5)-C(16)-H(16 A)$ & 119.1 \\
\hline$N(3)-C(17)-C(16)$ & $125.1(4)$ \\
\hline$N(3)-C(17)-H(17 A)$ & 117.4 \\
\hline$C(16)-C(17)-H(17 A)$ & 117.4 \\
\hline$N(3)-C(18)-H(18 A)$ & 109.5 \\
\hline$N(3)-C(18)-H(18 B)$ & 109.5 \\
\hline$H(18 A)-C(18)-H(18 B)$ & 109.5 \\
\hline$N(3)-C(18)-H(18 C)$ & 109.5 \\
\hline$H(18 A)-C(18)-H(18 C)$ & 109.5 \\
\hline$H(18 B)-C(18)-H(18 C)$ & 109.5 \\
\hline$N(3)-C(19)-H(19 A)$ & 109.5 \\
\hline$N(3)-C(19)-H(19 B)$ & 109.5 \\
\hline$H(19 A)-C(19)-H(19 B)$ & 109.5 \\
\hline$N(3)-C(19)-H(19 C)$ & 109.5 \\
\hline$H(19 A)-C(19)-H(19 C)$ & 109.5 \\
\hline$H(19 B)-C(19)-H(19 C)$ & 109.5 \\
\hline$F(2)-B(1)-F(1)$ & $109.2(4)$ \\
\hline$F(2)-B(1)-N(2)$ & 109.9(3) \\
\hline
\end{tabular}




$\begin{array}{ll}F(1)-B(1)-N(2) & 110.2(3) \\ F(2)-B(1)-N(1) & 110.8(4) \\ F(1)-B(1)-N(1) & 109.6(4) \\ N(2)-B(1)-N(1) & 107.0(3)\end{array}$

Symmetry transformations used to generate equivalent atoms: 
Table A-4. Anisotropic displacement parameters $\left(\AA^{2} \times 10^{3}\right)$ for 2.39. The anisotropic displacement factor exponent takes the form: $-2 p^{2}\left[h^{2} a * 2 u^{11}+\ldots+2 h k a * b * u^{12}\right]$

\begin{tabular}{|c|c|c|c|c|c|c|}
\hline & $\mathrm{U}^{11}$ & U22 & u33 & $u^{23}$ & U13 & $u^{12}$ \\
\hline$F(1)$ & $32(2)$ & $38(2)$ & $43(2)$ & $17(1)$ & $-15(1)$ & $-7(1)$ \\
\hline$F(2)$ & $28(1)$ & $22(1)$ & $68(2)$ & $-7(1)$ & $20(1)$ & $3(1)$ \\
\hline $\mathrm{O}(1)$ & $36(2)$ & $21(2)$ & $57(2)$ & $10(2)$ & $-2(2)$ & $-9(2)$ \\
\hline$O(2)$ & $23(2)$ & $41(2)$ & $84(3)$ & $-23(2)$ & $4(2)$ & $-7(2)$ \\
\hline $\mathrm{N}(1)$ & $17(2)$ & $17(2)$ & $27(2)$ & $1(2)$ & $0(2)$ & $2(1)$ \\
\hline$N(2)$ & $19(2)$ & $14(2)$ & $23(2)$ & $-1(2)$ & $1(2)$ & $2(1)$ \\
\hline$N(3)$ & $20(2)$ & $20(2)$ & $26(2)$ & $2(2)$ & $2(2)$ & $2(2)$ \\
\hline$C(1)$ & $18(2)$ & $21(2)$ & $31(3)$ & $0(2)$ & $2(2)$ & $2(2)$ \\
\hline$C(2)$ & $22(2)$ & $21(2)$ & $25(2)$ & $1(2)$ & $-3(2)$ & $-1(2)$ \\
\hline$C(3)$ & $22(2)$ & $21(2)$ & $21(2)$ & $1(2)$ & $-1(2)$ & $1(2)$ \\
\hline$C(4)$ & $17(2)$ & $17(2)$ & $20(2)$ & $-1(2)$ & $-1(2)$ & $4(2)$ \\
\hline$C(5)$ & $19(2)$ & $22(2)$ & $18(2)$ & $-2(2)$ & $2(2)$ & $1(2)$ \\
\hline$C(6)$ & $18(2)$ & $20(2)$ & $20(2)$ & $-3(2)$ & $1(2)$ & $3(2)$ \\
\hline$C(7)$ & $19(2)$ & $20(2)$ & $22(2)$ & $-2(2)$ & $0(2)$ & $1(2)$ \\
\hline$C(8)$ & $19(2)$ & $23(2)$ & $28(2)$ & $-6(2)$ & $5(2)$ & $-3(2)$ \\
\hline$C(9)$ & $24(2)$ & $20(2)$ & $23(2)$ & $-1(2)$ & $7(2)$ & $-2(2)$ \\
\hline$C(10)$ & $22(2)$ & $24(2)$ & $54(3)$ & $-4(2)$ & $0(2)$ & $4(2)$ \\
\hline$C(11)$ & $25(3)$ & $33(3)$ & $40(3)$ & $4(2)$ & $-4(2)$ & $-4(2)$ \\
\hline$C(12)$ & $23(2)$ & $19(2)$ & $43(3)$ & $1(2)$ & $-6(2)$ & $-1(2)$ \\
\hline$C(13)$ & $20(3)$ & $31(2)$ & $39(3)$ & $-10(2)$ & $-5(2)$ & $-2(2)$ \\
\hline$C(14)$ & $32(3)$ & $28(2)$ & $46(3)$ & $-10(2)$ & $5(3)$ & $-4(2)$ \\
\hline$C(15)$ & $30(3)$ & $21(2)$ & $35(3)$ & $3(2)$ & $5(2)$ & $1(2)$ \\
\hline$C(16)$ & $16(2)$ & $15(2)$ & $27(2)$ & $2(2)$ & $2(2)$ & $2(2)$ \\
\hline$C(17)$ & $19(2)$ & $16(2)$ & $23(2)$ & $-1(2)$ & $-1(2)$ & $2(2)$ \\
\hline$C(18)$ & $21(2)$ & $35(3)$ & $33(3)$ & $5(2)$ & $9(2)$ & $3(2)$ \\
\hline$C(19)$ & $26(3)$ & $31(2)$ & $33(3)$ & $5(2)$ & $5(2)$ & $7(2)$ \\
\hline $\mathrm{B}(1)$ & $20(3)$ & $19(2)$ & $28(3)$ & $0(2)$ & $-1(2)$ & $0(2)$ \\
\hline
\end{tabular}


Table A-5. Hydrogen coordinates $\left(\times 10^{4}\right)$ and isotropic displacement parameters $\left(\AA^{2} \times 10^{3}\right)$ for 2.39

\begin{tabular}{|c|c|c|c|c|}
\hline & $x$ & $y$ & $z$ & $U(e q)$ \\
\hline$H(10 A)$ & 456 & 6786 & 3597 & 50 \\
\hline $\mathrm{H}(10 \mathrm{~B})$ & 480 & 7022 & 5731 & 50 \\
\hline $\mathrm{H}(10 \mathrm{C})$ & 165 & 5836 & 4967 & 50 \\
\hline$H(11 A)$ & 324 & 4007 & 5477 & 39 \\
\hline $\mathrm{H}(12 \mathrm{~A})$ & 2449 & 3092 & 5773 & 43 \\
\hline $\mathrm{H}(12 \mathrm{~B})$ & 2362 & 3076 & 3622 & 43 \\
\hline $\mathrm{H}(12 \mathrm{C})$ & 1838 & 2545 & 4906 & 43 \\
\hline$H(13 A)$ & 3949 & 6475 & 6292 & 45 \\
\hline $\mathrm{H}(13 \mathrm{~B})$ & 4150 & 7805 & 6798 & 45 \\
\hline$H(13 C)$ & 4319 & 7266 & 4857 & 45 \\
\hline $\mathrm{H}(14 \mathrm{~A})$ & 3474 & 10756 & 5140 & 42 \\
\hline$H(15 A)$ & 1936 & 9995 & 3386 & 43 \\
\hline$H(15 B)$ & 2535 & 10792 & 3705 & 43 \\
\hline $\mathrm{H}(15 \mathrm{C})$ & 2108 & 10437 & 5382 & 43 \\
\hline $\mathrm{H}(16 \mathrm{~A})$ & 3166 & 4251 & 4682 & 23 \\
\hline$H(17 A)$ & 3780 & 6110 & 2826 & 23 \\
\hline $\mathrm{H}(18 \mathrm{~A})$ & 4671 & 5752 & 1460 & 45 \\
\hline $\mathrm{H}(18 \mathrm{~B})$ & 4734 & 4380 & 906 & 45 \\
\hline $\mathrm{H}(18 \mathrm{C})$ & 5130 & 4901 & 2549 & 45 \\
\hline$H(19 A)$ & 4118 & 3505 & 5262 & 45 \\
\hline $\mathrm{H}(19 \mathrm{~B})$ & 4691 & 3170 & 4008 & 45 \\
\hline $\mathrm{H}(19 \mathrm{C})$ & 4007 & 2905 & 3325 & 45 \\
\hline
\end{tabular}


Table A-1. Crystal data and structure refinement for $\mathbf{2 . 3 9}$

Empirical formula

Formula weight

Temperature

Wavelength

Crystal system

Space group

Unit cell dimensions

Volume

Z

Density (calculated)

Absorption coefficient

$F(000)$

Crystal size

Diffractometer

Theta range for data collection

Index ranges

Reflections collected

Independent reflections

Completeness to theta $=25.242^{\circ}$

Absorption correction

Max. and min. transmission

Refinement method
$\mathrm{C}_{19} \mathrm{H}_{22} \mathrm{BF}_{2} \mathrm{~N}_{3} \mathrm{O}_{2}$

373.20

$147(2) \mathrm{K}$

$0.71073 \AA$

Orthorhombic

$\mathrm{P}$ n a 21

$a=21.7917(19) \AA \quad \alpha=90^{\circ}$.

$b=11.2285(10) \AA \quad \beta=90^{\circ}$.

$c=7.3897(6) \AA \quad \gamma=90^{\circ}$.

$1808.2(3) \AA^{3}$

4

$1.371 \mathrm{Mg} / \mathrm{m}^{3}$

$0.103 \mathrm{~mm}^{-1}$

784

$0.190 \times 0.120 \times 0.070 \mathrm{~mm}^{3}$

Bruker-Nonius Kappa-CCD

2.040 to $27.504^{\circ}$.

$-28<=h<=18,-13<=\mathrm{k}<=14,-9<=\mid<=9$

11348

$4098[R$ (int) $=0.0602]$

$99.8 \%$

Semi-empirical from equivalents

0.7456 and 0.6423

Full-matrix least-squares on $\mathrm{F}^{2}$ 
Data / restraints / parameters

Goodness-of-fit on $F^{2}$

Final $\mathrm{R}$ indices [ $\mathrm{I}>2 \operatorname{sigma}(\mathrm{I})$ ]

$\mathrm{R}$ indices (all data)

Extinction coefficient

Largest diff. peak and hole
4098 / 1 / 250

0.967

$\mathrm{R} 1=0.0492, \mathrm{wR} 2=0.0895$

$\mathrm{R} 1=0.1199, \mathrm{wR} 2=0.1116$

$\mathrm{n} / \mathrm{a}$

0.206 and -0.251 e. $\AA^{-3}$ 
Table A-2. Atomic coordinates $\left(\times 10^{4}\right)$ and equivalent isotropic displacement parameters $\left(\AA^{2} \times 10^{3}\right)$ for 2.39. $U(e q)$ is defined as one third of the trace of the orthogonalized $U^{i j}$ tensor.

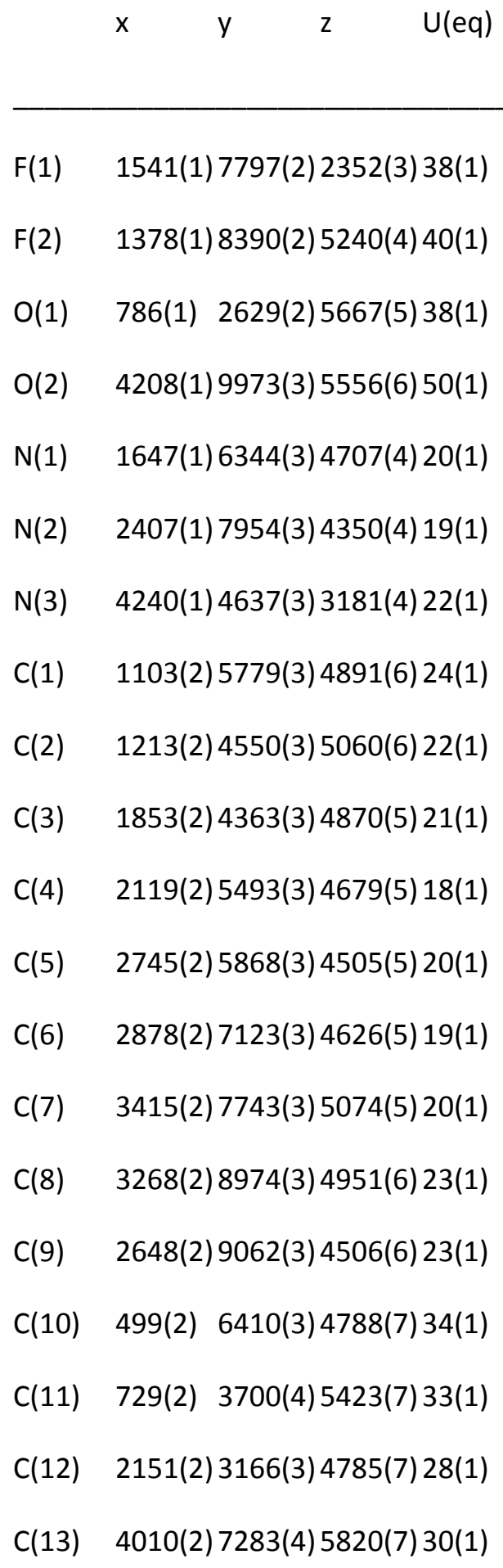


$C(14) \quad 3661(2) 9994(4) 5225(6) 35(1)$

$C(15) \quad 2275(2) 10167(3)$ 4220(6) 29(1)

$C(16) \quad 3217(2) 5040(3) 4241(5)$ 19(1)

C(17) 3756(2) 5340(3) 3352(5) 19(1)

$C(18) \quad 4735(2) 4943(4) 1919(6) 30(1)$

$C(19) \quad 4266(2) 3457(4) 4012(6) 30(1)$

$B(1) \quad 1725(2) 7652(4) 4147(7) 22(1)$ 
Table A-3. Bond lengths $[\AA ̊ \AA]$ and angles $\left[{ }^{\circ}\right]$ for $\mathbf{2 . 3 9}$.

\begin{tabular}{|c|c|}
\hline$F(1)-B(1)$ & $1.395(5)$ \\
\hline$F(2)-B(1)$ & $1.383(5)$ \\
\hline $\mathrm{O}(1)-\mathrm{C}(11)$ & $1.222(5)$ \\
\hline $\mathrm{O}(2)-\mathrm{C}(14)$ & $1.217(5)$ \\
\hline$N(1)-C(1)$ & $1.351(5)$ \\
\hline$N(1)-C(4)$ & $1.405(5)$ \\
\hline$N(1)-B(1)$ & $1.535(5)$ \\
\hline$N(2)-C(9)$ & $1.355(5)$ \\
\hline$N(2)-C(6)$ & $1.402(5)$ \\
\hline$N(2)-B(1)$ & $1.533(6)$ \\
\hline$N(3)-C(17)$ & $1.322(4)$ \\
\hline$N(3)-C(19)$ & $1.462(5)$ \\
\hline$N(3)-C(18)$ & $1.466(5)$ \\
\hline$C(1)-C(2)$ & $1.406(5)$ \\
\hline$C(1)-C(10)$ & $1.498(5)$ \\
\hline$C(2)-C(3)$ & $1.419(5)$ \\
\hline$C(2)-C(11)$ & $1.446(6)$ \\
\hline$C(3)-C(4)$ & $1.402(5)$ \\
\hline$C(3)-C(12)$ & $1.494(5)$ \\
\hline$C(4)-C(5)$ & $1.432(5)$ \\
\hline$C(5)-C(16)$ & $1.400(5)$ \\
\hline$C(5)-C(6)$ & $1.441(5)$ \\
\hline$C(6)-C(7)$ & $1.402(5)$ \\
\hline
\end{tabular}




\begin{tabular}{|c|c|}
\hline$C(7)-C(8)$ & $1.421(5)$ \\
\hline$C(7)-C(13)$ & $1.501(5)$ \\
\hline$C(8)-C(9)$ & $1.396(6)$ \\
\hline$C(8)-C(14)$ & $1.445(5)$ \\
\hline$C(9)-C(15)$ & $1.499(5)$ \\
\hline$C(10)-H(10 A)$ & 0.9800 \\
\hline $\mathrm{C}(10)-\mathrm{H}(10 \mathrm{~B})$ & 0.9800 \\
\hline$C(10)-H(10 C)$ & 0.9800 \\
\hline$C(11)-H(11 A)$ & 0.9500 \\
\hline$C(12)-H(12 A)$ & 0.9800 \\
\hline $\mathrm{C}(12)-\mathrm{H}(12 \mathrm{~B})$ & 0.9800 \\
\hline $\mathrm{C}(12)-\mathrm{H}(12 \mathrm{C})$ & 0.9800 \\
\hline$C(13)-H(13 A)$ & 0.9800 \\
\hline$C(13)-H(13 B)$ & 0.9800 \\
\hline $\mathrm{C}(13)-\mathrm{H}(13 \mathrm{C})$ & 0.9800 \\
\hline$C(14)-H(14 A)$ & 0.9500 \\
\hline$C(15)-H(15 A)$ & 0.9800 \\
\hline $\mathrm{C}(15)-\mathrm{H}(15 \mathrm{~B})$ & 0.9800 \\
\hline $\mathrm{C}(15)-\mathrm{H}(15 \mathrm{C})$ & 0.9800 \\
\hline$C(16)-C(17)$ & $1.389(5)$ \\
\hline$C(16)-H(16 A)$ & 0.9500 \\
\hline$C(17)-H(17 A)$ & 0.9500 \\
\hline $\mathrm{C}(18)-\mathrm{H}(18 \mathrm{~A})$ & 0.9800 \\
\hline $\mathrm{C}(18)-\mathrm{H}(18 \mathrm{~B})$ & 0.9800 \\
\hline $\mathrm{C}(18)-\mathrm{H}(18 \mathrm{C})$ & 0.9800 \\
\hline
\end{tabular}




$$
\begin{array}{cc}
\mathrm{C}(19)-\mathrm{H}(19 \mathrm{~A}) & 0.9800 \\
\mathrm{C}(19)-\mathrm{H}(19 \mathrm{~B}) & 0.9800 \\
\mathrm{C}(19)-\mathrm{H}(19 \mathrm{C}) & 0.9800
\end{array}
$$

$\begin{array}{ll}C(1)-N(1)-C(4) & 108.9(3) \\ C(1)-N(1)-B(1) & 125.0(3) \\ C(4)-N(1)-B(1) & 124.4(3) \\ C(9)-N(2)-C(6) & 108.4(3) \\ C(9)-N(2)-B(1) & 125.9(3) \\ C(6)-N(2)-B(1) & 125.2(3) \\ C(17)-N(3)-C(19) & 122.1(3) \\ C(17)-N(3)-C(18) & 120.4(3) \\ C(19)-N(3)-C(18) & 116.8(3) \\ N(1)-C(1)-C(2) & 108.8(3) \\ N(1)-C(1)-C(10) & 122.9(3) \\ C(2)-C(1)-C(10) & 128.2(4) \\ C(1)-C(2)-C(3) & 107.7(3) \\ C(1)-C(2)-C(11) & 122.7(4) \\ C(3)-C(2)-C(11) & 129.6(3) \\ C(4)-C(3)-C(2) & 106.4(3) \\ C(4)-C(3)-C(12) & 129.1(3) \\ C(2)-C(3)-C(12) & 124.4(3) \\ C(3)-C(4)-N(1) & 108.1(3) \\ C(3)-C(4)-C(5) & 131.9(3) \\ N(1)-C(4)-C(5) & \\ C .9(3)\end{array}$




\begin{tabular}{|c|c|}
\hline$C(16)-C(5)-C(4)$ & $121.1(3)$ \\
\hline$C(16)-C(5)-C(6)$ & $120.7(4)$ \\
\hline$C(4)-C(5)-C(6)$ & $118.2(3)$ \\
\hline$N(2)-C(6)-C(7)$ & $108.3(3)$ \\
\hline$N(2)-C(6)-C(5)$ & 119.6(3) \\
\hline$C(7)-C(6)-C(5)$ & $132.0(4)$ \\
\hline$C(6)-C(7)-C(8)$ & $106.3(3)$ \\
\hline$C(6)-C(7)-C(13)$ & $129.5(3)$ \\
\hline$C(8)-C(7)-C(13)$ & $123.6(3)$ \\
\hline$C(9)-C(8)-C(7)$ & $107.6(3)$ \\
\hline$C(9)-C(8)-C(14)$ & $123.4(4)$ \\
\hline$C(7)-C(8)-C(14)$ & $129.0(4)$ \\
\hline$N(2)-C(9)-C(8)$ & $109.2(3)$ \\
\hline$N(2)-C(9)-C(15)$ & $122.6(4)$ \\
\hline$C(8)-C(9)-C(15)$ & $128.2(4)$ \\
\hline$C(1)-C(10)-H(10 A)$ & 109.5 \\
\hline$C(1)-C(10)-H(10 B)$ & 109.5 \\
\hline$H(10 A)-C(10)-H(10 B)$ & 109.5 \\
\hline$C(1)-C(10)-H(10 C)$ & 109.5 \\
\hline$H(10 A)-C(10)-H(10 C)$ & 109.5 \\
\hline$H(10 B)-C(10)-H(10 C)$ & 109.5 \\
\hline$O(1)-C(11)-C(2)$ & $127.1(4)$ \\
\hline$O(1)-C(11)-H(11 A)$ & 116.5 \\
\hline$C(2)-C(11)-H(11 A)$ & 116.5 \\
\hline$C(3)-C(12)-H(12 A)$ & 109.5 \\
\hline
\end{tabular}




\begin{tabular}{|c|c|}
\hline$C(3)-C(12)-H(12 B)$ & 109.5 \\
\hline$H(12 A)-C(12)-H(12 B)$ & 109.5 \\
\hline$C(3)-C(12)-H(12 C)$ & 109.5 \\
\hline$H(12 A)-C(12)-H(12 C)$ & 109.5 \\
\hline$H(12 B)-C(12)-H(12 C)$ & 109.5 \\
\hline$C(7)-C(13)-H(13 A)$ & 109.5 \\
\hline$C(7)-C(13)-H(13 B)$ & 109.5 \\
\hline$H(13 A)-C(13)-H(13 B)$ & 109.5 \\
\hline$C(7)-C(13)-H(13 C)$ & 109.5 \\
\hline$H(13 A)-C(13)-H(13 C)$ & 109.5 \\
\hline$H(13 B)-C(13)-H(13 C)$ & 109.5 \\
\hline$O(2)-C(14)-C(8)$ & $126.4(4)$ \\
\hline $\mathrm{O}(2)-\mathrm{C}(14)-\mathrm{H}(14 \mathrm{~A})$ & 116.8 \\
\hline$C(8)-C(14)-H(14 A)$ & 116.8 \\
\hline$C(9)-C(15)-H(15 A)$ & 109.5 \\
\hline$C(9)-C(15)-H(15 B)$ & 109.5 \\
\hline$H(15 A)-C(15)-H(15 B)$ & 109.5 \\
\hline$C(9)-C(15)-H(15 C)$ & 109.5 \\
\hline$H(15 A)-C(15)-H(15 C)$ & 109.5 \\
\hline$H(15 B)-C(15)-H(15 C)$ & 109.5 \\
\hline$C(17)-C(16)-C(5)$ & $121.8(4)$ \\
\hline$C(17)-C(16)-H(16 A)$ & 119.1 \\
\hline$C(5)-C(16)-H(16 A)$ & 119.1 \\
\hline$N(3)-C(17)-C(16)$ & $125.1(4)$ \\
\hline$N(3)-C(17)-H(17 A)$ & 117.4 \\
\hline
\end{tabular}




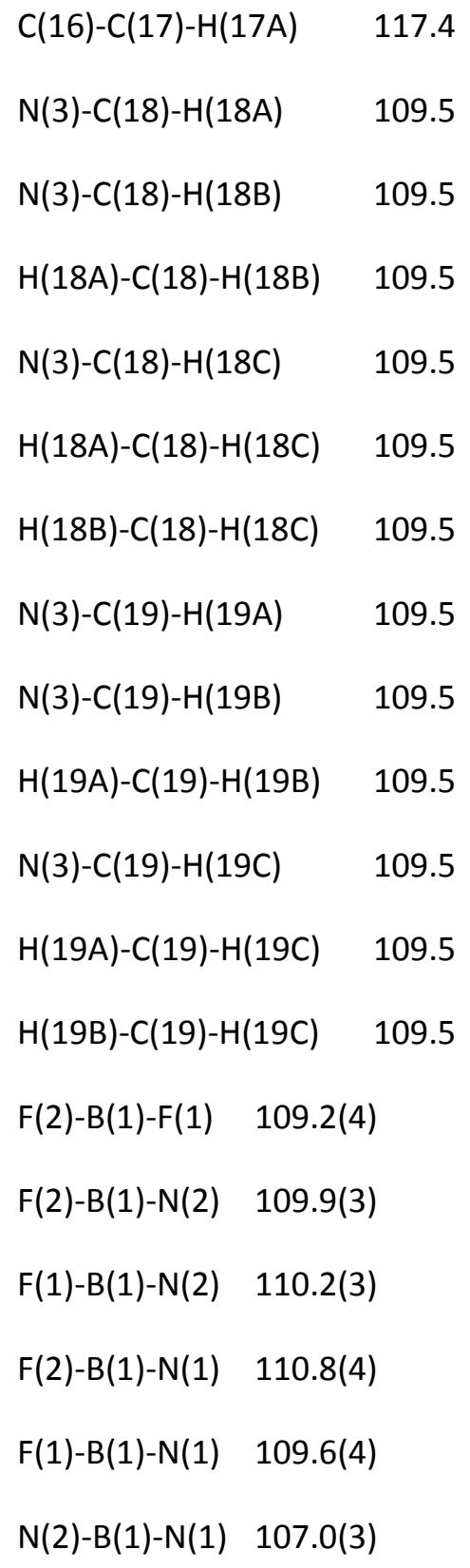


Table A-4. Anisotropic displacement parameters $\left(\AA^{2} \times 10^{3}\right)$ for 2.39. The anisotropic displacement factor exponent takes the form: -2$]^{2}\left[h^{2} a * 2 u^{11}+\ldots+2 h k a^{*} b^{*} u^{12}\right]$

$$
u^{11} \quad u^{22} \quad u^{33} \quad u^{23} \quad u^{13} \quad u^{12}
$$

\begin{tabular}{|c|c|c|c|c|c|c|}
\hline$F(1)$ & $32(2)$ & $38(2)$ & $43(2)$ & $17(1)$ & $-15(1)$ & $-7(1)$ \\
\hline$F(2)$ & $28(1)$ & $22(1)$ & $68(2)$ & $-7(1)$ & $20(1)$ & $3(1)$ \\
\hline $\mathrm{O}(1)$ & $36(2)$ & $21(2)$ & $57(2)$ & $10(2)$ & $-2(2)$ & $-9(2)$ \\
\hline$O(2)$ & $23(2)$ & $41(2)$ & $84(3)$ & $-23(2)$ & $4(2)$ & $-7(2)$ \\
\hline $\mathrm{N}(1)$ & $17(2)$ & $17(2)$ & $27(2)$ & $1(2)$ & $0(2)$ & $2(1)$ \\
\hline$N(2)$ & $19(2)$ & $14(2)$ & $23(2)$ & $-1(2)$ & $1(2)$ & $2(1)$ \\
\hline$N(3)$ & $20(2)$ & $20(2)$ & $26(2)$ & $2(2)$ & $2(2)$ & $2(2)$ \\
\hline$C(1)$ & $18(2)$ & $21(2)$ & $31(3)$ & $0(2)$ & $2(2)$ & $2(2)$ \\
\hline$C(2)$ & $22(2)$ & $21(2)$ & $25(2)$ & $1(2)$ & $-3(2)$ & $-1(2)$ \\
\hline$C(3)$ & $22(2)$ & $21(2)$ & $21(2)$ & $1(2)$ & $-1(2)$ & $1(2)$ \\
\hline$C(4)$ & $17(2)$ & $17(2)$ & $20(2)$ & $-1(2)$ & $-1(2)$ & $4(2)$ \\
\hline$C(5)$ & $19(2)$ & $22(2)$ & $18(2)$ & $-2(2)$ & $2(2)$ & $1(2)$ \\
\hline$C(6)$ & $18(2)$ & $20(2)$ & $20(2)$ & $-3(2)$ & $1(2)$ & $3(2)$ \\
\hline$C(7)$ & $19(2)$ & $20(2)$ & $22(2)$ & $-2(2)$ & $0(2)$ & $1(2)$ \\
\hline$C(8)$ & $19(2)$ & $23(2)$ & $28(2)$ & $-6(2)$ & $5(2)$ & $-3(2)$ \\
\hline$C(9)$ & $24(2)$ & $20(2)$ & $23(2)$ & $-1(2)$ & $7(2)$ & $-2(2)$ \\
\hline$C(10)$ & $22(2)$ & $24(2)$ & $54(3)$ & $-4(2)$ & $0(2)$ & $4(2)$ \\
\hline$C(11)$ & $25(3)$ & $33(3)$ & $40(3)$ & $4(2)$ & $-4(2)$ & $-4(2)$ \\
\hline$C(12)$ & $23(2)$ & $19(2)$ & $43(3)$ & $1(2)$ & $-6(2)$ & $-1(2)$ \\
\hline$C(13)$ & $20(3)$ & $31(2)$ & $39(3)$ & $-10(2)$ & $-5(2)$ & $-2(2)$ \\
\hline
\end{tabular}




$\begin{array}{lllllll}C(14) & 32(3) & 28(2) & 46(3) & -10(2) & 5(3) & -4(2) \\ C(15) & 30(3) & 21(2) & 35(3) & 3(2) & 5(2) & 1(2) \\ C(16) & 16(2) & 15(2) & 27(2) & 2(2) & 2(2) & 2(2) \\ C(17) & 19(2) & 16(2) & 23(2) & -1(2) & -1(2) & 2(2) \\ C(18) & 21(2) & 35(3) & 33(3) & 5(2) & 9(2) & 3(2) \\ C(19) & 26(3) & 31(2) & 33(3) & 5(2) & 5(2) & 7(2) \\ B(1) & 20(3) & 19(2) & 28(3) & 0(2) & -1(2) & 0(2)\end{array}$


Table A-5. Hydrogen coordinates $\left(\times 10^{4}\right)$ and isotropic displacement parameters $\left(\AA^{2} \times 10^{3}\right)$ for $\mathbf{2 . 3 9}$

\begin{tabular}{|c|c|c|c|c|}
\hline & $x$ & $y$ & z & $\mathrm{U}(\mathrm{eq})$ \\
\hline$H(10 A)$ & 456 & 6786 & 3597 & 50 \\
\hline$H(10 B)$ & 480 & 7022 & 5731 & 50 \\
\hline$H(10 C)$ & 165 & 5836 & 4967 & 50 \\
\hline$H(11 A)$ & 324 & 4007 & 5477 & 39 \\
\hline$H(12 A)$ & 2449 & 3092 & 5773 & 43 \\
\hline$H(12 B)$ & 2362 & 3076 & 3622 & 43 \\
\hline $\mathrm{H}(12 \mathrm{C})$ & 1838 & 2545 & 4906 & 43 \\
\hline$H(13 A)$ & 3949 & 6475 & 6292 & 45 \\
\hline$H(13 B)$ & 4150 & 7805 & 6798 & 45 \\
\hline$H(13 C)$ & 4319 & 7266 & 4857 & 45 \\
\hline$H(14 A)$ & 3474 & 10756 & 5140 & 42 \\
\hline$H(15 A)$ & 1936 & 9995 & 3386 & 43 \\
\hline$H(15 B)$ & 2535 & 10792 & 3705 & 43 \\
\hline$H(15 C)$ & 2108 & 10437 & 5382 & 43 \\
\hline$H(16 A)$ & 3166 & 4251 & 4682 & 23 \\
\hline$H(17 A)$ & 3780 & 6110 & 2826 & 23 \\
\hline$H(18 A)$ & 4671 & 5752 & 1460 & 45 \\
\hline$H(18 B)$ & 4734 & 4380 & 906 & 45 \\
\hline $\mathrm{H}(18 \mathrm{C})$ & 5130 & 4901 & 2549 & 45 \\
\hline
\end{tabular}




\begin{tabular}{|c|c|c|c|c|}
\hline$H(19 A)$ & 4118 & 3505 & 5262 & 45 \\
\hline $\mathrm{H}(19 \mathrm{~B})$ & 4691 & 3170 & 4008 & 45 \\
\hline $\mathrm{H}(19 \mathrm{C})$ & 4007 & 2905 & 3325 & 45 \\
\hline
\end{tabular}


APPENDIX B: NMR SPECTRA 


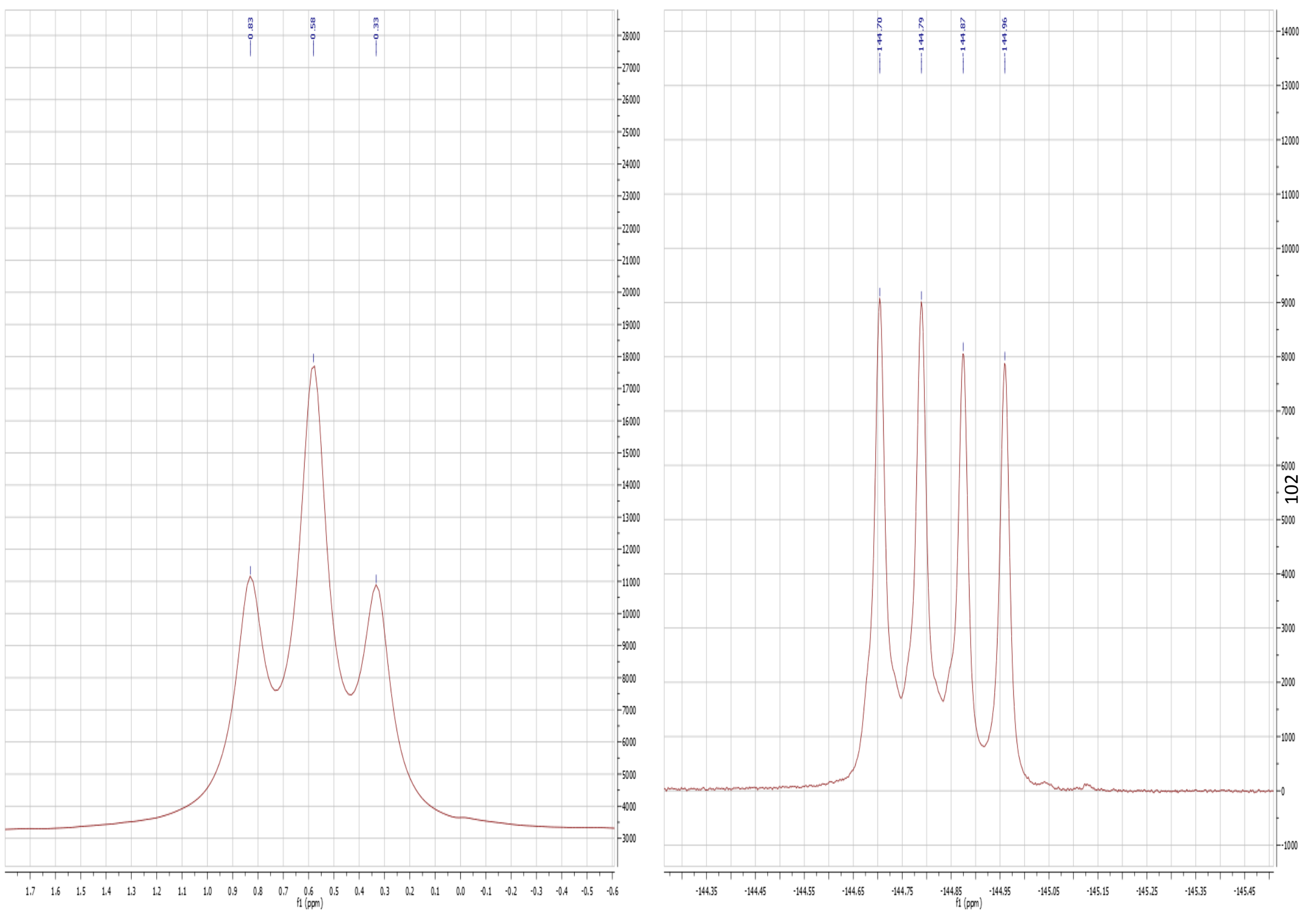




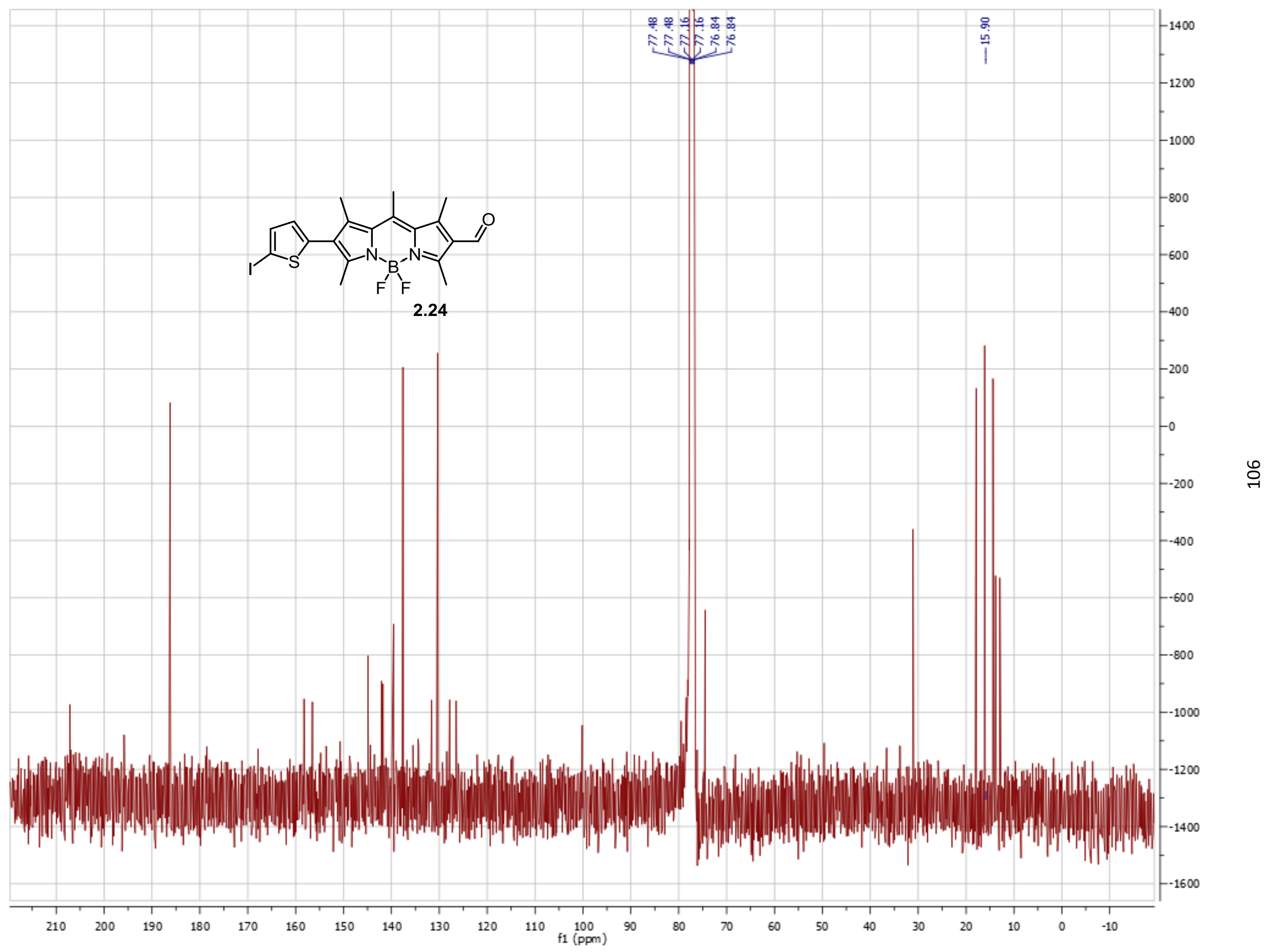




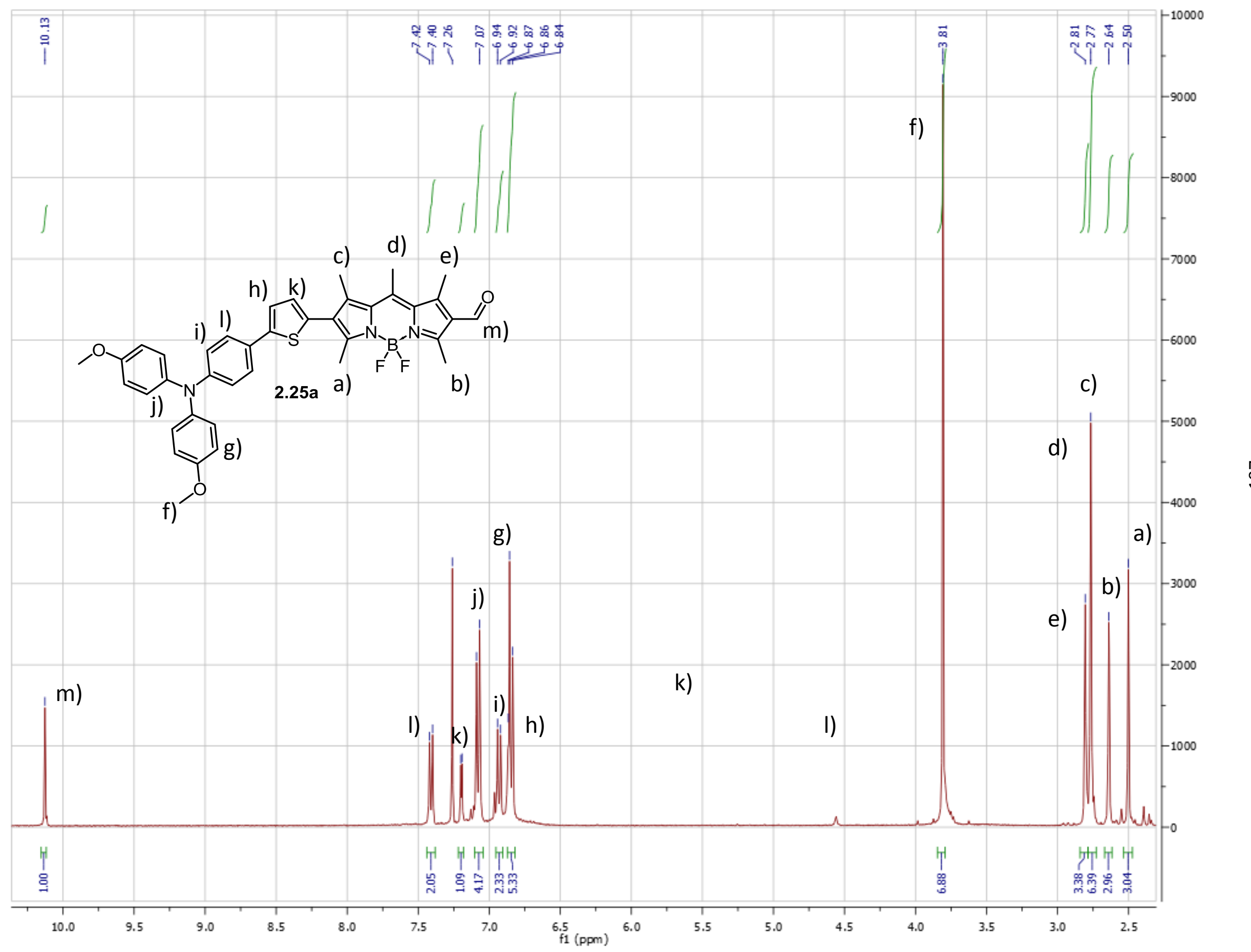



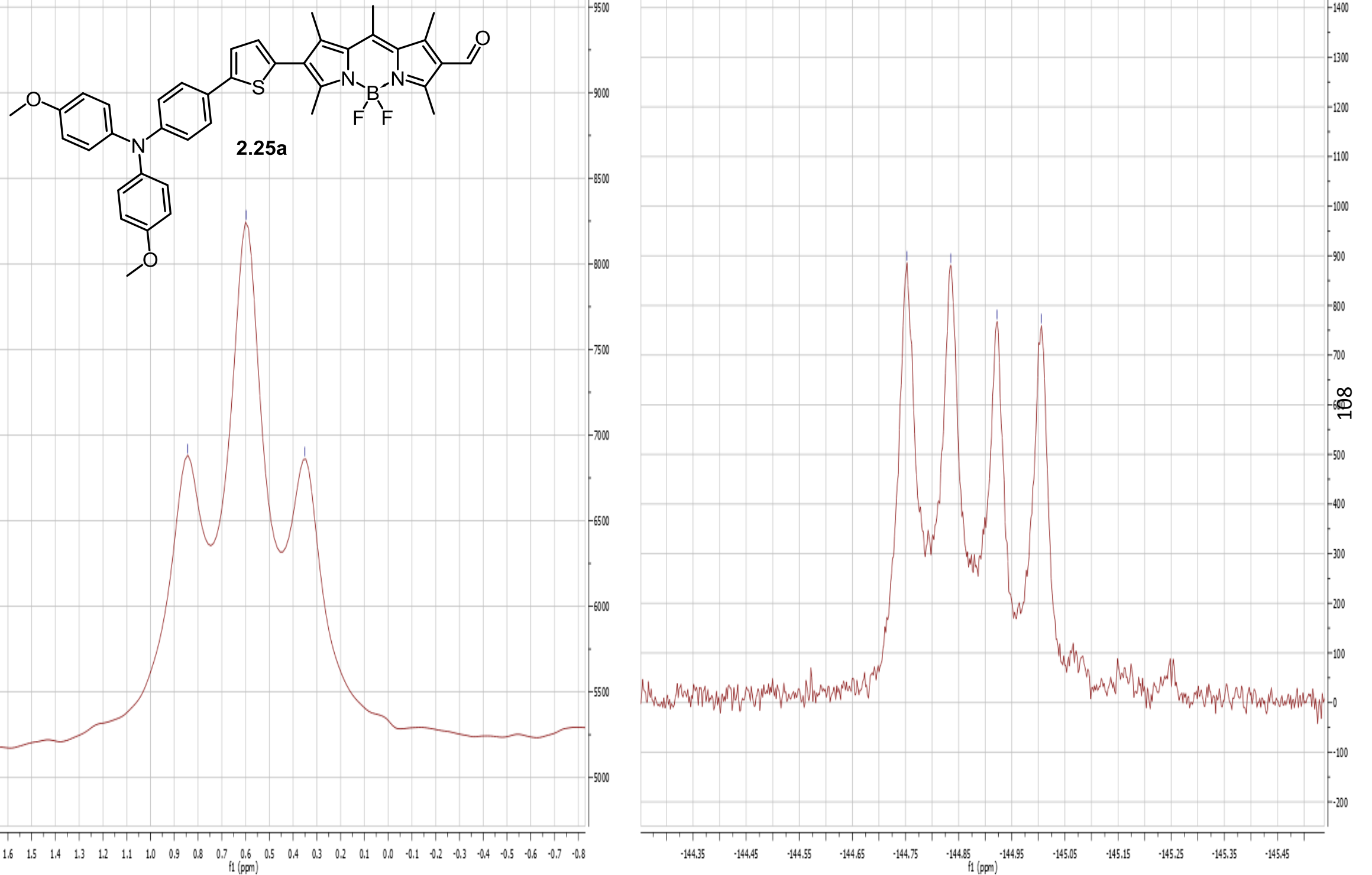


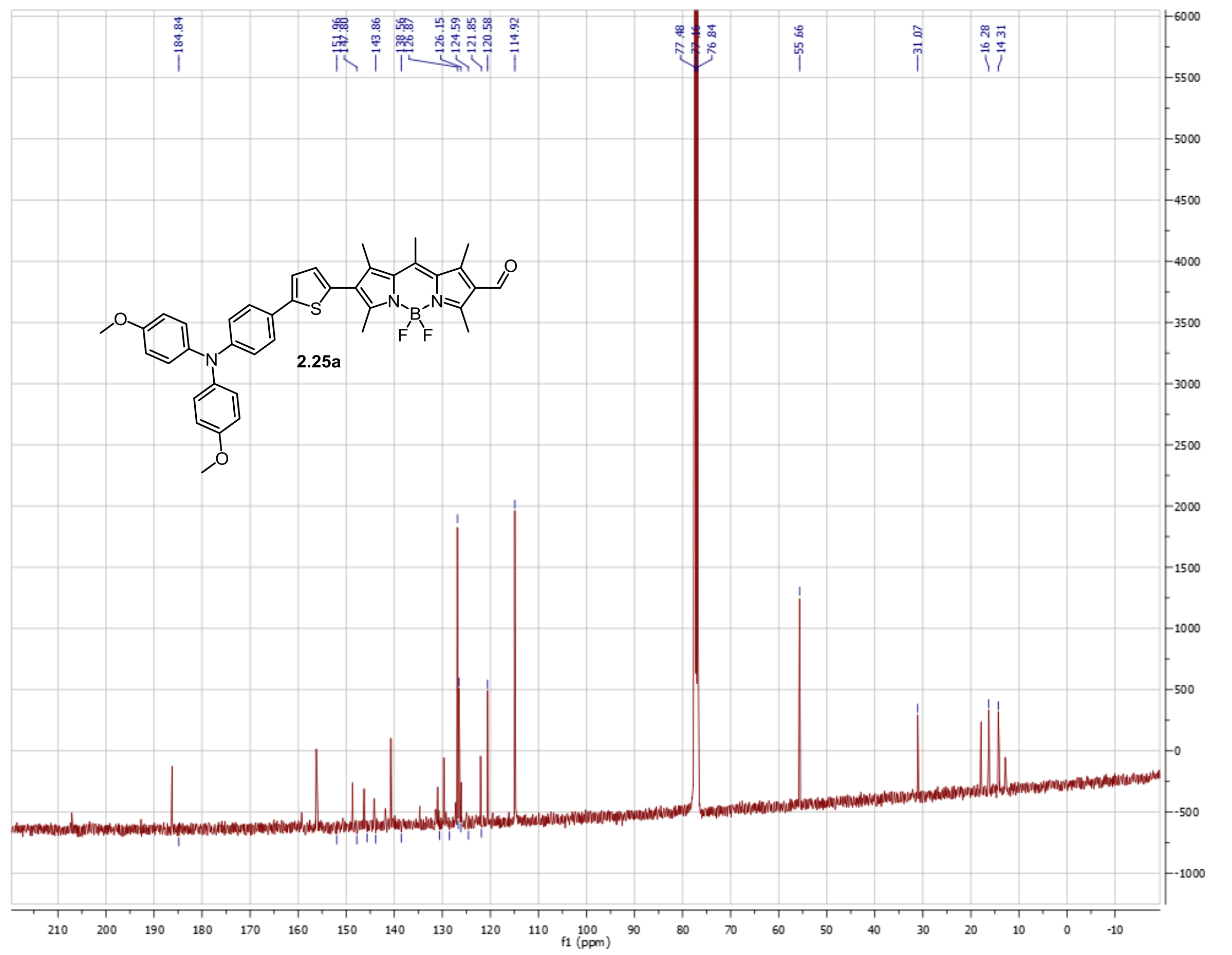

암 . 


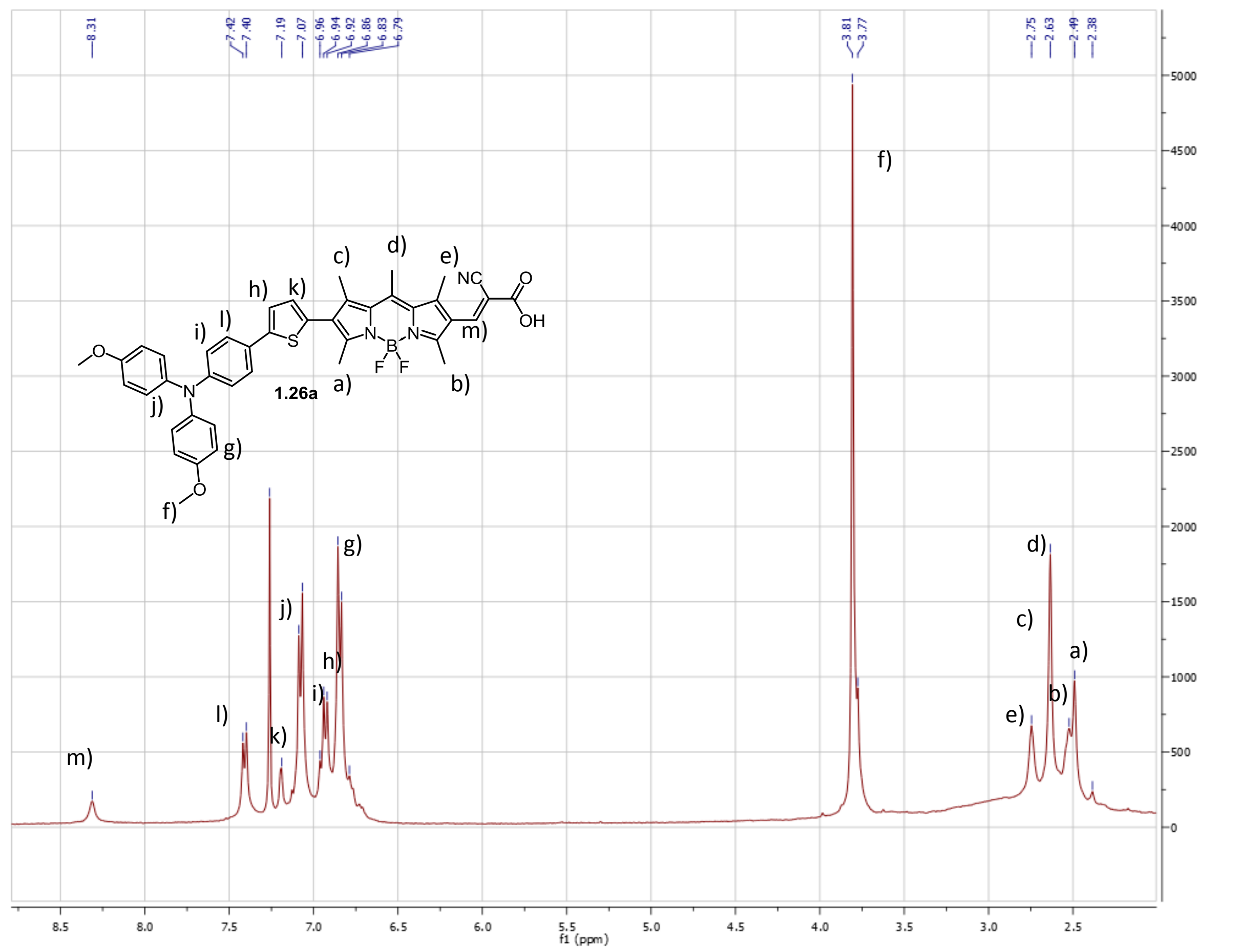




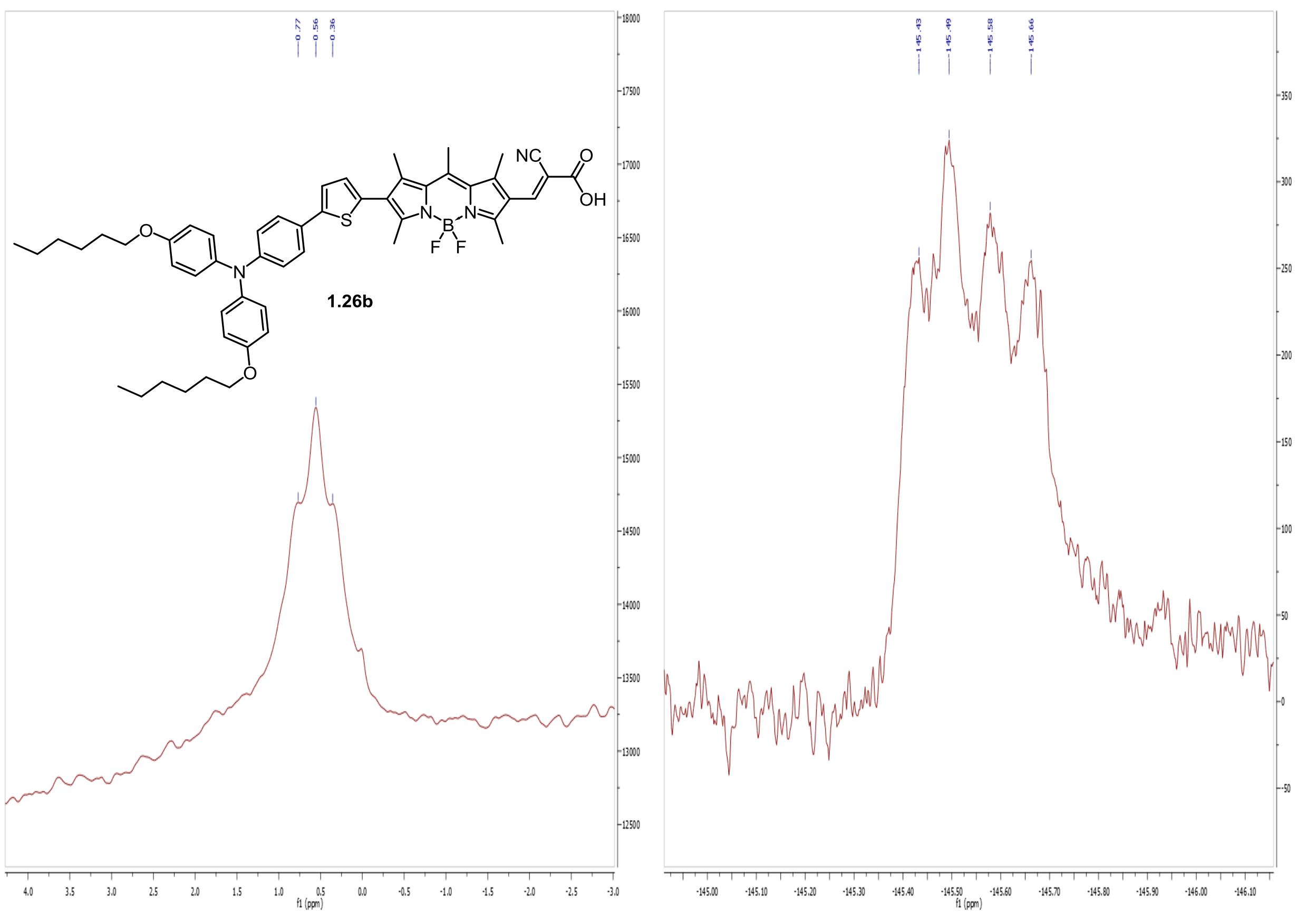




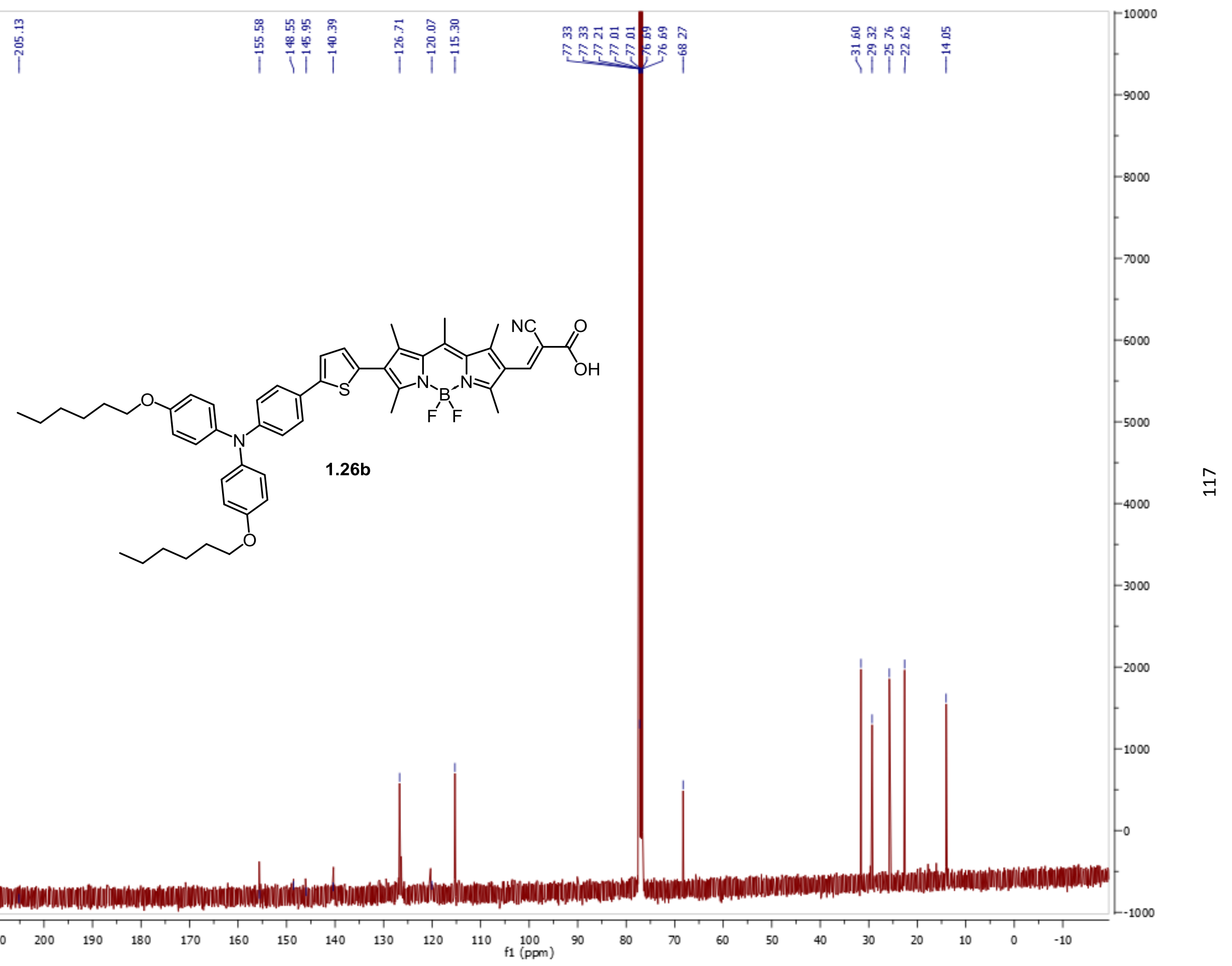




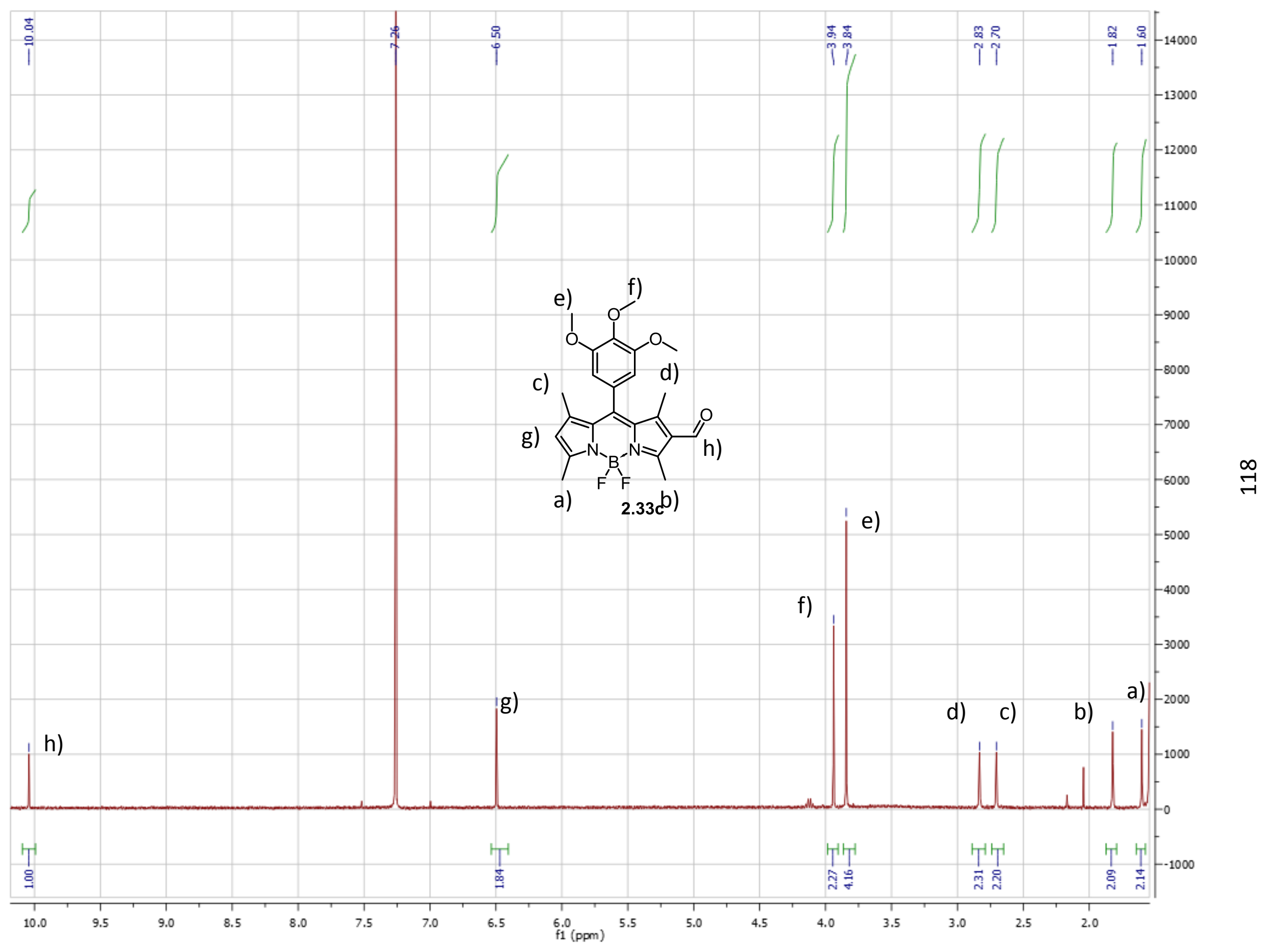




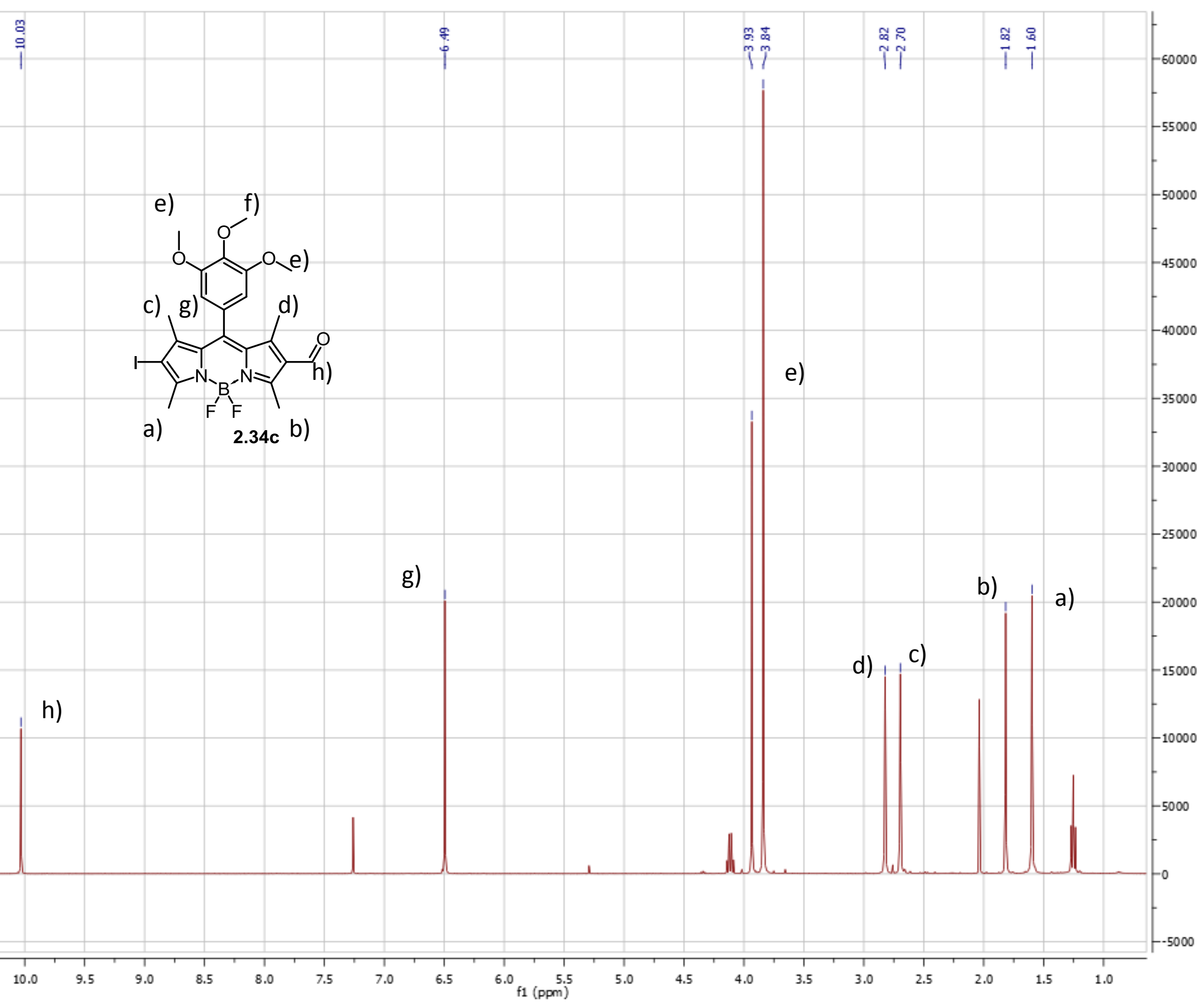




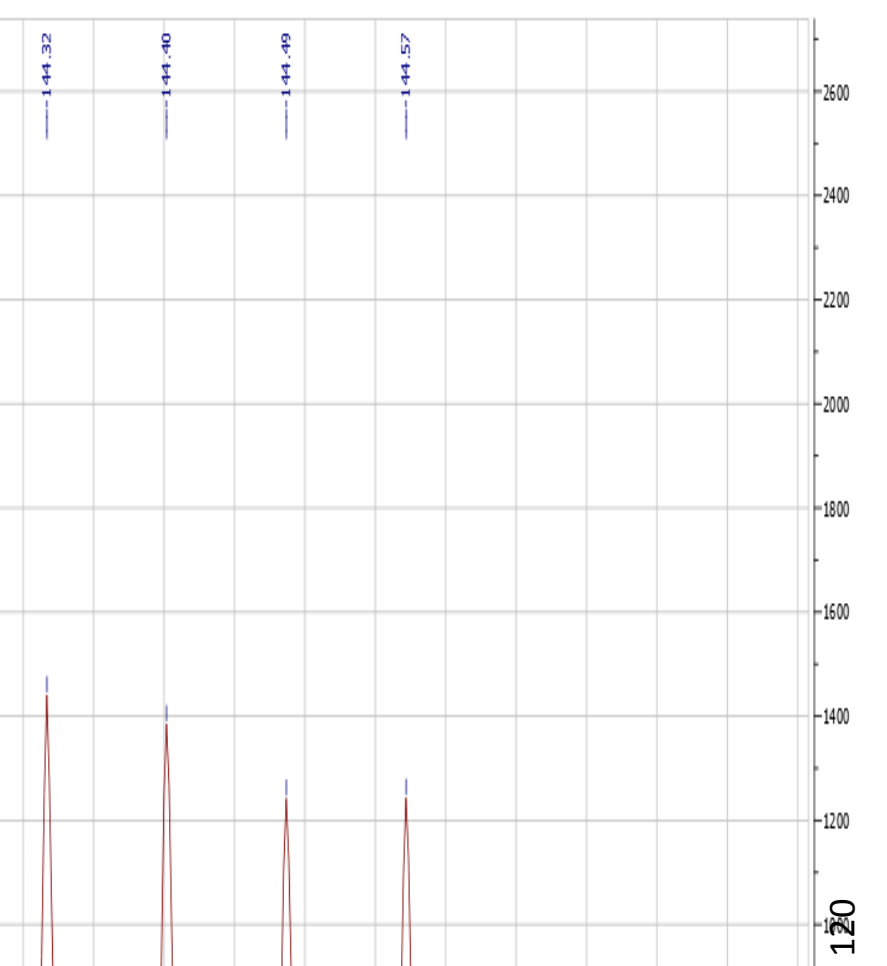




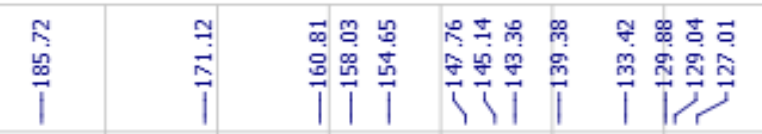

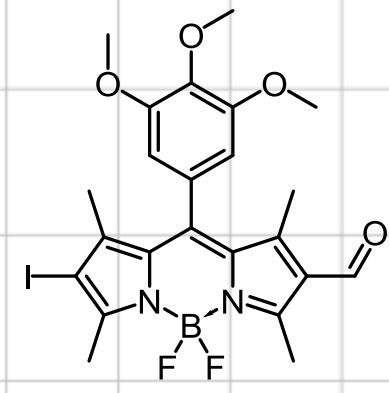

2.34c 


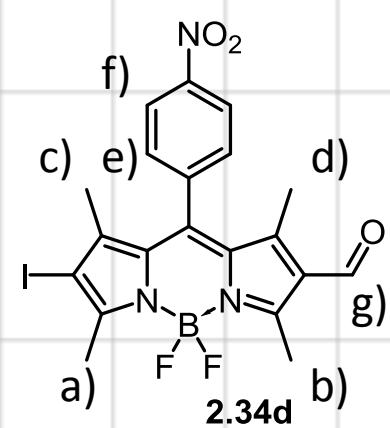

e)

g)

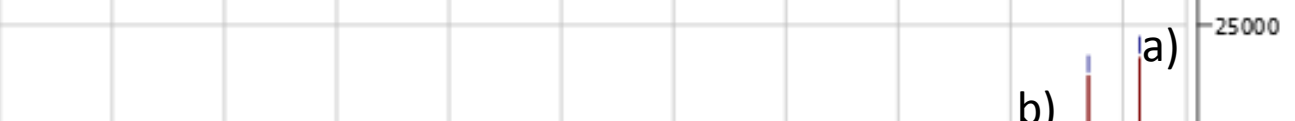

b)

1 $($ e

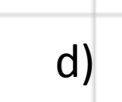

d $\mid \mathrm{c})$ 

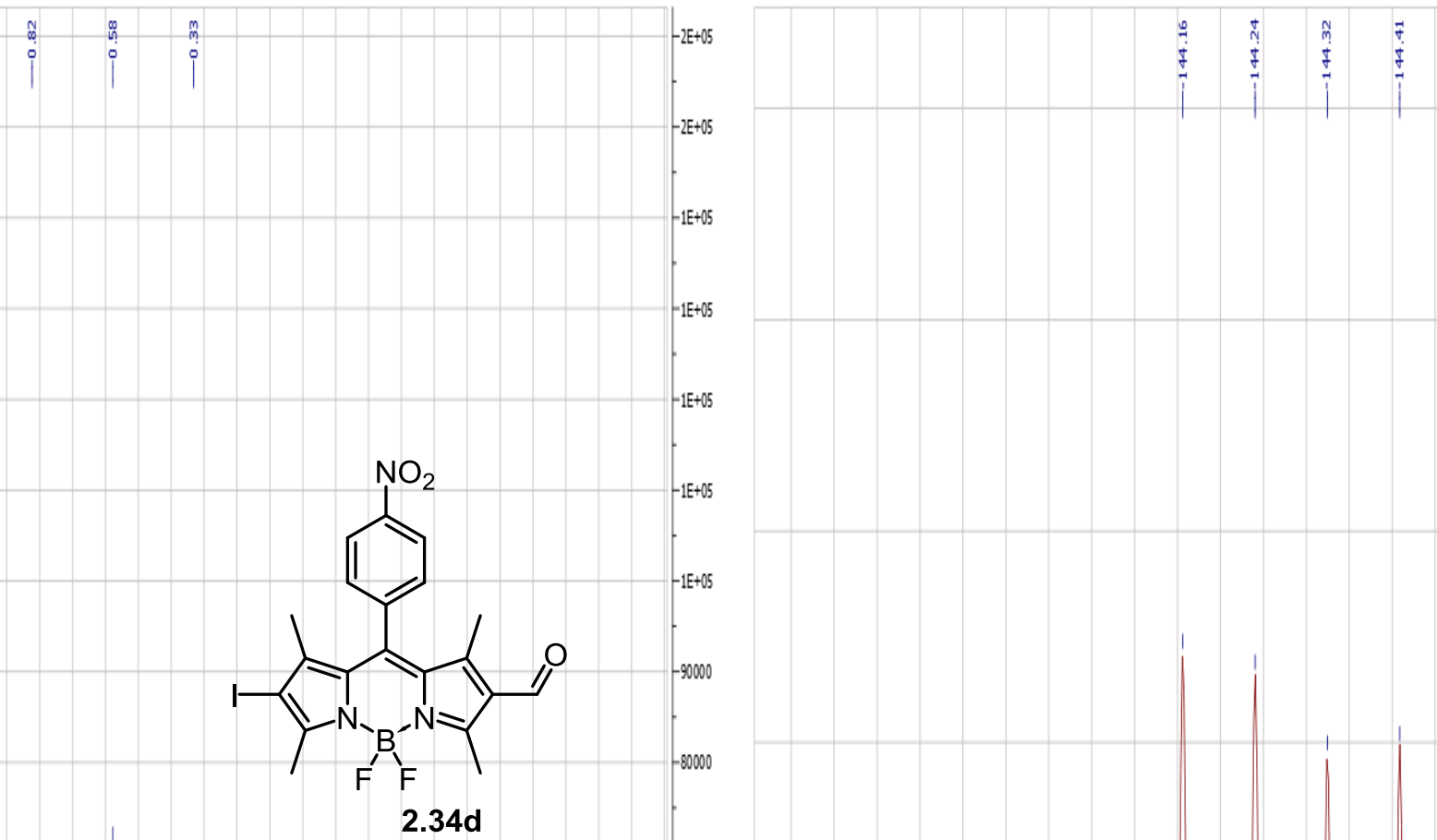

\section{o5}

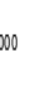

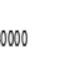

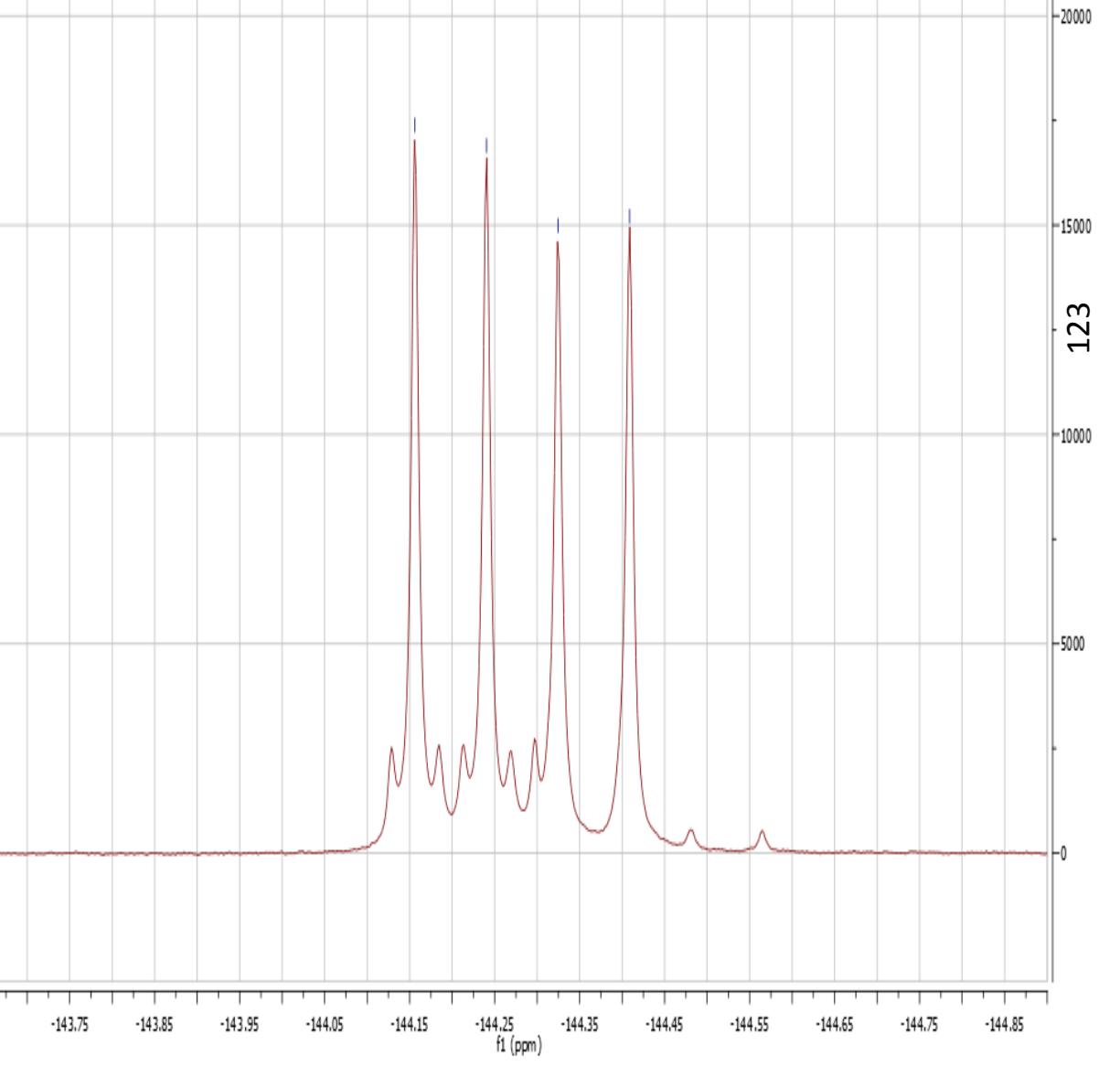



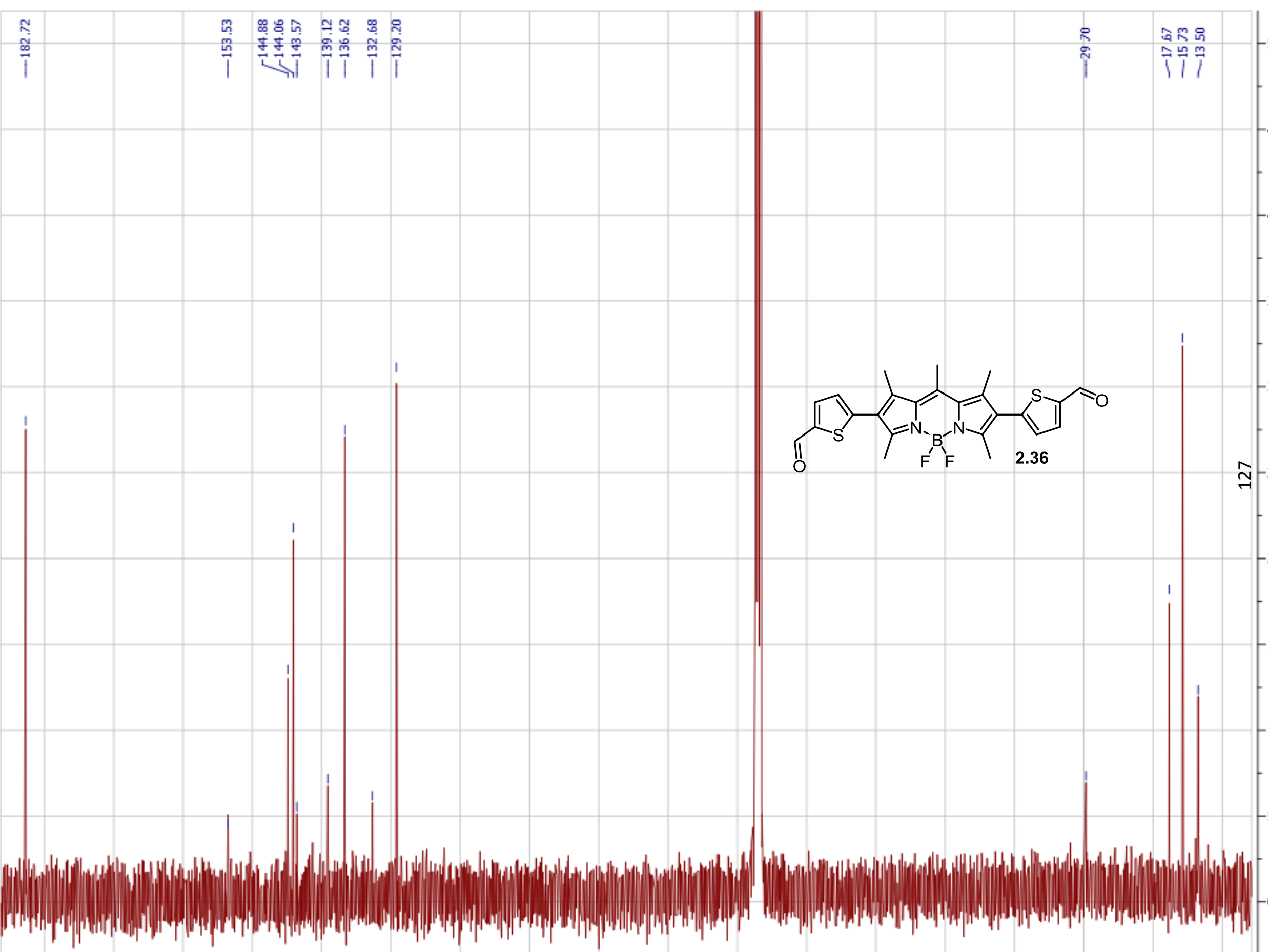


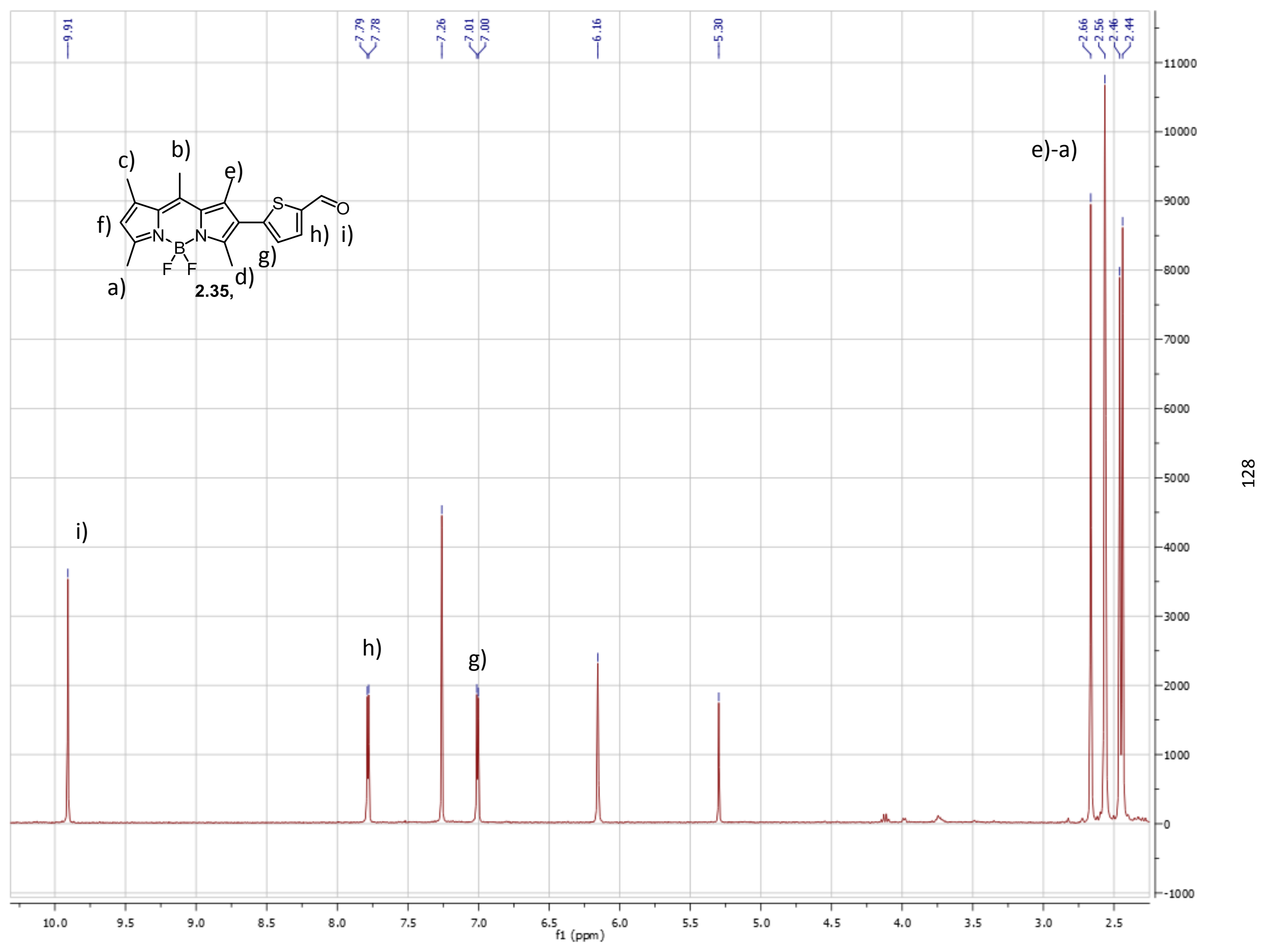




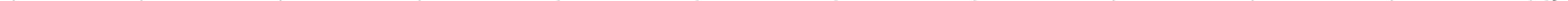




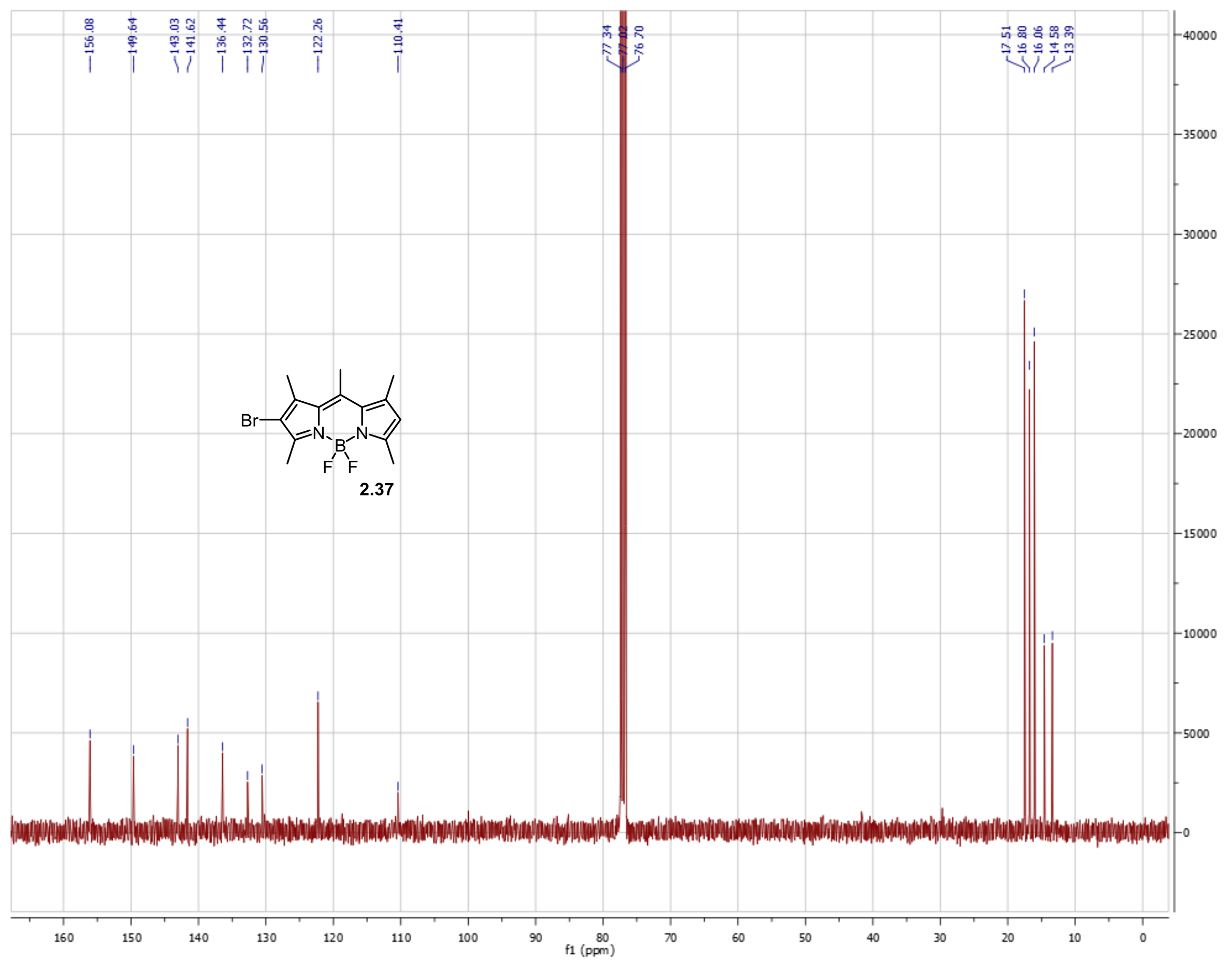




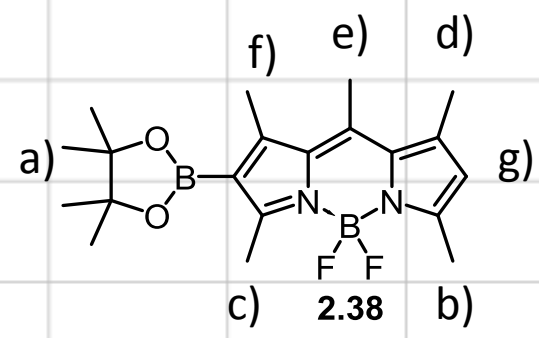

g)

e) d)

d) -8000

\begin{tabular}{|l|}
\hline \\
\hline \\
\hline
\end{tabular}

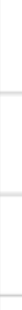

c)

b) 


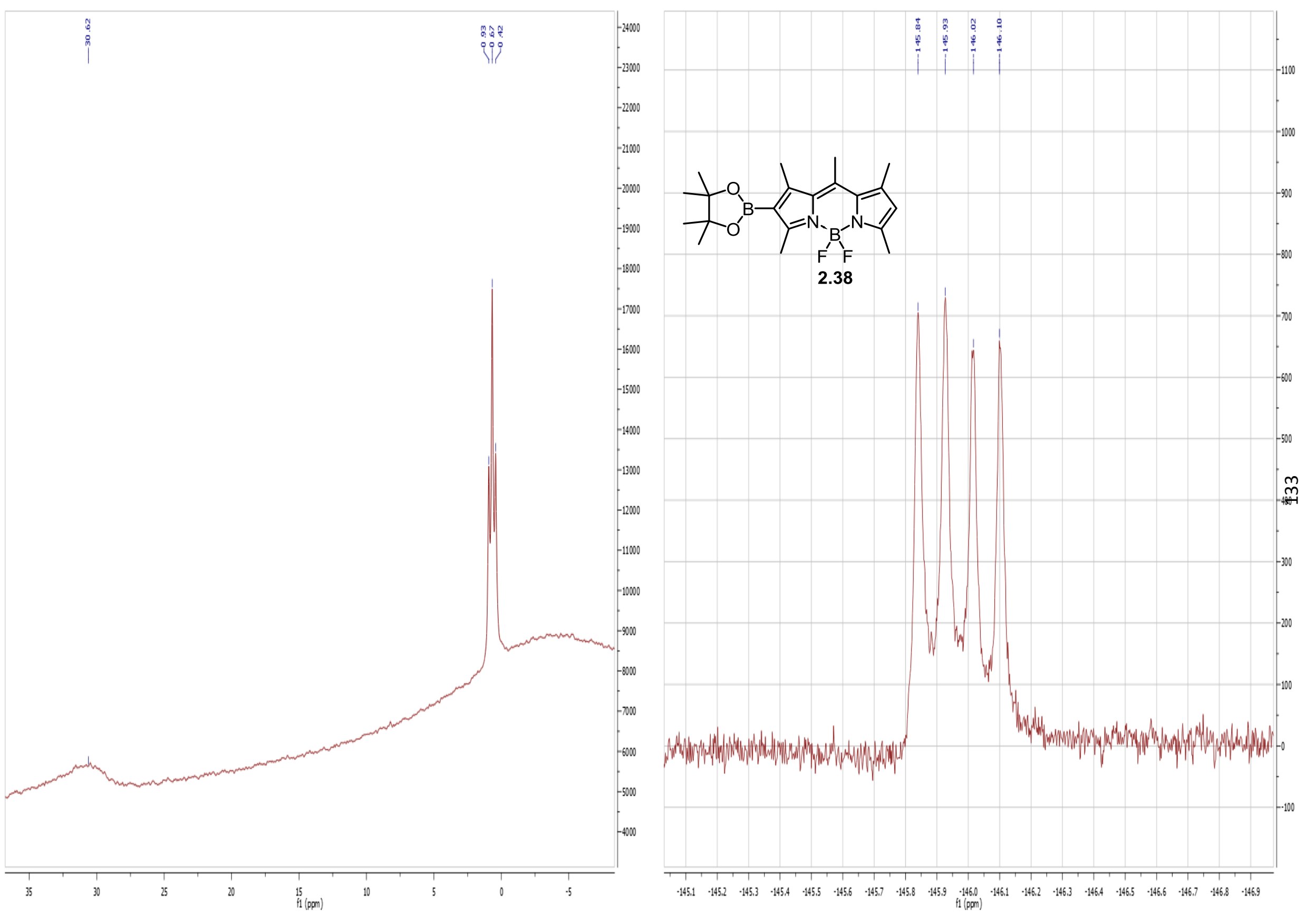




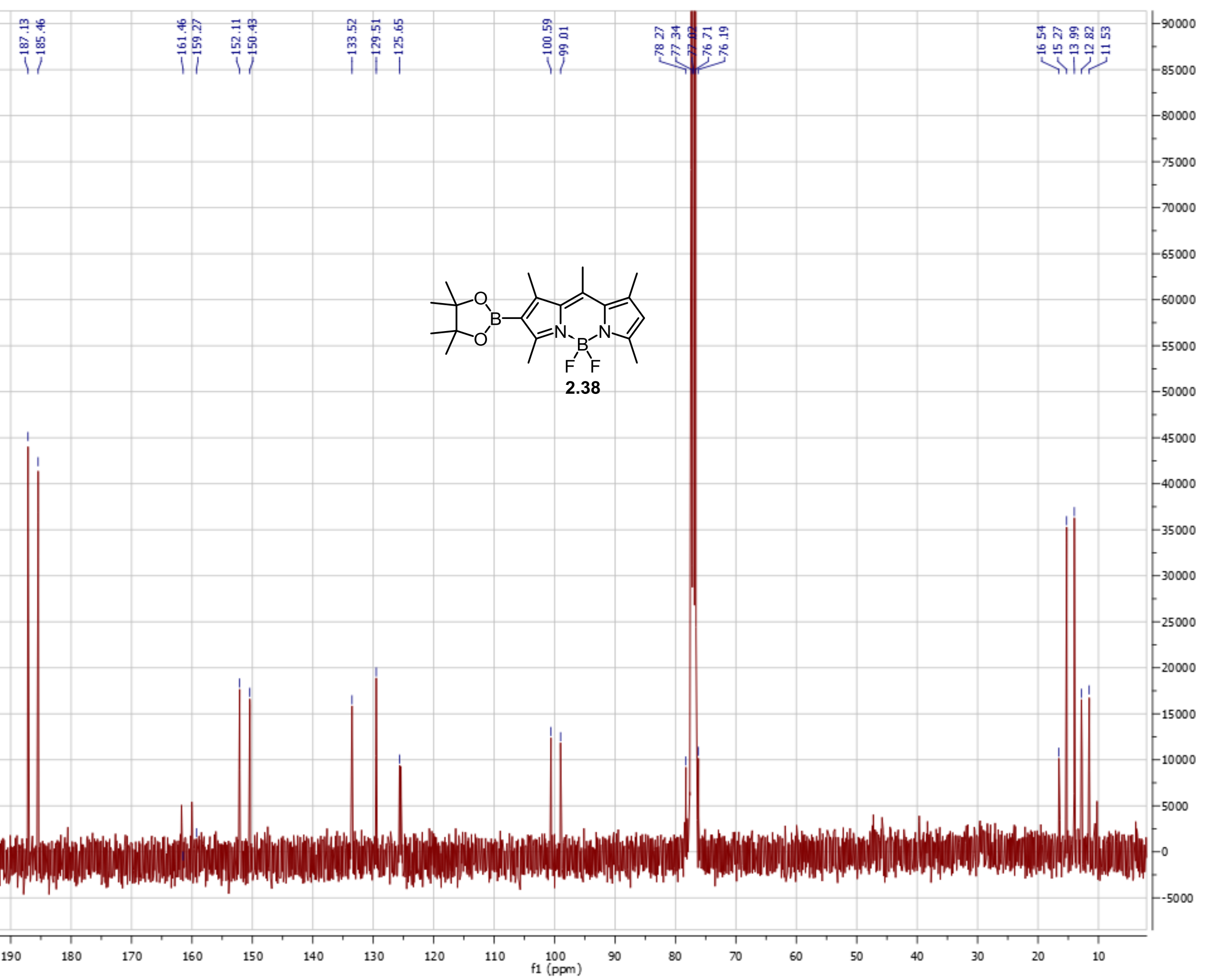




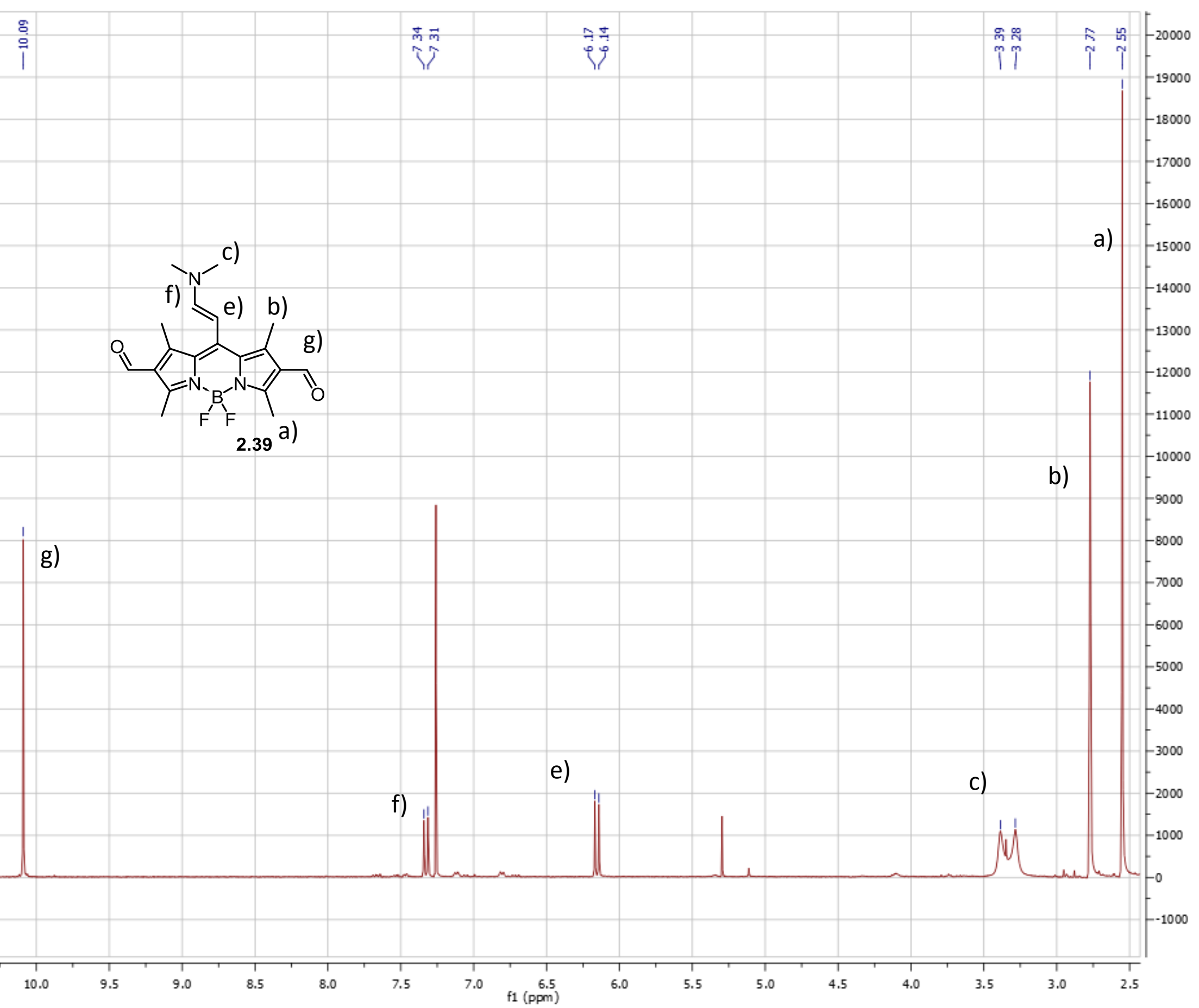



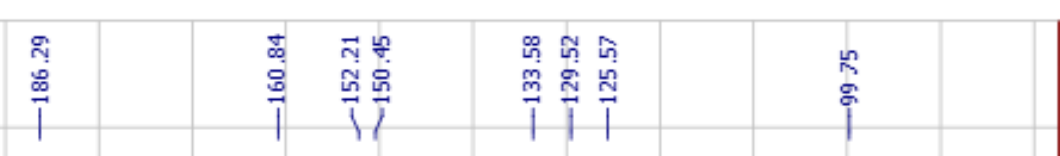


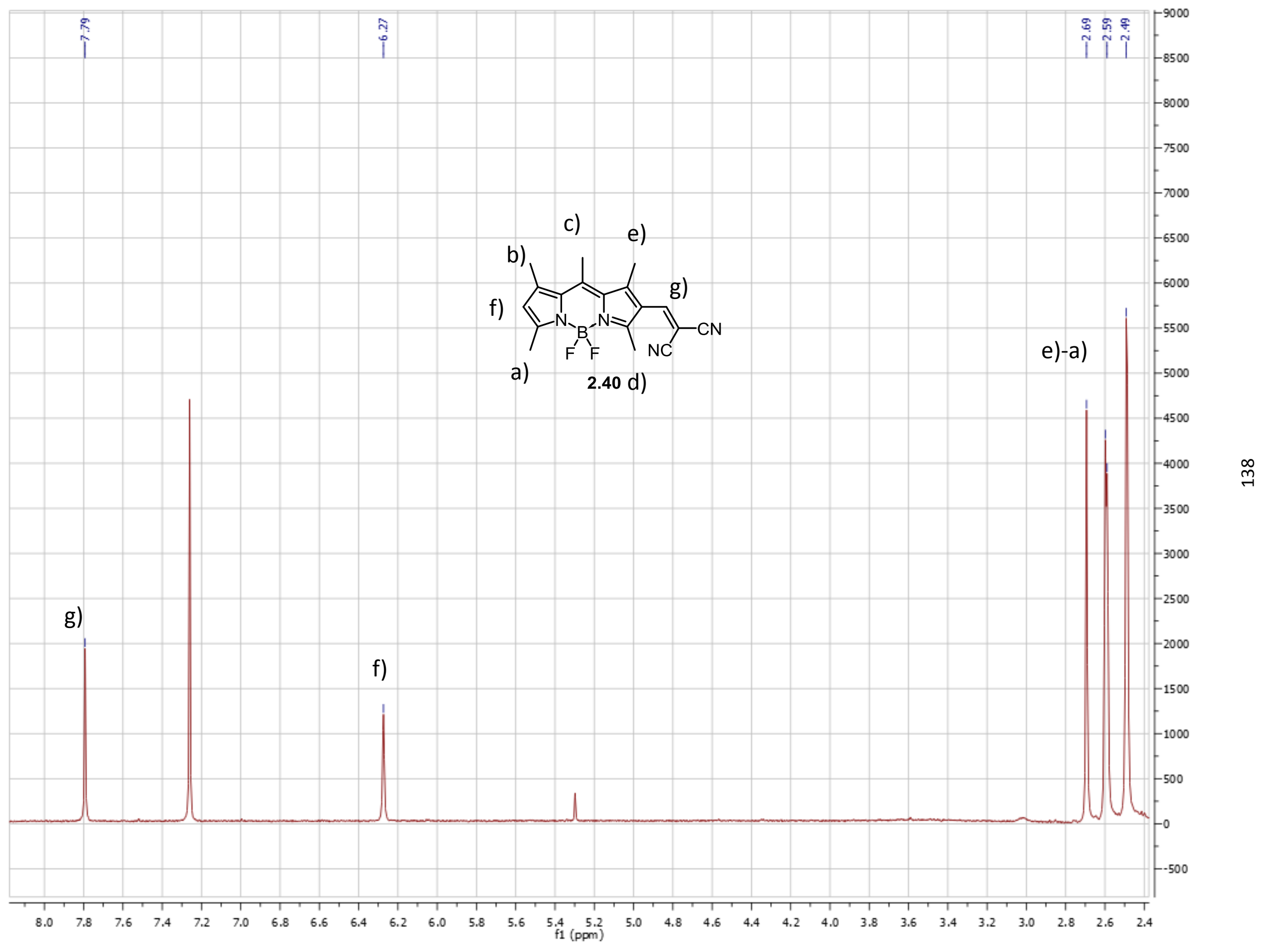




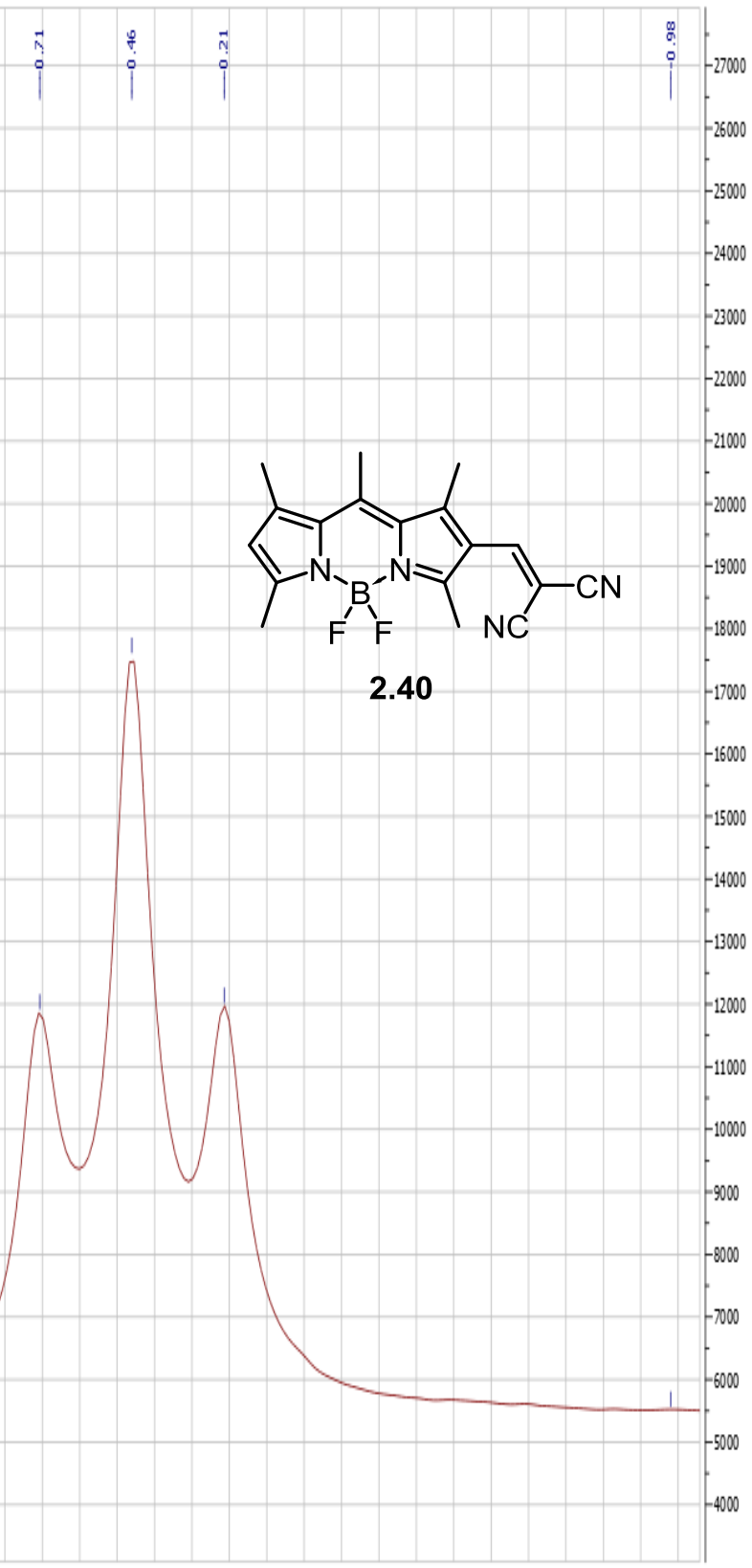

$\begin{array}{lllllllllllllllllllllllllllll}1.8 & 1.7 & 1.6 & 1.5 & 1.4 & 1.3 & 1.2 & 1.1 & 1.0 & 0.9 & 0.8 & 0.7 & 0.6 & 0.5 & 0.4 & 0.3 & 0.2 & 0.1 & 0.0 & 0.1 & 0.2 & 0.3 & 0.4 & 0.5 & 0.6 & 0.7 & 0.8 & 0.9 & 1.0\end{array}$ 


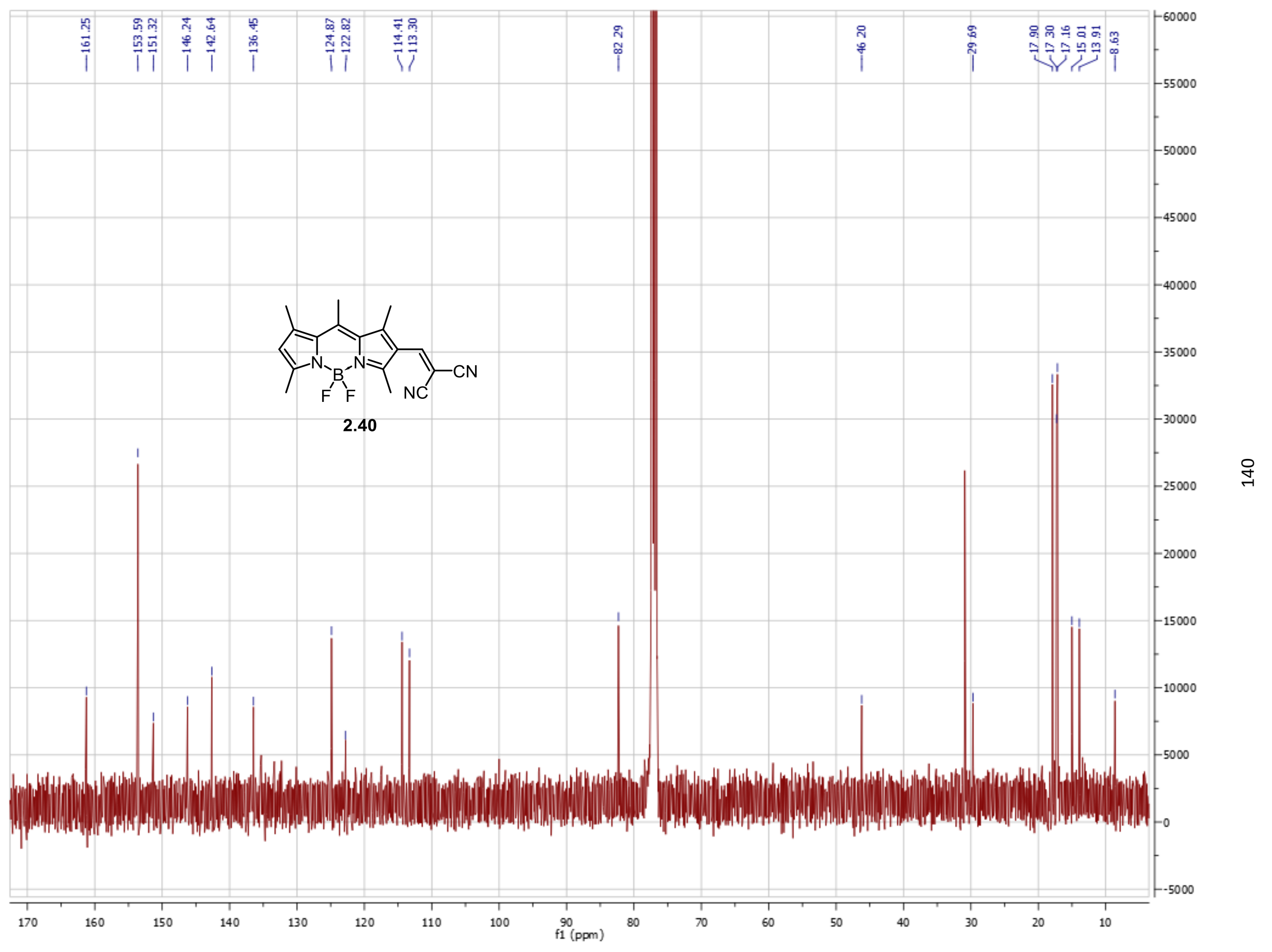




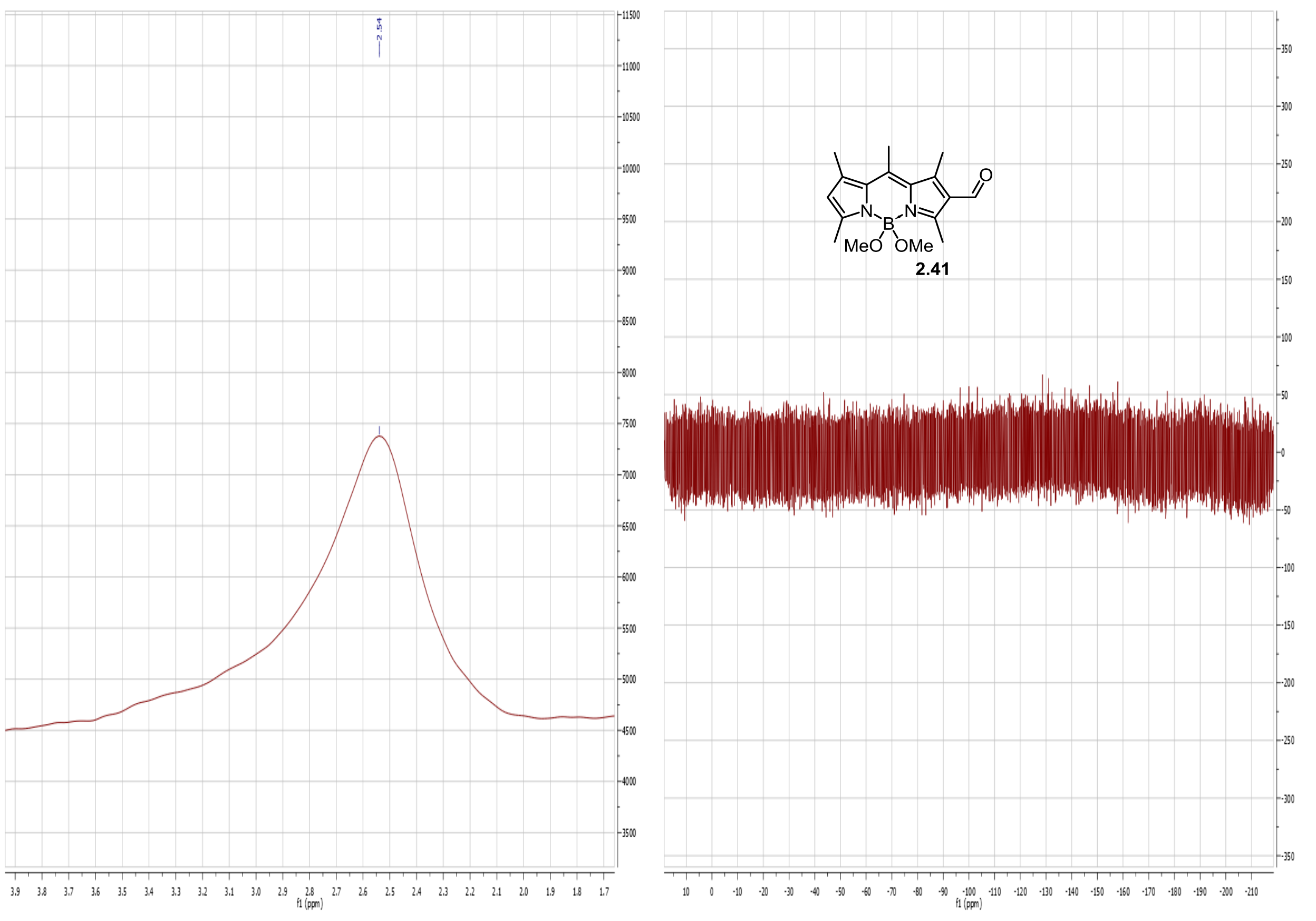




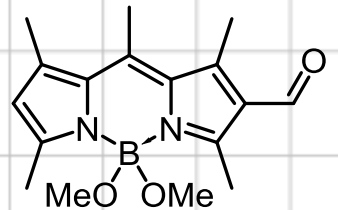

2.41 


\section{REFERENCESS}

(1) Kander, A. Economic growth, energy consumption and $\mathrm{CO} 2$ emissions in Sweden 18002000; Lund University, 2002; Vol. 19.

(2) administration, e. i. 2014.

(3) Asafu-Adjaye, J. Energy economics 2000, 22, 615.

(4) Lund, H. Energy 2007, 32, 912.

(5) Bax, A.; Clore, G. M.; Gronenborn, A. M. Journal of Magnetic Resonance (1969) 1990, 88, 425.

(6) Hoffert, M. I.; Caldeira, K.; Jain, A. K.; Haites, E. F.; Harvey, L. D. D.; Potter, S. D.;

Schlesinger, M. E.; Schneider, S. H.; Watts, R. G.; Wigley, T. M. L.; Wuebbles, D. J. Nature 1998, 395, 881.

(7) Mathiesen, B. V.; Lund, H.; Karlsson, K. Applied Energy 2011, 88, 488.

(8) Hoogwijk, M.; Faaij, A.; van den Broek, R.; Berndes, G.; Gielen, D.; Turkenburg, W. Biomass and bioenergy 2003, 25, 119.

(9) Routley, R.; Routley, V. Inquiry 1978, 21, 133.

(10) Schiermeier, Q.; Tollefson, J.; Scully, T.; Witze, A.; Morton, O. Nature 2008, 454, 816.

(11) Hagfeldt, A.; Boschloo, G.; Sun, L.; Kloo, L.; Pettersson, H. Chem. Rev. 2010, 110,

6595.

(12) Green, M. A.; Emery, K.; Hishikawa, Y.; Warta, W.; Dunlop, E. D. Progress in photovoltaics: research and applications 2012, 20, 12.

(13) Fthenakis, V. National Photovoltaic Environmental Health and Safety Assistance Center, Brookhaven National Laboratory, Upton/USA 2002.

(14) NREL; Energy, Ed. Online, 2012.

(15) Burschka, J.; Pellet, N.; Moon, S.-J.; Humphry-Baker, R.; Gao, P.; Nazeeruddin, M. K.; Gratzel, M. Nature 2013, 499, 316.

(16) Nazeeruddin, M. K.; Kay, A.; Rodicio, I.; Humphry-Baker, R.; Mueller, E.; Liska, P.; Vlachopoulos, N.; Graetzel, M. J. Am. Chem. Soc. 1993, 115, 6382.

(17) O'Regan, B. C.; Durrant, J. R. Accounts of chemical research 2009, 42, 1799.

(18) Boschloo, G.; Hagfeldt, A. Accounts of chemical research 2009, 42, 1819.

(19) Hu, K.; Robson, K. C. D.; Johansson, P. G.; Berlinguette, C. P.; Meyer, G. J. J. Am. Chem. Soc. 2012, 134, 8352.

(20) Tian, H.; Yu, Z.; Hagfeldt, A.; Kloo, L.; Sun, L. J. Am. Chem. Soc. 2011, 133, 9413.

(21) Wang, H.; Liu, M.; Zhang, M.; Wang, P.; Miura, H.; Cheng, Y.; Bell, J. Physical Chemistry Chemical Physics 2011, 13, 17359.

(22) Yum, J. H.; Chen, P.; Grätzel, M.; Nazeeruddin, M. K. ChemSusChem 2008, 1, 699.

(23) Pedersen, T. G.; Johansen, P. M.; Pedersen, H. C. Physical Review B 2000, 61, 10504.

(24) Chen, J.; Wang, M. Chemical Research in Chinese Universities 2013, $29,584$.

(25) Clifford, J. N.; Martínez-Ferrero, E.; Viterisi, A.; Palomares, E. Chemical Society Reviews 2011, 40, 1635.

(26) Mishra, A.; Fischer, M. K.; Bäuerle, P. Angewandte Chemie International Edition 2009, $48,2474$.

(27) Justin Thomas, K.; Hsu, Y.-C.; Lin, J. T.; Lee, K.-M.; Ho, K.-C.; Lai, C.-H.; Cheng, Y.-M.; Chou, P.-T. Chemistry of Materials 2008, 20, 1830.

(28) Feldt, S. M.; Gibson, E. A.; Gabrielsson, E.; Sun, L.; Boschloo, G.; Hagfeldt, A. J. Am. Chem. Soc. 2010, 132, 16714. 
(29) O'Regan, B.; Gratzel, M. Nature 1991, 353, 737.

(30) Péchy, P.; Renouard, T.; Zakeeruddin, S. M.; Humphry-Baker, R.; Comte, P.; Liska, P.; Cevey, L.; Costa, E.; Shklover, V.; Spiccia, L.; Deacon, G. B.; Bignozzi, C. A.; Grätzel, M. J. Am. Chem. Soc. 2001, 123, 1613.

(31) Ardo, S.; Meyer, G. J. Chemical Society Reviews 2009, 38, 115.

(32) Robson, K. C. D.; Koivisto, B. D.; Gordon, T. J.; Baumgartner, T.; Berlinguette, C. P. Inorganic Chemistry 2010, 49, 5335.

(33) Robson, K. C. D.; Sporinova, B.; Koivisto, B. D.; Schott, E.; Brown, D. G.; Berlinguette, C. P. Inorganic Chemistry 2011, 50, 6019.

(34) Robson, K. C. D.; Koivisto, B. D.; Yella, A.; Sporinova, B.; Nazeeruddin, M. K.; Baumgartner, T.; Grätzel, M.; Berlinguette, C. P. Inorganic Chemistry 2011, $50,5494$.

(35) Probst, B.; Guttentag, M.; Rodenberg, A.; Hamm, P.; Alberto, R. Inorganic Chemistry 2011, 50, 3404.

(36) Koivisto, B. D.; Robson, K. C. D.; Berlinguette, C. P. Inorganic Chemistry 2009, 48, 9644.

(37) Chen, C.; Yang, X.; Cheng, M.; Zhang, F.; Zhao, J.; Sun, L. RSC Advances 2013, 3, 12688.

(38) Lee, W.; Yang, Y.; Cho, N.; Ko, J.; Hong, J.-I. Tetrahedron 2012, 68, 5590.

(39) Kloo, L. Chemical Communications 2013, 49, 6580.

(40) Bonnier, C.; Machin, D. D.; Abdi, O.; Robson, K.; Koivisto, B. D. Organic \& Biomolecular Chemistry 2013.

(41) Zhang, G.; Bala, H.; Cheng, Y.; Shi, D.; Lv, X.; Yu, Q.; Wang, P. Chemical Communications 2009, 2198.

(42) Tian, H.; Yang, X.; Chen, R.; Pan, Y.; Li, L.; Hagfeldt, A.; Sun, L. Chemical Communications $2007,3741$.

(43) Robertson, N. Angewandte Chemie International Edition 2006, 45, 2338.

(44) Hagberg, D. P.; Marinado, T.; Karlsson, K. M.; Nonomura, K.; Qin, P.; Boschloo, G.; Brinck, T.; Hagfeldt, A.; Sun, L. The Journal of Organic Chemistry 2007, 72, 9550.

(45) Mishra, A.; Fischer, M. K. R.; Bauerle, P. Angewandte Chemie, International Edition 2009, $48,2474$.

(46) Qu, S.; Hua, J.; Tian, H. Science China Chemistry 2012, 55, 677.

(47) Hagberg, D. P.; Yum, J.-H.; Lee, H.; De Angelis, F.; Marinado, T.; Karlsson, K. M.; Humphry-Baker, R.; Sun, L.; Hagfeldt, A.; Grätzel, M. J. Am. Chem. Soc. 2008, 130, 6259.

(48) Joly, D.; Pellejà, L.; Narbey, S.; Oswald, F.; Chiron, J.; Clifford, J. N.; Palomares, E.; Demadrille, R. Sci. Rep. 2014, 4.

(49) Zeng, W. D.; Cao, Y. M.; Bai, Y.; Wang, Y. H.; Shi, Y. S.; Zhang, M.; Wang, F. F.; Pan, C. Y.; Wang, P. Chemistry of Materials 2010, 22, 1915.

(50) Zeng, W.; Cao, Y.; Bai, Y.; Wang, Y.; Shi, Y.; Zhang, M.; Wang, F.; Pan, C.; Wang, P. Chemistry of Materials 2010, 22, 1915.

(51) Burschka, J.; Pellet, N.; Moon, S.-J.; Humphry-Baker, R.; Gao, P.; Nazeeruddin, M. K.; Grätzel, M. Nature 2013, 499, 316.

(52) Lu, H.-P.; Tsai, C.-Y.; Yen, W.-N.; Hsieh, C.-P.; Lee, C.-W.; Yeh, C.-Y.; Diau, E. W.-G. The Journal of Physical Chemistry C 2009, 113, 20990.

(53) Loudet, A.; Burgess, K. Chem. Rev. 2007, 107, 4891.

(54) Yee, M.-C.; Fas, S. C.; Stohlmeyer, M. M.; Wandless, T. J.; Cimprich, K. A. Journal of Biological Chemistry 2005, 280, 29053.

(55) Kumaresan, D.; Thummel, R. P.; Bura, T.; Ulrich, G.; Ziessel, R. Chem.-Eur. J. 2009, 15, 6335. 
(56) de Wael, E. V.; Pardoen, J. A.; van Koeveringe, J. A.; Lugtenburg, J. Recueil des Travaux Chimiques des Pays-Bas 1977, 96, 306.

(57) Karolin, J.; Johansson, L. B.-A.; Strandberg, L.; Ny, T. J. Am. Chem. Soc. 1994, 116, 7801.

(58) Loudet, A.; Burgess, K. Chem. Rev. 2007, 107, 4891.

(59) Erten-Ela, S.; Yilmaz, M. D.; Icli, B.; Dede, Y.; Icli, S.; Akkaya, E. U. Organic Letters 2008, 10, 3299.

(60) Kolemen, S.; Bozdemir, O. A.; Cakmak, Y.; Barin, G.; Erten-Ela, S.; Marszalek, M.; Yum, J.-H.; Zakeeruddin, S. M.; Nazeeruddin, M. K.; Graetzel, M.; Akkaya, E. U. Chemical Science 2011, 2, 949.

(61) Mao, M.; Wang, J.-B.; Xiao, Z.-F.; Dai, S.-Y.; Song, Q.-H. Dyes Pigm. 2012, 94, 224.

(62) Ooyama, Y.; Hagiwara, Y.; Mizumo, T.; Harima, Y.; Ohshita, J. New Journal of Chemistry 2013, 37, 2479.

(63) Mao, M.; Zhang, X.-L.; Fang, X.-Q.; Wu, G.-H.; Ding, Y.; Liu, X.-L.; Dai, S.-Y.; Song, Q.-H. Organic Electronics 2014, 15, 2079.

(64) Wang, J.-B.; Fang, X.-Q.; Pan, X.; Dai, S.-Y.; Song, Q.-H. Chemistry - An Asian Journal 2012, 7, 696 .

(65) Jiang, Z.; Zhang, W.; Yao, H.; Yang, C.; Cao, Y.; Qin, J.; Yu, G.; Liu, Y. Journal of Polymer Science Part A: Polymer Chemistry 2009, 47, 3651.

(66) Chang, H. W.; Lin, K. H.; Chueh, C. C.; Liou, G. S.; Chen, W. C. Journal of Polymer Science Part A: Polymer Chemistry 2009, 47, 4037.

(67) Invitrogen 2013.

(68) Shivran, N.; Mula, S.; Ghanty, T. K.; Chattopadhyay, S. Organic Letters 2011, 13, 5870.

(69) M. J. Frisch, G. W. T., H. B. Schlegel, G. E. Scuseria, ; M. A. Robb, J. R. C., G. Scalmani, V. Barone, B. Mennucci, ; G. A. Petersson, H. N., M. Caricato, X. Li, H. P. Hratchian, ; A. F. Izmaylov, J. B., G. Zheng, J. L. Sonnenberg, M. Hada, ; M. Ehara, K. T., R. Fukuda, J. Hasegawa, M. Ishida, T. Nakajima, ; Y. Honda, O. K., H. Nakai, T. Vreven, J. A. Montgomery, Jr., ; J. E. Peralta, F. O., M. Bearpark, J. J. Heyd, E. Brothers, ; K. N. Kudin, V. N. S., T. Keith, R. Kobayashi, J. Normand, ; K. Raghavachari, A. R., J. C. Burant, S. S. Iyengar, J. Tomasi, ; M. Cossi, N. R., J. M. Millam, M. Klene, J. E. Knox, J. B. Cross, ; V. Bakken, C. A., J. Jaramillo, R. Gomperts, R. E. Stratmann, ; O. Yazyev, A. J. A., R. Cammi, C. Pomelli, J. W. Ochterski, ; R. L. Martin, K. M., V. G. Zakrzewski, G. A. Voth, ; P. Salvador, J. J. D., S. Dapprich, A. D. Daniels, ; O. Farkas, J. B. F., J. V. Ortiz, J. Cioslowski, ; and D. J. Fox; Gaussian Inc.,: Wallingford Ct, 2010.

(70) Romeny, B. M. H. Front-end vision and multi-scale image analysis: multi-scale computer vision theory and applications, written in mathematica; Springer, 2003; Vol. 27.

(71) Kasha, M. Discussions of the Faraday Society 1950, 9, 14.

(72) Kohn, W.; Rostoker, N. Physical Review 1954, 94, 1111.

(73) Garrity, K. F.; Bennett, J. W.; Rabe, K. M.; Vanderbilt, D. Computational Materials Science 2014, 81, 446.

(74) Al-Sehemi, A. G.; Irfan, A.; Asiri, A. M.; Ammar, Y. A. Spectrochimica Acta Part A: Molecular and Biomolecular Spectroscopy 2012, 91, 239.

(75) Sekiya, M.; Umezawa, K.; Sato, A.; Citterio, D.; Suzuki, K. Chemical Communications 2009, 3047.

(76) Yamanishi, H.; Tomita, I.; Ohta, K.; Endo, T. Molecular Crystals and Liquid Crystals Science and Technology. Section A. Molecular Crystals and Liquid Crystals 2001, 369, 47.

(77) Teng, C.; Yang, X.; Yang, C.; Li, S.; Cheng, M.; Hagfeldt, A.; Sun, L. The Journal of Physical Chemistry C 2010, 114, 9101.

(78) Li, R.; Liu, J.; Cai, N.; Zhang, M.; Wang, P. The Journal of Physical Chemistry B 2010, 114, 4461. 
(79) Yum, J.-H.; Hagberg, D. P.; Moon, S.-J.; Karlsson, K. M.; Marinado, T.; Sun, L.; Hagfeldt, A.; Nazeeruddin, M. K.; Grätzel, M. Angewandte Chemie International Edition 2009, 48, 1576.

(80) Chen, L.; Zhang, B.; Cheng, Y.; Xie, Z.; Wang, L.; Jing, X.; Wang, F. Adv. Funct. Mater. 2010, 20, 3143.

(81) Meek, S. T.; Nesterov, E. E.; Swager, T. M. Organic Letters 2008, 10, 2991.

(82) Steinberger, S.; Mishra, A.; Reinold, E.; Mena-Osteritz, E.; Muller, H.; Uhrich, C.; Pfeiffer, M.; Bauerle, P. Journal of Materials Chemistry 2012, 22, 2701.

(83) He, Y.; Lin, M.; Li, Z.; Liang, X.; Li, G.; Antilla, J. C. Organic Letters 2011, 13, 4490.

(84) Antina, E. V.; Guseva, G. B.; Loginova, A. E.; Semeikin, A. S.; V'yugin, A. I. Russ J Gen Chem 2010, 80, 2374.

(85) Wu, W.; Cui, X.; Zhao, J. Chemical Communications 2013, 49, 9009.

(86) Bonardi, L.; Ulrich, G.; Ziessel, R. Organic Letters 2008, 10, 2183.

(87) Bonnier, C.; Machin, D. D.; Abdi, O.; Koivisto, B. D. Organic \& Biomolecular Chemistry 2013, 11, 3756.

(88) Dienes, Y.; Durben, S.; Kárpáti, T.; Neumann, T.; Englert, U.; Nyulászi, L.; Baumgartner, T. Chemistry - A European Journal 2007, 13, 7487.

(89) Zhang, C.; Zhao, J.; Wu, S.; Wang, Z.; Wu, W.; Ma, J.; Guo, S.; Huang, L. J. Am. Chem. Soc. 2013, 135, 10566.

(90) Jiao, L.; Yu, C.; Li, J.; Wang, Z.; Wu, M.; Hao, E. The Journal of Organic Chemistry 2009, $74,7525$.

(91) Meng, G.; Velayudham, S.; Smith, A.; Luck, R.; Liu, H. Macromolecules 2009, 42, 1995.

(92) Singh, S.; Venugopalan, V.; Krishnamoorthy, K. Physical Chemistry Chemical Physics 2014, 16, 13376.

(93) Zhu, S.; Zhang, J.; Vegesna, G.; Tiwari, A.; Luo, F.-T.; Zeller, M.; Luck, R.; Li, H.; Green, S.; Liu, H. RSC Advances 2012, 2, 404.

(94) Brady, O. L. E. G. V. Analyst 1926, 51, 77. 